NBS

PUBLICATIONS

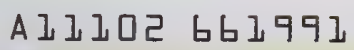

NAT'L INST OF STANDARDS \& TECH R.I.C.

A11102661991

Stone, Wullam C/Engineering aspects of
TA435. U58 NO.165 1987 V 1987 C.2 NBS-PUB

TA435.U58 No.165

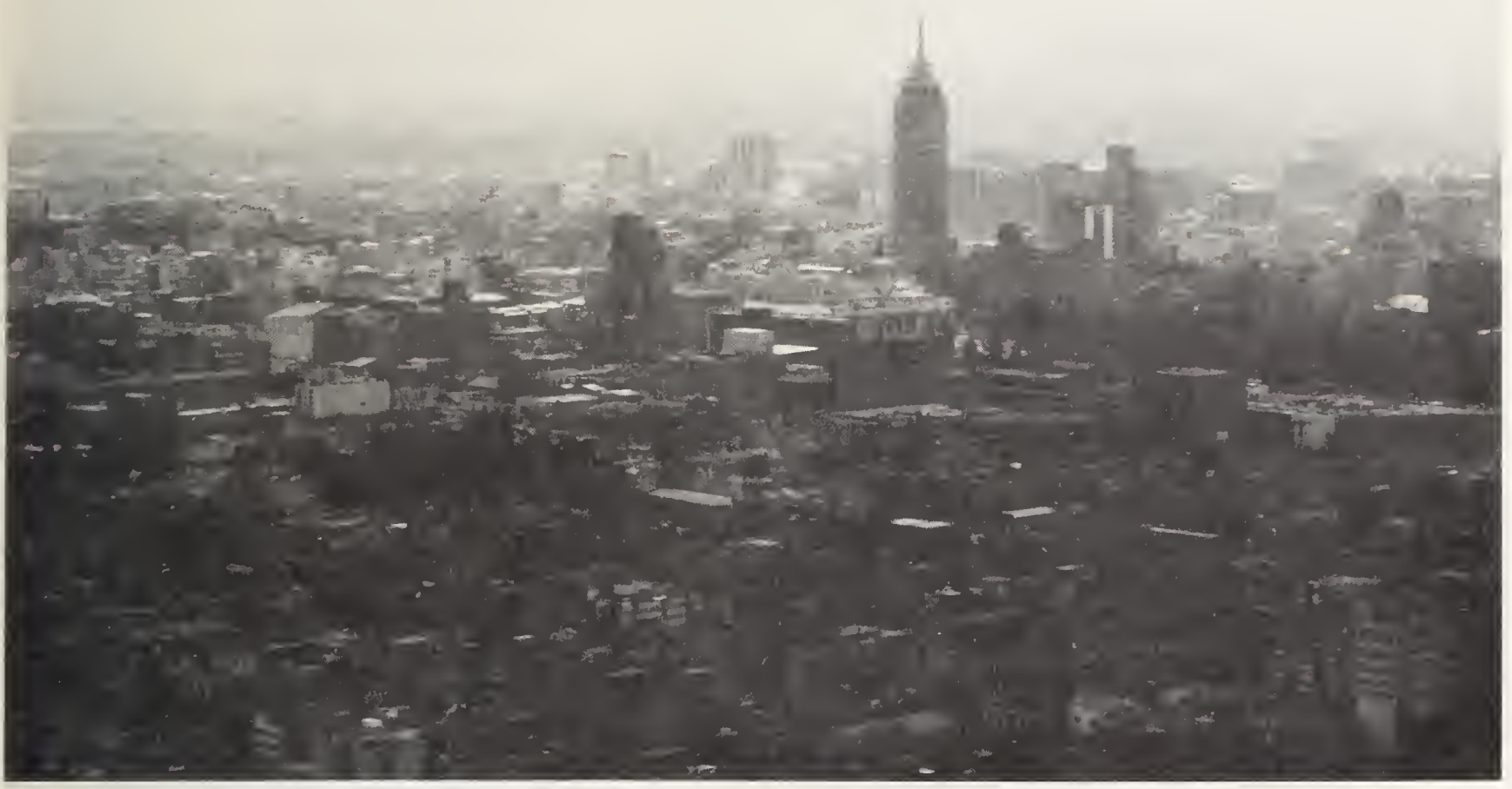

NBS BUILDING SCIENCE SERIES 165

\title{
Engineering Aspects of the September 19, 1985 Mexico Earthquake
}

TA

435

.458

EPARTMENT OF COMMERCE • NATIONAL BUREAU OF STANDARDS N0. 165 
he National Bureau of Standards' was established by an act of Congress on March 3, 1901. The Bureau's overall goal is to strengthen and advance the nation's science and technology and facilitate their effective application for public benefit. To this end, the Bureau conducts research to assure international competitiveness and leadership of U.S. industry, science ard technology. NBS work involves development and transfer of measurements, standards and related science and technology, in support of continually improving U.S. productivity, product quality and reliability, innovation and underlying science and engineering. The Bureau's technical work is performed by the National Measurement Laboratory, the National Engineering Laboratory, the Institute for Computer Sciences and Technology, and the Institute for Materials Science and Engineering.

\section{The National Measurement Laboratory}

Provides the national system of physical and chemical measurement; coordinates the system with measurement systems of other nations and furnishes essential services leading to accurate and uniform physical and chemical measurement throughout the Nation's scientific community, industry, and commerce; provides advisory and research services to other Government agencies; conducts physical and chemical research; develops, produces, and distributes Standard Reference Materials; provides calibration services; and manages the National Standard Reference Data System. The Laboratory consists of the following centers:
- Basic Standards ${ }^{2}$

- Radiation Research

- Chemical Physics

- Analytical Chemistry

\section{The National Engineering Laboratory}

Provides technology and technical services to the public and private sectors to address national needs and to solve national problems; conducts research in engineering and applied science in support of these efforts; builds and maintains competence in the necessary disciplines required to carry out this research and technical service; develops engineering data and measurement capabilities; provides engineering measurement traceability services; develops test methods and proposes engineering standards and code changes; develops and proposes new engineering practices; and develops and improves mechanisms to transfer results of its research to the ultimate user. The Laboratory consists of the following centers:

\section{The Institute for Computer Sciences and Technology}

Conducts research and provides scientific and technical services to aid Federal agencies in the selection, acquisition, application, and use of computer technology to improve effectiveness and economy in Government operations in accordance with Public Law 89-306 (40 U.S.C. 759), relevant Executive Orders, and other directives; carries out this mission by managing the Federal Information Processing Standards Program, developing Federal ADP standards guidelines, and managing Federal participation in ADP voluntary standardization activities; provides scientific and technological advisory services and assistance to Federal agencies; and provides the technical foundation for computer-related policies of the Federal Government. The Institute consists of the following divisions:
- Applied Mathematics

- Electronics and Electrical Engineering ${ }^{2}$

- Manufacturing Engineering

- Building Technology

- Fire Research

- Chemical Engineering ${ }^{3}$

\section{The Institute for Materials Science and Engineering}

Conducts research and provides measurements, data, standards, reference materials, quantitative understanding and other technical information fundamental to the processing, structure, properties and performance of materials; addresses the scientific basis for new advanced materials technologies; plans research around cross-cutting scientific themes such as nondestructive evaluation and phase diagram development; oversees Bureau-wide technical programs in nuclear reactor radiation research and nondestructive evaluation; and broadly disseminates generic technical information resulting from its programs. The Institute consists of the following Divisions:
- Information Systems Engineering

- Systems and Software Technology

- Computer Security

- Systems and Network Architecture

- Advanced Computer Systems

\footnotetext{
${ }^{1}$ Headquarters and Laboratories at Gaithersburg, MD, unless otherwise noted; mailing address Gaithersburg, MD 20899.

${ }^{2}$ Some divisions within the center are located at Boulder, CO 80303.

${ }^{3}$ Located at Boulder, CO, with some elements at Gaithersburg, MD
} 


\section{Engineering Aspects of the September 19, 1985 Mexico Earthquake}

William C. Stone

Felix Y. Yokel

U.S. Department of Commerce National Bureau of Standards National Engineering Laboratory Center for Building Technology Gaithersburg, MD 20899

and

Mehmet Celebi

Thomas Hanks

Edgar V. Leyendecker

U.S. Department of the Interior

Geological Survey

Office of Earthquakes, Volcanoes, and Engineering

Menlo Park, CA 94025

Golden, CO 80401

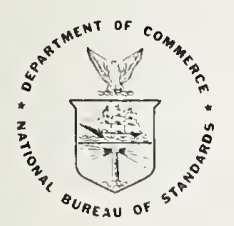

Issued May 1987

U.S. DEPARTMENT OF COMMERCE, Malcolm Baldrige, Secretary NATIONAL BUREAU OF STANDARDS, Ernest Ambler, Director 
Library of Congress Catalog Card Number: 87-619819

National Bureau of Standards Building Science Series 165

Natl. Bur. Stand. (U.S.), Bldg. Sci. Ser. 165, 215 pages (May 1987) CODEN: BSSNBV

U.S. GOVERNMENT PRINTING OFFICE

WASHINGTON: 1987

For sale by the Superintendent of Documents, U.S. Government Printing Office, Washington, DC 20402 


\section{Abstract}

Following the september 19, 1985 Mexico earthquake, a team consisting of four engineers and one seismologist from the National Bureau of Standards (NBS) and the United states Geological survey (USGS) was dispatched to Mexico City to provide technical advice to the US rescue effort and to assess structural damage. This report is primarily based on data gathered by the team, but it also contains a compilation of other available information. The report addresses the origin and characteristics of the observed ground motion, the ability of buildings designed in accordance with present and proposed seismic design provisions to resist this type of ground motion, and observed data on structural and foundation failures.

Key words: building codes; earthquake; foundations; geology; geotechnical engineering; ground motion; response spectra; seismology; seismic design; standards; structural engineering 
Acknowledgement

The NBS/USGS team is indebted to several groups who helped substantially during the conduct of the field investigation. We would particularly like to thank the office of Foreign Disaster Assistance for their help in making arrangements for the team to enter Mexico. Special thanks are also due to past U.S. Ambassador to Mexico John Gavin and his staff at the embassy; U.S. Embassy Science Attache Dr. Reynaldo Morales; and the A.I.D. office at the Embassy during the weeks following the earthquake for their assistance in arranging for ground transportation and access permission to structural collapse sites.

Numerous researchers at the University of Mexico's (UNAM) Instituto de Ingenieria freely provided timely and extremely useful data on the earthquake within days of the tremor and assisted us with our search for background material on subsurface conditions, building codes, and structural performance. We are particularly grateful to Professors Jorge Prince, Roberto Meli, Miguel $P$. Romo and Neftali Rodriguez Cuevas for their cooperation during our visits to Mexico City, and to Professor Romo for reviewing an advanced draft of some of the material presented in the report. Furthermore, we wish to extend our thanks to Mexico city consulting engineers Francisco serna and Enrique Martinez Romero for providing further statistics on the extent of structural damage, photos of critical structural details not available at the time of visit, and their illuminating comments on structural behavior and construction practices in Mexico City. 
Preface

This report conveys the findings of a team of engineers and seismologists from the National Bureau of Standards (NBS) and the United states Geological Survey (USGS), sent to Mexico by the U.S. government shortly after the september 19, 1985 earthquake which struck Mexico city. The mission of this team was to provide technical advice through the office of Foreign Disaster Assistance, and to make an assessment of structural performance. Team members, whose specialty areas are shown in parentheses, were: Dr. Mehmet Celebi, USGS, (earthquake engineering); Dr. Thomas Hanks, USGS, (seismology and strong ground motion); Dr. Edgar V. Leyendecker, USGS, (structural engineering); Dr. William C. Stone, NBS, (structural engineering); and Dr. Felix Y. Yokel, NBS, (geotechnical and structural engineering).

The team advised U.S. rescue workers and Mexican officials on means to more rapidly remove debris from collapsed buildings in order to speed the search for survivors, and worked with Mexican experts to identify fruitful opportunitites for in depth studies of structural performance. Team representatives also briefed the U.S. Ambassador to Mexico and his staff on the earthquake.

The dispatch of the above team to Mexico city represented the first effort conducted as part of the Interagency committee on Seismic Safety in Construction (ICSSC) post-earthquake reconnaissance activity. The mission of the ICSSC subcommittee on Post-Earthquake Response Activities, jointly chaired by NBS and USGS, is to:

" Be aware of existing Federal procedures and representative state, local and private sector procedures with respect to 
post-earthquake response for damage assessment and analysis, and to establish guidelines, operating procedures and criteria for the conduct of post-earthquake response activities in the event of a damaging earthquake. Activities include: general assessments, deployment of instruments and certain in-depth studies of structural performance, technical assistance to affected Federal agencies, and technical support for those Federal officials who have the responsibillity for carrying out the National Plan in the event of a damaging earthquake".

The ICSSC plans to conduct reconnaissance activities under the auspices of the Federal Emergency Management Agency (FEMA) following earthquakes in the U.S. 
TABLE OF CONTENTS

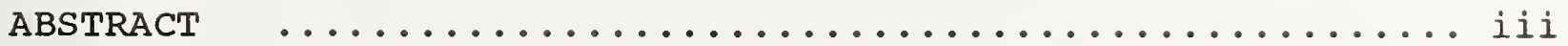

ACKNOWLEDGEMENT $\quad \ldots \ldots \ldots \ldots \ldots \ldots \ldots \ldots \ldots \ldots \ldots \ldots \ldots$ iv

PREFACE $\quad \ldots \ldots \ldots \ldots \ldots \ldots \ldots \ldots \ldots \ldots \ldots \ldots \ldots \ldots \ldots \ldots \ldots \ldots$

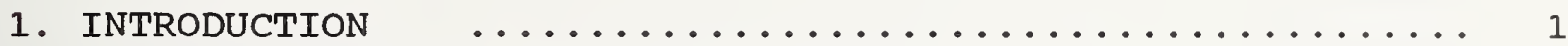

2. EARTHQUAKE ORIGIN AND CHARACTERISTICS $\ldots \ldots \ldots \ldots \ldots \ldots \ldots$

3. GEOLOGIC SETTING AND GROUND MOTION IN MEXICO CITY $\ldots . . .13$

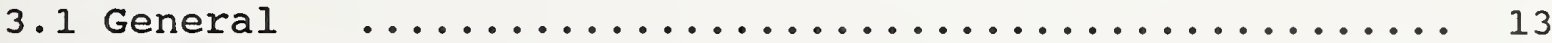

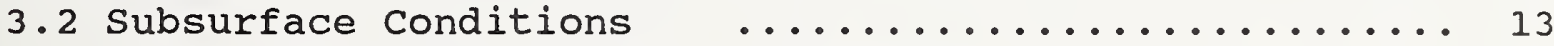

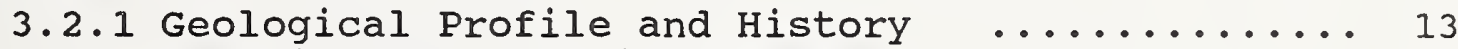

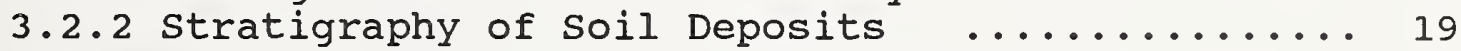

3.2.3 Engineering Characteristics of Soil Deposits . 25

3.3 Ground Motions in the Mexico City Area ........... 34

3.3.1 Ground Motion Characteristics .............. 34

3.3.2 Effect of Subsurface Conditions on Ground Motion 43

3.3.3 Comparison of Response Spectra With Design

Spectra Used in Mexico City and the U.S. ...... 52

4. FOUNDATION FAILURES $\ldots \ldots \ldots \ldots \ldots \ldots \ldots \ldots \ldots \ldots \ldots \ldots \ldots$

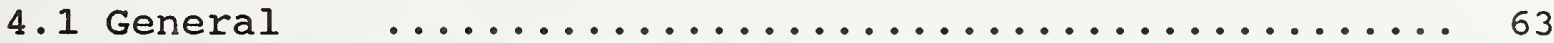

4.2 Loss of Shear Resistance of Piles $\ldots \ldots \ldots \ldots \ldots . \ldots 6$

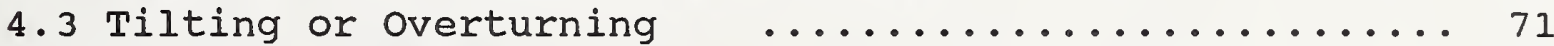

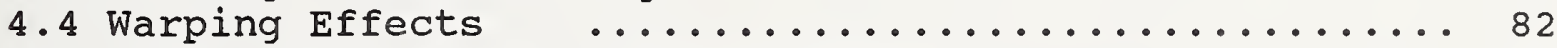

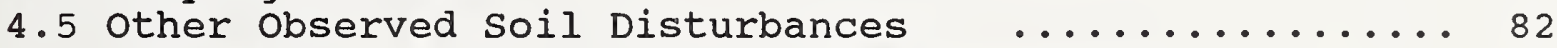

4.6 Discussion of Foundation Failure Mechanisms _.... 87

5. STRUCTURAL FAILURES $\ldots \ldots \ldots \ldots \ldots \ldots \ldots \ldots \ldots \ldots$

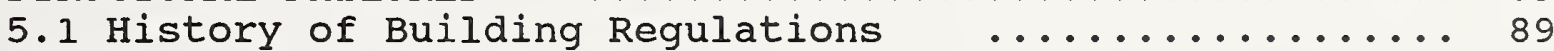

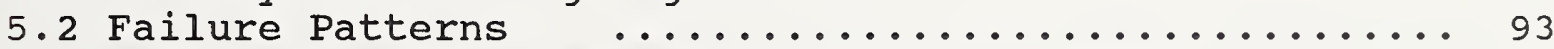

5.3 Performance of Different structural systems......... 95

5.4 Reinforced Concrete Frame structures ........... 95

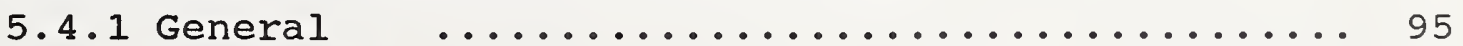

5.4 .2 Hospitals $\ldots \ldots \ldots \ldots \ldots \ldots \ldots \ldots \ldots \ldots \ldots \ldots . \ldots \ldots$

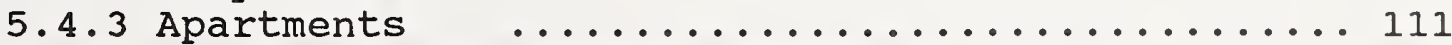

5.5 Flat Plate and Waffle Slab Buildings ............ 122

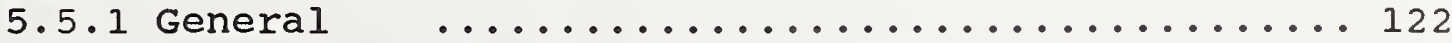

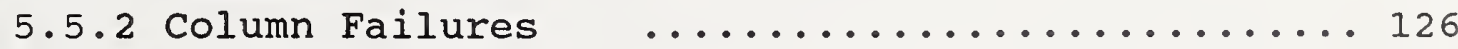

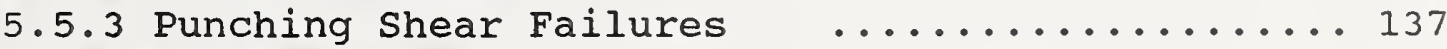

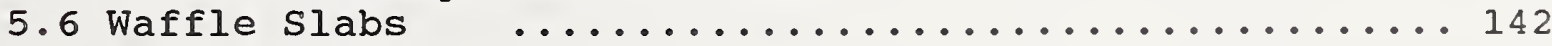

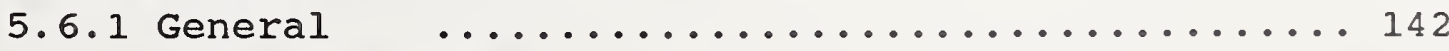

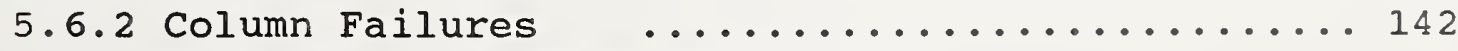

5.6.3 Porous Pan Formed Waffle Slabs ........... 143 


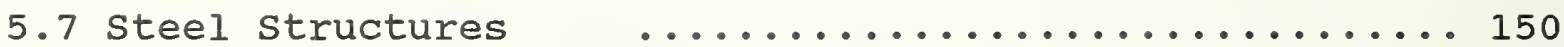

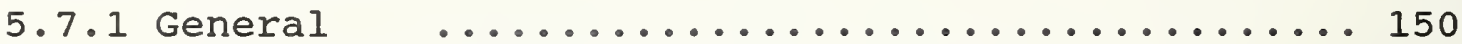

5.7.2 Steel Frame Structures That Failed ........ 151

5.7.3 Tall Moment Resisting steel structures That

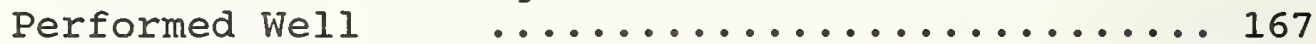

5.8 Building Configuration and Design Problems ........ 169

5.8 .1 Building separation (Hammering) ........... 169

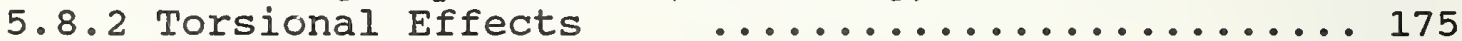

5.8 .3 Upper story Collapses $\ldots \ldots \ldots \ldots \ldots \ldots \ldots \ldots \ldots$

5.9 Masonry structures ......................... 190

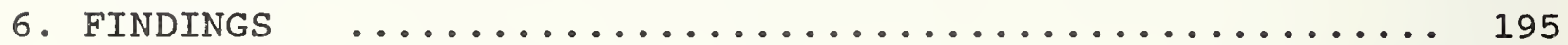

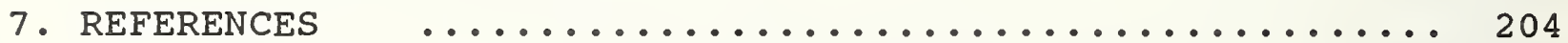




\section{INTRODUCTION}

As a result of the september 19, 1985 Mexico City Earthquake 4,287 persons lost their lives, 2,000 are unaccounted for, 14,268 were injured and 150,000 lost their jobs. The above figures are from an official count by Mexico city authorities [1]. Unconfirmed statistics of casualties were estimated to be much higher [2] and will probably never be known precisely. The official count also lists damage estimates as 5,728 damaged buildings of which $15 \%$ suffered total or partial collapse, $38 \%$ suffered major damage (approximately half will be demolished) and $47 \%$ suffered minor damage. Pavement damage occurred along 310 streets, there were 5285 breaks in water mains, and 14,500 interrupted phones. In addition, all long distance phone service was disrupted for an extended period of time.

According to a block by block survey of the damaged area conducted by a team from the National Autonomous University of Mexico (UNAM-Universidad Nacional Autonoma De Mexico) [3], about 330 buildings collapsed or were heavily damaged (a higher damage estimate was made on the basis of aerial photographs). The total damage incurred by the city, not including the long term cost of rebuilding, was estimated by the Economic commission for Latin America at \$ 4 billion [1]. 
Even though this was a disaster of major dimensions, it is important to realize that Mexico City has a population of 18 million and that there are over 800,000 buildings in the affected area. The earthquake $\left(\mathbb{M}_{S}=8.1\right)$ struck at 7:18 AM Mexico time [4]. The epicenter was located in Michoacan Province near the Pacific Coast of Mexico, approximately $30 \mathrm{~km}$ from the small town of Lazaro Cardenas, about $400 \mathrm{~km}$ to the west of Mexico City. The main shock reached Mexico City at about 7:19 AM. At that early hour many people were commuting to work and thus office buildings were largely unoccupied. Had the earthquake struck during working hours the number of fatalities could have been much greater, since many of the collapsed buildings were office buildings.

The damage pattern observed was highly selective. Most of the severe damage was confined to buildings in the height range of 7 to 18 stories. Many other buildings performed well, even though they were located in the same area as those which suffered structural failure. Subway tunnels sustained very little damage. However, many underground utility lines had to be repaired or replaced. The zone of damage was principally confined to the "Lake Region" of Mexico City, which is underlain by deep layers of soft clays and silts. Other areas of Mexico City sustained little damage.

Most of the observed building collapses were attributed to structural failure; relatively few foundation failures were observed. However, subsurface conditions had a profound effect on the characteristics of the ground motion, and thus on structural performance.

One unfortunate aspect of the september 19, 1985 Mexico City earthquake (Richter scale magnitude $\mathrm{M}_{S}=8.1$ ) is that in many essential respects it was a repeat of the July 28, 1957 earthquake $\left(\mathbb{M}_{S}=7.5\right)$, differing mainly in the number of destroyed buildings and confirmed dead and missing people. The following 
statements are quotations from the August 1, 1957 issue of "Engineering News Record", describing the effects of the 1957 earthquake in Mexico City; all but the first were written under the by-line of senior editor Frederick s. Meritt.

"The problem of enough separation between buildings with different modes of vibrations to keep them from banging against one another also appears as a result of the quake damage."

"The earthquake...affected principally the taller buildings. Few under five stories high were damaged if they had good foundations and were not pounded by adjoining buildings."

"It appears highly probable that due to peculiar subsurface conditions the shock may have been many times as severe on some buildings as on structures only a few hundred feet away."

"There is much evidence that peak vibrations of the ground in this quake coincided with the natural frequency of many of the tall buildings that were damaged severely."

"Emilio Rosenblueth, consulting engineer, Mexico city, believes the magnification factor [of incoming seismic amplitudes relative to hard rock at the resonant frequencies] may reach 12 or more."

It will be seen in the following chapters that every one of these statements could be applied to the 1985 earthquake. In 1985, of course, the magnitude of the tragedy was considerably greater than in 1957. 
Damage of the sort sustained in Mexico City only rarely occurs at $400 \mathrm{~km}$ distance from an earthquake of any magnitude. The special geologic conditions of the sedimentary basin underlying Mexico City are the cause of this phenomenon. Many aspects of past and present design and construction practices contributed to the observed building failures, and much can probably be learned from the more than 800,000 buildings that survived the earthquake with only minor damage.

Chapter 2 discusses the origin and characteristics of the earthquake. In Chapter 3, the character of the Mexico City ground motion, the unique subsurface conditions which caused the great amplification of the ground motion, and the ability of present and proposed design provisions to protect structures against this type of ground motion are discussed. Foundation and structural failures are described in Chapters 4 and 5, respectively. Conclusions and recommendations are presented in chapter 6. 


\section{EARTHQUAKE ORIGIN AND CHARACTERISTICS}

The september 1985 Michoacan, Mexico earthquake occurred as a result of the subduction of the cocos Plate along the Middle American Trench beneath the North American and Carribean plates, a process that has been ongoing for millions of years. The location and relative motion of the plates is shown in figure 2.1. The earthquake initiated at $18.2^{\circ} \mathrm{N}, 102.6^{\circ} \mathrm{W}$, with a focal depth of approximately $18 \mathrm{~km}$ [4], and propagated approximately $170 \mathrm{~km}$ to the southeast (length of slip area $=170 \mathrm{~km}$. width $=50$ $\mathrm{km}$ [4]). This event ruptured much but not all of the "Michoacan seismic gap" [5] an area along the subduction zone which did not generate a major earthquake in recent history while adjacent areas generated major earthquakes. Because of the unrelieved accumulated strains caused by the slip movement (about 57 mm/year), the area was believed to have the potential for a major earthquake. The magnitude of the earthquake $\left(\mathrm{M}_{\mathrm{S}}\right)$ was originally given as 7.8 on the Richter scale, but later revised to 8.1 by the National Earthquake Information service (NEIS) on september 26, 1985. Similarly, $M_{S}$ of the major aftershock occurring 36 hours later was upgraded from 7.3 to 7.5 . Otherwise, the aftershock sequence of an event that large was surprisingly lean. In the first month following the main shock, only two other earthquakes above $\mathrm{M}_{\mathrm{S}}=5$ occurred. A preliminary estimate of the seismic moment (the product of the shear modulus of the rock, the average slip along the area of rupture, and the 


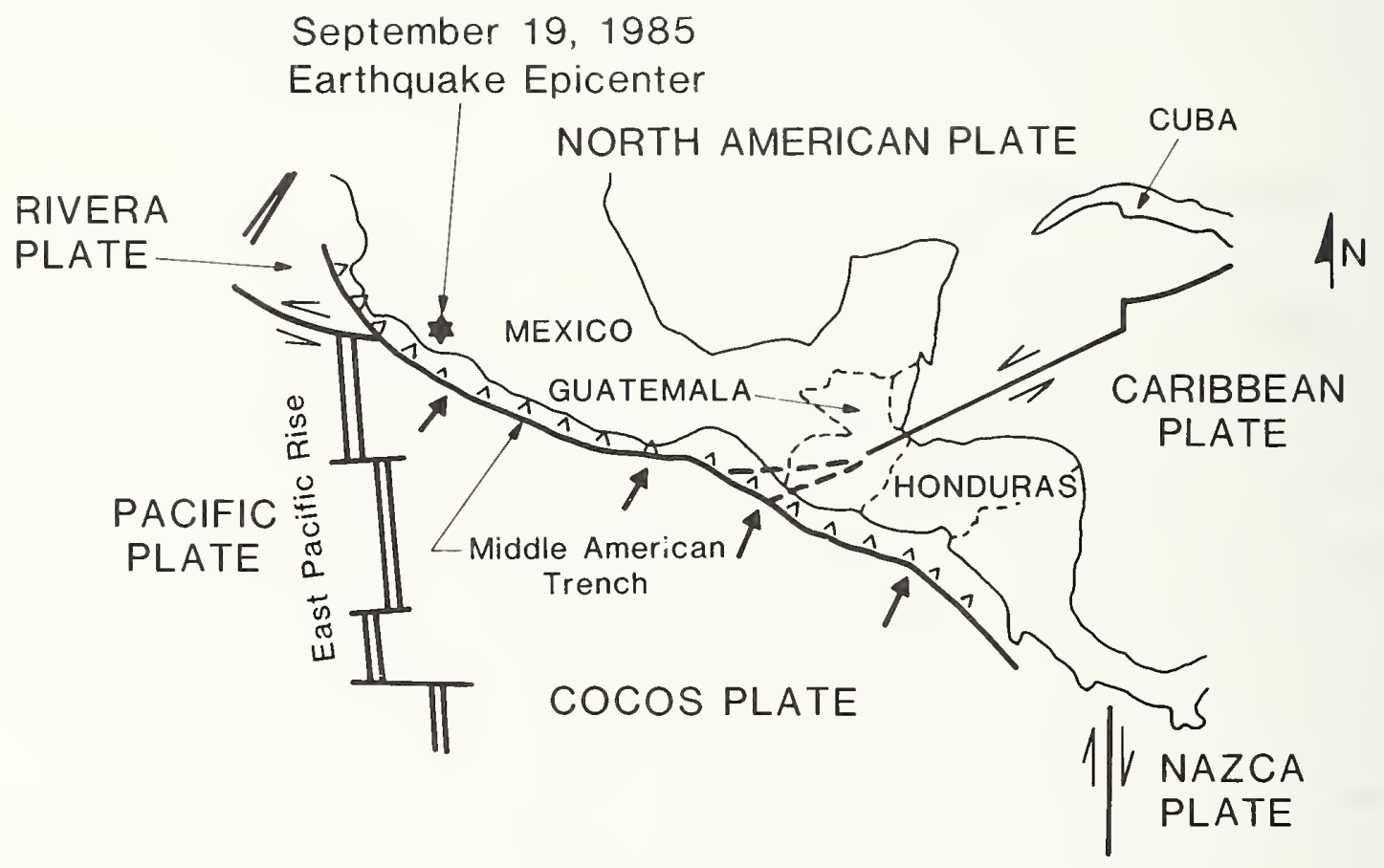

Figure 2.1 Location and relative motion of major tectonic plates in southwestern Mexico. (from Ref. [2]) 
area of rupture) for the main shock is $0.9-1.5 \times 10^{28}$ dyne-cm $\left(0.9-1.5 \times 10^{21} \mathrm{~N}-\mathrm{m}\right)$ [4], yielding a moment magnitude of 7.97 to 8.12 for the main shock.

Such earthquakes are no strangers along and near the Middle American trench, as can be seen in figure 2.2, which shows the location of epicenters of past earthquakes, and a space-time diagram, in which the epicenters are projected down and plotted at the year of occurrence [4]. Dozens of $\mathrm{M}_{\mathrm{S}} \geq 7$ earthquakes have occurred at comparable epicentral distances from Mexico city since the turn of the century, and more are sure to come. Two noteworthy features of the main shock are that: (1) it is as large (to 0.1 magnitude units) as any of its companion earthquakes known in the historic record; and (2) this event and its aftershock occurred within a longstanding gap for $\mathrm{M}_{S} \geq 7.5$, as can be clearly seen from the space-time plot $([5],[6])$.

An important achievement was the installation of the Guerrero strong-motion accelerograph array (figure 2.3) prior to the occurrence of the recent earthquake, a cooperative venture of the Institute of Geophysics and Planetary Physics, U.C. San Diego (J.N. Brune and J.G. Anderson) and the Instituto de Ingenieria, UNAM (J. Prince and J.G. Singh). The array provided extensive information from stations in the general area near the epicenter and to a distance of $230 \mathrm{~km}$ in the direction of Mexico city.

Data on the ground motion characteristics of the main shock are given in table 2.1 and figure 2.4 [4]. The data in figure 2.4 are for the east-west component of the ground motion for three sections in the Guerrero array. These stations were chosen because they are located in the general direction from the epicenter to Mexico City: La Villita, which has an epicentral distance of $44 \mathrm{~km}$, La Union, which has an epicentral distance of $84 \mathrm{~km}$, and Teacalco which has an epicentral distance of $333 \mathrm{~km}$ 


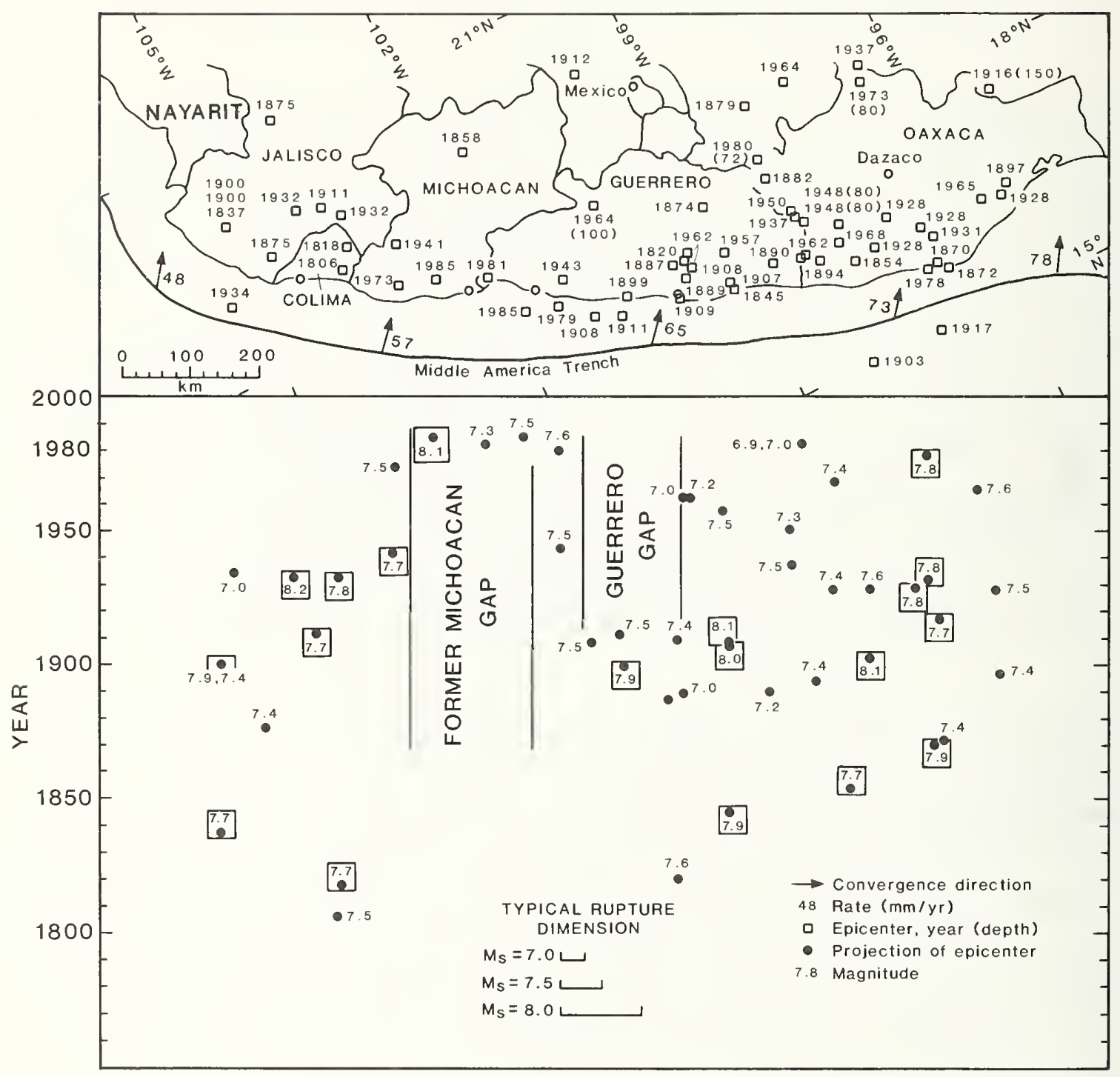

Figure 2.2. Historical seismicity of southwest Mexico. Bottom half of figure is a space-time diagram for the purpose of recognizing seismic gaps. September 1985 events are drawn in. (from Ref. [4]) 

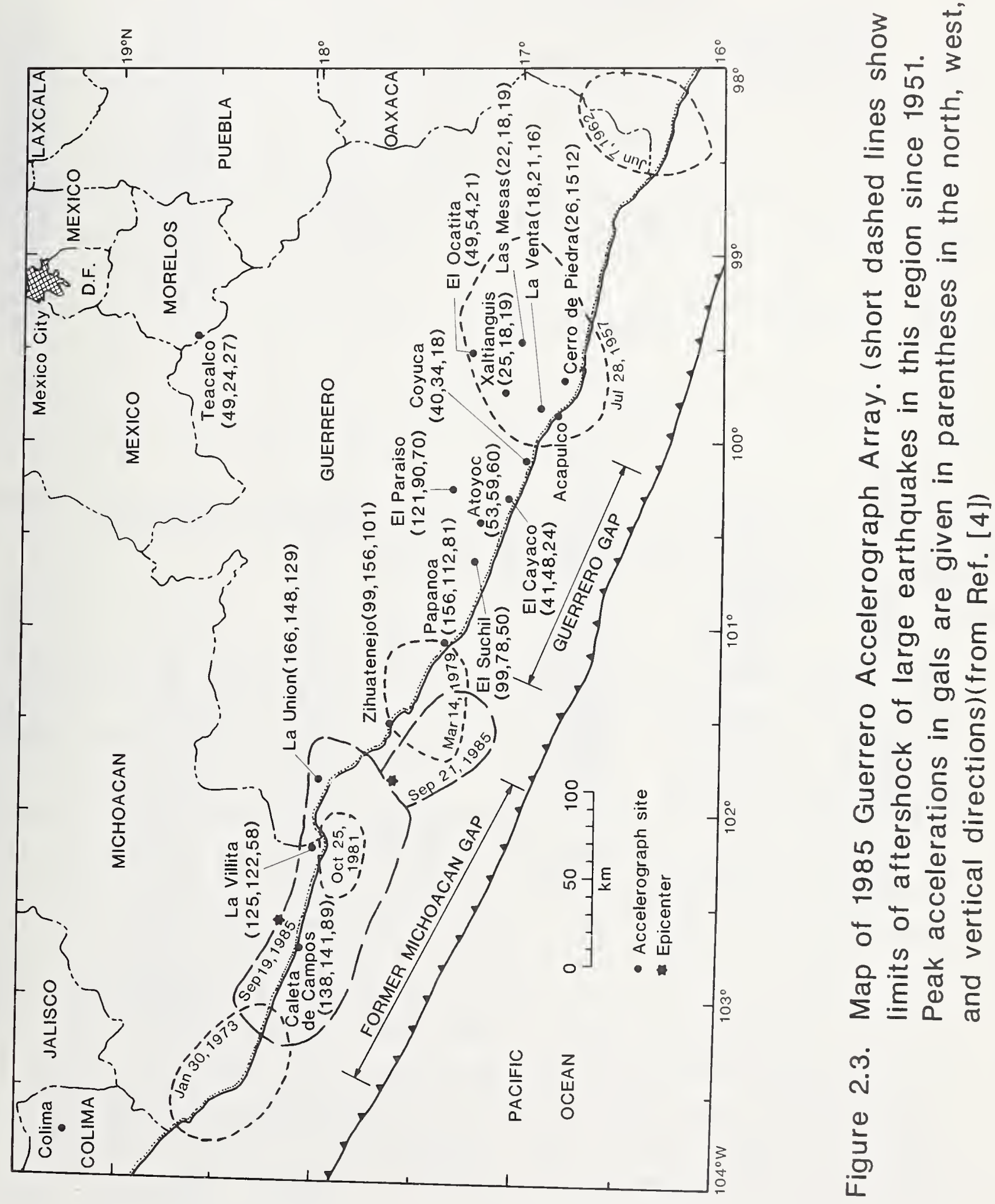
Table 2.1 Strong Motion Data from the Guerrero Array

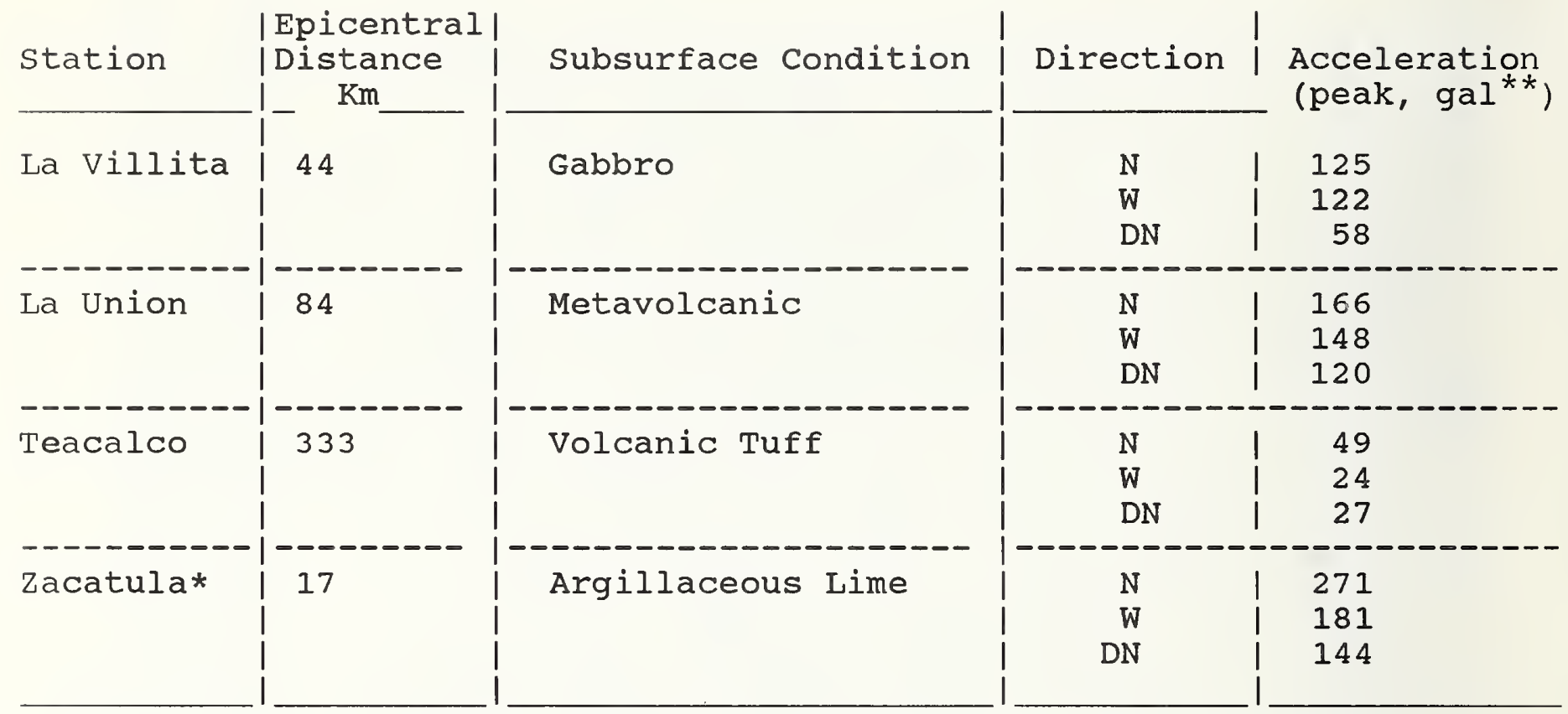

* not part of the Guerrero Array but provided here for comparison and to show effect of subsurface condition

$* 1$ gal $=10 \mathrm{~mm} / \mathrm{sec}^{2}$

and is about $100 \mathrm{~km}$ from Mexico City. All of these stations were placed on "the most competent rock outcrop consistent with the target location" [4]. It is therefore reasonable to assume that these accelerograms were not substantially modified by the effects of wave propagation through unconsolidated deposits. None of these stations recorded peak accelerations in excess of the 168 gal peak acceleration in the east-west direction ( $W$ ) recorded in Mexico City. For comparison, figure 2.5 shows acceleration records from a fourth station at a distance $17 \mathrm{~km}$ from the epicenter. This latter station, Zacatula is not part of the Guerrero array. The records presented by UNAM [7] show peak accelerations of 271 gal in the north-south direction. The station is located on a compact argillaceous lime formation and it is reasoned that the ground motion was amplified by that formation [4]. More extreme ground motion amplifications were encountered in Mexico City. 


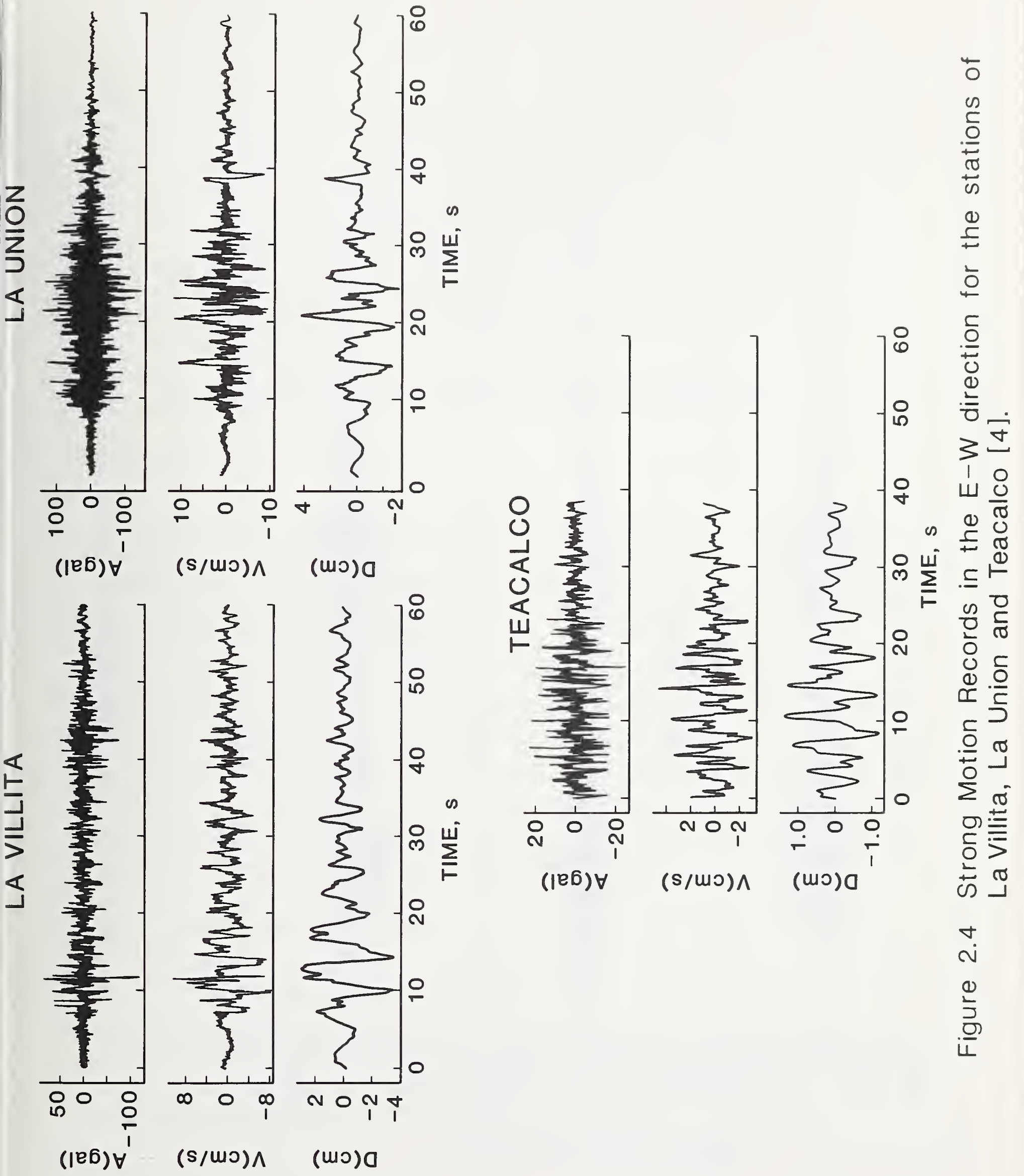




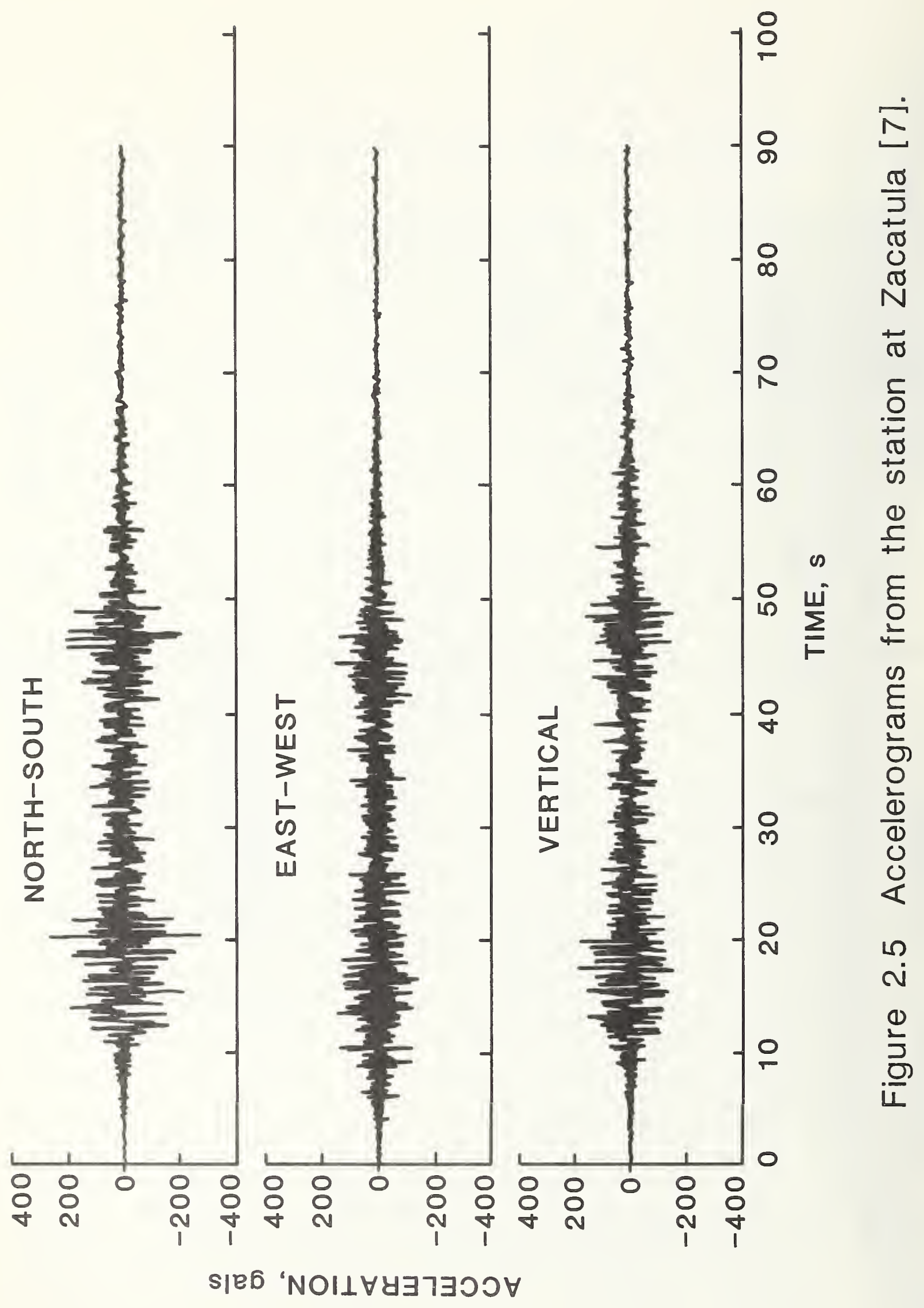




\section{GEOLOGIC SETTING AND GROUND MOTION IN MEXICO CITY}

\subsection{General}

The now well known unusual ground motion characteristics of Mexico city have been known at least since 1957, and site resonances within the city have been documented with instrumental recordings of two earthquakes in May 1962 at two sites: Torre Latino Americana and Alameda Park, several hundred meters to the west [8]. As proven once more during the september 19, 1985 earthquake, the unusual characteristics and the regional variation of the ground motions, as well as the response of structures to the ground motion, are directly related to the subsurface conditions in the Mexico city area. In this chapter information on the subsurface conditions and their effect on the ground motion in the Mexico city area is provided.

\subsection{Subsurface Conditions}

\subsubsection{Geological Profile and History}

Mexico City lies in the southwestern quadrant of a broad basin which was originally formed by block faulting of an uplifted plateau, approximately 30 million years ago. 
Figure 3.1, which was published by Marsal (1975) [9], shows a schematic geological cross section through the Mexico city area in the west to east direction. The figure was developed from information from one $2065 \mathrm{~m}$ deep boring (PPI in the figure), many shallower borings, geophysical explorations and surface studies. The age of the various formations encountered in boring PP1, as determined by $\mathrm{C}^{14}$ and $\mathrm{K}$-Ar dating, is shown in table 3.1, which is also taken from Ref.[9]. Figure 3.2 shows the surficial geology of the area. The geology of the area is discussed in references [9] and [10].

The basin that was originally formed by faulting was subsequently blocked by successive lava flows that formed a dam across the valley just south of Mexico City. This dam resulted in the formation of Lake Texcoco, which slowly began to fill with silt, clay, and ash from nearby volcanoes. Changes in the climate during this period led to oscillations in the level of the lake. Remnants of ancient beaches indicate that about 7000 years ago the level of the Lake was about $160 \mathrm{~m}$ above the main level of the present city. Indian civilizations developed around the lake, and the Aztecs built their capital on an island in Lake Texcoco, connected to the shore by causeways.

The spaniards, after conquering the Aztecs, destroyed the causeways. However, they soon learned that the causeways played an important role in flood control for the Aztec city. To solve the flood problem, canals were built to drain the lake to the north. Originally, drainage was provided by the Nechistongo cut which was completed in 1789. At the beginning of this century the two Tesquisquiac Tunnels and the Grand Drainage Canal were constructed, followed by a modern $45 \mathrm{~km}$ drainage tunnel. The maximum water level of Lake Texcoco at the end of the 19th century is outlined in figure 3.3 . 


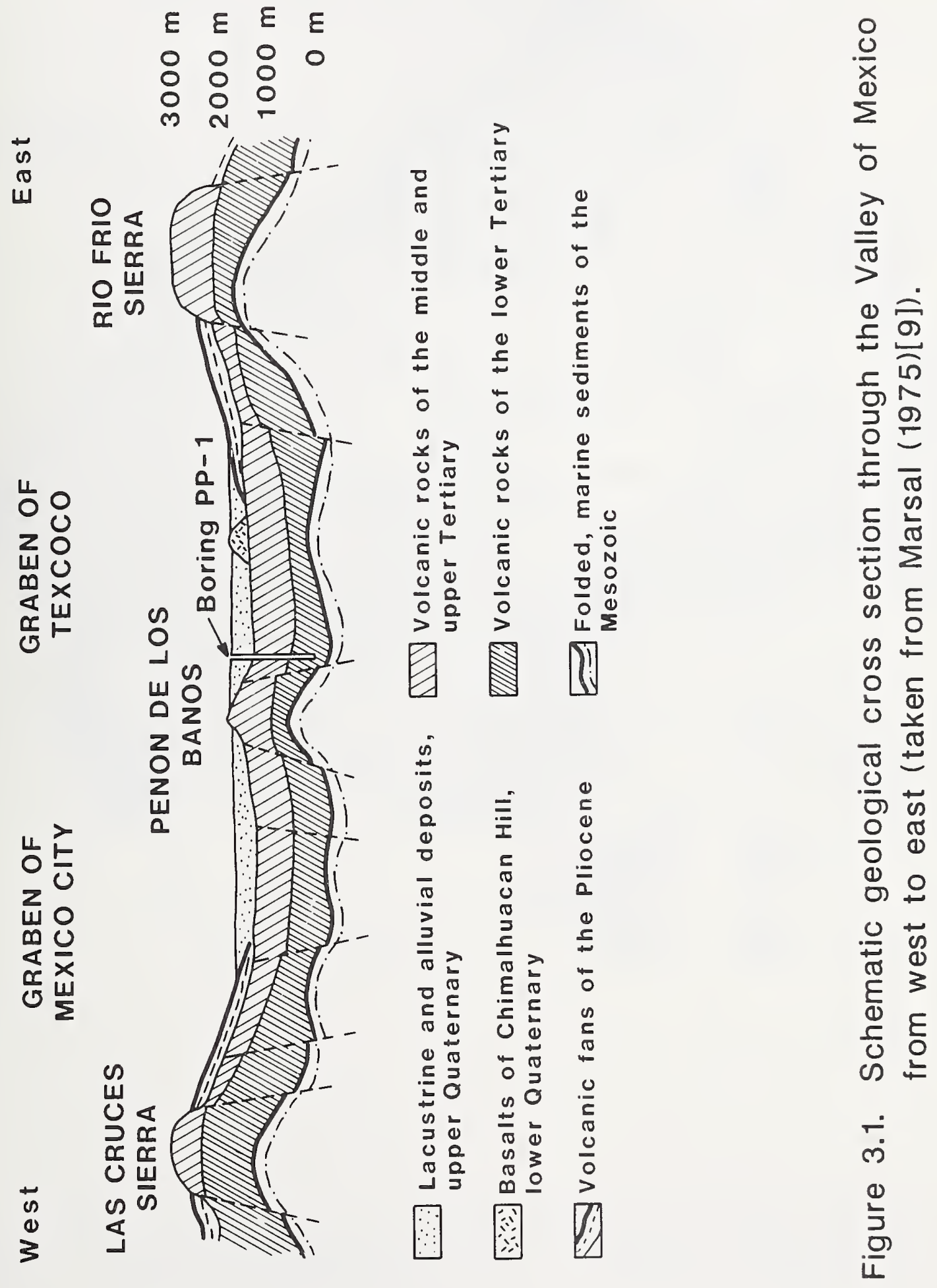


TABLE 3.1 STRATIGRAPHIC SEQUENCE AT LAKE TEXOCCO

(Taken from Marsal (1975) [9])

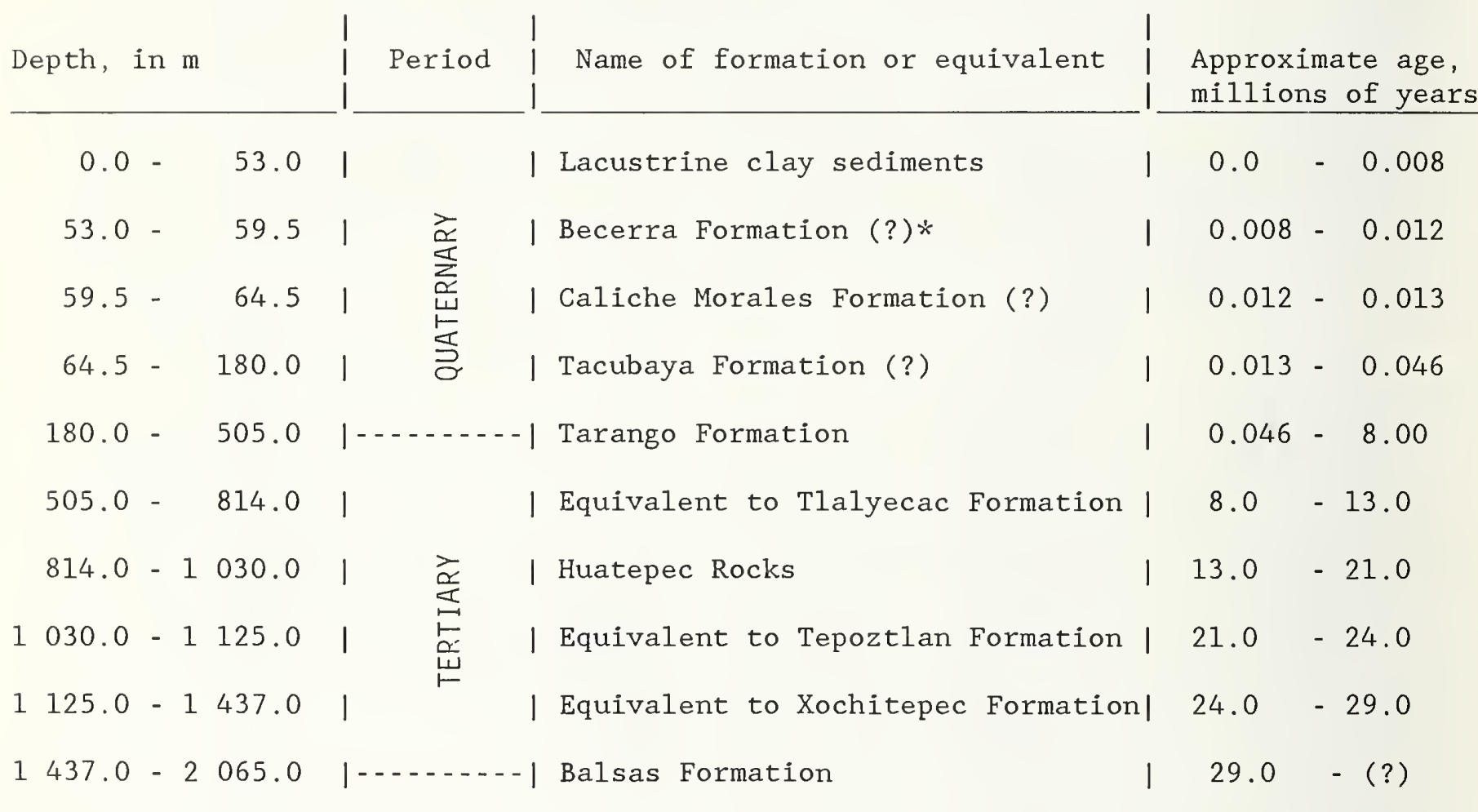

*Question marks indicate uncertain identification 


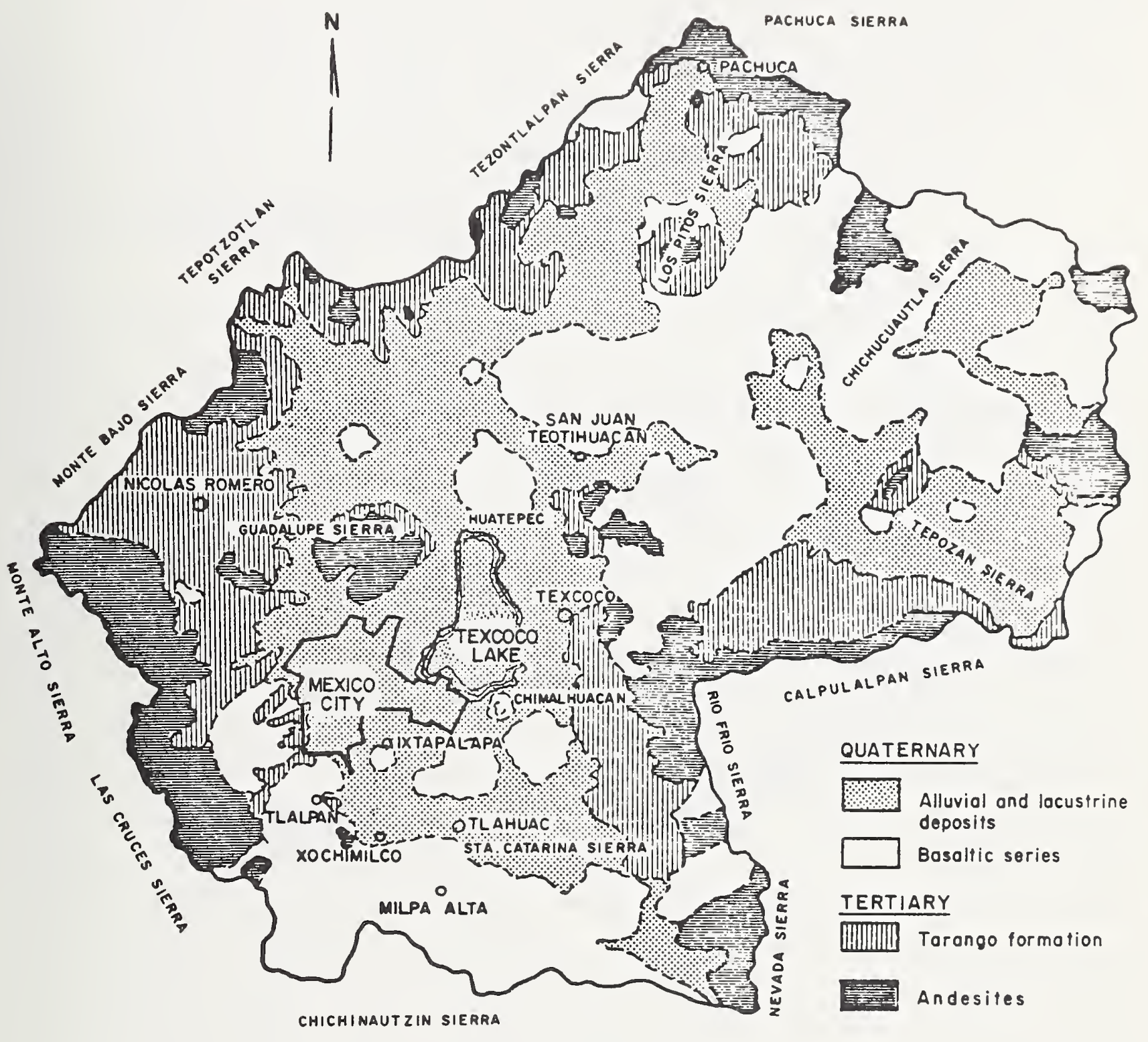

Figure 3.2 Surficial geology of the Mexico City area (taken from Marsal (1975)[9]). 


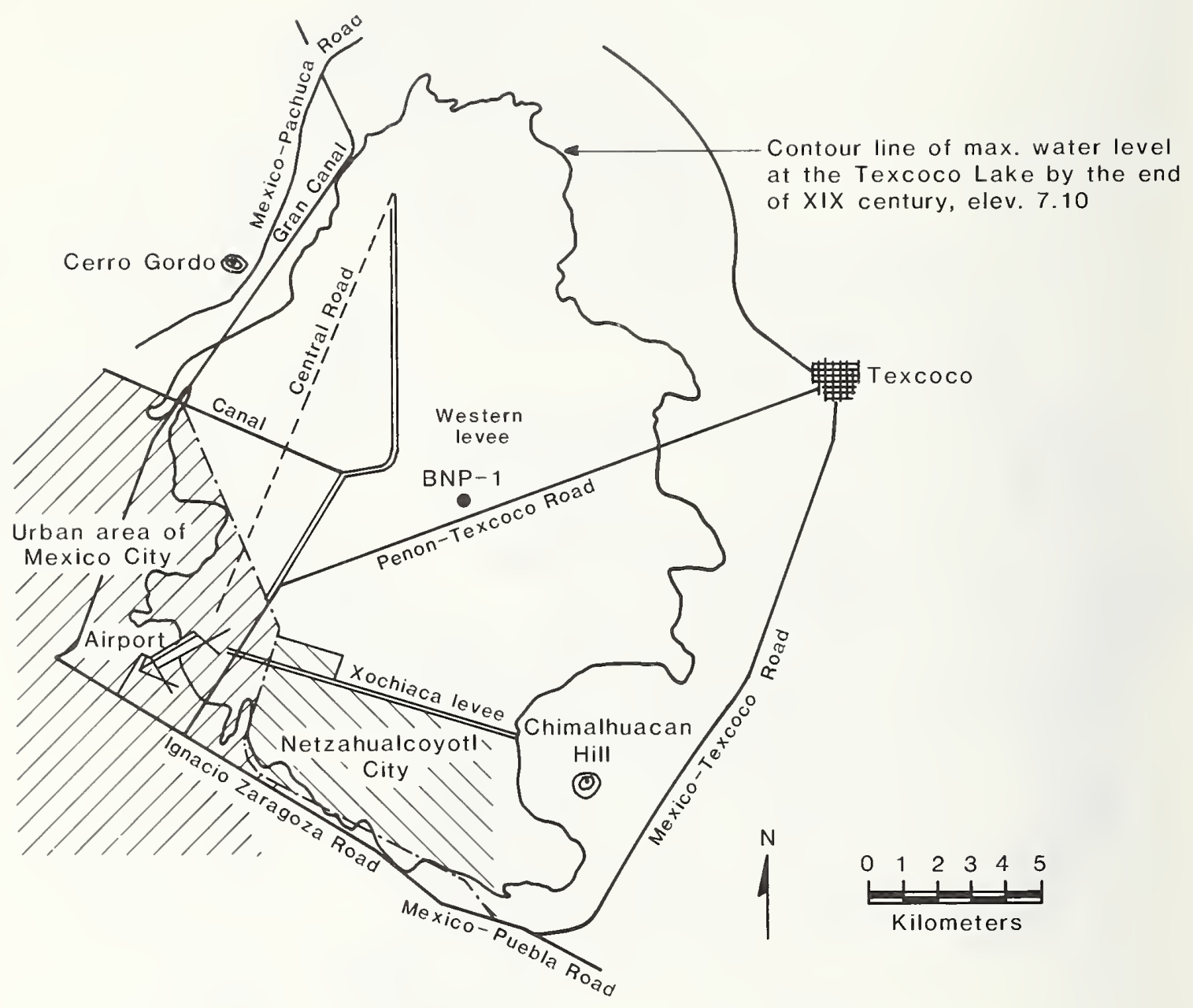

Figure 3.3. The Lake Texcoco area (taken from Marsal (1975)[9]. 
As the water level dropped, several small lakes were formed from the single lake and portions of the old lake bed were exposed around the ancient Aztec capital. This lake bed has been used for the expansion of Mexico City. Today much of the city rests on lake deposits, which overlay older sedimentary sequences.

\subsubsection{Stratigraphy of Soil Deposits}

Soil deposits generally consist of three consecutive layers of clays, separated by thinner layers of alluvial deposits, and underlain by a thick layer of dense deposits. Near the center of Lake Texcoco (boring BNP 1 in figure 3.3) the upper clay layer is approximately $35 \mathrm{~m}$ thick and is underlain by an approximately $3 \mathrm{~m}$ thick dense sandy clayey layer. The second clay layer is about $15 \mathrm{~m}$ thick and rests on a second sandy layer between 55 and $60 \mathrm{~m}$ below surface. A third clay layer extends to a depth of $82 \mathrm{~m}$ below surface and is underlain by another 100m of compact strata of sands, silts, and clays, intermized with some gravel. Figure 3.4 shows the soil profile at BNP 1 together with a plot of the water content $w_{i}=$ (weight of water/weight of solids) $x 100$ which is a measure of the density of the deposits. Note that the water content of the clay layers varies from 150 to 500 percent and tends to diminish with depth. The water content of the first sandy layer is about 100 percent, and that of the deep alluvial deposits is low. For comparison, figure 3.5 shows a boring log taken near the center of the city. Near the surface is a $5 \mathrm{~m}$ layer of man-made fill and desiccated clay. The upper clay layer is about $30 \mathrm{~m}$ thick and has water contents between 100 and 400 percent. The second clay layer is about 10m thick with a 200 percent water content and the third clay layer between 62 and $70 \mathrm{~m}$ below surface is quite dense. The difference between the stratigraphic profiles near the center of lake Texcoco and the profile shown in figure 3.5 is attributable to two factors: (1) the deposits near the center of the city have been compressed by the weight of man-made fill and buildings and by groundwater 


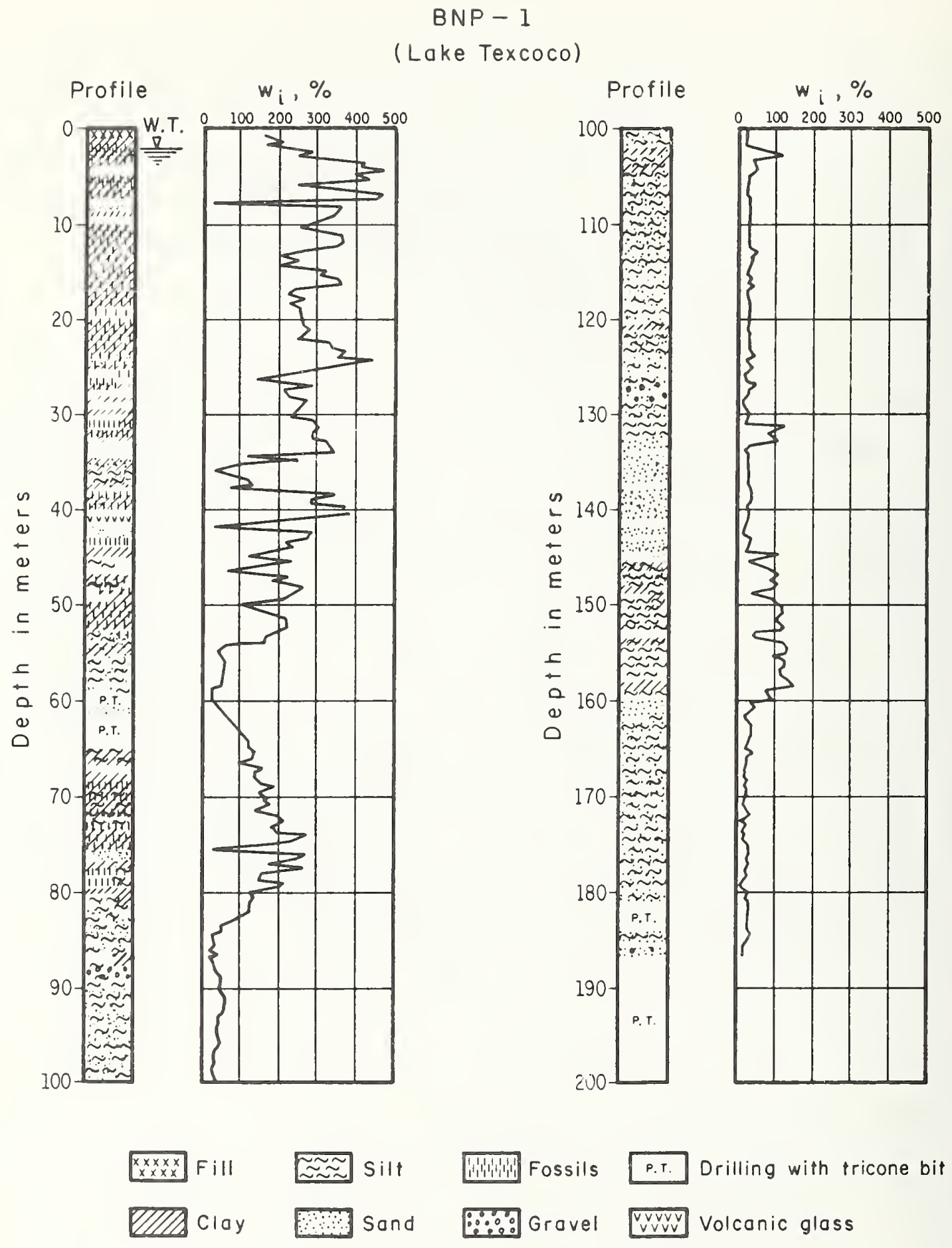

Figure 3.4. Soil profile near center of Lake Texcoco (Boring BNP1, taken from Marsal (1975)[9]). 


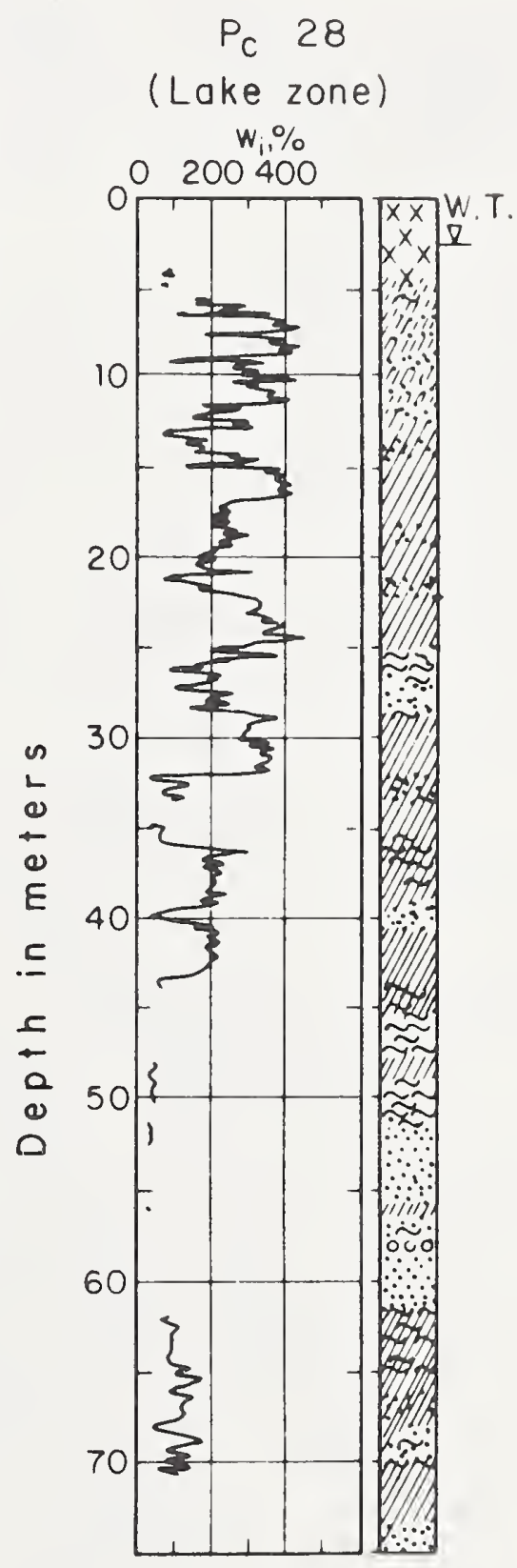

Figure 3.5. Typical boring log from the lake region of Mexico City (Boring PC 28, taken from Marsal (1975)[9]). 
withdrawal resulting in an increase in density and decrease in thickness; (2) the thickness of the deposits in general tends to decrease toward the edge of the basin, where there is a transition to shallow soil.

The effects of groundwater withdrawal on the consolidation of the deposits can be explained by their low permeability. Any volume change requires displacement of water from the pores of the soil. This process is very slow and may take decades or even centuries. In the meantime part of the load acting on the soil is supported by excess pore water pressures. When water is pumped out from intermediate sand layers, excess porewater pressures are relieved and negative pressure gradients are often created which further increase overburden pressures causing consolidation settlements, which can be of the order of several meters.

Figures 3.6 and 3.7 give an overview of the soil conditions in the part of Mexico City which is underlain by deep deposits (the "Lake Zone"). Figure 3.6 shows equal depth contours for the bottom of the upper clay layer that is the top of the first compact sandy layer which is called "capa dura" or "hard cap." This layer, which is from 0 to $6 \mathrm{~m}$ thick and averages about $3 \mathrm{~m}$ supports many of the pile foundations for the taller structures. Figure 3.7 shows equal depth contours for the top of the "deep deposits," which may also include the third clay layer. overall data on the depth of bedrock are not available, since most borings stop either at the first sand layer or near the top of the deep deposits. The depth of the phreatic surface is approximately $2 \mathrm{~m}$ over most of the "Lake Zone" of Mexico City.

In accordance with the different types of foundation conditions encountered, Mexico City has been subdivided into three principal zones: the "Lake Zone" which is underlain by deep deposits; the "Transition Zone" where the soil deposits become progressively shallower and consist of erratically interspersed alluvial and 

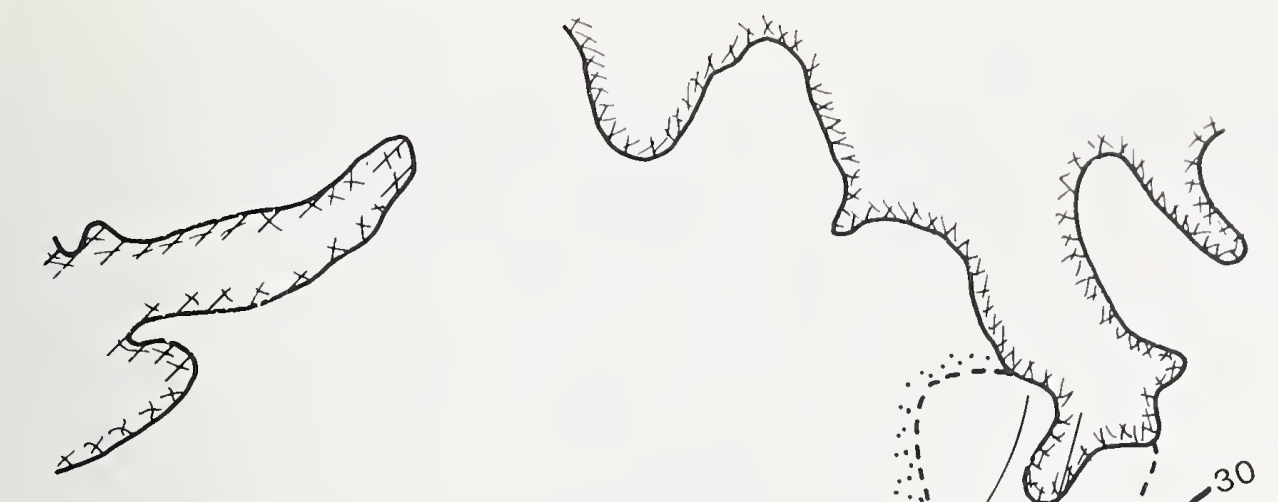
- Strong motion
seismographs

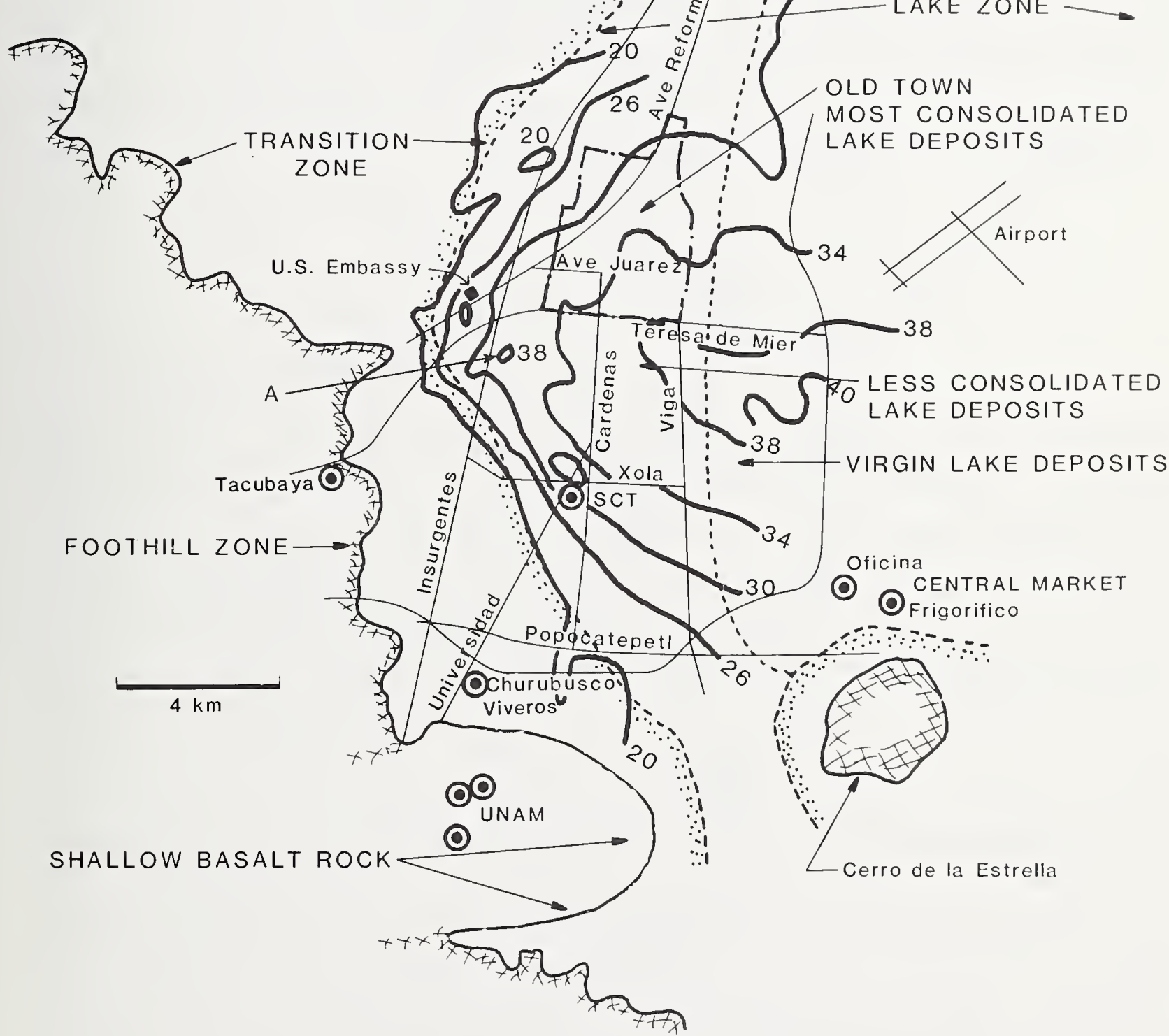

Figure 3.6. Depth contours for bottom of upper clay layer (after Resendiz et al. (1970)[11]. 

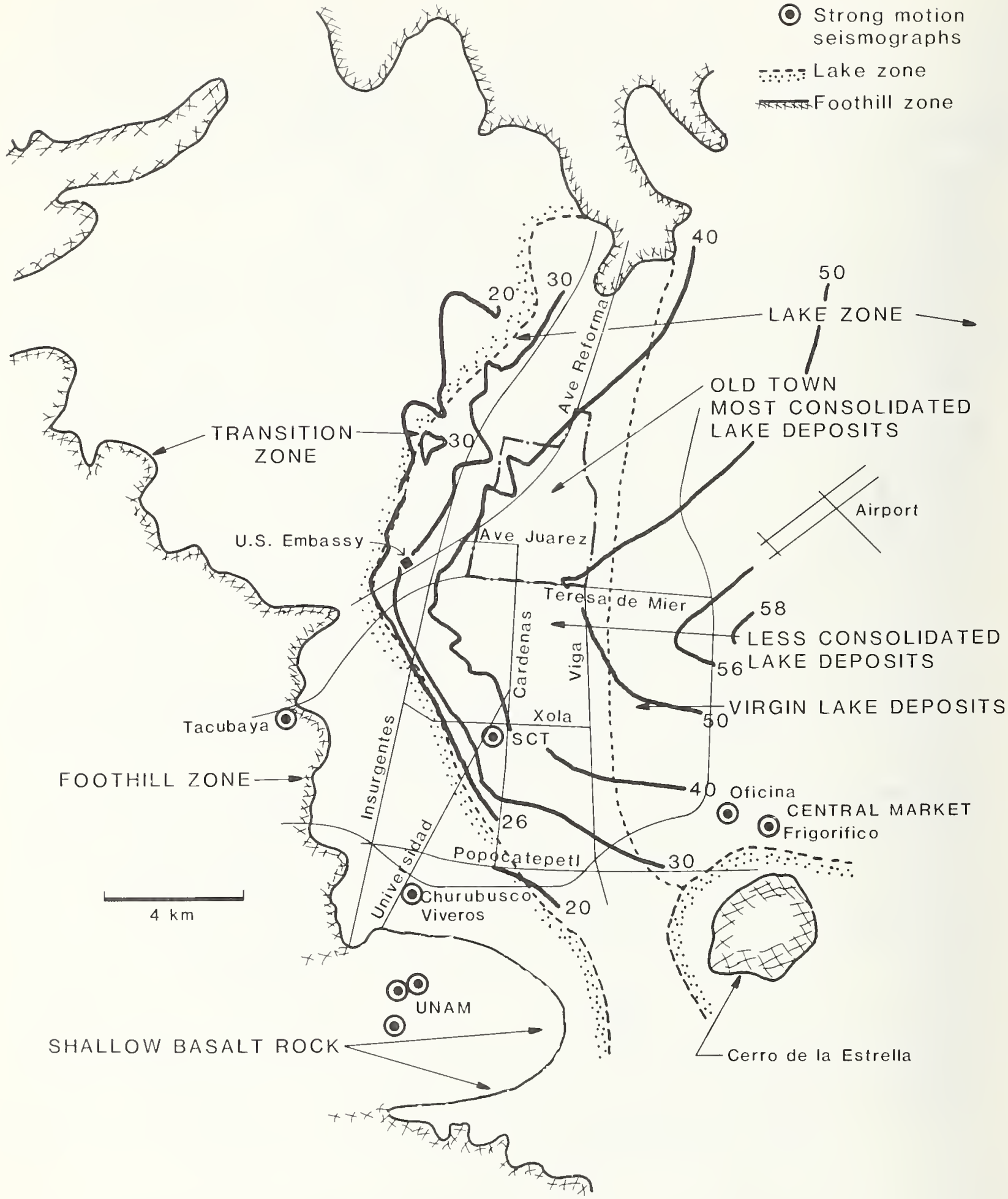

Figure 3.7. Depth contours for top of deep deposits (after Resendiz et al. (1970)[11]. 
lake deposits, and the "Foothill Zone" where shallow, compact deposits of lava rock are encountered. The three zones are shown in figure 3.8. Only the Lake zone will be discussed herein, since earthquake damage in the other zones has been minor. Note that within the Lake zone the limits of the old city are delineated, since in that area the consolidation of the clay layers, resulting from man-made fill, construction, and groundwater withdrawal was the greatest. The lake zone is further subdivided into "consolidated" (often overconsolidated) lake deposits (by loading and groundwater withdrawal in the zone of the city center) and "virgin" (normally consolidated) lake deposits (Central de Abastos, airport and toward the east).

3.2.3. Engineering Characteristics of Soil Deposits

(1) Mechanical Properties

The average properties of the three clay layers encountered in the borings in figures 3.4 and 3.5 are shown in table 3.2 . Note that the initial void ratio is lower in the soils within the city. Figure 3.9 shows a plot of the average mechanical properties of clays, derived from many tests, as a function of the water content. As expected, strength increases and compressibility decreases with decreasing water content. Note that there is a large difference between the undisturbed unconfined compressive strength ( $\left.q_{u i}\right)$ and the remolded strength ( $q_{u r}$ ). This means that the clays are sensitive and will lose much of their shear strength when subjected to large shear deformations. Another important property when evaluating earthquake effects is the dynamic shear modulus. Some determinations have been made by Marsal, et al (1959) [10] by torsional dynamic tests. Typical values of the dynamic shear modulus (G) reported by Marsal are $1.2 \mathrm{MPa}$ for $\mathrm{w}_{i}>250$ percent, and $2.5 \mathrm{MPa}$ for 150 percent $<\mathrm{w}_{i} \leq$ 250 percent. More recent information obtained in UNAM indicates that the maximum dynamic shear modulus for the clay deposits 
Table 3.2 Average Values of Index Properties in Borings BNP-1 and $\mathrm{P}_{\mathrm{C}}-28$

\begin{tabular}{|c|c|c|c|c|c|c|}
\hline \multirow[b]{2}{*}{ Property } & \multicolumn{3}{|c|}{ BNP - 1} & \multicolumn{3}{|c|}{$P_{C}-28$} \\
\hline & FAS & $C D$ & FAI & FAS & $C D$ & FAI \\
\hline $\begin{array}{l}\text { Natural water content, w } \\
\text { in } 8\end{array}$ & 290 & 78 & 203 & 270 & 58 & 191 \\
\hline Liquid limit $w_{L}$, in $\frac{8}{8}$ & 299 & 85 & 254 & 300 & 59 & 288 \\
\hline Plastic limit, $\mathrm{w}_{\mathrm{p}}$, in $\frac{8}{8}$ & 72 & 34 & 66 & 86 & 45 & 68 \\
\hline Specific gravity, $\mathrm{s}_{\mathrm{s}}$ & 2.55 & 2.60 & 2.61 & 2.30 & 2.58 & 2.31 \\
\hline Initial void ratio, $e_{i}$ & 7.89 & 1.40 & 6.59 & 6.17 & 1.36 & 4.53 \\
\hline $\begin{array}{l}\text { Unconfined compressive } \\
\text { strength, } \mathrm{q}_{u} \text {, in } \mathrm{kg} / \mathrm{cm}^{2}\end{array}$ & 0.72 & $>2.0$ & 1.0 & 0.85 & 2.4 & 1.6 \\
\hline FAS = upper clay layer & & & & & & \\
\hline FAI = lower (second) clay & & & & & & \\
\hline$C D=$ capa dura (first sano & & & & & & \\
\hline
\end{tabular}



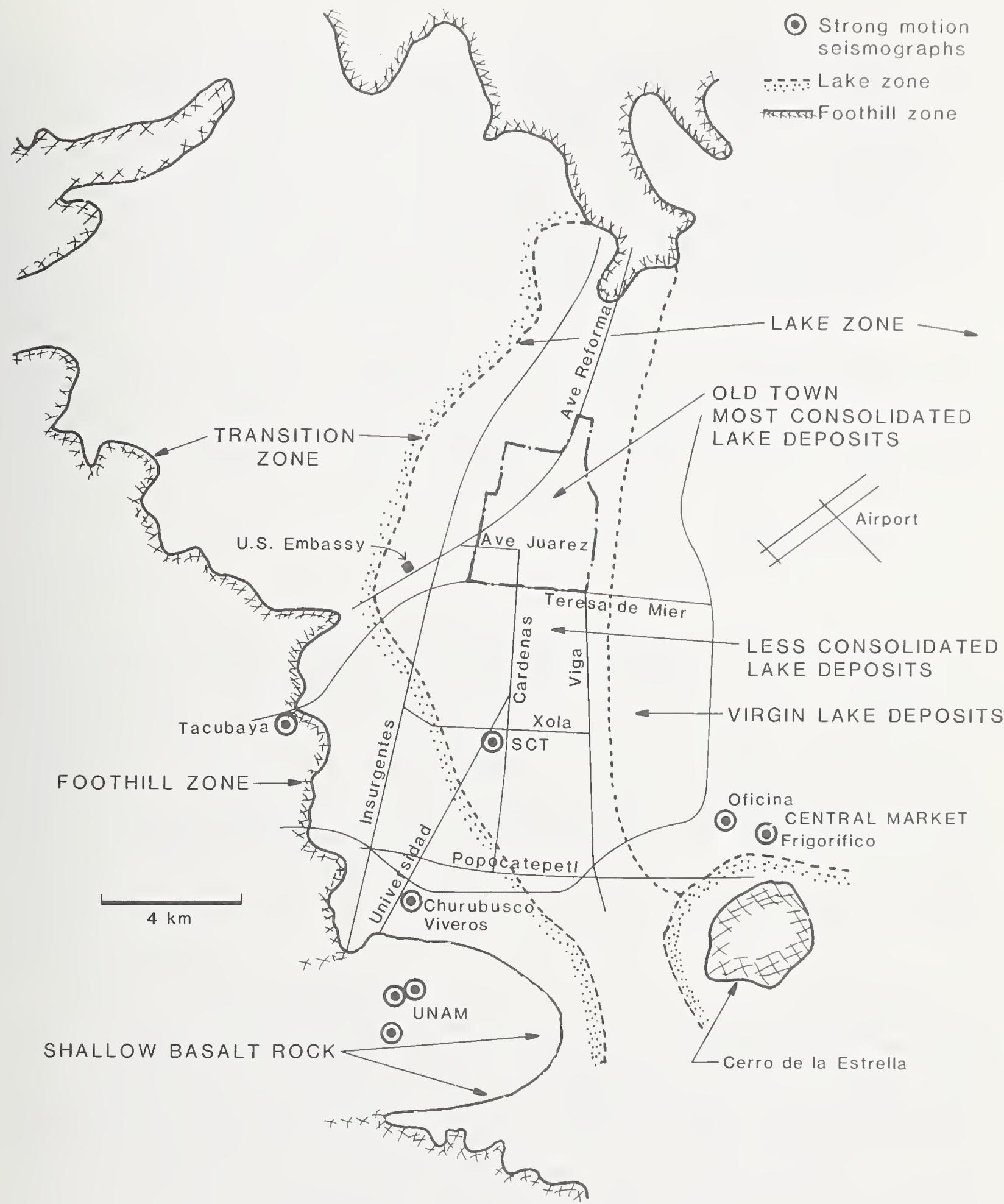

Figure 3.8. Zoning of Mexico City in accordance with subsurface conditions. 

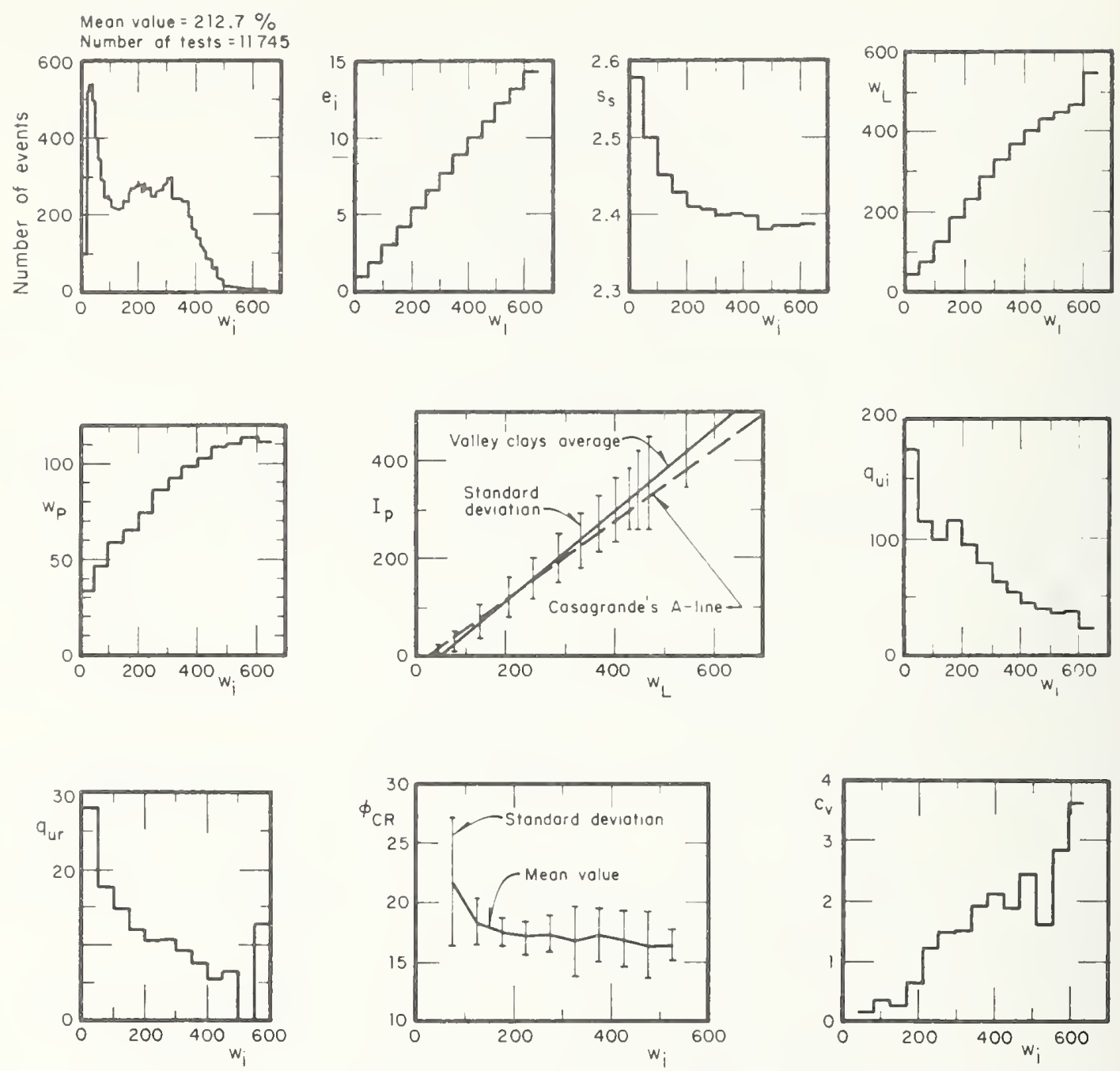

List of Symbols:
$w_{i}$, natural water content, in percent
$q_{u}$, compressive strength
$e_{i}$, initial vold ratio
ss, specific gravity
wh, liquid limit, in percent
$w_{p}$, plastic limit, in percent
$q_{u r}$, compressive strength (undisturbed), in kPa
(remolded) in $\mathrm{kPa}$
${ }^{\phi}$ CR. friction angle, con-
$l_{p}$, plasticity index $=W_{L}-W_{P}$ solldated-undrained tests tion, in $\mathrm{mm}^{2} / \mathrm{sec} \times 10^{-1}$

Figure 3.9. Mechanical properties of Mexico City clays as a function of water content (taken from Resendiz, et al (1970)[11]). 
ranges from 3 to 6-7 $\mathrm{MPa}$ and that the Damping Ratio for strains in the order of $10^{-1} \%$ is approximately 6 percent. It is also important to note that the water content decreases with a decreasing thickness of the clay layer. This tendency is illustrated in figure 3.10 which was presented by Resendiz, et al. (1970) [11]. The phenomenon is attributed to the increase in the rate of consolidation with decreasing layer thickness.

The properties of the first firm layer (capa dura) were also well defined. Figure 3.11 shows histograms of layer thickness, grain size characteristics, and standard Penetration Test (SPT) blow count.

(2) Subsidence

The clay deposits in the Mexico city area are slowly consolidating under the effect of their own weight, the weight of superimposed fill and structures, and the effect of groundwater withdrawal. Thus, the Lake Region of Mexico City is subsiding. Figure 3.12 illustrates the problem. The Monument of the Revolution, which is supported by end bearing timber piles, slowly emerges as the surrounding ground subsides. As the elevation difference increases, steps have to be added around the periphery of the monument.

The rate of subsidence is not uniform and depends on the amount of water withdrawal and surface loading. Since the turn of the century, subsidence in the center of the city ranged from 3 to $8.5 \mathrm{~m} \mathrm{[9].} \mathrm{The} \mathrm{rate} \mathrm{of} \mathrm{settlement} \mathrm{was} \mathrm{greatest} \mathrm{in} \mathrm{the} \mathrm{1950's}$ (about $0.5 \mathrm{~m} /$ year) and has since decreased to less than $0.1 \mathrm{~m} /$ year as the rate of groundwater pumping was reduced. There is evidence that in many locations the pattern of settlement was irregular resulting in erratic subsurface conditions [11]. Data in Reference 11 indicate that in one case about 60 percent of the settlement was attributed to the compression of the upper clay layer. 


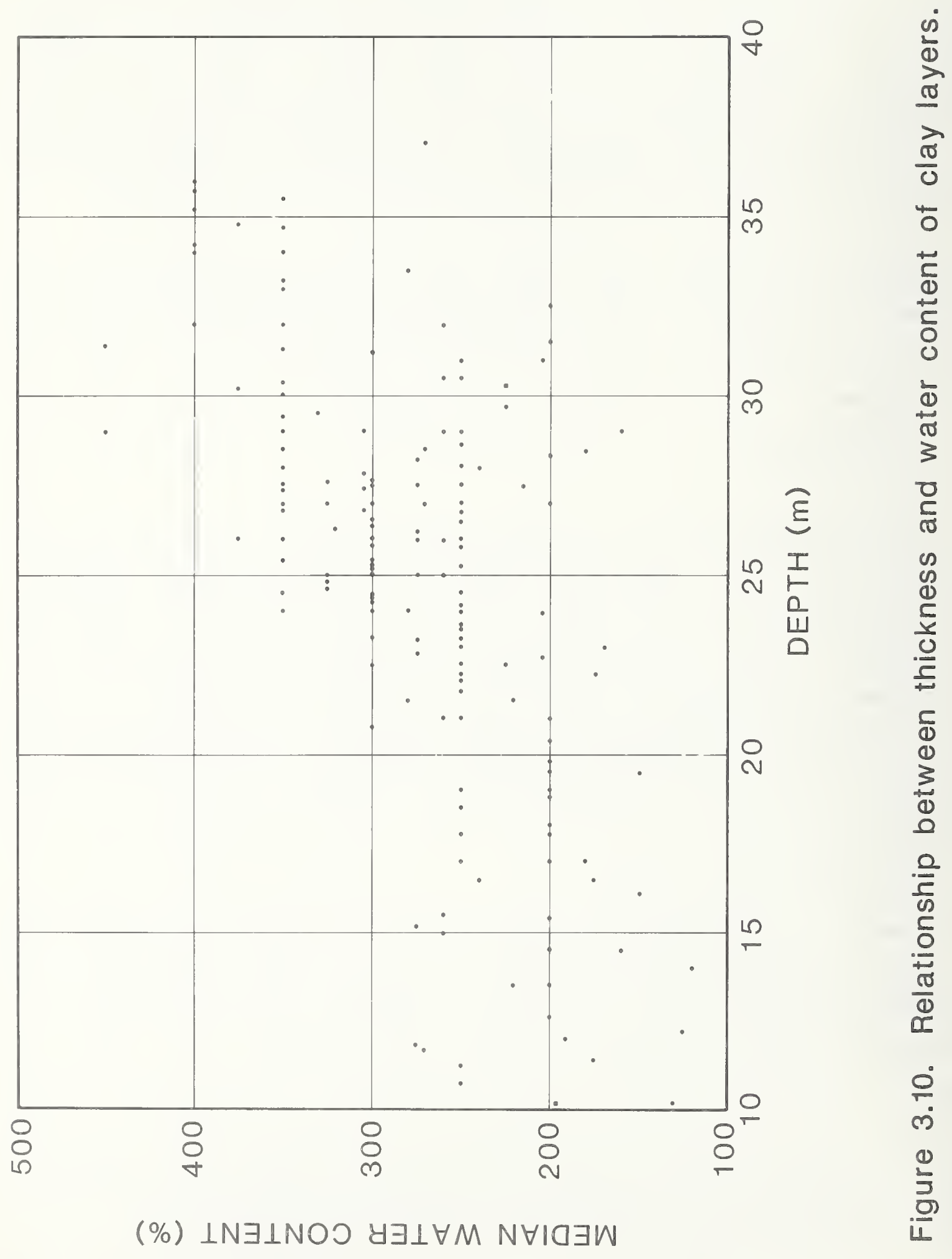



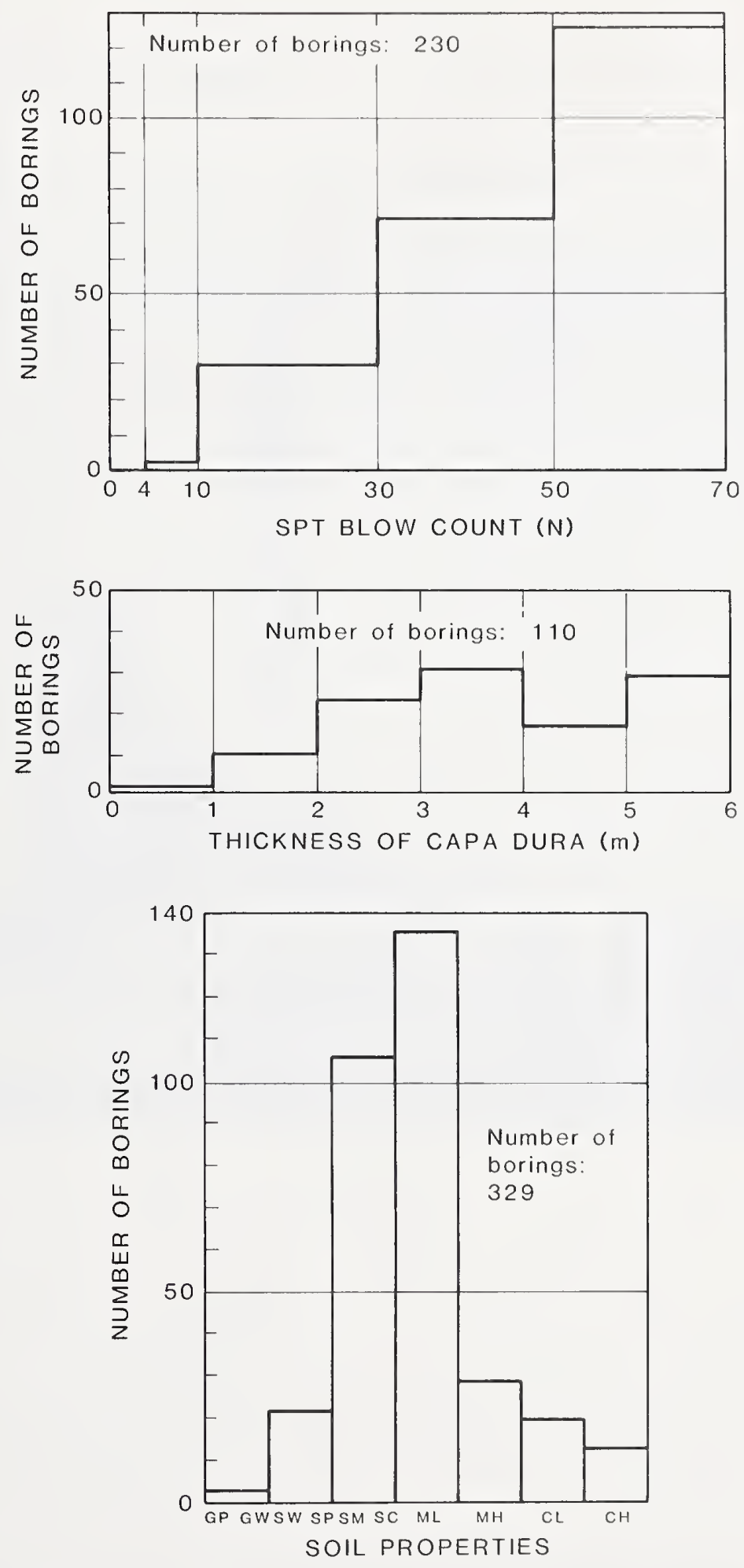

Figure 3.11. Physical characteristics of the Capa Dura. 


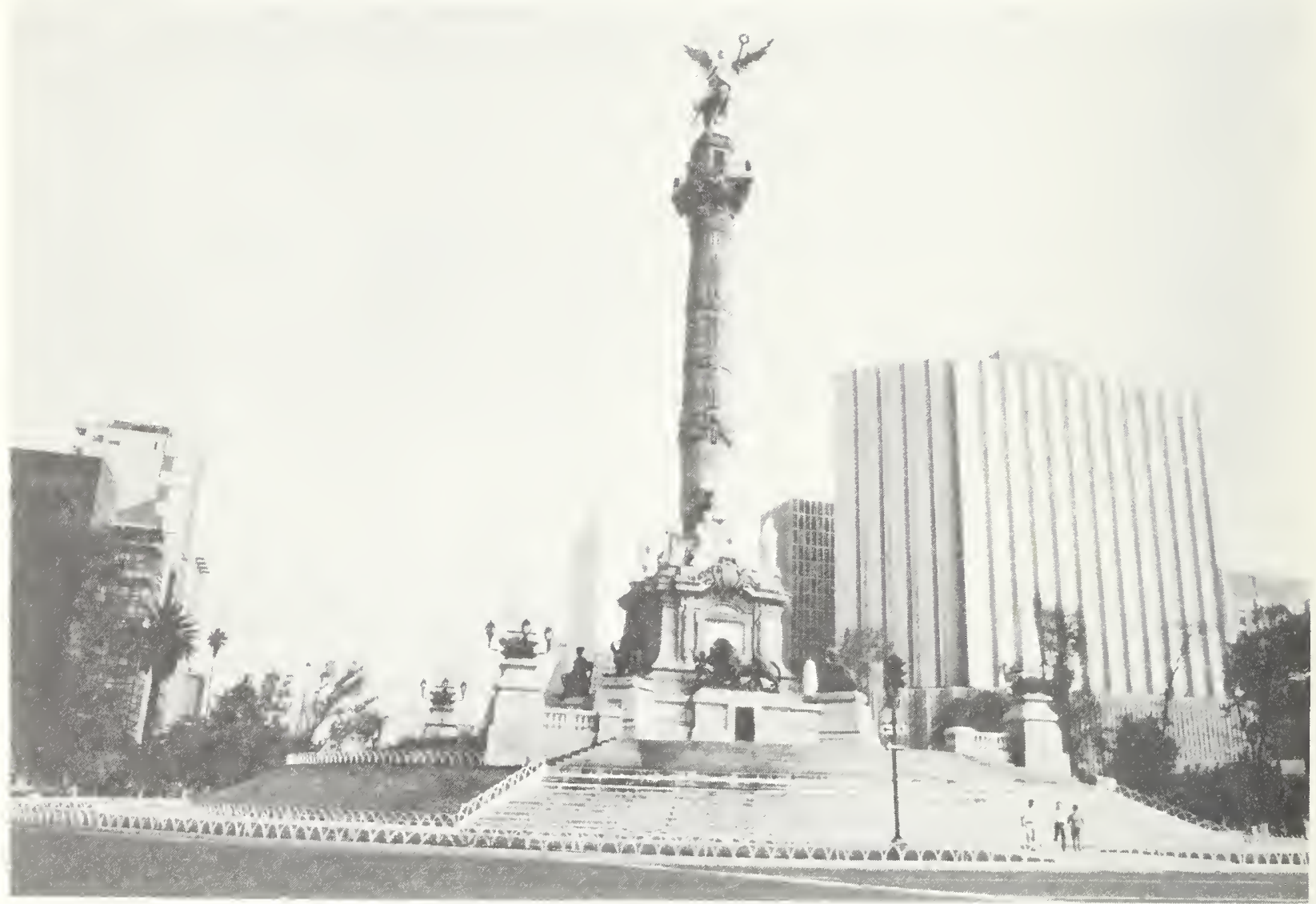

Figure 3.12. Emergence of the Monument of the Revolution from the surrounding terrain. 
(3) Foundation Characteristics

Foundation design in Mexico city has always been dominated by settlement control. Even many of the antique colonial structures were supported by 5 to $15 \mathrm{~m}$ long timber piles (pile driving is relatively easy in the sensitive clays). The most common foundation types used are: spread footings for very low structures ( 1 to 2 stories), mat foundations which sometimes use inverted arches or box foundations to spread the load, friction pile foundations within the upper clay layer and pile foundations resting on the "capa dura" or below the capa dura. The pile foundations are usually combined with mats, box foundations or heavy gradebeams. Excavation is widely used to compensate for all or part of the building weight, however, the use of this technique is limited by stability, heave, and settlement problems associated with deeper excavations. Sometimes excavations are executed in stages to minimize vertical and horizontal displacements of adjacent structures, caused by ground movement associated with bottom heave in the excavation. Foundation piles are subjected to large negative friction forces (downdrag forces exerted on the pile by the surrounding soil) as the penetrated clay layer is compressed. The ratio of negative friction forces to tip resistance of piles is sometimes artificially increased by reduced sections for piles penetrating to the capa dura or by design configurations of pile groups, in order to facilitate downward displacement as negative friction forces become large, and thereby to minimize the emergence of the supported buildings. Sometimes special piles are installed to provide the reaction forces for correcting excessive tilting caused by differential settlement. 
Under these conditions, it is reasonable to assume that:

1) many building foundations are subject to stresses introduced by differential settlements caused by nonuniform soil conditions and adjacent construction

2) many buildings were out of plumb before the earthquake struck, causing a " P - delta" effect (eccentricity of gravity loads which exerts moments on columns).

3) pile foundations are subjected to negative friction forces.

These conditions contributed to some of the structural failures caused by the earthquake.

3.3 Ground Motions in the Mexico City Area

\subsubsection{Ground Motion Characteristics}

Peak accelerations for stations in the Mexico City area are summarized in table 3.3, which also lists subsurface characteristics at these stations (refer to figure 3.8 for locations). For comparison, the Teacalco record from table 2.1 is also shown in table 3.3. Figures 3.13, through 3.16 show acceleration records obtained from stations at UNAM, the Communications Center (SCT), and the Central Produce Market, respectively [12-14]. Figure 3.17 shows a comparison of the east-west acceleration records for four stations in the Mexico City area. Figures 3.18 and 3.19 show strong motion records in the east-west direction for the SCT station [13] and the central Produce Market site [14], respectively, to provide information on the magnitude of ground displacements and velocities. 
Table 3.3 Peak accelerations in the Mexico City Area

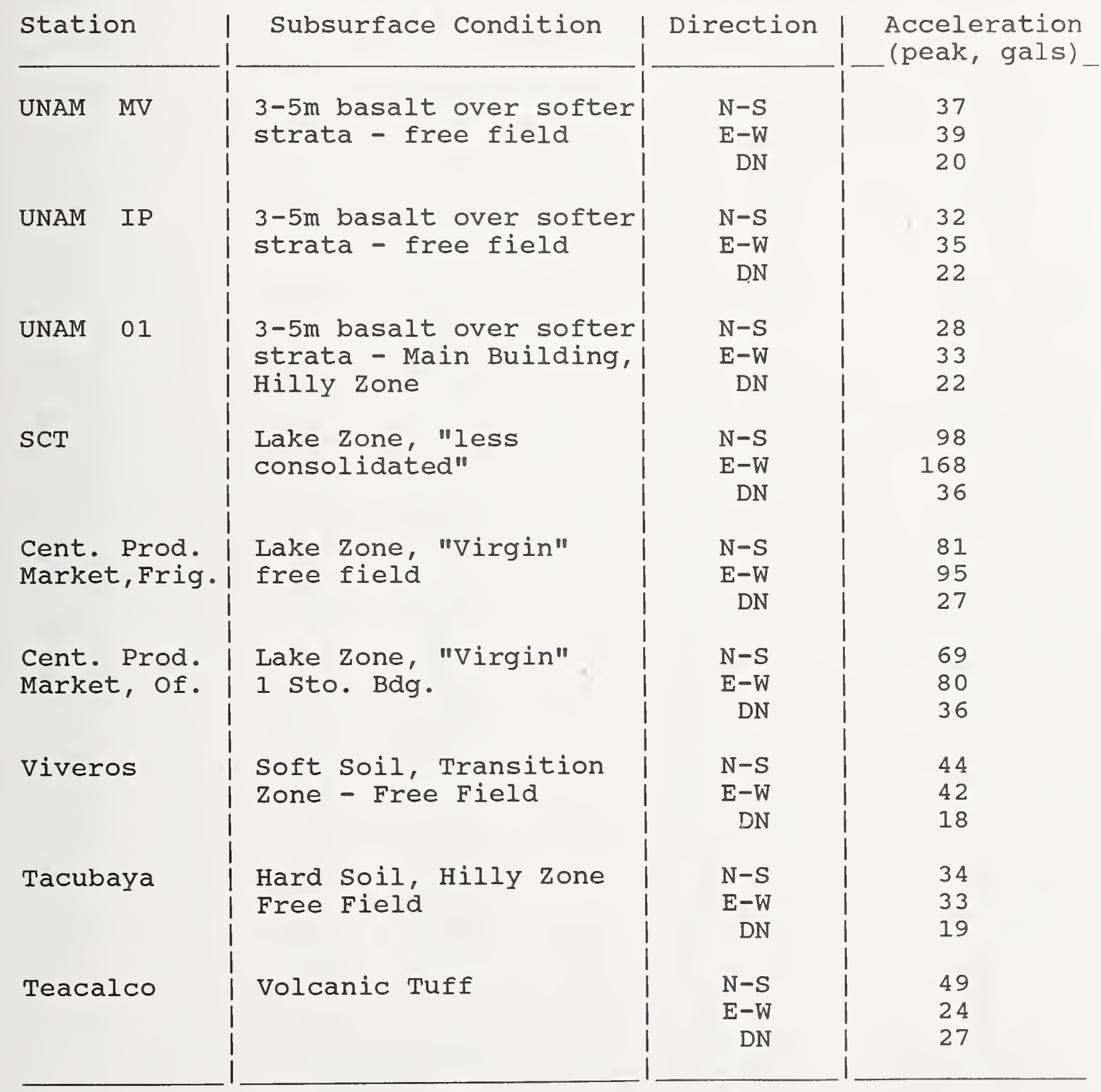




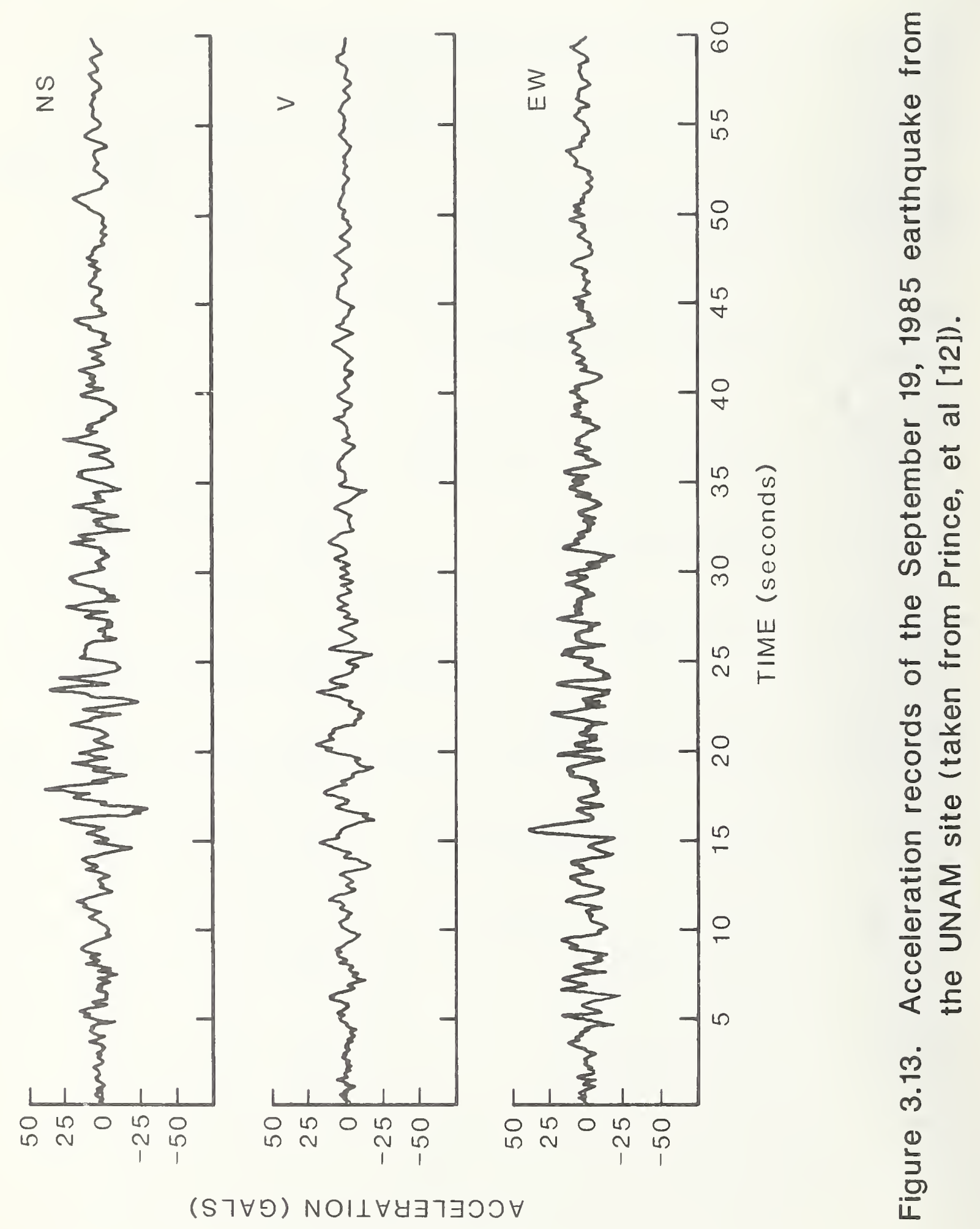




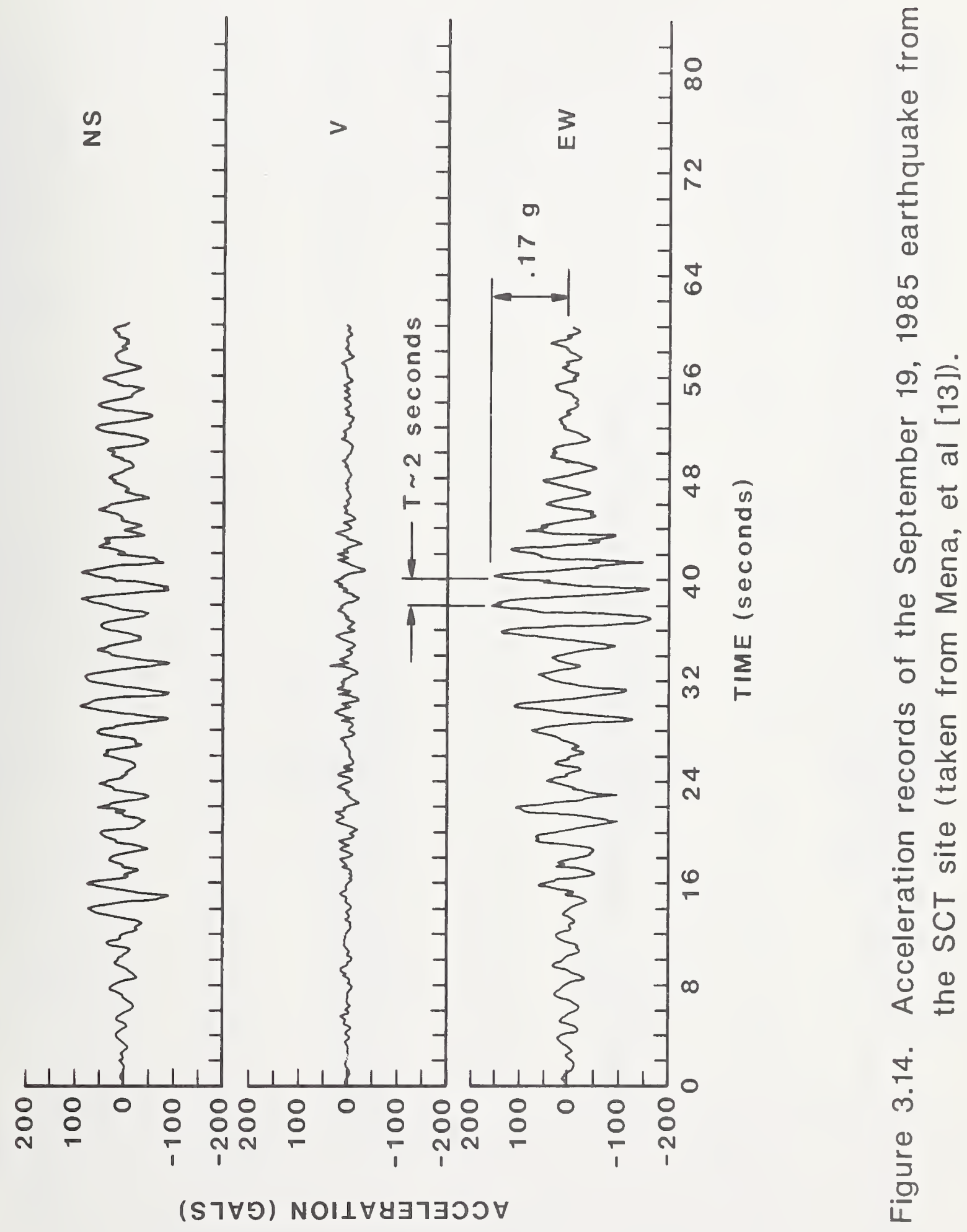




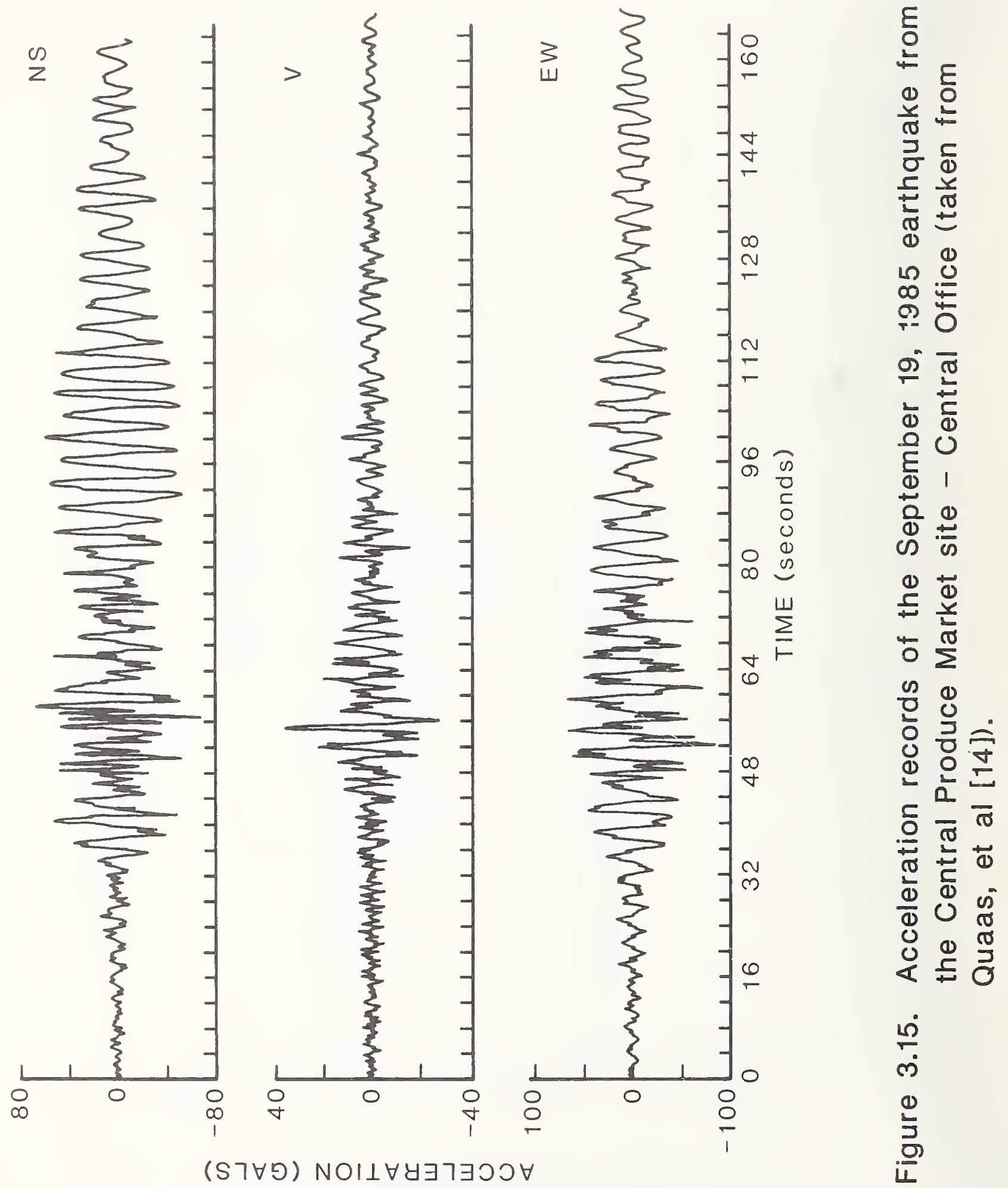




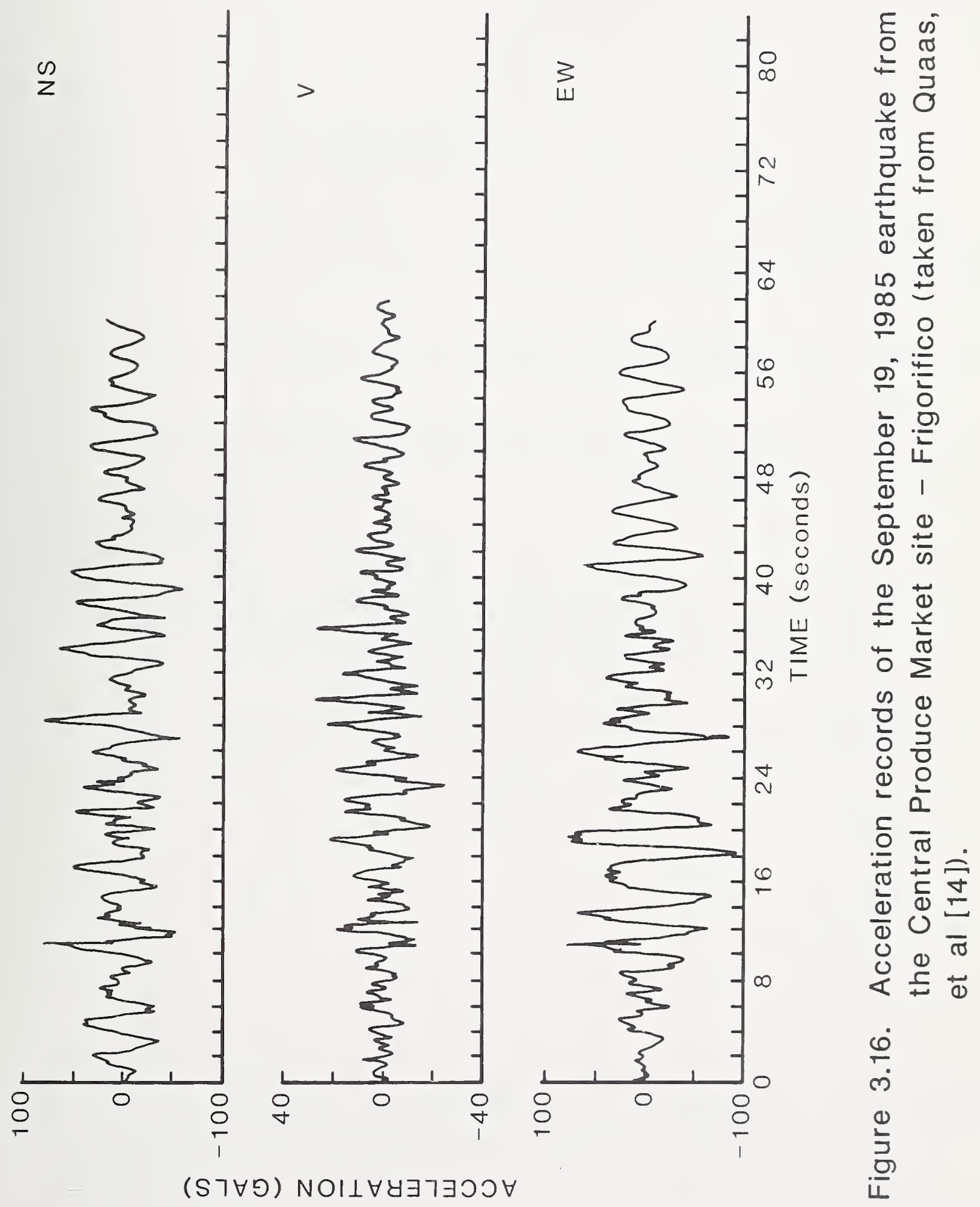




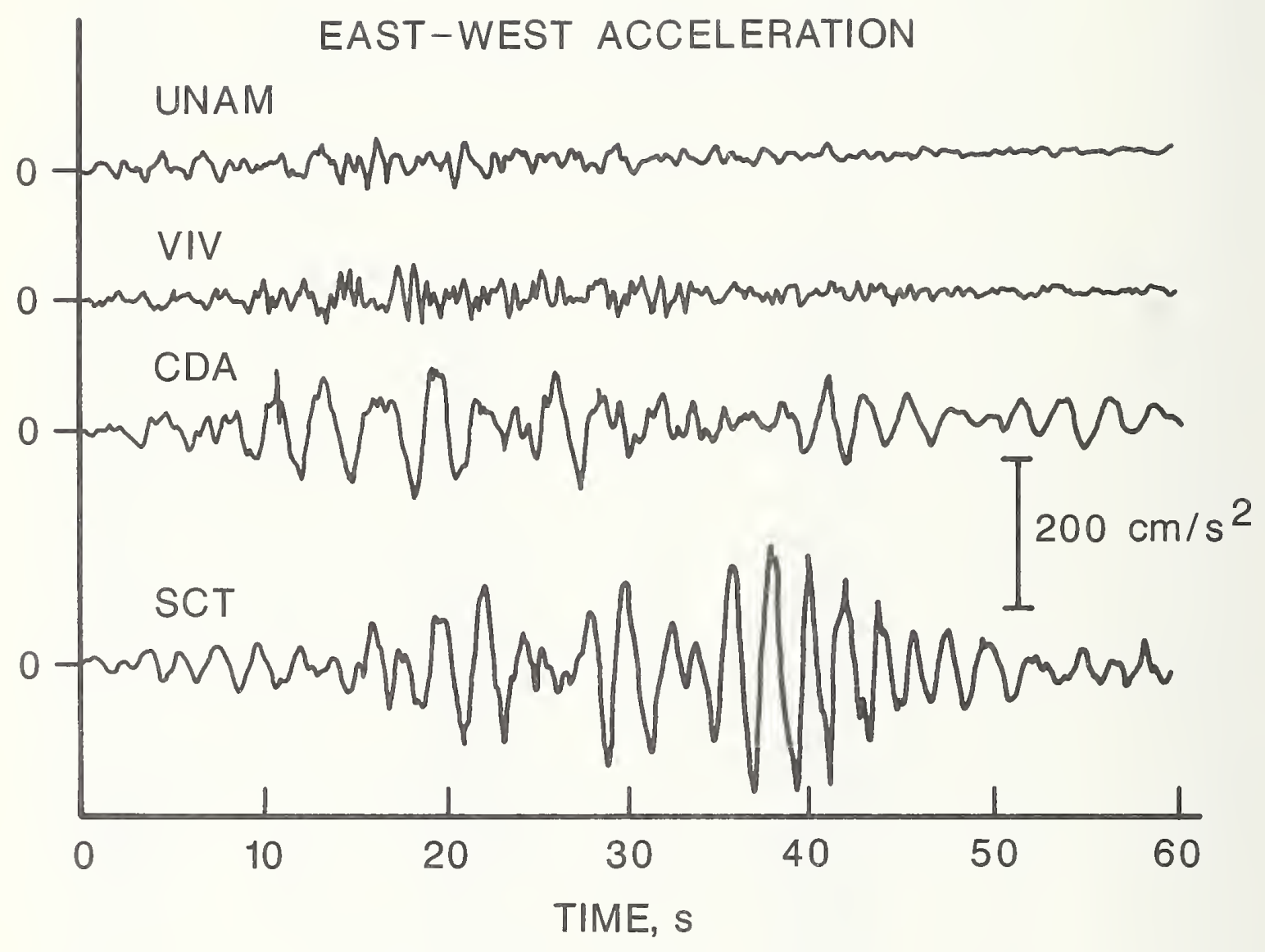

Figure 3.17. Comparison of acceleration records in the east-west direction from the Mexico City area (from Ref. [4]). 


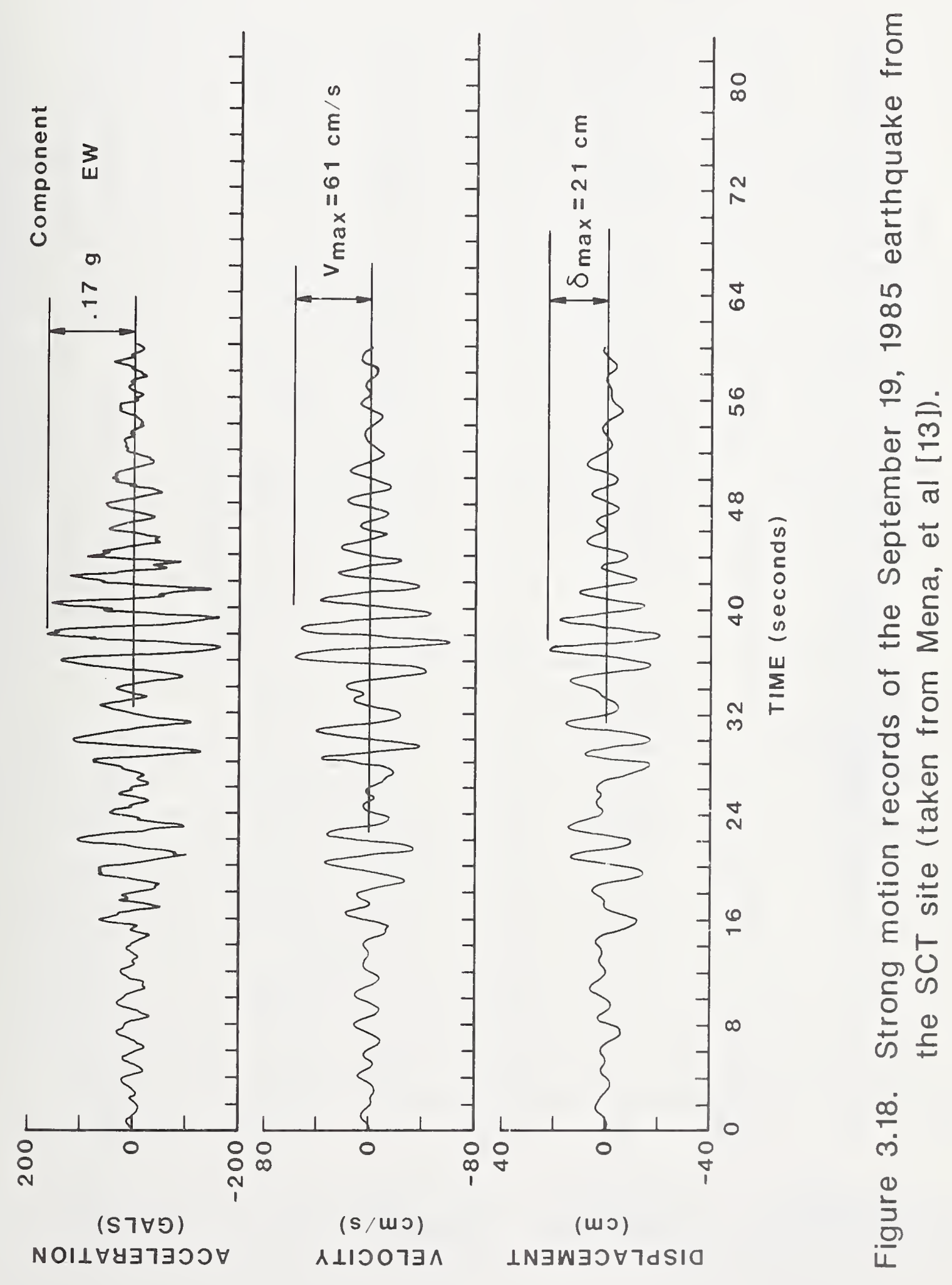




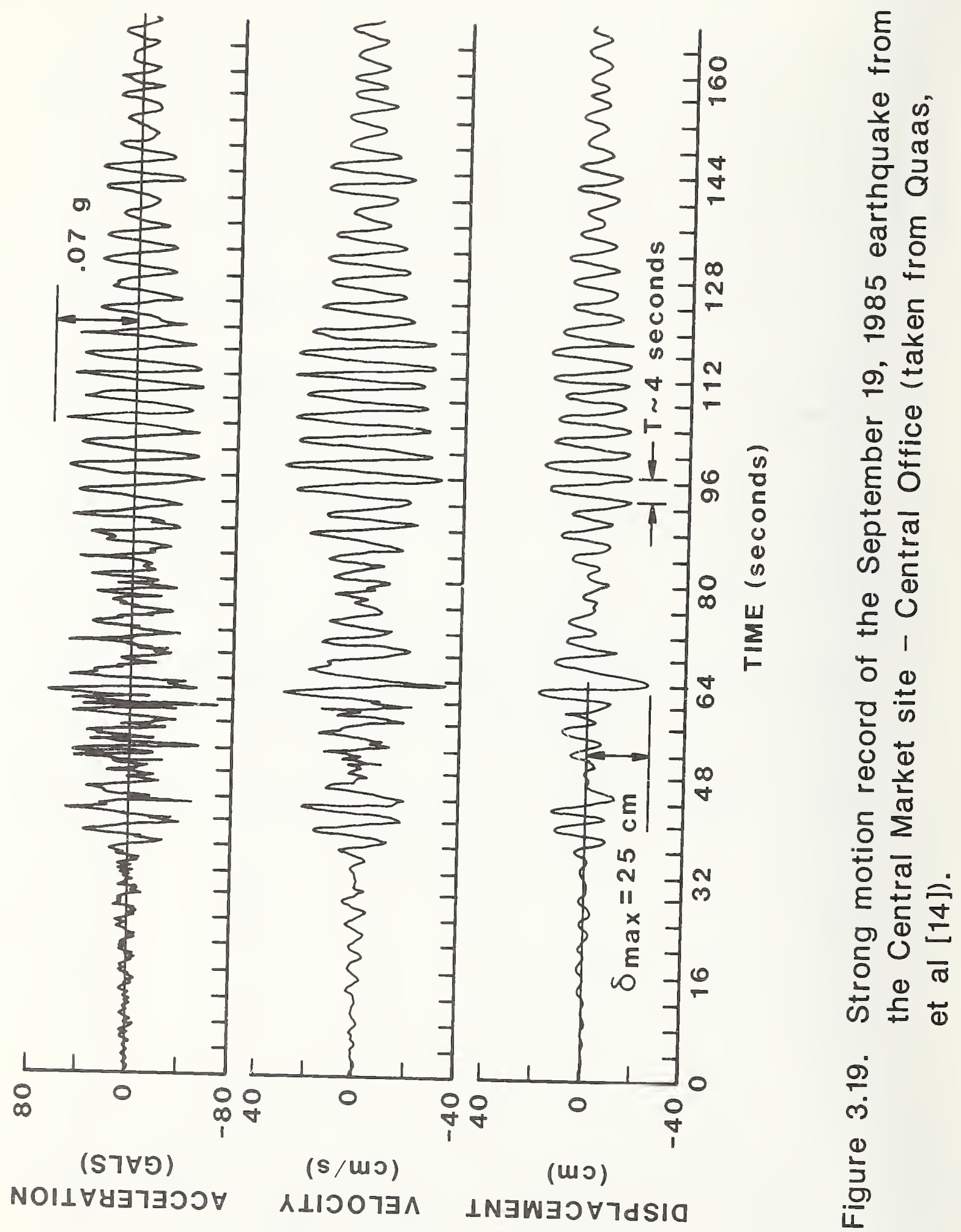


It can be seen from figure 3.4 that the strong motion records vary considerably from site to site. The variation is not only in amplitude and frequency content of the ground motion, but also in the duration of the strong motion, indicating that some sites continued to vibrate even after cessation of large amplitude ground motions in the underlying bedrock. This phenomenon is particularly pronounced at the Central Produce Market site record shown in figure 3.19, where high amplitude motions continued for about 100 seconds, as compared to about 60 seconds at the UNAM site (figure 3.13). Note that, of the strong motion records shown, only the UNAM stations are located on rock deposits. However even these stations are located on a basaltic deposit of recent origin, which rests on weaker deposits of unknown depth. Data on the frequency content of the strong motion of the bedrock underlying the various soil deposits would help explain the amplification of the ground motion associated with these deposits.

\subsubsection{Effect of Subsurface Conditions on Ground Motion}

A comparison of the records from the various stations in the Mexico City area gives an indication of the effect of the subsurface conditions on the ground motion. The UNAM site is in the Foothill zone. It is underlain by a 3-5m thick basaltic rock layer of recent origin. However, this layer is on top of softer strata of unknown thickness. The Tacubaya site is also in the foothill zone, but the instrument is located on shallow deposits of compact soil, rather than bedrock. The Viveros station is on shallow deposits of soft soils in the transition zone, and the SCT and Central Market (CDA) stations are located in the Lake Zone of Mexico city.

The comparison of the ground motion observed at the two stations in the lake zone (SCT and CDA) with that of the other stations in the Mexico City area (see Table 3.3) gives an indication of the 
effect of the lake deposits on the ground motion at their surface. It can be seen from these records that the ground motion is affected by the deep deposits in two ways: (1) the ground motion is amplified; and (2) the dominant period of the ground motion is modified by the dynamic characteristics of the soil column. These two observed effects are discussed below:

Amplification: As previously noted, none of the records in Mexico City presented herein was taken on competent bedrock. The nearest strong motion record on bedrock is from Teacalco, about $100 \mathrm{~km}$ west, in the direction of the epicenter. In Teacalco, as well as in most of the other stations of the Guerrero array, the north-south component of the acceleration record tended to have a larger amplitude than the east-west component. The reverse is true for the records taken in the lake zone of Mexico City. This is probably related to the frequency content of the strong motion. One would expect that the amplitude of the rock motion in Teacalco was somewhat attenuated over the $100 \mathrm{~km}$ distance to Mexico City. The north-south components of the ground acceleration at the UNAM and Tacubaya stations are somewhat smaller than the acceleration at Teacalco and also consistent with each other. The East-west components, on the other hand, are greater than that at Teacalco.

From table 3.3 it can be seen that the peak accelerations at the SCT station were approximately $500 \%$ of those at the UNAM stations in the east-west direction and $325 \%$ in the north-south direction and at the Central Market station (frigorifico) they were approximately $290 \%$ of those at the UNAM stations in the east-west direction and $250 \%$ in the north south direction. 
To further illustrate the amplification of ground motions, the spectral ratios derived from the vertical and horizontal components of motions at the SCT station with respect to the UNAM station are shown in figure 3.20 (taken from unpublished USGS open file report: Celebi M. et al., Mexico City site Response studies). These spectral ratios are frequency dependent amplification ratios and depict that at the 2 second period the horizontal accelerations at the SCT site were 7-10 times those at the UNAM site.

Dominant Period: The dominant period of the ground motion at the SCT station was 2 seconds, and those at the two central Market stations were close to 3 seconds at frigorifico and close to 4 seconds at the central office. It can be seen from figures 3.18 and 3.19 that the low frequency components of the ground motion in the lake zone were damped out and during part of the record the dynamic response was almost perfectly sinusoidal.

The dynamic response of the soil column can be correlated with two parameters: its damping ratio and its natural frequency. As previously noted the damping ratio of the clay deposits at a shear strain of $0.1 \%$ is approximately $6 \%$ of critical damping. Strains actually experienced during the earthquake may have exceeded $0.1 \%$ and thus the damping ratio may have been somewhat higher. Assuming that it was $6 \%$ or more, the maximum possible amplification of the ground motion by the soil column (as measured by the ratio of peak accelerations) would be $830 \%$. The actual amplification of any particular ground motion at the base of the column would depend on the frequency content of that ground motion. The fact that a 500\% amplification occurred indicates that the ground motion of the bedrock at the base of 
EW

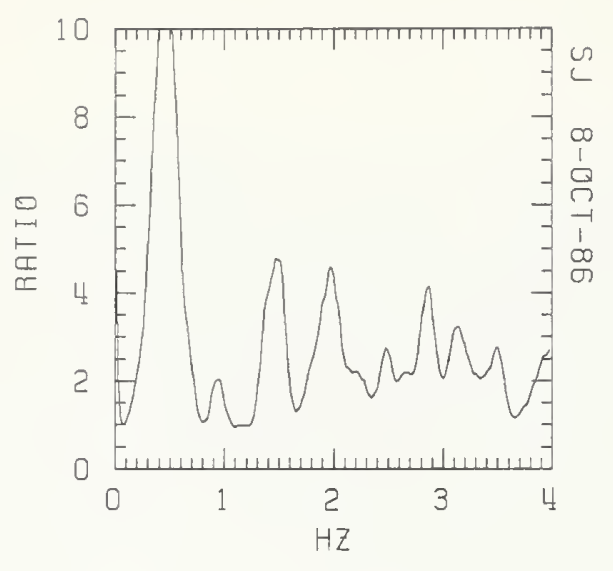

NS

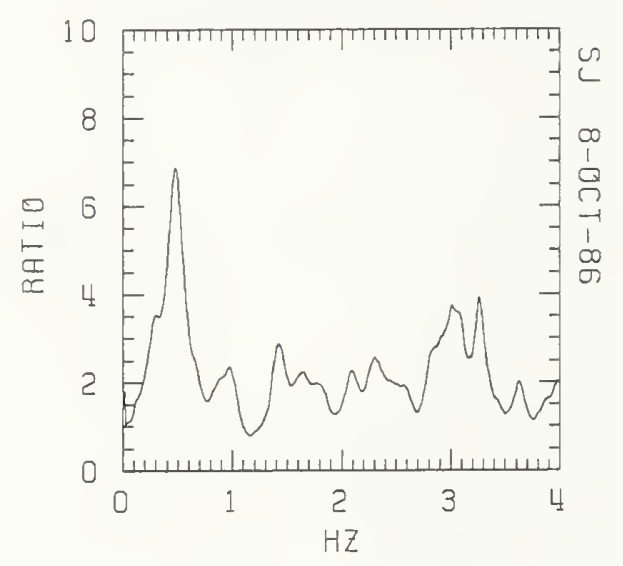

VERT.

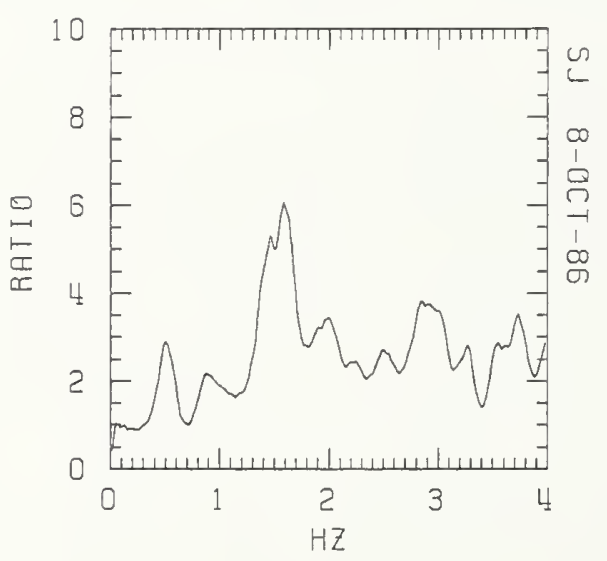

Figure 3.20 Frequency-Dependent Spectral Ratios Determined from the Strong-Motion Acceleration Records of the September 19, 1985 Mexico City Earthquake from the SCT and UNAM Stations. (Ratios are plotted as SCT acceleration/UNAM acceleration). 
the lake region had a significant energy content close to the 0.5 $\mathrm{Hz}$ frequency of the soil column.

The frequency contents of the ground motions at SCT, UNAM, and Tacubaya, which were obtained by a spectral analysis of the acceleration records, are shown in figures 3.21 to 3.23 . As expected, the north-south and east-west components of the SCT motion shown in figure 3.21 had a dominant frequency of 0.5 $\mathrm{Hz}$. The frequency content of the vertical component of the SCT motion, which is in part attributable to compression waves, is much more scattered and generally indicates that the natural frequency of the soil column in compression is much higher than that in shear. This is attributable to the low compressibility of the saturated clay which was previously discussed.

All three components of the Tacubaya spectra shown in figure 3.22, but particularly the vertical component, have a dominant $0.5 \mathrm{~Hz}$ frequency. Since the Tacubaya station is in the foothill zone and on shallow compact soil (the natural frequency of the soil column is much higher than $0.5 \mathrm{~Hz}$ ) this is taken as an indication that the motion of the underlying bedrock had a dominant $0.5 \mathrm{~Hz}$ frequency. Response spectra developed for the ground motion at the UNAM site [15] show significant amplification at the 2 s period.

The UNAM record in figure 3.23 also shows that in the east-west and the vertical direction significant energy was concentrated in the $0.5 \mathrm{~Hz}$ frequency range. In the north-south direction the dominant frequency is not as pronounced.

Even though the ground motions in this earthquake had a larger amplitudes than those observed in previous earthquakes, the amplification and frequency responses associated with the deep lake deposits can be compared with previous observations. 


\section{SCT1 N9OW \\ (East-West)}

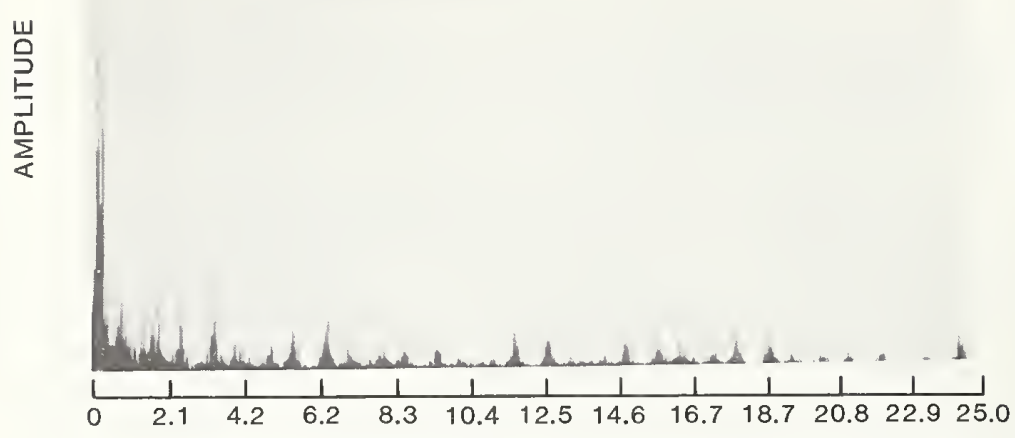

SCT1_SOOE

(North-South)

岁

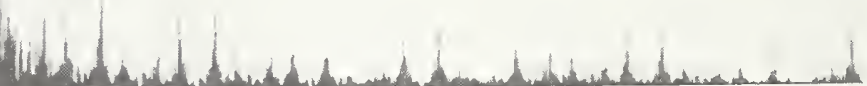
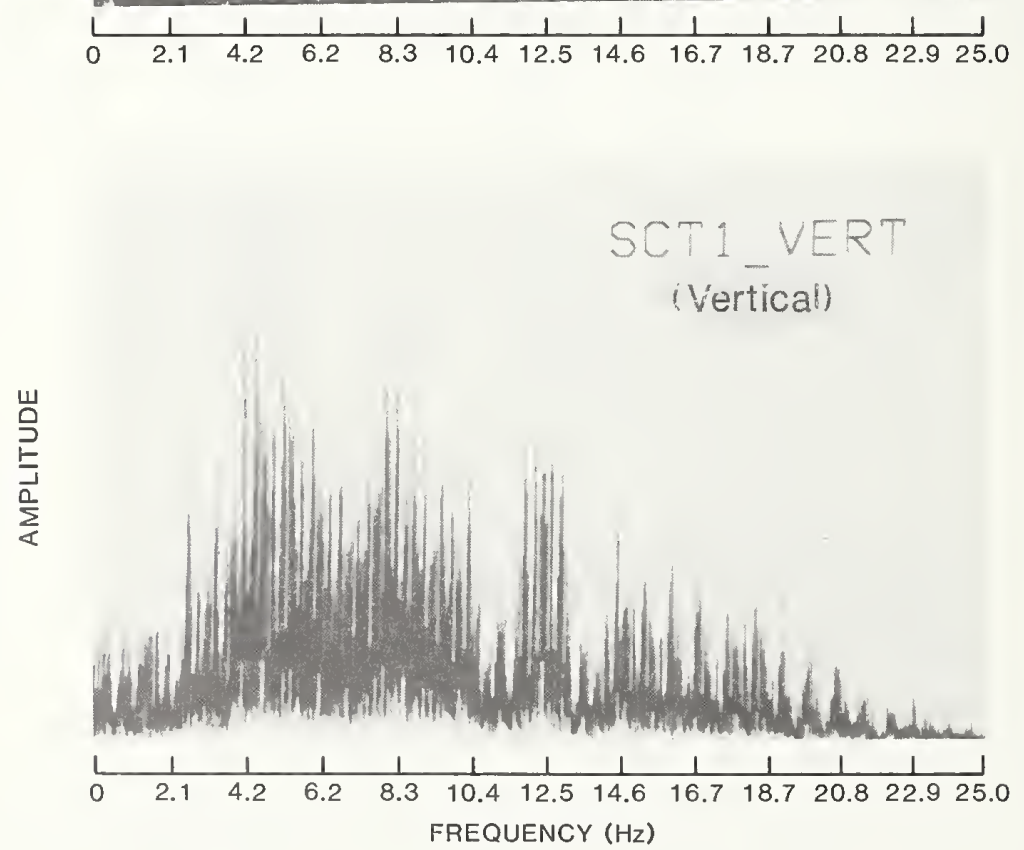

Figure 3.21. Spectral analysis of the ground motion at the SCT Station. 

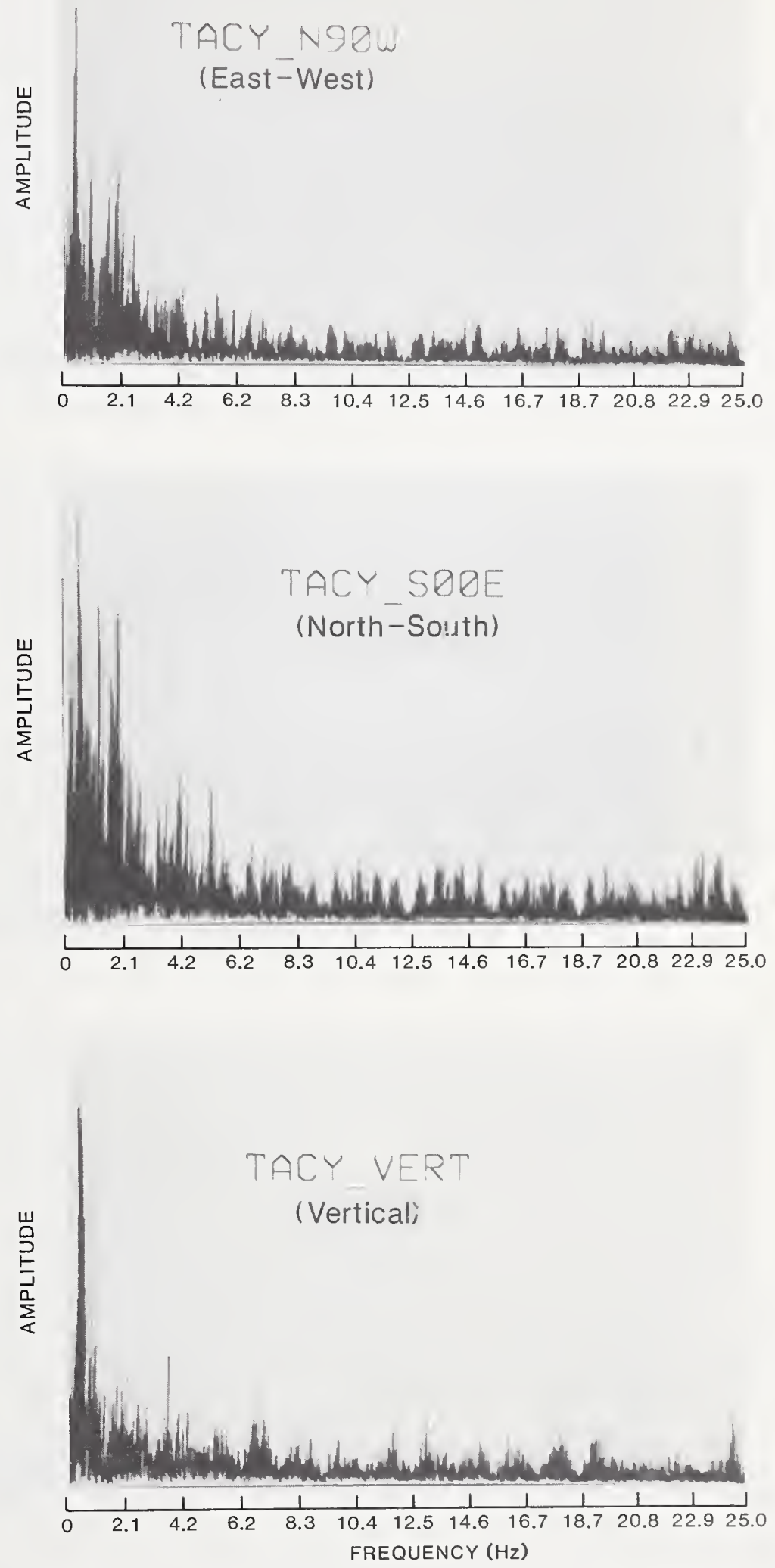

Figure 3.22. Spectral analysis of the ground motion at Tacubaya. 

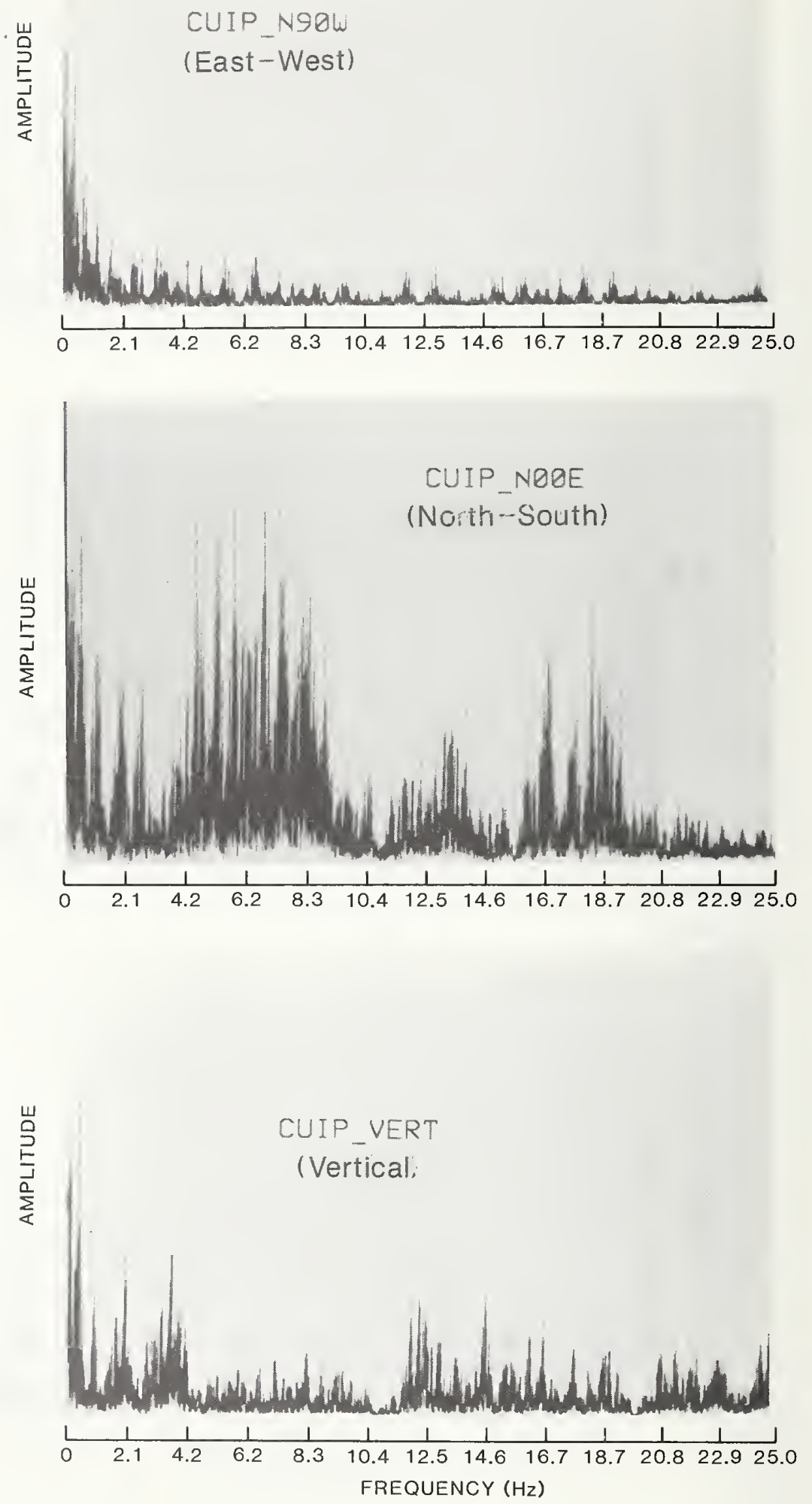

Figure 3.23. Spectral analysis of the ground motion at UNAM. 
Rosenblueth (1979) [16] stated that "soil amplification, particularly for long periods, is extreme in the soft clays of the Valley of Mexico. In acceleration spectra prevailing periods of 2-2.5s are common, and at one site (the sports palace) they reached 5s." The 100 year return period maximum ground accelerations and velocities for the lake zone in Mexico city have been estimated by Faccioli, et al. (1975) [17] to be 0.14G and $0.81 \mathrm{~m} / \mathrm{s}$, respectively. These can be compared with the $0.17 \mathrm{G}$ maximum acceleration and $0.61 \mathrm{~m} / \mathrm{s}$ maximum velocity shown in figure 3.18. Reference [18] lists accelerations measured in the March 14, 1979 earthquake at the UNAM site and in the basement of the National Lottery Building in downtown Mexico City (Reforma at Juarez) as $21 \mathrm{gal}$ and $55 \mathrm{gal}$, respectively, in the east-west direction. This represents an amplification of peak accelerations in excess of 250 percent. A free field measurement would have probably recorded a larger acceleration response than that in the basement of a building.

Thus the amplitude of the ground motion measured at the SCT site, and the amplification effect and prevailing period associated with that ground motion are not at all inconsistent with previous observations and estimates.

A boring in the vicinity of the SCT station (\#231 in Ref.[11]) shows the following soil profile: a $6 \mathrm{~m}$ surface layer; a $26 \mathrm{~m}$ thick upper clay layer with a water content of 275 percent; a $6 \mathrm{~m}$ thick capa dura with an SPT blowcount of 30 blows per $0.3 \mathrm{~m}$; a $3 \mathrm{~m}$ thick lower clay layer with a water content of 200 percent; and deep deposits at $41 \mathrm{~m}$. The boring was not continued beyond the $42 \mathrm{~m}$ depth. However, other information indicates that the thickness of the deep deposits is approximately $38 \mathrm{~m}$. If it is assumed that: at the strain level experienced in the earthquake, the shear wave velocities of the two clay layers are $70 \mathrm{~m} / \mathrm{s}$ for the upper and $120 \mathrm{~m} / \mathrm{s}$ for the lower (UNAM data indicate that shear 
wave velocities range from $60 \mathrm{~m} / \mathrm{s}$ to $120 \mathrm{~m} / \mathrm{s}$ ); the shear wave velocities for the upper layer and the capa dura are $250 \mathrm{~m} / \mathrm{s}$; and the deep deposits are about $38 \mathrm{~m}$ deep and have a shear wave velocity of $300 \mathrm{~m} / \mathrm{s}$ (these are estimates, since data on dynamic moduli are only available for the clay); then the natural period of the site would be about 2 to 2.1 seconds which is the dominant period of the SCT record.

Figure 3.24 shows a plot of the locations of severely damaged or collapsed buildings, on which depth contours for the top of the capa dura and the top of the deep deposits at the boundary of the damage zone are superimposed. From this plot it is apparent that most of the damage area is between the $30 \mathrm{~m}$ and the $38 \mathrm{~m}$ depth contours for the top of the capa dura and the $38 \mathrm{~m}$ and the $50 \mathrm{~m}$ contours for the top of the deep deposits. There is another limited area of damaged buildings to the south, outside the area covered in figure 3.24 (between the UNAM stations and Cerra del Estrella in figure 3.8). That latter area is also in the lake zone. If it is assumed that: the thickness of the deep deposits is $30 \mathrm{~m}$ at the shallow end of the damage zone and $40 \mathrm{~m}$ at the deep end of the zone; the shear wave velocities of the first clay layer is $70 \mathrm{~m} / \mathrm{s}$ at the shallow boundary and $60 \mathrm{~m} / \mathrm{s}$ at the deep boundary; and the shear wave velocity of the second clay layer was $120 \mathrm{~m} / \mathrm{s}$; then the earthquake damage was concentrated in a zone where the estimated natural period of the site was between 1.9 and 2.8 seconds. Not much damage occurred outside that zone. The damage can be attributed to both the amplification of the ground motion by the soil column and the natural period of the damaged buildings.

3.3.3 Comparison of Response Spectra With Design Spectra Used in Mexico City and the U.S.

The significance of the ground motion record in the Lake zone is illustrated by the response spectra shown in figures 3.25 and 3.26 for the SCT and the central Market sites, respectively. The 


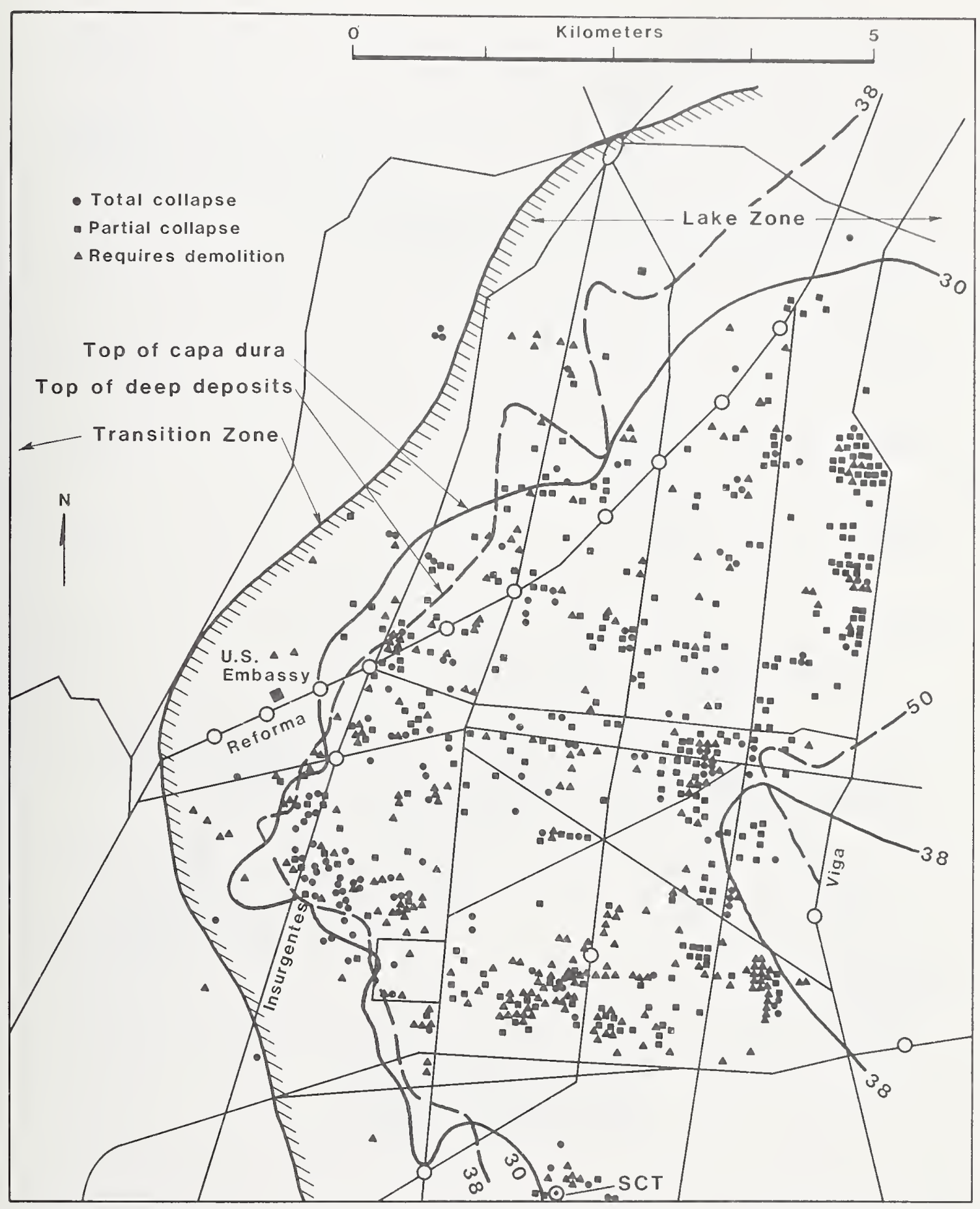

Figure 3.24. Soil depth contours at the boundary of the damage zone. 


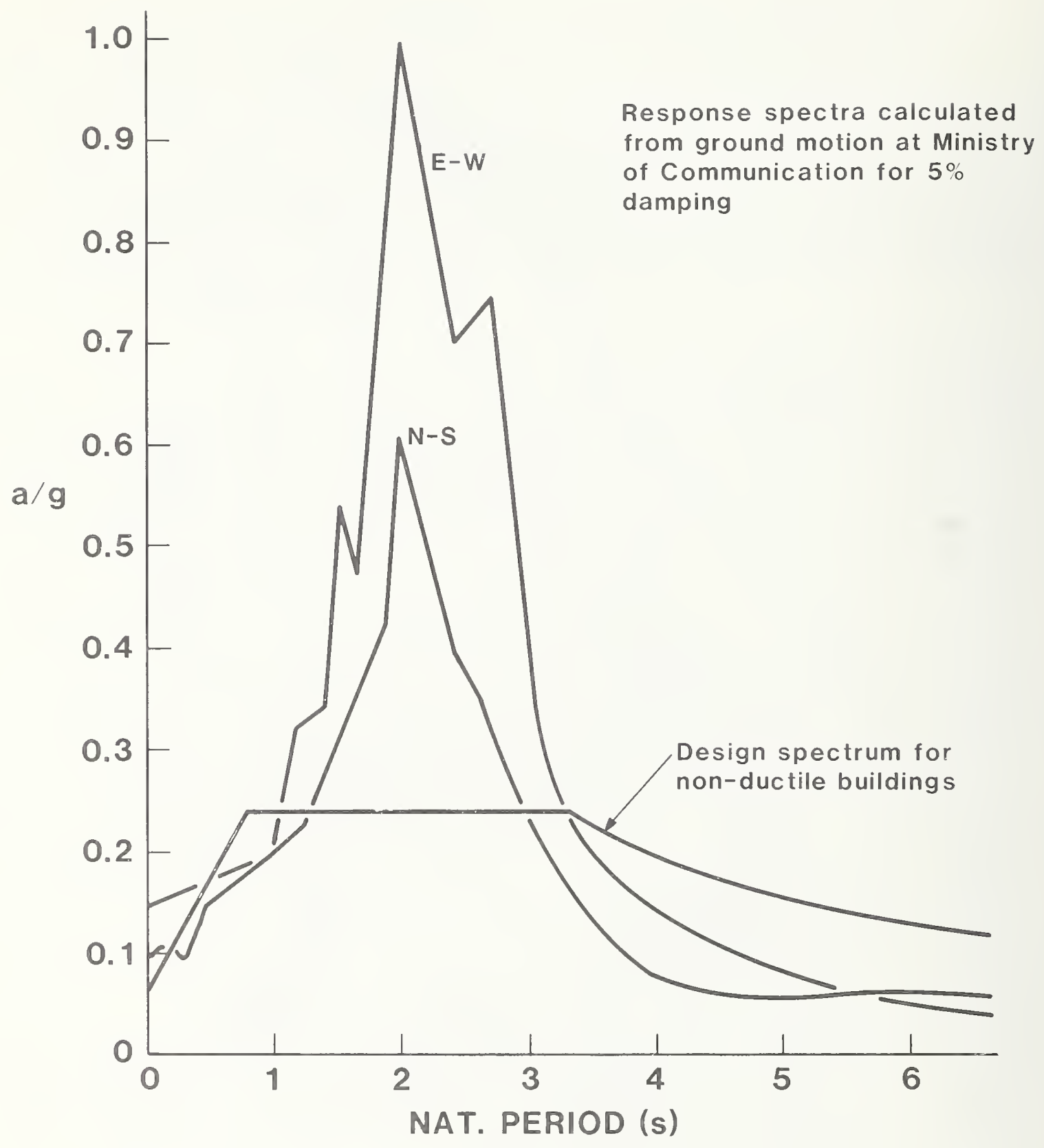

Figure 3.25. Comparison of acceleration response spectra calculated from $5 \%$ damping for the SCT site (taken from Mena, et a! [13]) with the design spectrum for nonductile structures in the lake zone included in the 1976 Mexico Federal District Building Code. 


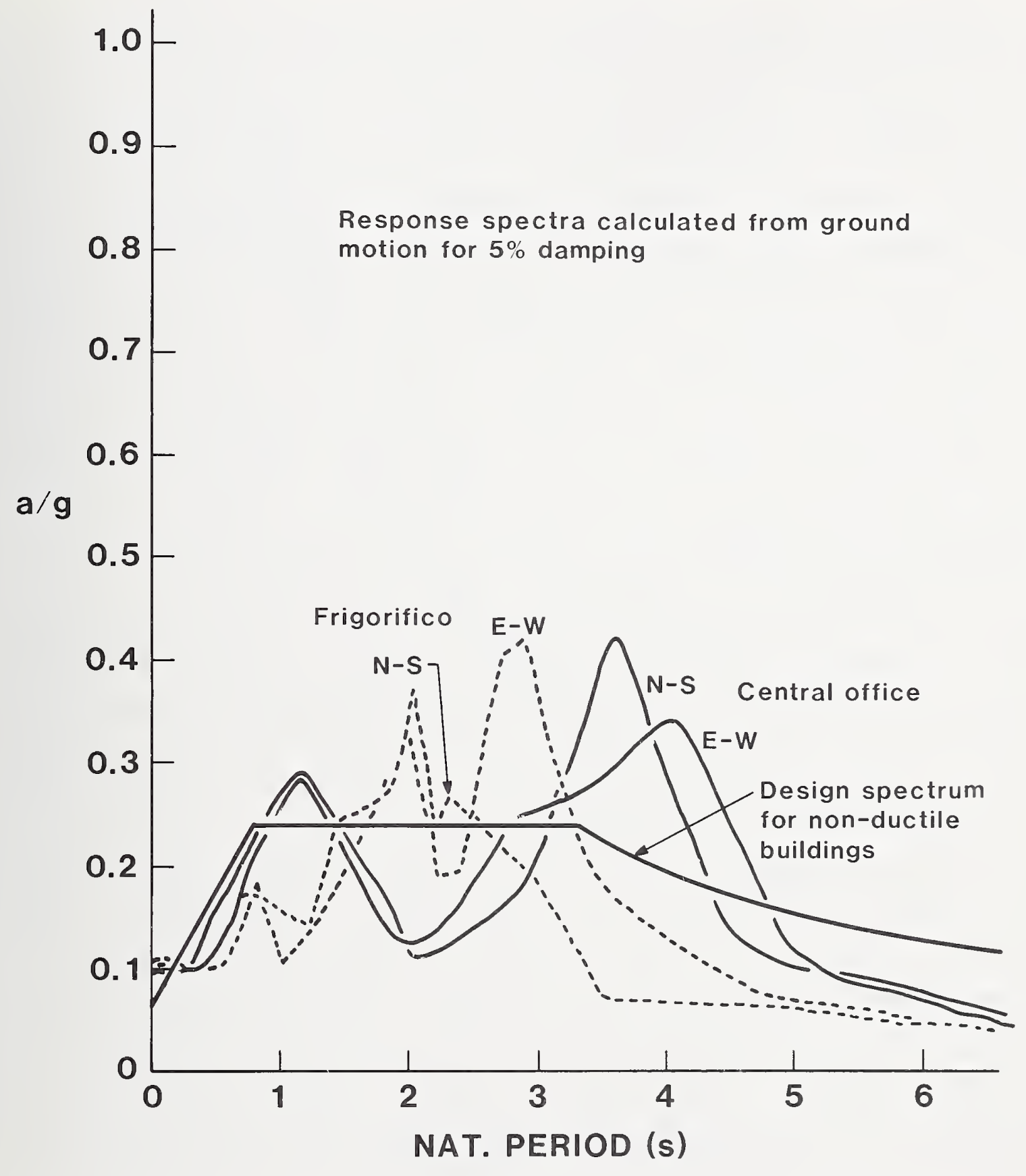

Figure 3.26. Comparison of acceleration response spectra calculated for $5 \%$ damping for the Central Market site (taken from Quaas, et al [14]) with the design spectrum for nonductile structures in the lake zone included in the 1976 Mexico Federal District Building Code. 
response spectra, which were taken from References [13] and [14], are for a single degree of freedom resonator with 5 percent viscous damping, and provide a measure of the magnitude of the base shear that the ground motion would produce in buildings, as a function of their fundamental period. For comparison, the design spectrum for nonductile buildings incorporated in the Mexico Federal District Building code [19], which was developed on the basis of previous seismic events and was used as a basis for design of many of the modern buildings, is also plotted in the figures. It can be seen that buildings with natural periods close to 2 seconds located in the zone which experienced ground motions similar to that at SCT were subjected to shear forces far in excess of the forces specified in the design spectrum. Safety margins inherent in the applicable design procedures would not compensate for this large discrepancy. This probably accounts for the observed selective failure pattern, where buildings between 7 and 18 stories high suffered the greatest damage. It should be noted that the natural period of buildings in the affected area was lowered by the interaction between the structure and the supporting soil and by initial damage. An examination of figure 3.18 indicates that there were 9 load cycles in which the acceleration was close to the maximum. Thus buildings subjected to this ground motion had to survive 9 reverse cycles of maximum lateral forces. Ground motions similar to that at the central Market site would have been critical for taller buildings. Fortunately, there are no tall buildings in that area. Had there been such buildings, they would have been subjected to 30 reverse cycles of maximum lateral acceleration ${ }^{1}$.

Figures 3.27 shows a comparison of the response spectra for the SCT site, as well as those calculated for the observed ground motions from the Central Produce Market site, with design spectra

1 Reference 6 notes that the central office record may have been affected by the building. The other record from that site (Frigorifico) does not cover the entire duration of the earthquake. 


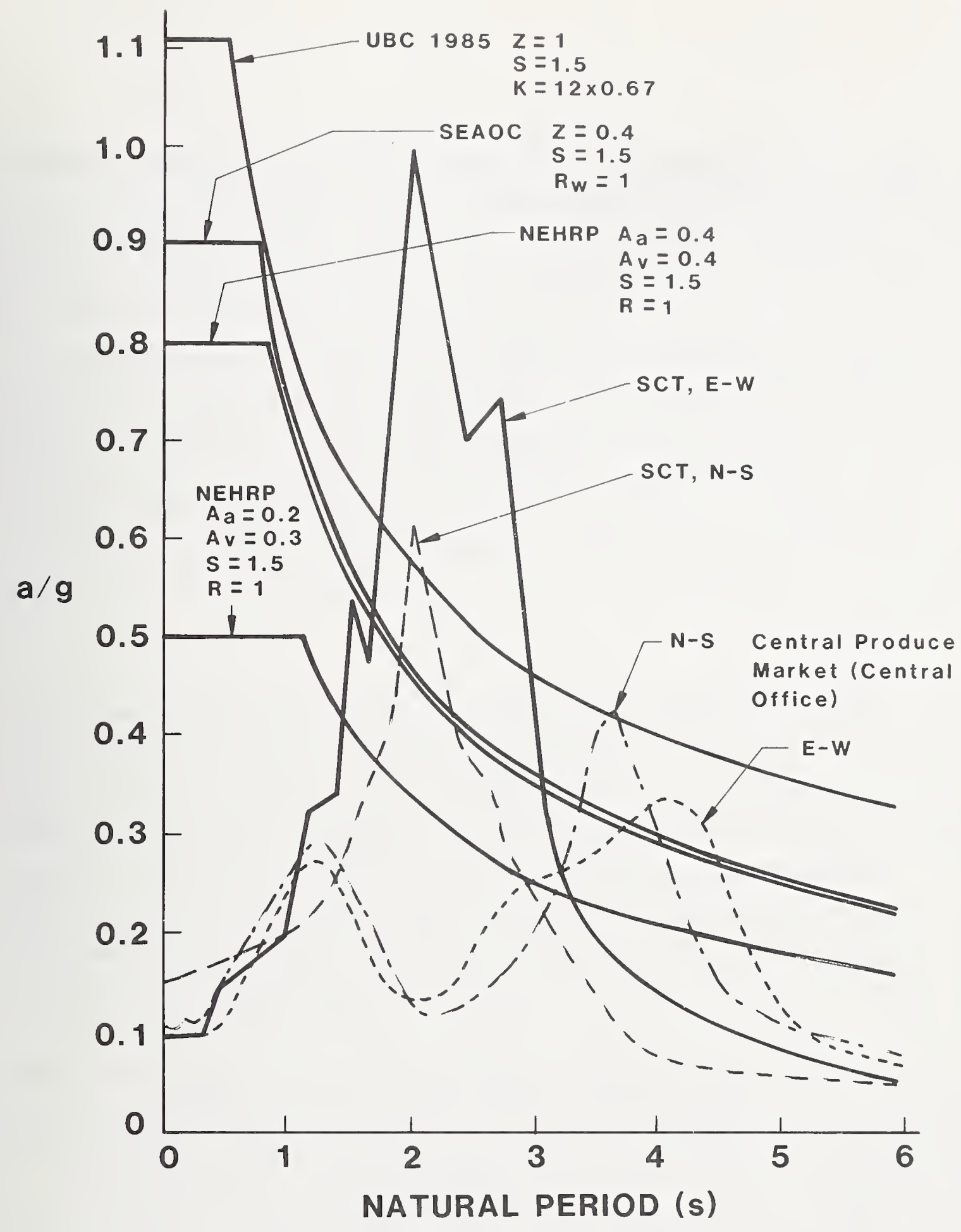

Figure 3.27. Comparison of design spectra for non-ductile structure stipulated in present and proposed U.S. design provisions with response spectra for $5 \%$ damping calculated for the ground motions observed during the September 19, 1985 earthquake at the SCT and Central Produce Market sites in Mexico City. 
developed in accordance with presently used or proposed U.S. design provisions. These include the 1985 edition of the Uniform Building Code (UBC) [20], the NEHRP "Recommended Provisions for the Development of Seismic Regulations for New Buildings" [21], and the Tentative Lateral Force Requirements of the Structural Engineers Association of California (SEAOC) [23] . The notations used in Figure 3.27 are taken from the referenced documents: $\mathrm{A}_{\mathrm{a}}$ = coefficient representing effective peak acceleration and $A_{V}=$ coefficient representing effective peak velocity from Ref.[21]; $S$ = coefficient for soil profile characteristics from Refs.[20,21, and 22]; $R$ and $R_{W}$ are seismic response modification coefficients taken from Refs.[21] and [22], respectively.

Te upper NEHRP spectrum and the UBC and SEAOC spectra are for the most severe condition envisioned for the U.S [a site with $30 \mathrm{ft}$ (10m) or more depth of soft to medium stiff clays or sands in the San Francisco Bay area or an area with similar anticipated ground motion severity]. The NEHRP and SEAOC spectra were obtained by plotting the equations for the coefficients for seismic base shear, calculated for $R$ or $R_{W}$ values of 1 . It is reasoned that these spectra represent ultimate loads for non ductile structures (the NEHRP provisions specify strength design; the SEAOC provisions are written for working stress design, but they use larger response modification factors than those in the NEHRP provisions and thereby compensate for the difference between working load and ultimate load). The UBC spectrum was calculated for a hypothetical $\mathrm{K}$ value of $0.67 \times 12$. The rationale for this $\mathrm{K}$ value is that 0.67 is the $U B C \mathrm{~K}$ value for ductile moment resistant space frames, for which the SEAOC document specifies an $R_{W}$ value of 12. Since both the SEAOC and the UBC documents are written for working stress design, the $S E A O C$ response spectrum for $R_{W}=1$ would correspond to the $\mathrm{UBC}$ response spectrum for $\mathrm{K}=0.67 \times 12$. The lower NEHRP spectrum is for a site for which the seismic coefficient representing the effective peak velocity is 0.3 , and that 
representing the effective peak acceleration is 0.2 , which could conceivably have been chosen for Mexico city before the last earthquake occurred [refer to Ref. 21 for definition of the seismic coefficients).

A comparison of the response spectra calculated for the Mexico City earthquake for a $5 \%$ damping ratio with the design spectra drawn in figure 3.27 gives a reasonable indication how structures designed by present or proposed U.S. provisions may have performed in the Mexico City earthquake. It is evident that structures with natural periods ranging from 1.8 to 3 seconds could have failed when subjected to ground motions similar to those measured at the SCT site, even if they were designed for the most severe U.S. conditions envisioned. The situation would have been even more critical, had these structures been designed in accordance with the design spectrum shown by the lower NEHRP curve (or curves for similar conditions derived from the UBC or SEAOC documents), which most probably would have been the case in absence of the benefit of the hindsight we now posses. In the latter case, structures with natural periods ranging from 3.4 to 4.4 seconds may also have performed poorly in the vicinity of the Central Produce Market.

It is important to examine the reasons for the conclusions that can be drawn from figure 3.27. The design spectra in References 20 to 22 were developed on the basis of generalized assumptions on ground motion characteristics, derived from information from many sites, which apply to most situations likely to be encountered in the U.S., but do not apply to the conditions encountered in the Lake zone of Mexico city, where large-amplitude ground motions occurred at low frequencies. This situation can occur when two conditions exist: 1. The site has a relatively long natural period and the soil deposits have a low damping ratio; and 2 . the underlying bedrock transmits ground motions whose frequency content it such that they can be 
amplified by the soil column. The question arises whether these conditions are predictable.

The first condition is amenable to analysis, since its parameters can be estimated. We can in most instances estimate the natural period of sites with deep clay deposits similar to those in the lake region of Mexico city on the basis of past strong motion records or appropriate in situ and laboratory measurements. We can also get an indication of damping ratios from laboratory tests on undisturbed samples, which usually can be obtained in cohesive soils. We can also determine the natural period of buildings with a reasonable allowance for the structure/foundation interaction, and thus predict which buildings would be vulnerable to the ground motion.

The second condition is much more elusive. It seems much more difficult to estimate the probable frequency content of the anticipated ground motions of the bedrock underlying the soil column. Incorrect assumptions could lead to unduly conservative requirements or may cause us to underestimate seismic risks.

Some consideration should be given to the introduction of an alternate method of calculating design amplification factors as a function of the ratio between the natural period of the site and that of the supported buildings. This would permit us to selectively increase lateral load requirements for buildings which have natural periods close to that of the site and thereby prevent the kind of selective damage pattern that occurred in Mexico City (the 1975 edition of UBC used a "site-structure resonance coefficient", $S$, but the resulting response spectrum did not exceed the UBC spectrum drawn in figure 3.26). This method could then be applied in areas of soft to medium stiff deep clay deposits which are thought to be at risk [clays, rather than granular deposits, are of concern because of the low damping ratios observed in some clays (for instance $6 \%$ for shear strains 
in the order of $10^{-3}$ for the Mexico city clays)], and design criteria could conceivably be pre-determined by microzonation. 



\section{FOUNDATION FAILURES}

\subsection{General}

Table 4.1 summarizes building characteristics which were observed to contribute to failures during the earthquake. The percentages given in the table add up to more than $100 \%$, since several causes can be observed to contribute to any one building failure. It can be seen from the table, that in about 15\% of all failures unsatisfactory foundation performance or prior differential settlements were observed to be major contributing causes. There may have been other instances where foundation failures, such as shear failures in piles, occurred and were not observed because they were below ground. In addition, stresses introduced by differential settlements which were not visually observable probably reduced the load resistance of many structural members. Nevertheless, the percentage of foundation related failures was surprisingly low, given the difficult foundation conditions in the lake region of Mexico City, even if an allowance is made for possible unobserved failures or causes of failure. To fully appreciate this fact, one should examine the response spectra shown in figure 3.25, which give an indication that many building foundations were subjected to overturning forces far in excess of those assumed in their design. 
Table 4.1 Causes of Building Failures in Mexico City (from Ref.[23])

\begin{tabular}{l|c} 
Observed Characteristics Contributing to & Percent of cases \\
Failure & \\
\hline Corner buildings & 42 \\
Intermediate story failure & 38 \\
Upper story failure & 15 \\
Pronounced asymmetry in stiffness & 15 \\
Pounding & 9 \\
Unsatisfactory foundation performance & 8 \\
Excessive mass & 5 \\
Weak first story & 4 \\
Previous earthquake damage & 3 \\
Punching in wafle slab & 2 \\
Short columns & \\
Previous differential settlement &
\end{tabular}

There are several reasons for this relatively good performance of structural foundations:

(1) The permeability of the lacustrine deposits is very low. Thus, volume change which requires the displacement of pore water cannot occur within the time frame of an earthquake. Major settlements are therefore inhibited (according to information obtained from UNAM faculty minor settlement can however occur as a result of fissures in the clay).

(2) The soils in the lake region of Mexico city are predominantly cohesive and will therefore not liquefy during an earthquake. In many instances, liquefaction 
would cause major devastation in an earthquake of that magnitude.

(3) Shear deformations and shear failures which do not require volume change (Poisson's Ratio $=0.5$ ) $\mathrm{can}$ and did occur, however the time element involved in the development of major rotational slides in clays may have inhibited or limited many shear failures which otherwise would have occurred under the prevailing equilibrium conditions.

\subsection{Loss of Shear Resistance of Piles}

Figure 4.1 shows a view of the sidewalk next to the Bank of America building on 122 Reforma. Point $A$ is on a sloped portion of the sidewalk pavement which is attributed to differential settlement distortions between the building and the surrounding area which predated the earthquake (some cosmetic repairs are evident). Point B shows a drop of approximately $80 \mathrm{~mm}$ between the sidewalk and the building which is attributed to the earthquake. Figure 4.2 shows some disturbance in the sidewalk pavement near the building, that probably resulted from the $80 \mathrm{~mm}$ drop in the pavement. Similar patterns of distress were observed in many other locations, for instance, the differential slips shown in figures 4.3 and 4.4 which occurred in two buildings at the intersection of Reforma and calle Versalles.

These disturbances did not cause major damage, but the interpretation of the mechanism that caused the disturbances has important implications. As previously noted, piles in the lake Region (particularly end bearing piles) are subjected to progressively increasing negative friction forces (downdrag exerted by the surrounding soil) as the surrounding area subsides. These friction forces cause an upward warping of the surrounding soil layers, as their downward displacement is inhibited. If these negative friction forces between the soil and the pile are 


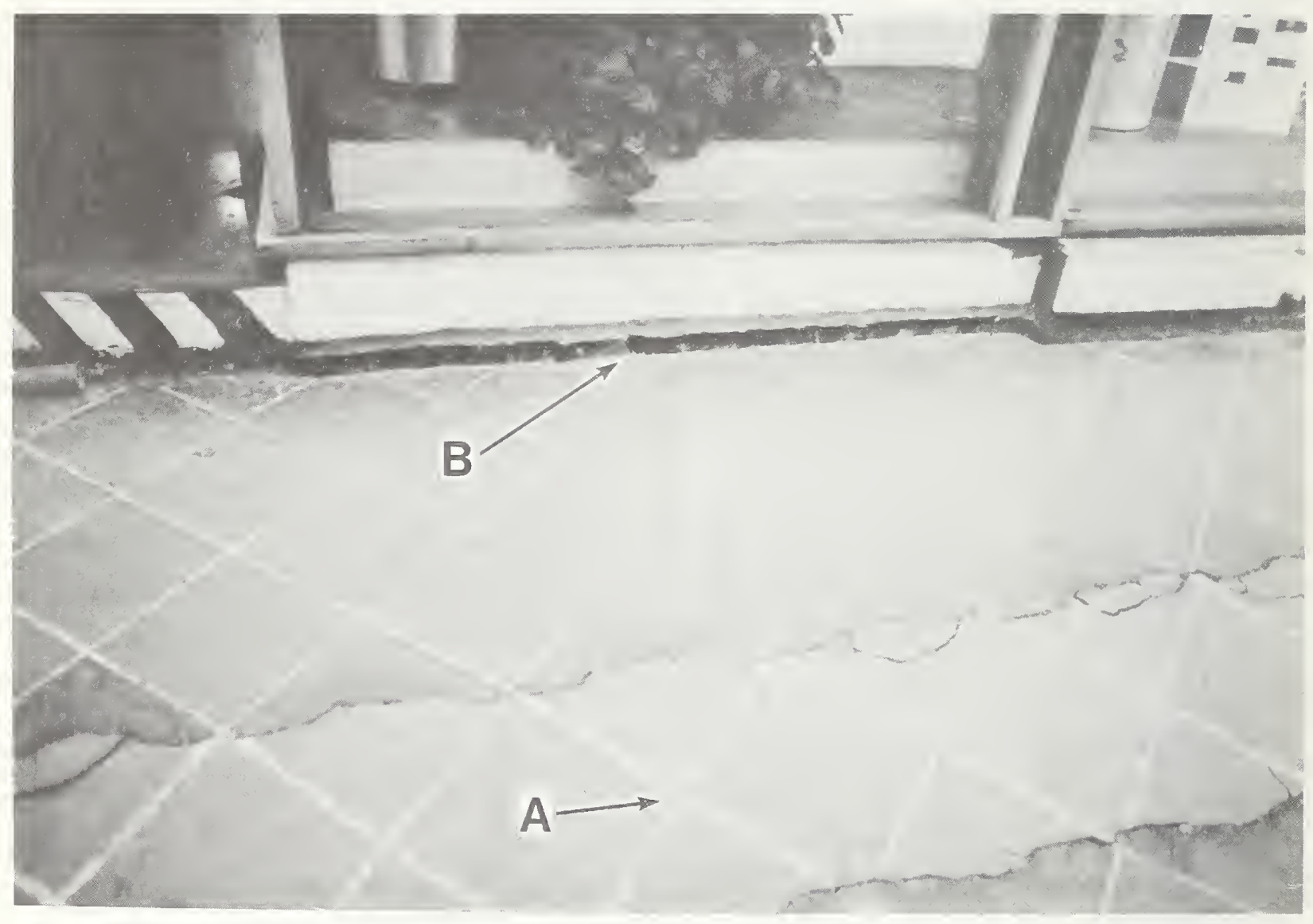

Figure 4.1. Differential displacements at the sidewalk near the Bank of America Building. 


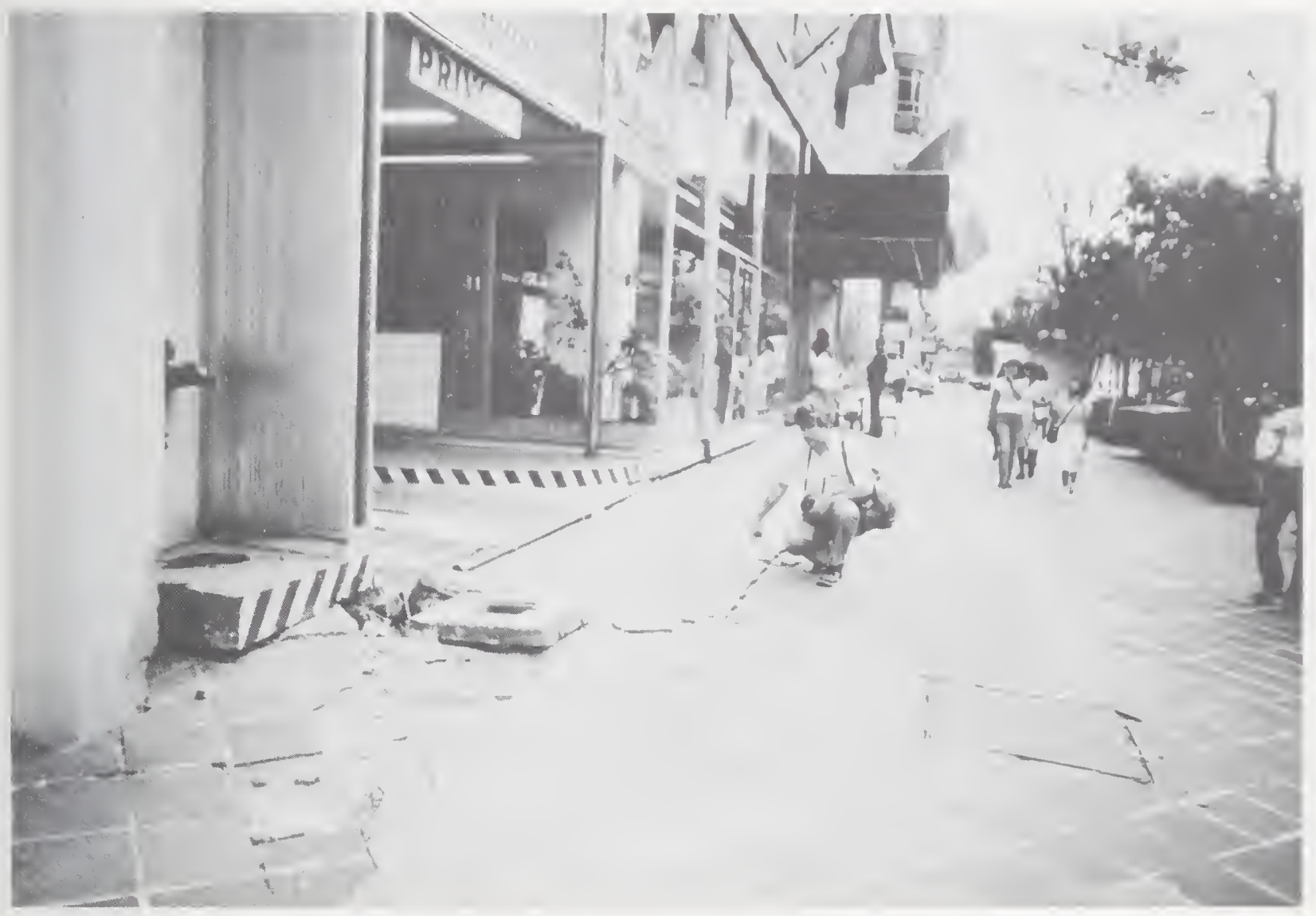

Figure 4.2. Disturbances caused by differential displacement between the sidewalk and the Bank of America Building. 


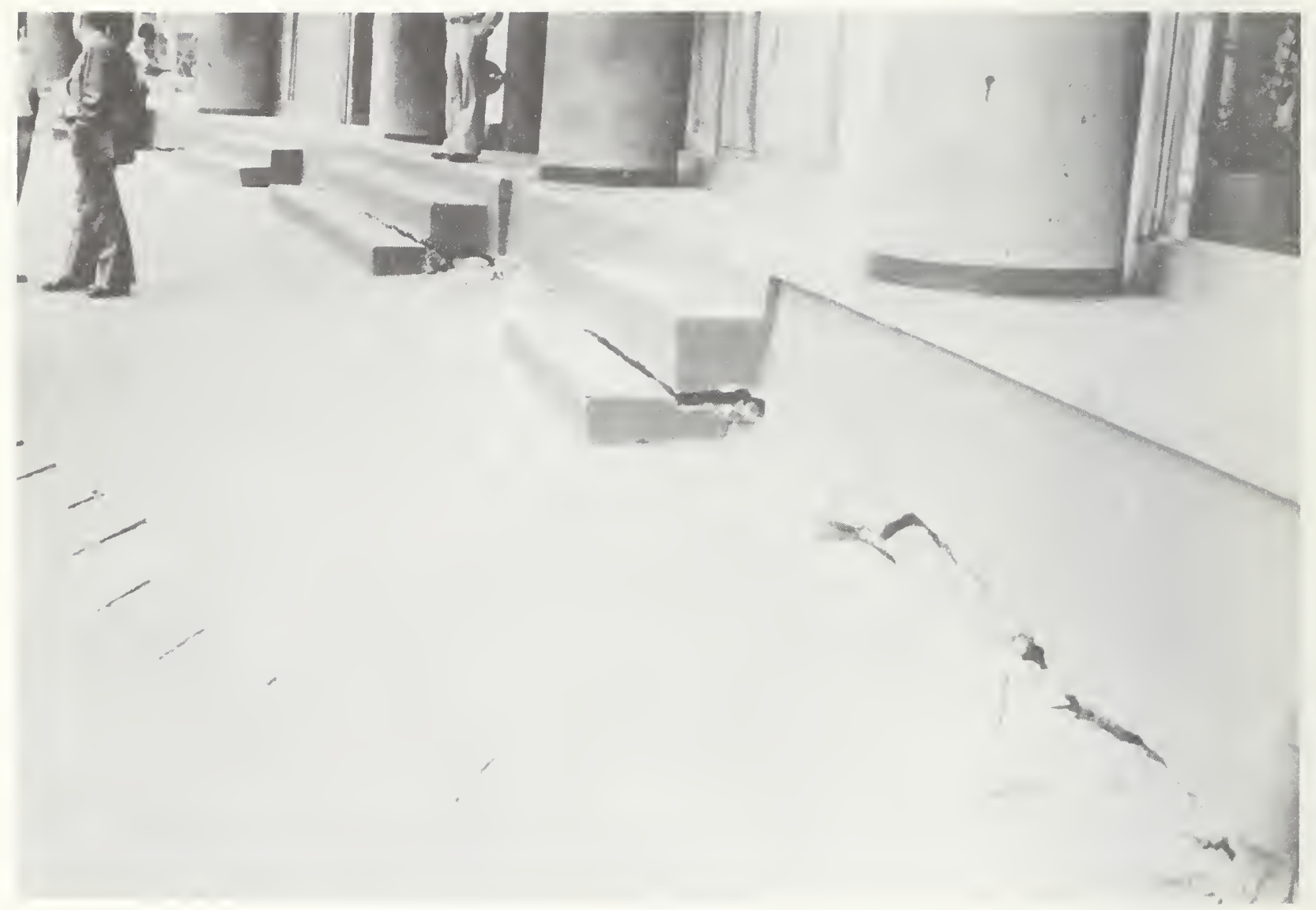

Figure 4.3 Differential displacement between sidewalk and building at the east corner of Versalles and Reforma. 


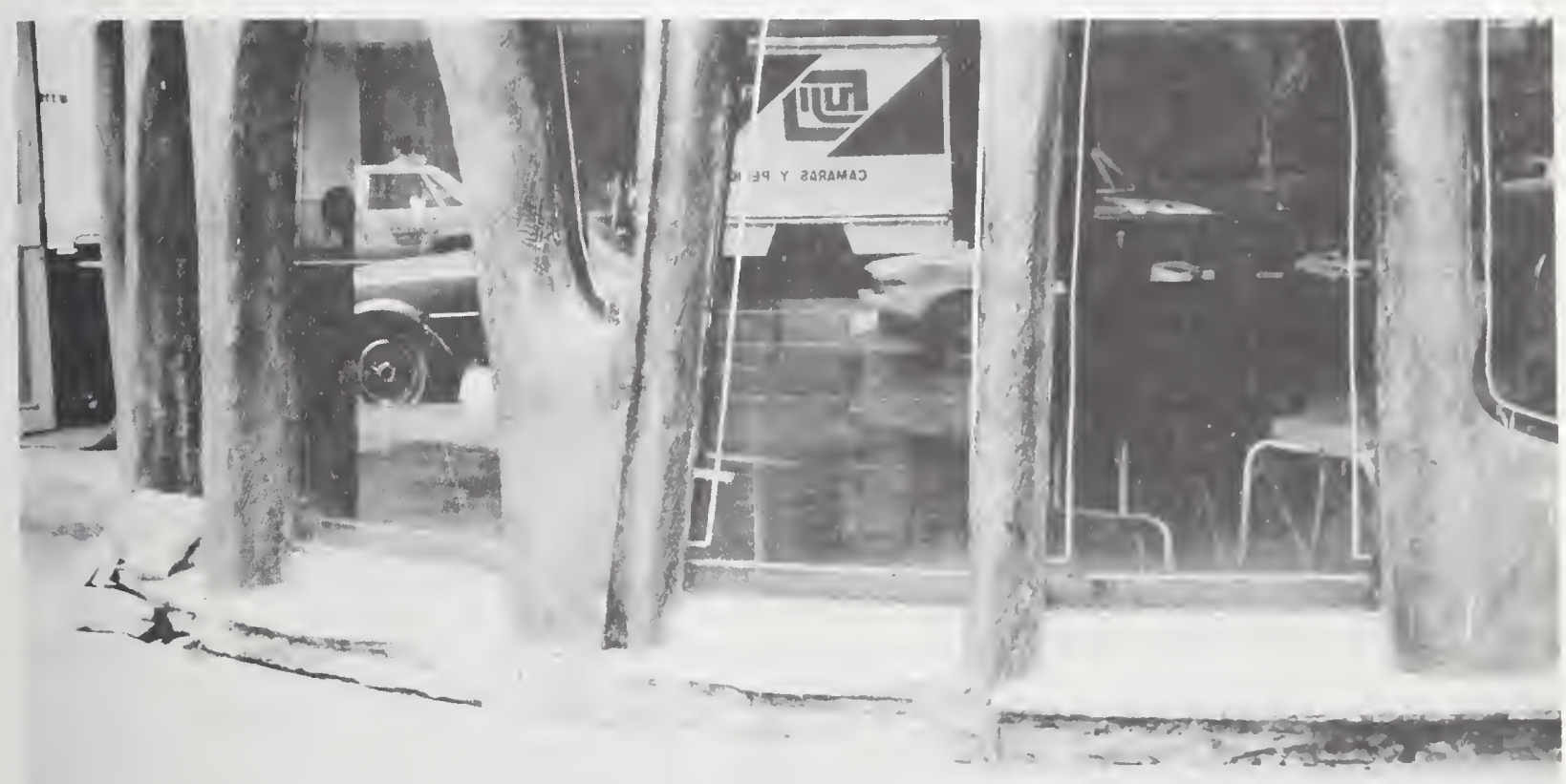

Figure 4.4. Differential displacement between sidewalk and building at the west corner of Versalles and Reforma. 
released, the soil surrounding the pile will displace downward, and the pile itself will slightly rebound elastically. In figure 4.1 , the slope at point $A$ is an indication of the past emergence of the building from the surrounding terrain which in turn is a proof that negative friction forces were acting on the piles prior to the earthquake. The $80 \mathrm{~mm}$ displacement at point $B$, as well as the ground disturbances shown in figure 4.2, are the result of the combined elastic rebound of the pile (which is estimated to be less than $10 \mathrm{~mm}$ and the downward displacement of the soil surrounding the piles. Even though the saturated clay cannot develop consolidation settlements during the duration of an earthquake, soil deformations not associated with a volume change (Poisson's Ratio =0.5), such as those associated with the relaxation of shear stresses, can occur instantaneously.

Thus, it is reasoned that the phenomena observed in figures 4.1 through 4.4 are the result of a relaxation in the negative friction forces acting on the piles. This relaxation is the result of loss of shear strength. The loss of shear strength occurred because the clays are sensitive (refer to figure 3.9) and was caused by shear deformations associated with the relative motion between the piles and the surrounding soil. From available data [8] it is estimated that between 85 and 88 percent of the shear strength can be lost. This loss of shear strength does not necessarily lead to an overall foundation failure (it did not cause such a failure in the buildings shown in figures 20 to 23), particularly, since it also results in the relaxation of negative friction forces which the pile had to resist, but it is an important limit state, which should be considered in the design of earthquake-resistant structures founded on sensitive clays. 
Figure 4.5 shows a tilted ten-story building in the southwest corner of the intersection of Lazaro cardenas and Fernando. Relative displacements between the building and the sidewalk to the north are shown in figure 4.6, and figure 4.7 shows damage caused to adjacent two-story buildings by the tilting structure. This building is in the vicinity of the severely damaged communications center (SCT) where several buildings collapsed. Figure 4.8 shows another tilted building in the same general area in the northwest corner of the intersection of Xola and University. This ten-story building also suffered severe structural and cladding damage. Figure 4.9 shows two- and three-story buildings a short distance to the south on University and opposite the severely damaged communications center which apparently did not suffer damage. Likewise, many two-story residential buildings on University to the north of Xola, where two multi-story reinforced concrete buildings (one of them post-tensioned) collapsed, also appeared undamaged.

on the other hand, to the east of the building in figure 4.5 on Toledo and Galicia there are evidence of severe ground disturbance and also of damage to many of the two-story residential buildings. Some of the ground disturbance is shown in figure 4.10. There is some indication that, at least in part, the ground disturbance is attributable to differential movement between utilities and the surrounding soil.

Tilting of structures did not always result in adverse effects. The 20-story microwave tower next to the communications center which before the earthquake was reported to have a tilt displacement of $600 \mathrm{~mm}$ experienced a substantial reduction in this tilt displacement as a result of the earthquake (information obtained from UNAM). Soil conditions in the vicinity of SCT were 


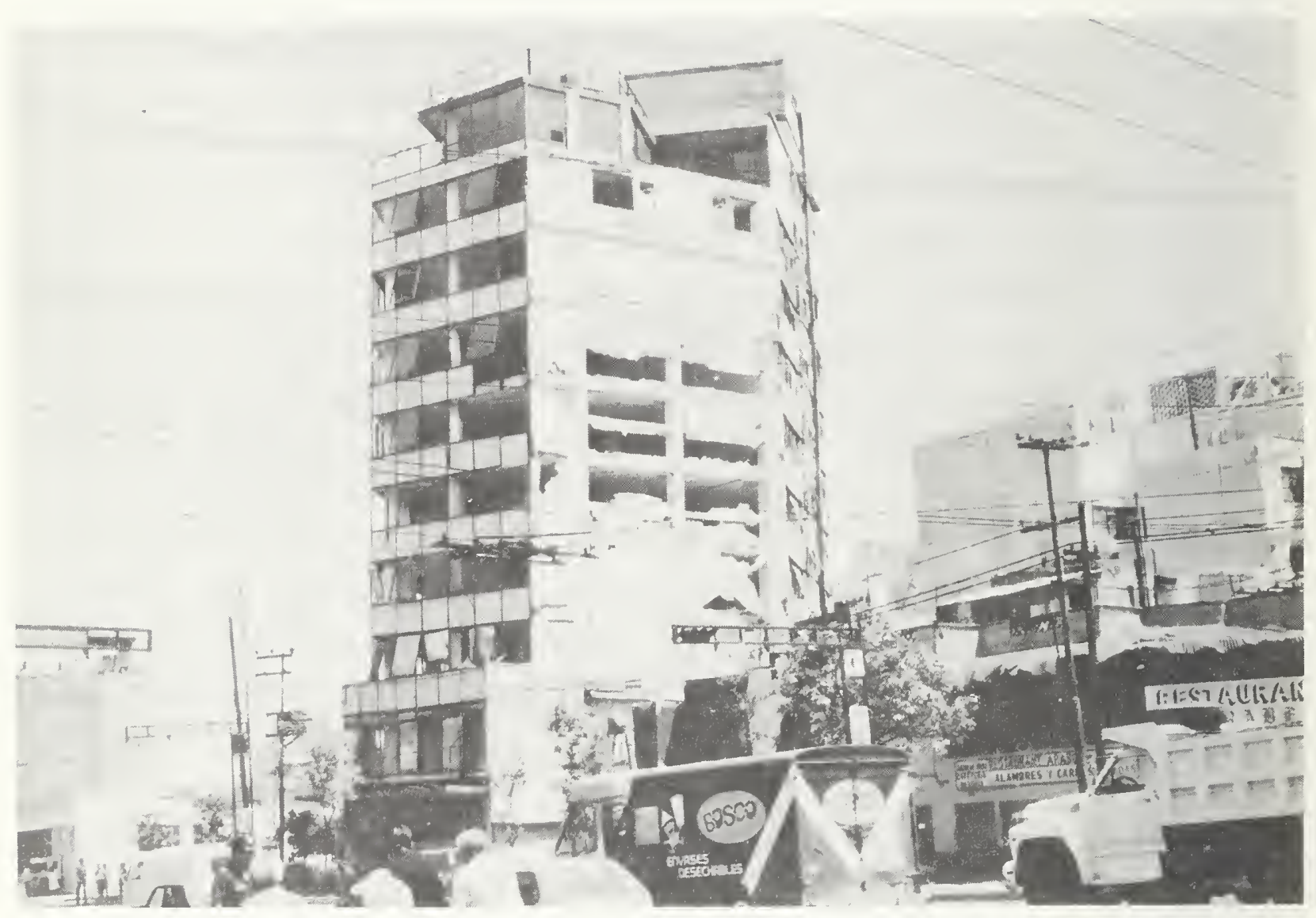

Figure 4.5. Tilted ten story building at Lazaro Cardenas and Fernando. 


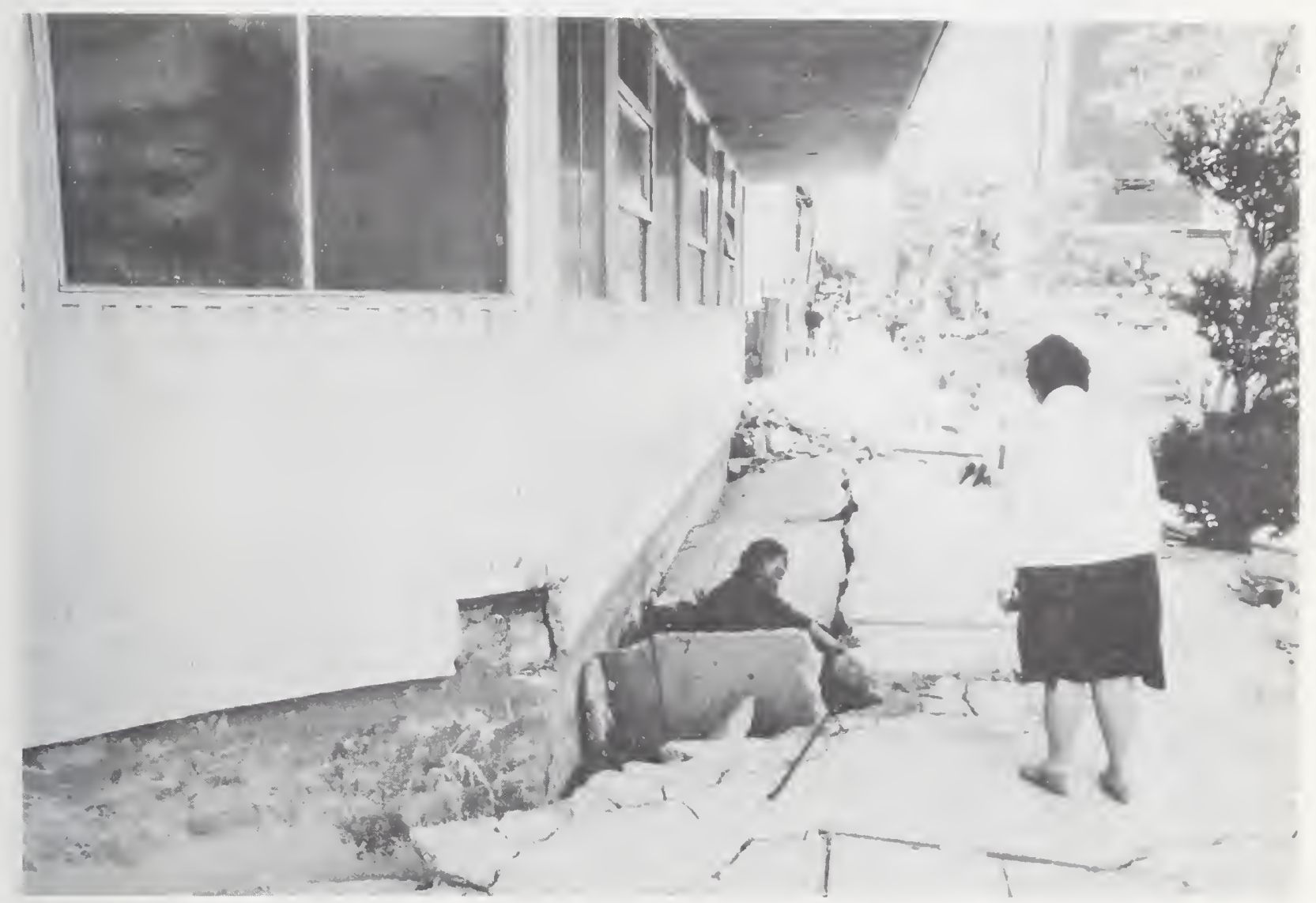

Figure 4.6. Relative displacement between sidewalk and tilted building at Lazaro Cardenas and Fernando. 


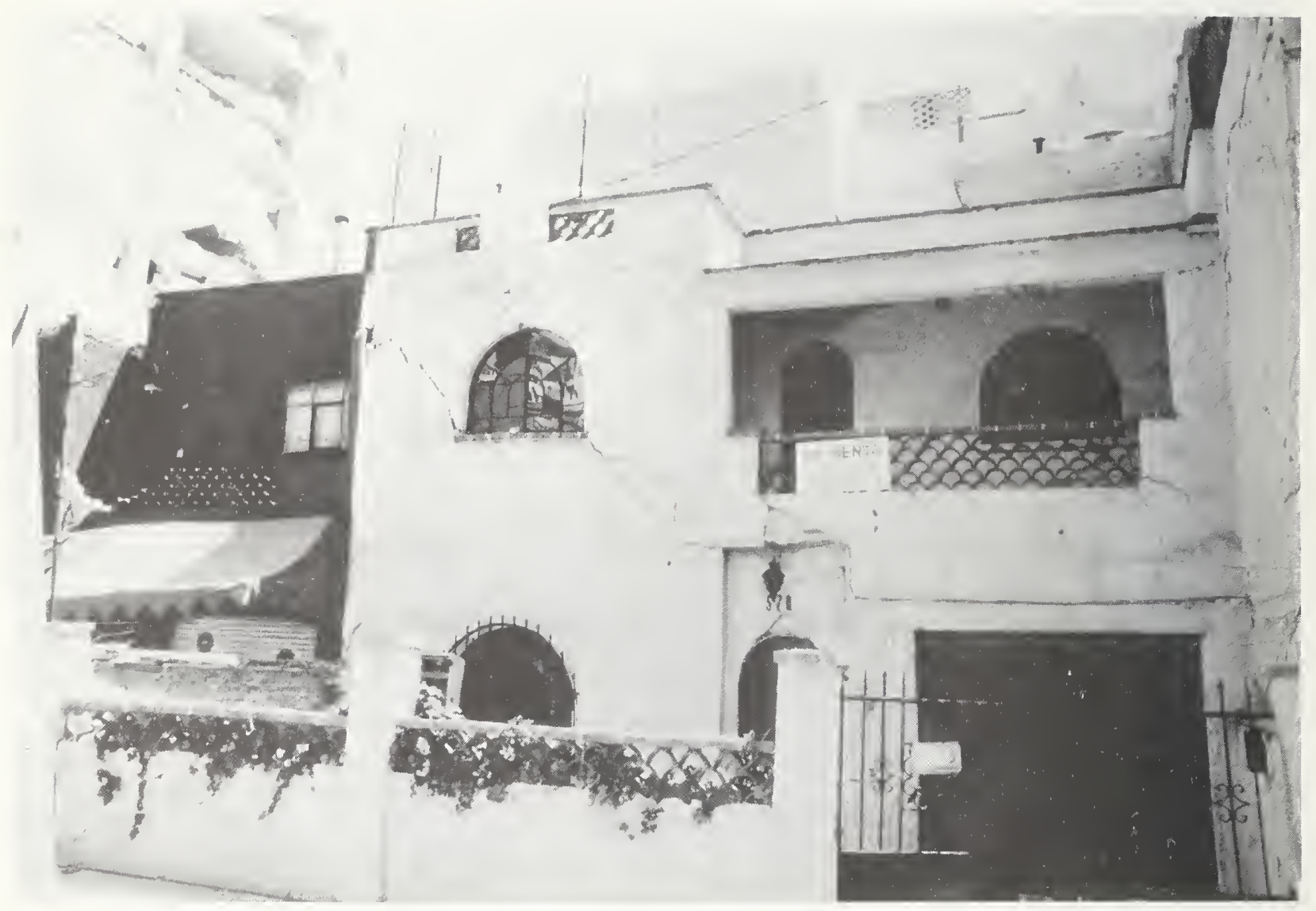

Figure 4.7. Damage to adjacent structures caused by the tilting of a ten story building at Lazaro Cardenas and Fernando. 


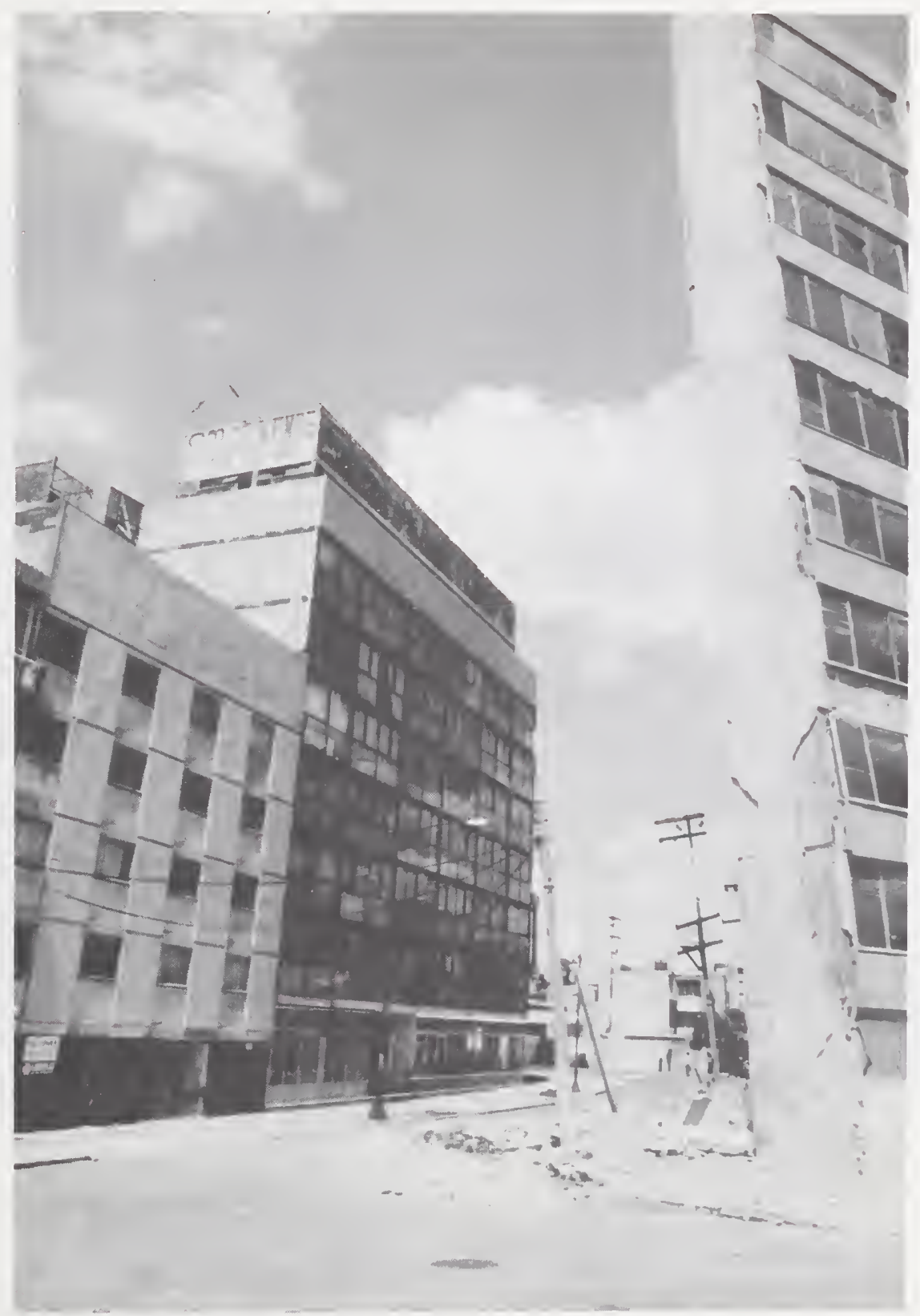

Figure 4.8. Tilted ten story building at University and Xola. 


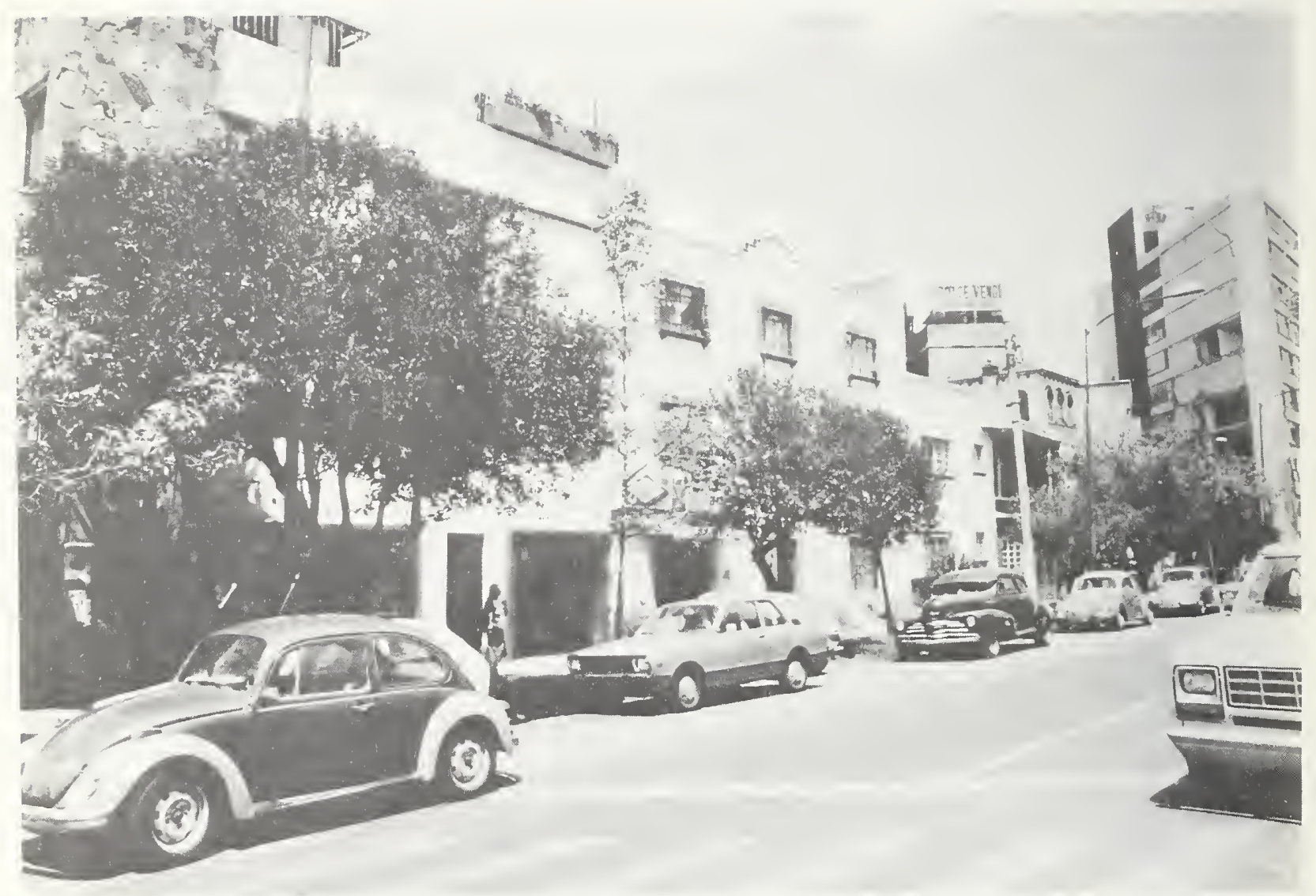

Figure 4.9. Undamaged two and three story buildings on University Boulevard opposite the severely damaged Communications Center. 


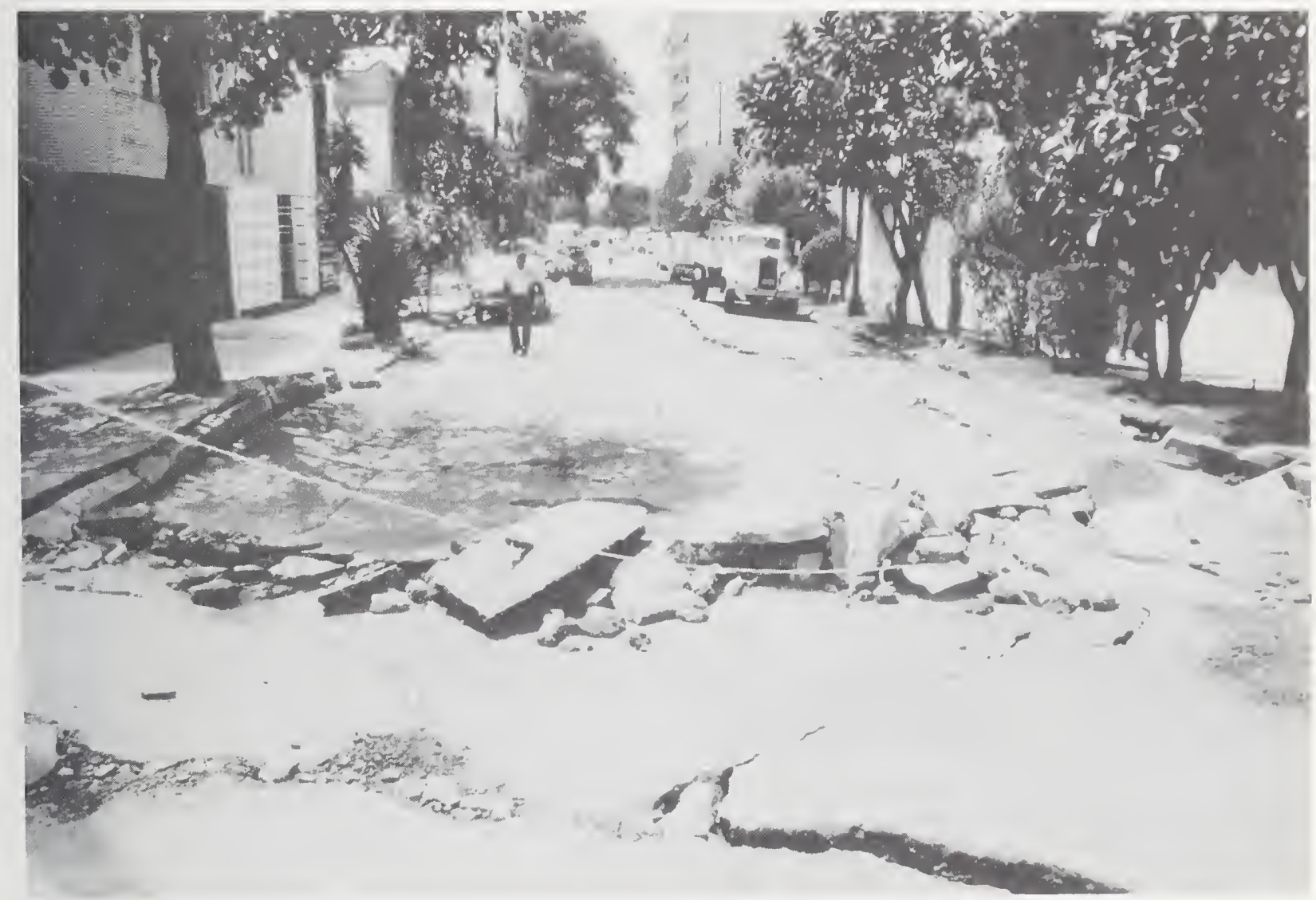

Figure 4.10. Ground disturbance on Galacia viewed from intersection of Toledo in a westerly direction. 
previously discussed and include a $6 \mathrm{~m}$ surface layer (some of it fill) and a $26 \mathrm{~m}$ upper clay layer with a water content of 275 percent.

An example of an overturned building is shown in figures 4.11 to 4.13. The building is located on the southeast corner of the intersection of Zacatecas and orizaba, an area where there is some irregularity in the surface elevation of the capa dura, which dips from a depth of $32 \mathrm{~m}$ to almost $40 \mathrm{~m}$ (see $A$ in figure 3.6). Figures 4.12 and 4.13 show the exposed pile foundation and a pulled out pile. Inspection of the dowels connecting the piles to the grade beam indicated that the connection was very weak. Apparently no tensile forces were anticipated at that point. Since only one pile was actually pulled from the ground, it is possible that the failure was triggered by a failure of the connections between the piles and the stiff foundation.

Tilting was observed in many severely damaged or collapsed buildings, but it was difficult to determine to what degree settlements contributed to the structural failures which caused the damage. One example is the office complex at Pino suarez, where steel frame buildings collapsed. The buildings which collapsed are discussed elsewhere and collapse is attributed to column failures. However, other buildings in the same complex close to the collapsed buildings, which did not collapse, were observed to be considerably out of plumb (figure 4.14). In this case, it is unlikely that tilting contributed to the collapse since the collapsed buildings were located on top of an underground subway station which suffered relatively minor damage. However, the stiff base provided by the subway station may have caused an increase in the shear forces, which otherwise would have been attenuated by structure foundation interaction. In other cases, the P-delta effect associated with tilting 


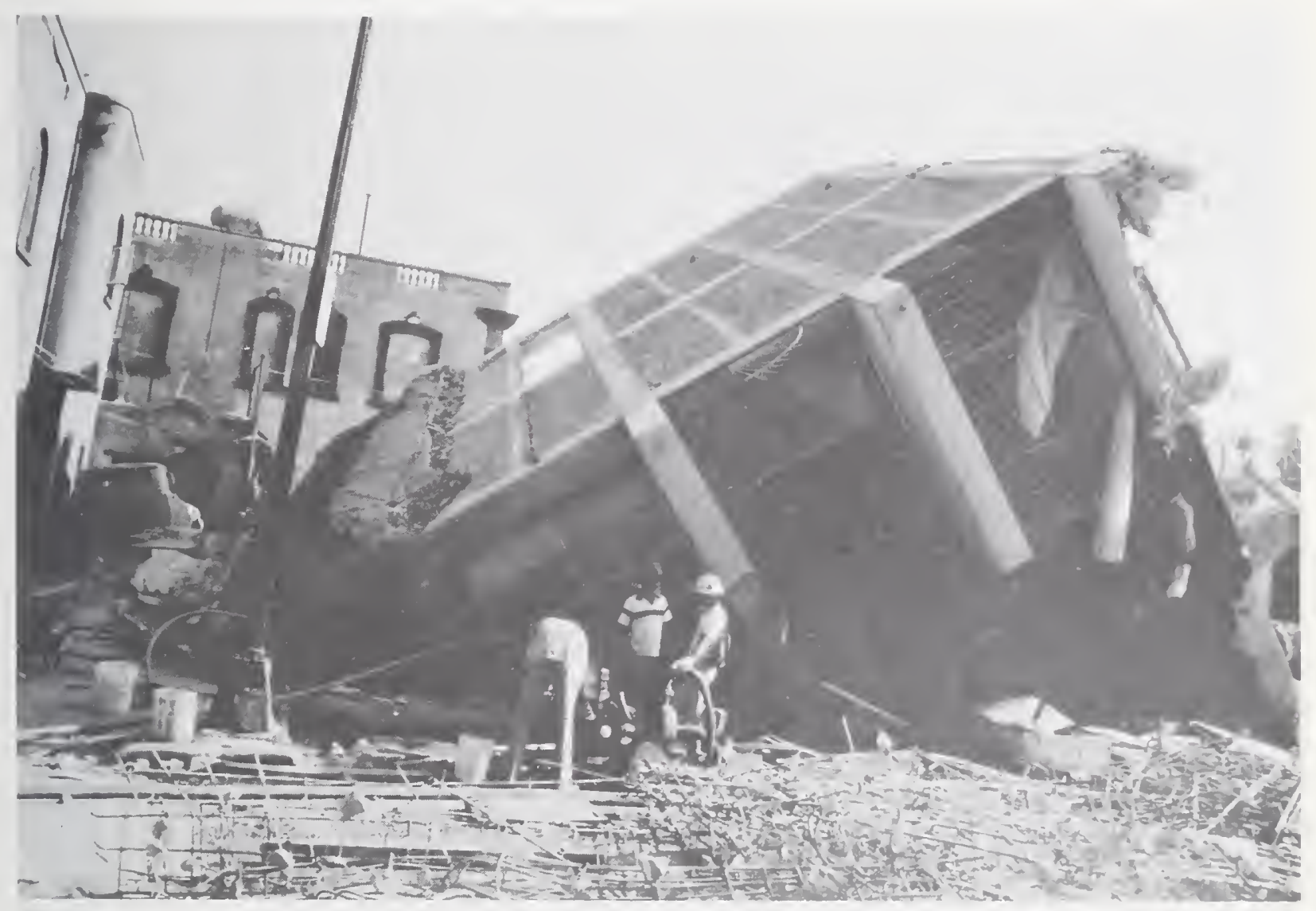

Figure 4.11. Oveturned building at southeast corner of Zacatecas and Orizaba. 


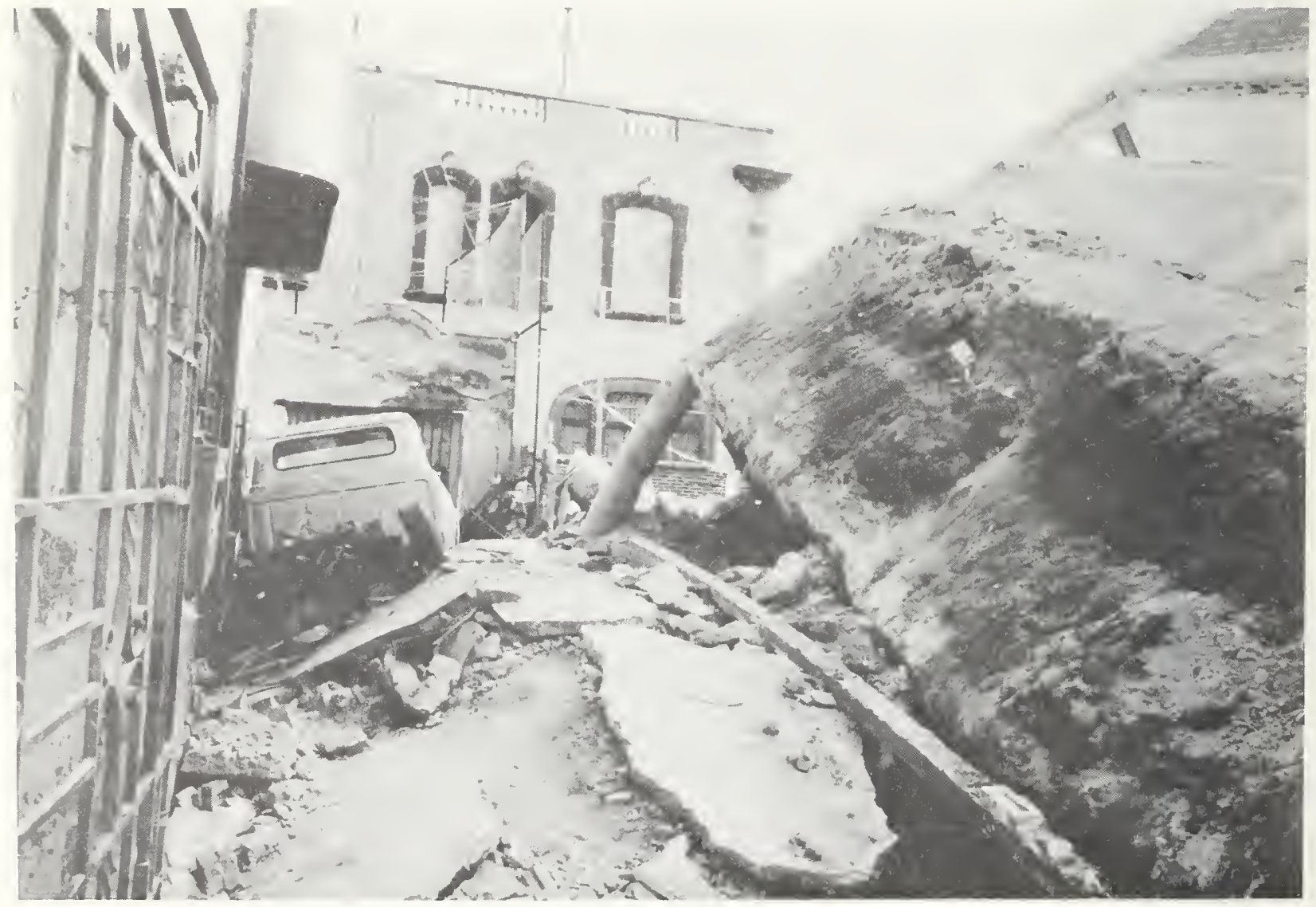

Figure 4.12. Exposed foundation of overturned building at Zacatecas and Orizaba. 


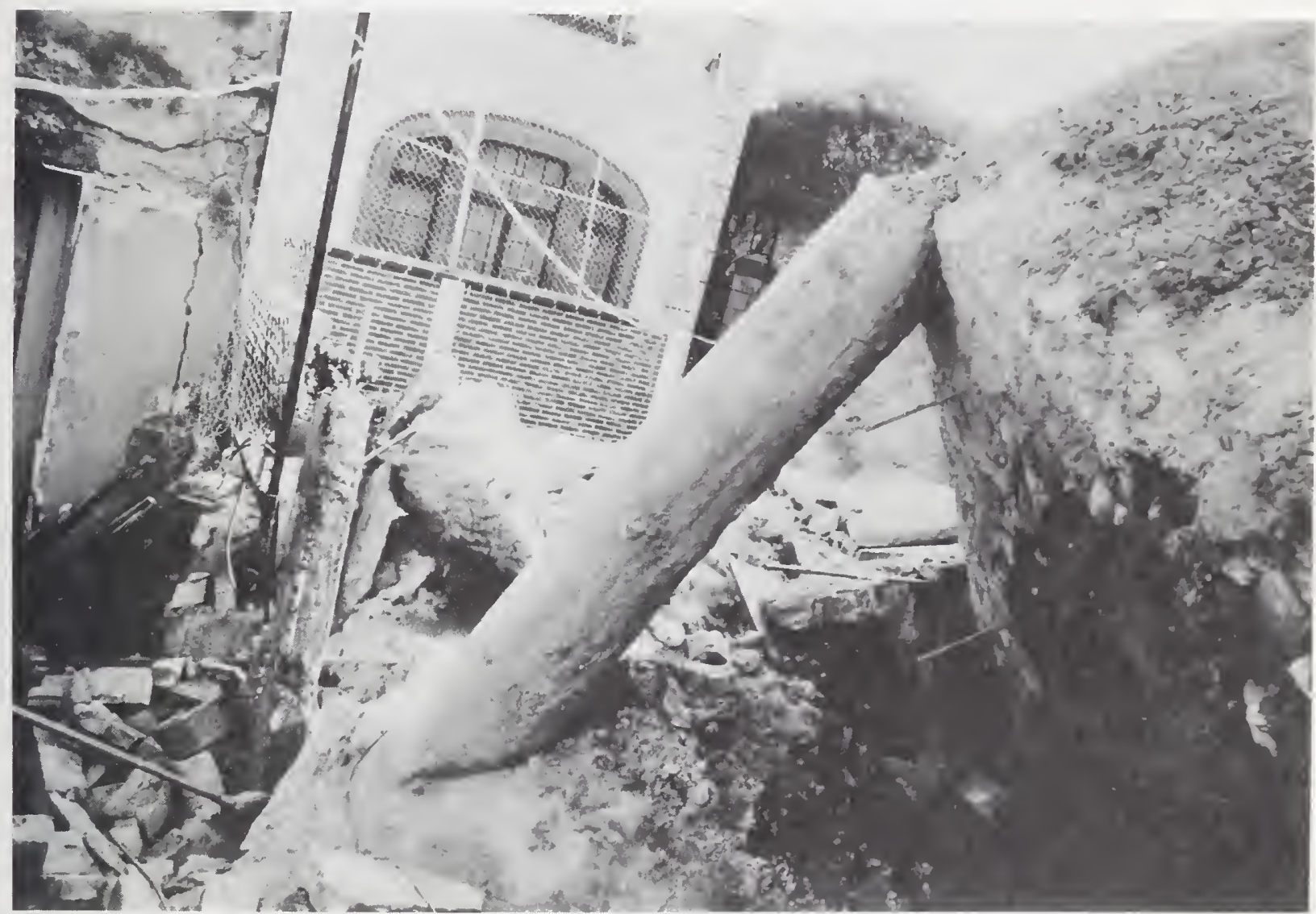

Figure 4.13. Exposed pile and dowels of the foundation of overturned building at Zacatecas and Orizaba. 
during the earthquake and lack of plumbness prior to the earthquake substantially contributed to structural failures.

\subsection{Warping Effects}

Many buildings were damaged as a result of distortions caused by differential foundation settlements. An example is shown in figures 4.14 and 4.15. The far corner (SW) of the building shown in figure 4.14 which is located on the south side of Teresa De Mier just to the east of Medico Militar settled more than the other corners. This differential settlement resulted in a warping distortion which can be seen in the wall shown in figure 4.15 .

The building shown in figure 4.14, as well as the Pino Suarez complex discussed in Chapter 5, the collapsed Juarez Hospital, and the San Pablo Cathedral, one tower of which overturned, are all in an area of a few blocks, where other tilted buildings were observed. In this area at boring \#391 [11] which is at the Juarez Hospital the capa dura is at a depth of $36 \mathrm{~m}$ and the upper clay layer is $29 \mathrm{~m}$ thick and has a 300 percent water content (which is relatively high). The subsurface conditions may have played a critical roll in all the structural failures in that area.

\subsection{Other Observed Soil Disturbances}

In many locations the ground surface over utility lines was uplifted. An example is shown in figure 4.17 which shows a photograph taken at the intersection of Monterrey and obregon. Figure 4.18 shows old trolley rails which had been covered over by pavement. The rails buckled as a result of the earthquake motion. This phenomenon repeated itself on Alvarado obregon from Monterrey to the east, always at the same location, just to the east of every road intersection. The buckling is attributed to 


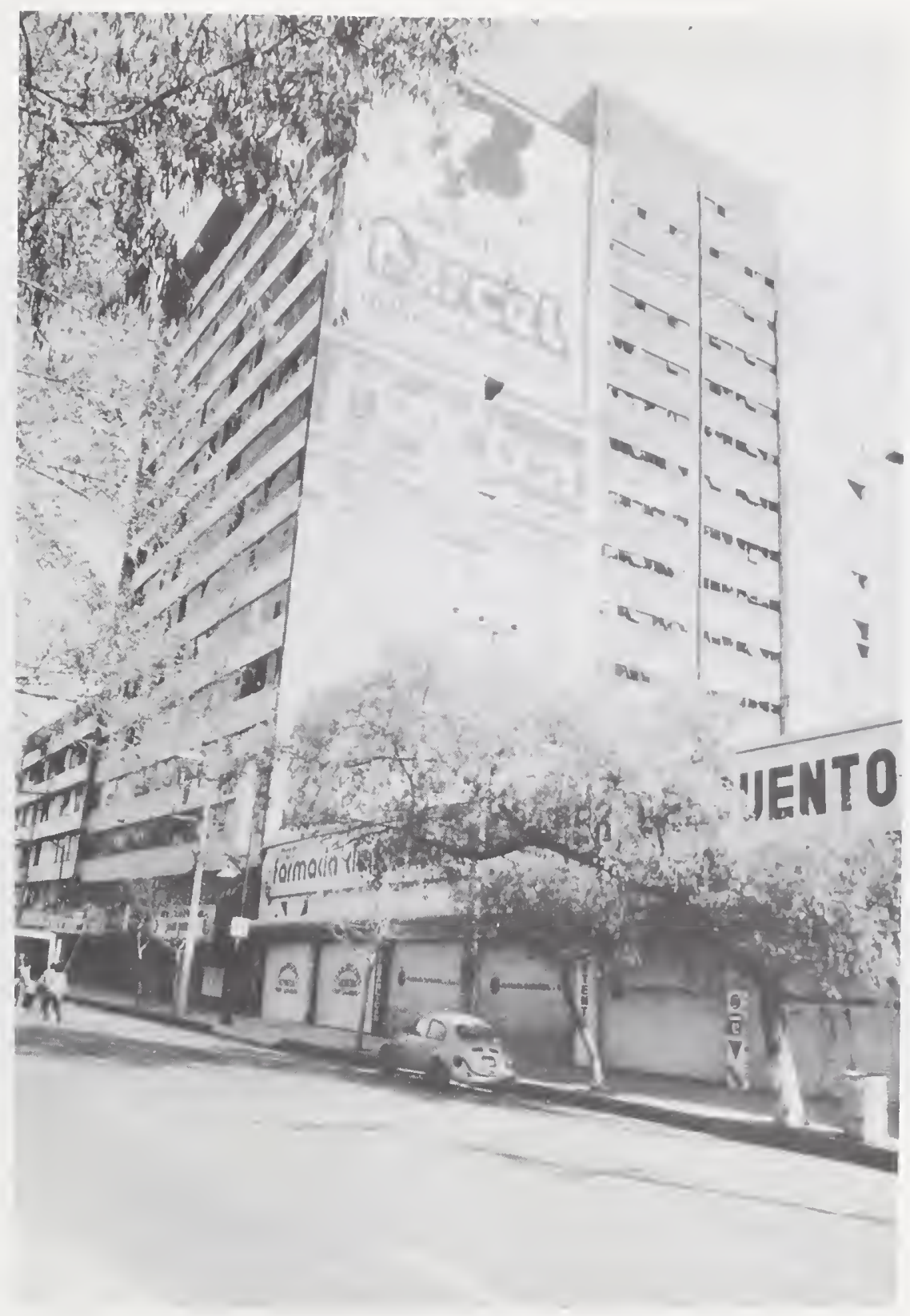

Figure 4.14. Building on the south side of Teresa de Mier which settled in one corner. 


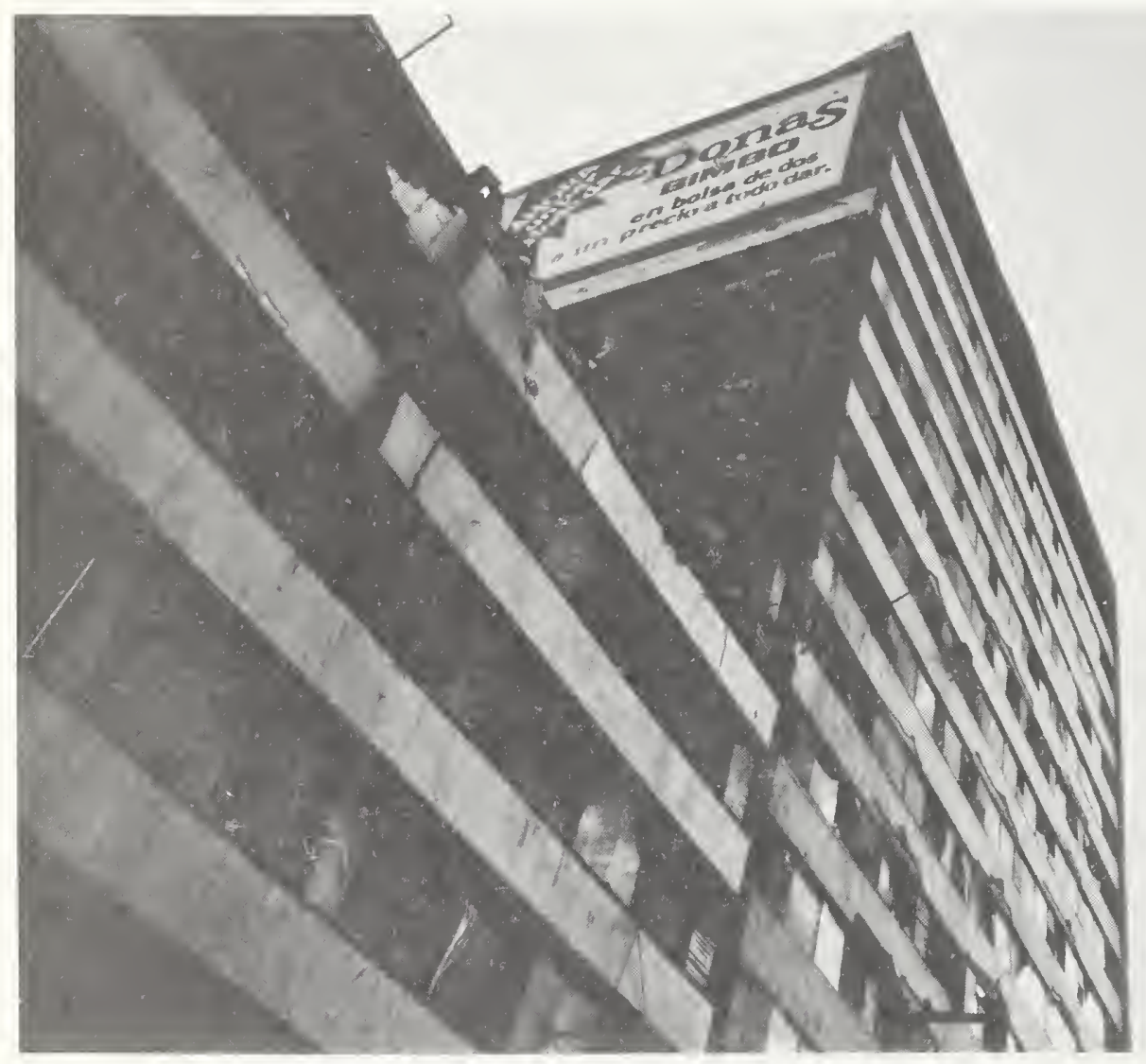

Figure 4.15. Warped wall on the north side of building on Teresa de Mier. 


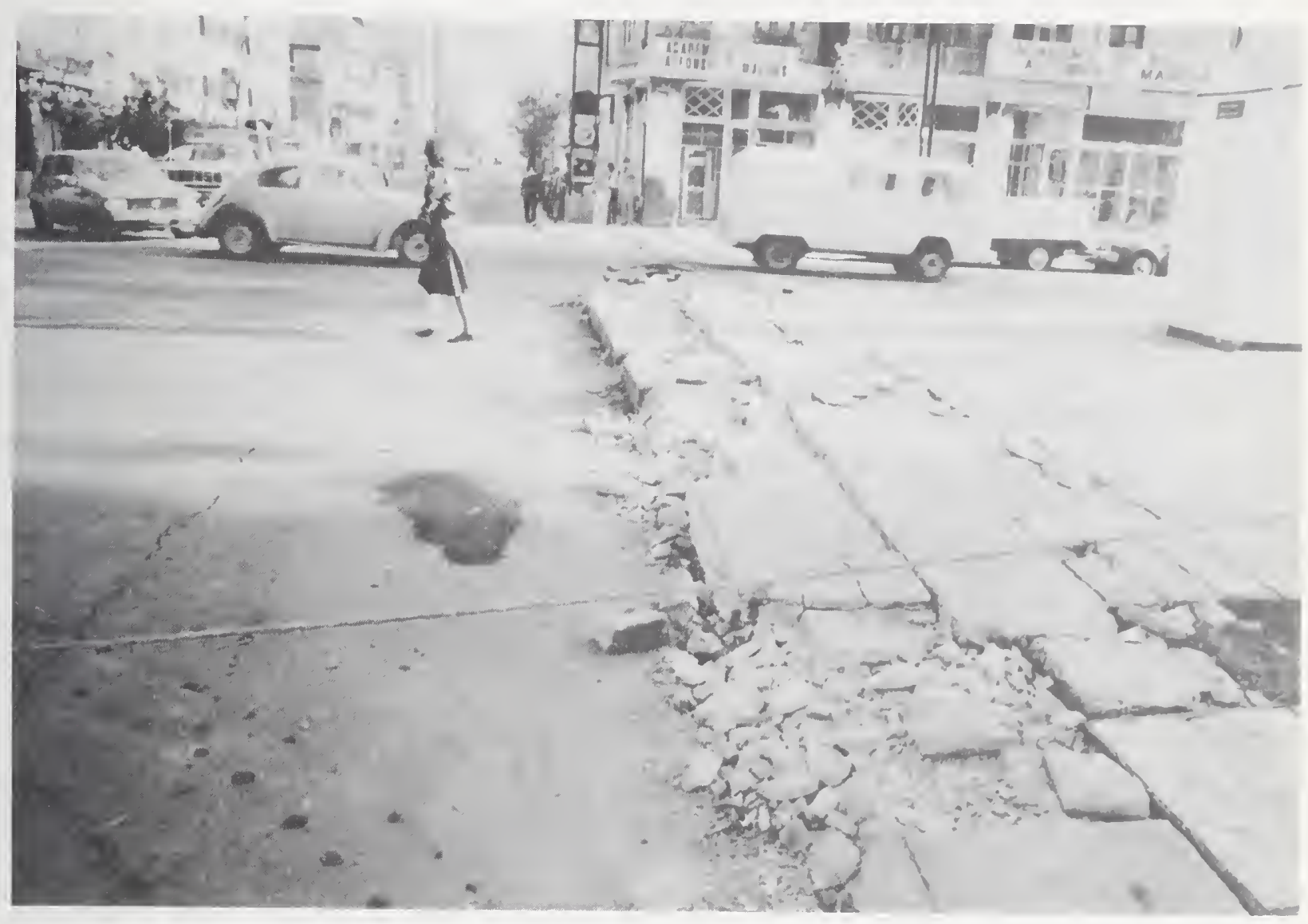

Figure 4.16. Soil disturbance over utility line at the intersection of Monterrey and Obregon. 


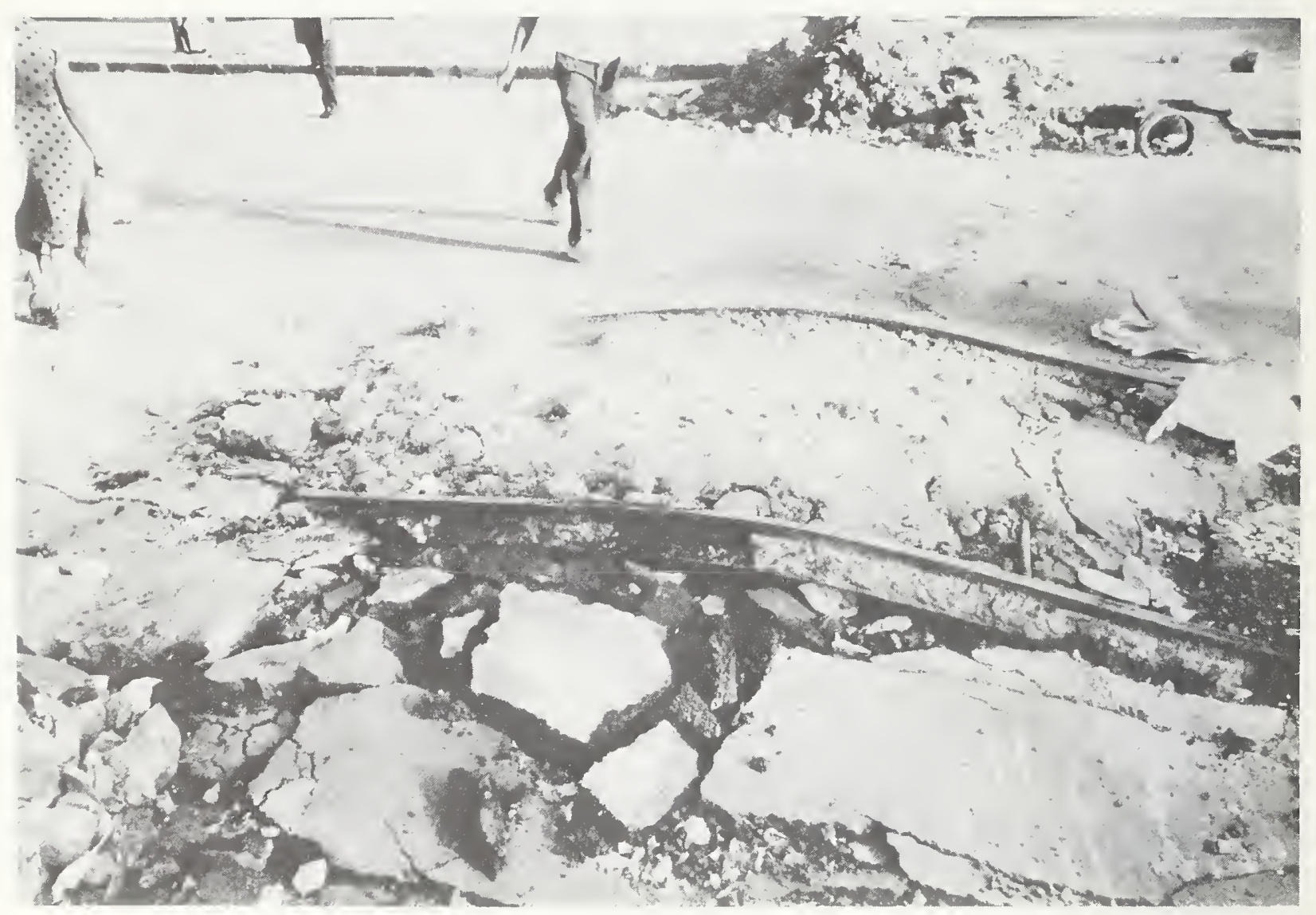

Figure 4.17. Buckled old trolley line on Obregon. 
accumulated compressive stress in the rail lines, caused by sliding interaction with the surrounding soil as a result of the horizontal earthquake motion. The rails buckled upwards because of lack of confinement in that direction and probably failed at a weak spot created by the excavation and backfilling of utility lines. Heave at the utility line may also have contributed to the buckling.

4.6 Discussion of Foundation Failure Mechanisms

Since volume change in the soil is inhibited by low permeability, and liquefaction or cyclic mobility are ruled out as failure mechanisms, it is reasoned that the observed soil displacements associated with tilting, differential settlements (warping) and the release of negative friction forces acting on piles were associated either with shear failures or with shear deformations, and only minor settlement could occur as a result of compressive forces.

However, since the compressive forces generated by the earthquake were resisted by excess porewater pressures, it is not ruled out that gradual settlements could occur over a'period of time, as the excess porewater pressures generated by the earthquake gradually dissipate. Similar phenomena were observed after previous earthquakes [11].

Special importance is attributed to the previously discussed observation that many foundation piles lost most of their frictional resistance during the earthquake. This limit state, as well as the fact that the clays lose much of their shear strength when large shear deformations occur, should be considered in the design of earthquake-resistant foundations.

In view of the potential magnitude of the shear forces and overturning moments that this earthquake could generate (refer to 
figure 3.7) it is noteworthy that many buildings apparently escaped serious structural or foundation damage. This phenomenon is attributed to the unique foundation conditions in Mexico City:

(1) The structure-foundation interaction will tend to limit the magnitude of the shear forces that can be resisted at the foundation level.

(2) Most taller buildings have stiff mat or box foundations (refer to figure 4.12). The settlement and tilting of these foundations would require long time increments since any volume change in the supporting clay layer is inhibited by its low permeability.

(3) Shear failures which may have occurred in foundation piles may have escaped detection. 


\section{STRUCTURAL FAILURES}

5.1 History of Building Regulations

Historically, Mexico City has been influenced by long distance effects of earthquakes on the coast. Since 1845, the most recent ground motion to have caused the collapse of a colonial church, a great number of quakes have registered magnitudes in excess of 7.5 on the Richter Scale along the Middle American Trench (See Fig. 2.2). It has been recorded that "While local officials were awaiting the entrance into the City of the leader of the revolution on June 7,1911 , there was a major earthquake at 4:26 A.M. The local barracks of San cosme were demolished as were other buildings and walls in different parts of the city. There were 39 badly wounded and 49 deaths. Other earthquakes were subsequently felt and church bells rang by themselves." [33] The earthquake of June 7,1911 was the most intense since that of 1845 .

The first building code containing earthquake-resistant design provisions in Mexico dates from 1942 [25]. This code, while provided minimal guidelines for seismic design. Prior to the 1950's there were few buildings in the city over 12 stories. The 1942 code required that joints between two adjacent structural elements be designed to have similar strength as the elements themselves. Each structure was to be designed and built to 
oscillate as a unit. Foundations were required to be designed so that the structure would not slide or overturn and that joints between piles and foundation girders or slabs would not fail. Maximum permissible pile overstressing during an earthquake was $33 \%$. This same percentage applied to any point of the bearing area of the ground or the foundation elements, as well as structural joints. Seismic design computations were required for structures over $16 \mathrm{~m}$ high, those with a height-width ratio greater than two, and any building intended for use by large groups of people.

Seismic design coefficients varied from zero for unimportant structures to 0.1 for the most important. Houses, hotels, and office buildings had a coefficient of 0.025 , which was constant for every story.

The 1942 code was found to be deficient following large damages sustained as a result of the July 28, 1957 earthquake. This shock had a Richter magnitude of 7.5 with peak accelerations of between $0.05-0.1 \mathrm{~g}$ and dominant periods of 0.9 to 1.8 seconds [28]. This was the worst shock the city had experienced since records were kept beginning in 1900. Emergency regulations were promptly issued. These regulations established base shear coefficients in terms of microzonation and recognized ductility. Equivalent base shears of $0.17 \mathrm{G}$ were stipulated for ordinary frame structures in the lake zone. An importance coefficient of 2 for critical structures was recommended. However, a 50\% overstress (working) was allowed for combined gravity and seismic loads. The 1957 regulations were later replaced by the 1966 code which reduced the importance factor to 1.3, allowed ultimate strength design, explicitly recognized slenderness effects, and recommended dynamic analysis. Buildings with floor areas larger than $10,000 \mathrm{~m}^{2}$ or higher than $45 \mathrm{~m}$ were required to be instrumented (a provision that was not implemented in practice). These provisions were subsequently revised in 1969. In 
the 1976 code, the three zones dividing Mexico City as in 1957 were readopted. The 1976 code [19] represented a substantial improvement, reflecting the state of the art in earthquake resistant design. Ultimate strength design provisions were recommended with a load factor of 1.4 for earthquake load. Lateral load coefficients reflected the known problem of spectral amplification. Design story shears were obtained by specifying horizontal accelerations proportional to elevation above ground, similar to those used in U.S. codes. Detailing requirements were practically comparable to that of Appendix A of ACI 318-83 [26] provisions. However, hoop reinforcement was still substantially less than that required in ACI provisions. The maximum design base shear coefficient for non-ductile frames with 5\% damping in the lake zone was 0.24 . The maximum reductions in design lateral shear forces permitted for ductile structures was by a factor of 6 . Permissible story drift was limited to 0.008 times the story height. This drift limitation can be compared with the UBC value of 0.005 . Thus the Mexican code permitted more flexible structures than the Uniform Building code.

It was with this background, that Mexico City was prepared for the earthquake of september 19, 1985. Following the earthquake, on October 18, 1985, emergency regulations were issued. In these regulations the design response spectrum for the lake zone was increased to a maximum base shear force coefficient of 0.4 for non ductile structures in the lake zone, and the maximum reduction factor for ductile structures was changed from 6 to 4 . Figure 5.1 shows a comparison of the 1976 and 1985 design spectra for non ductile structures. 


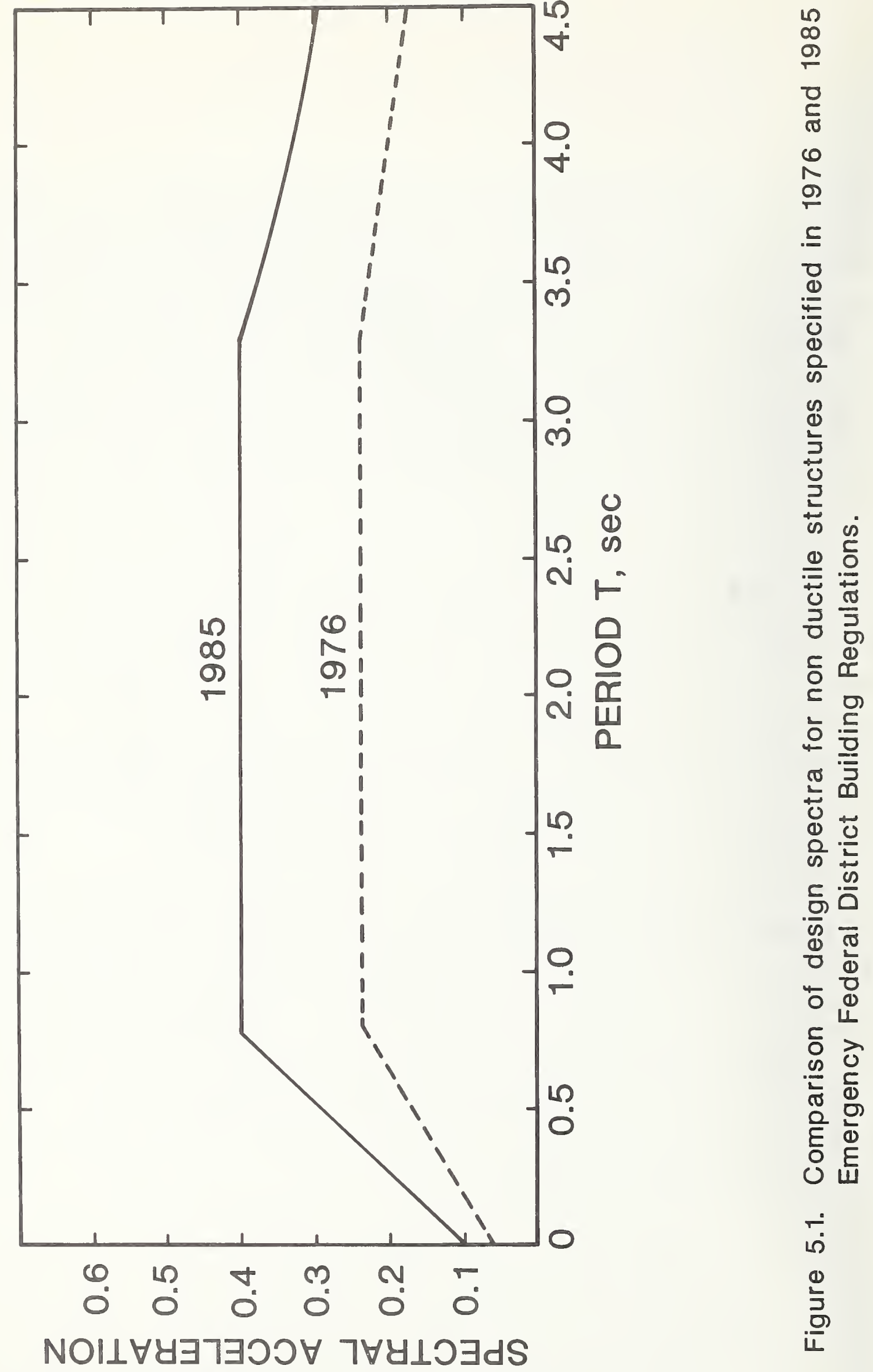


5.2 Failure Patterns

Table 5.1 shows the summary of a building damage tally for the Federal District carried out by UNAM [1]. Damage figures as a percentage of buildings in the surveyed area are given below:

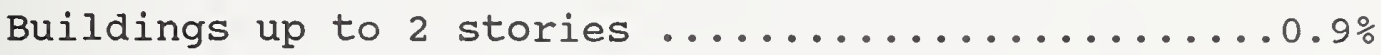

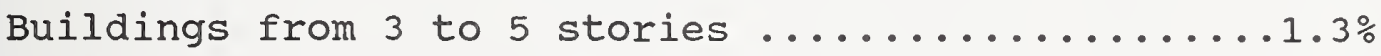

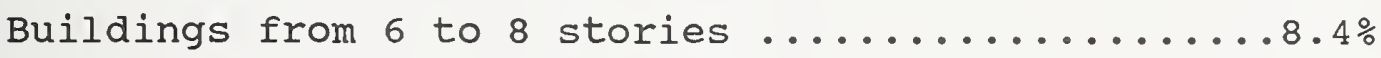

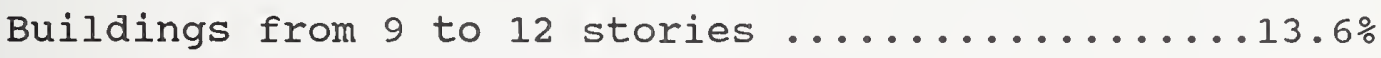

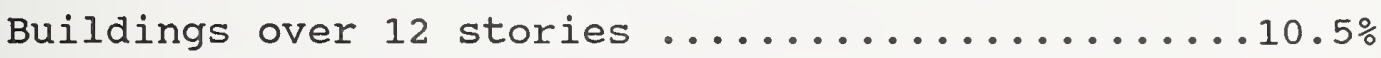

Total number of buildings in surveyed area.....53,356

Percent of total buildings heavily damaged .........4\%

There is no information and no reasonable way to find out what percentage of these buildings actually complied with the regulations which were in force at the time of their construction.

While other statistics on building characteristics that contributed to the failures were provided in Table 4.1, the most striking feature of the earthquake damage observed by teams surveying the earthquake damage was the selective damage pattern. Most buildings in the 5 to 20 story range either collapsed or were severely damaged, while the smaller 2 to 4 story buildings suffered little or no damage. Modern tall buildings (more than 30 stories) did not sustain any severe damage.

The cause for this damage pattern is the unique character of the ground motion in the lake region. As exemplified in the timehistory plots of ground motions in the lakebed zone in figures 3.3 and 3.4 and the response spectrum in figure 3.27 , large spectral accelerations within the dominant ground periods of 1.5 and 2.5 seconds were experienced. Therefore, buildings with fundamental periods in this range were subjected to very large 


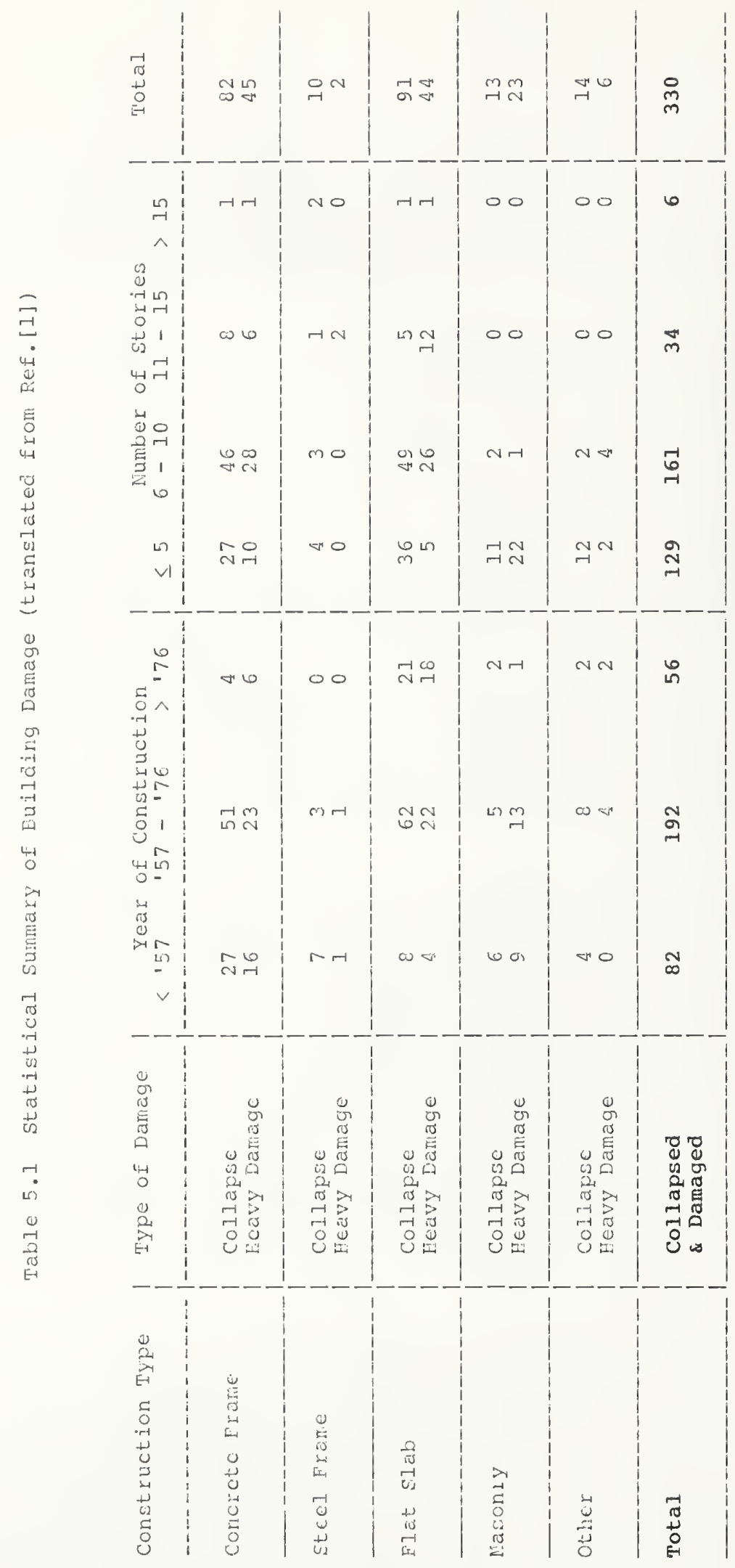


shear forces. Furthermore, since the fundamental period of structures are increased due to structural damage sustained by the building components and soil-structure interaction, there is every reason to believe that many structures experienced further damage as a result of this shifting of the fundamental period.

Another feature of the damage pattern is that in several cases in urban development areas identical structures were built at a particular site and only one or two of the group of structures collapsed. Some of the remaining buildings suffered only negligible damage. Irregular subsurface conditions, uneven construction quality control, and distribution of gravity loads can be cited as possible reasons for the variation of damage in a vicinity.

\subsection{Performance of Different Structural systems}

The great majority of buildings that collapsed were concrete structures (Table 5.1), which is economically attractive in Mexico City. Few steel frame structures failed as indicated by Table 5.1. However, steel construction represents only a small percentage of Mexico City's building inventory, due to the high cost of fabricated sections.

\subsection{Reinforced Concrete Frame Structures}

\section{4 .1 General}

Two types of reinforced concrete frame systems have been used in Mexico City. These can be classified as those in which: (1) The frame provides support for vertical loads only; seismic resistance is provided by shear walls or braced panels; and (2) the frame resists the vertical, as well as the seismic forces (Figure 4.2). 


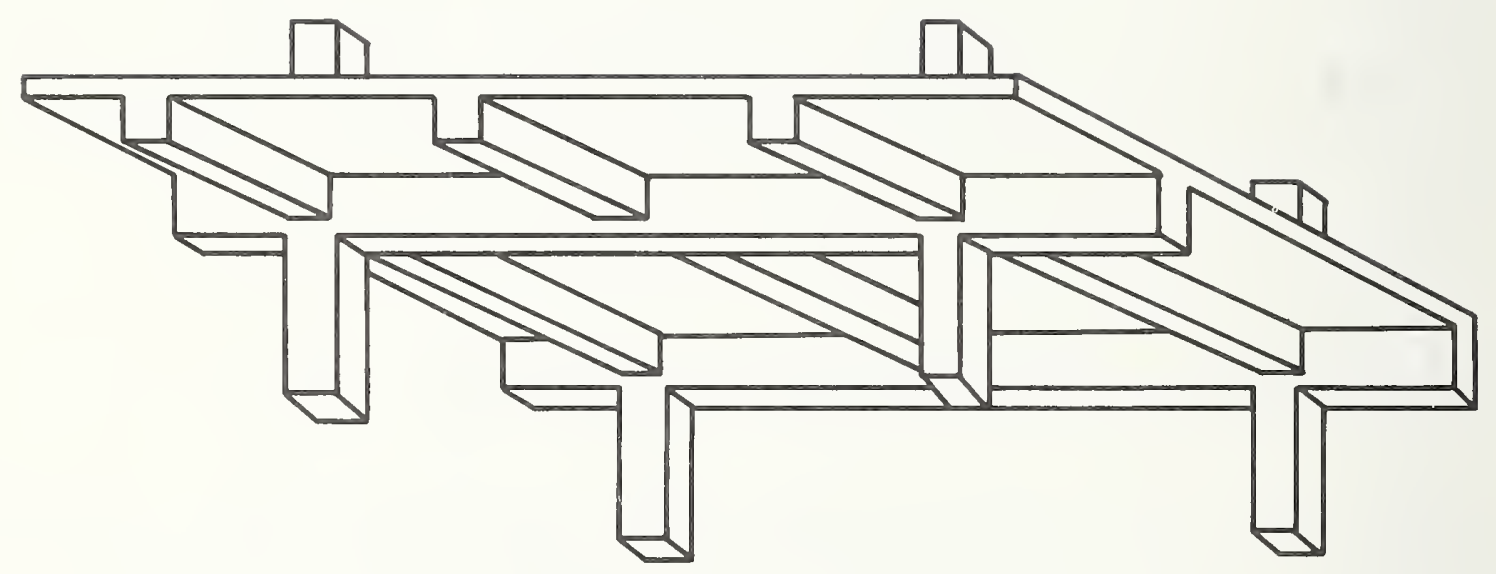

Figure 5.2. Schematic drawing of typical reinforced concrete framing system. 
In case (1) the frame is designed to carry the vertical load and only a small percentage of the earthquake load. Most of the older concrete frame structures in Mexico City are of this type. Shearwalls are normally constructed of brick, concrete masonry, or reinforced concrete. In some taller buildings the structures have been stiffened by diagonal reinforced concrete bracing members as shown in figure 5.3. Many of these buildings performed well. However, some of these structures collapsed when the shear-walls and/or infill walls failed (sometimes by out of plane bending). A special problem associated with this type of building has been the tendency to omit the shear-walls in the lower story, to leave room for storefronts, lobbies, and parking facilities. This practice generated a soft story, and resulted in unsymmetrically braced buildings which are subjected to torsion.

In case (2) the earthquake load is resisted entirely by frame action. In an earthquake the girders are required to carry the vertical slab loads to the columns, as well as absorb seismic energy through the formation of plastic hinges. Properly designed reinforced concrete frames are expected to behave in a ductile manner, and are more flexible than shear wall type structures. In any event, hinging in the columns at a column-beam connection is not desirable. Frame systems in which columns are permitted develop plastic hinges can result in stability failures during stress reversals, through mechanisms incapable of resisting lateral loads. Therefore, behavior of the frame in the inelastic range becomes an important feature in resistance strategy which relies on energy absorption capability while deforming beyond the elastic limit.

Consequently, in a reinforced concrete frame, it is desirable to have plastic hinges form in the beams rather than in the columns. Special transverse confining reinforcement -- in the form of a spiral or closed rectangular ties -- is necessary to insure the required ductility should plastic hinges form at column ends 


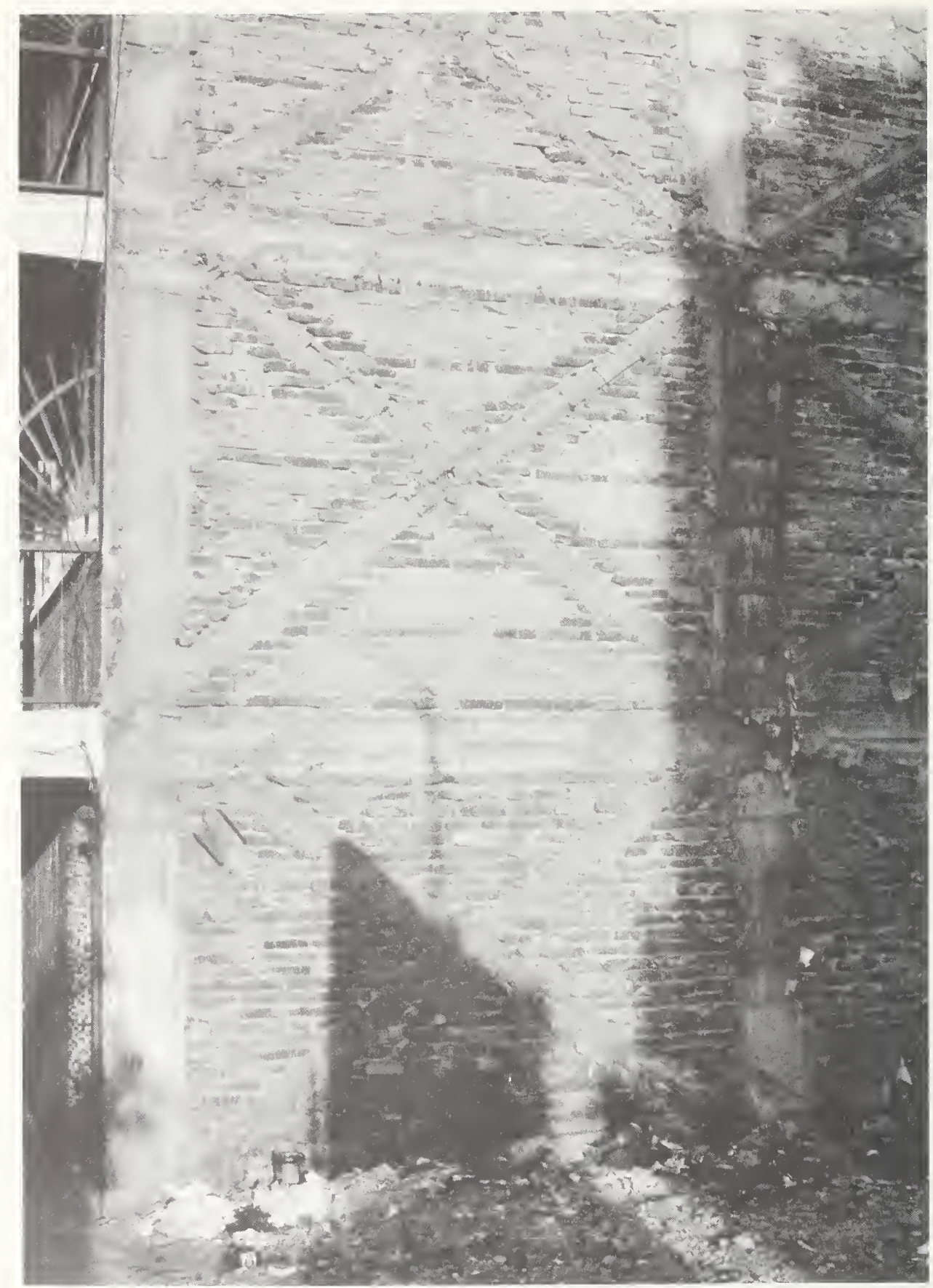

Figure 5.3. Typical reinforced concrete diagonal bracing with masonry infill used in Mexico City. 
during a seismic event. The ties compensate for strength loss should spalling occur in the concrete cover and serve as all or part of the web reinforcement. Furthermore, ties prevent buckling of compression reinforcement. Both ACI 318-83 Appendix A [26] and the 1976 Mexico City Building code [19] contain provisions which recognize these factors. With the above background we can now examine the performance of a number of reinforced concrete frame structures.

\section{4 .2 Hospitals}

Major buildings at three of the city's largest hospital complexes collapsed, thus impairing use of these critical facilities. All were reinforced concrete frames and typified a common failure mode for this type of construction. Some 1200 people were buried as six buildings collapsed at the centro Medico and Mexico General Hospital, one of the largest medical facilities in Latin America. Figure 5.4 shows an aerial view of this complex looking towards the southwest and the street intersection of cuatemoc and Cohuila boulevards. The central (easternmost) structure collapsed towards the east exhibiting a pancaking type collapse similar to those normally associated with flat plate construction. However, the failure mechanism is quite different in this case. Examination of debris from this structure (figure 5.5) showed negligible damage in the beams and girders. The edge spandrel beams were, in contrast to the above discussed weak-beam/strong-column philosophy, quite stiff in comparison to the columns. Consequently, failure was likely initiated by the formation of plastic hinges at the column ends, both above and below the floor level joints with the girders.

Figure 5.6 shows a close-up view of one of the edge columns. These were typically 14 -in $(30 \mathrm{~cm})$ deep by 12 -in $(25 \mathrm{~cm})$ wide. closed stirrup confinement consisted of approximately \#2 bars (visual evaluation) at $4-6-$ in $(10-15 \mathrm{~cm})$ spacing. Following 


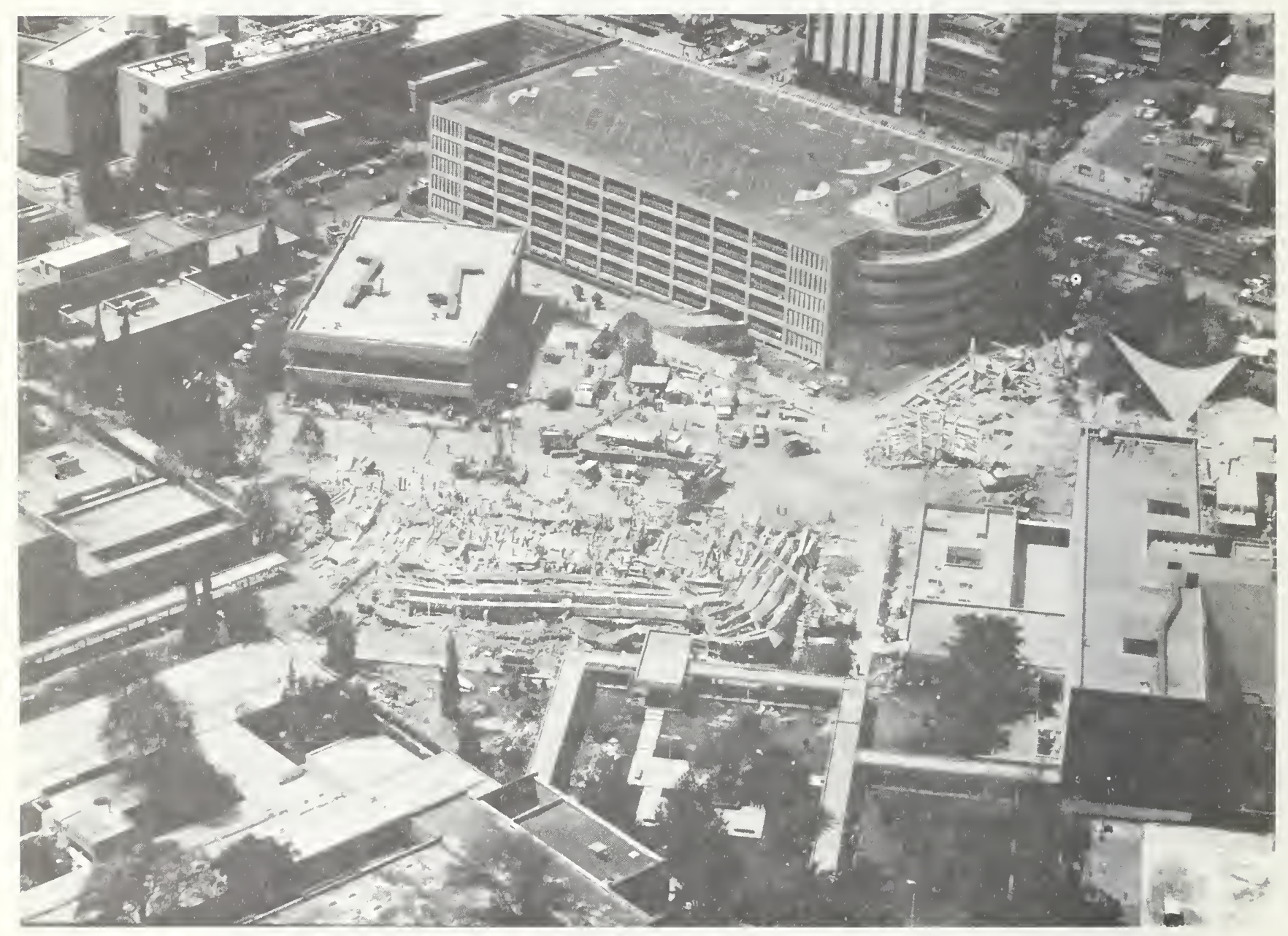

Figure 5.4. Aerial view of Mexico General Hospital. 


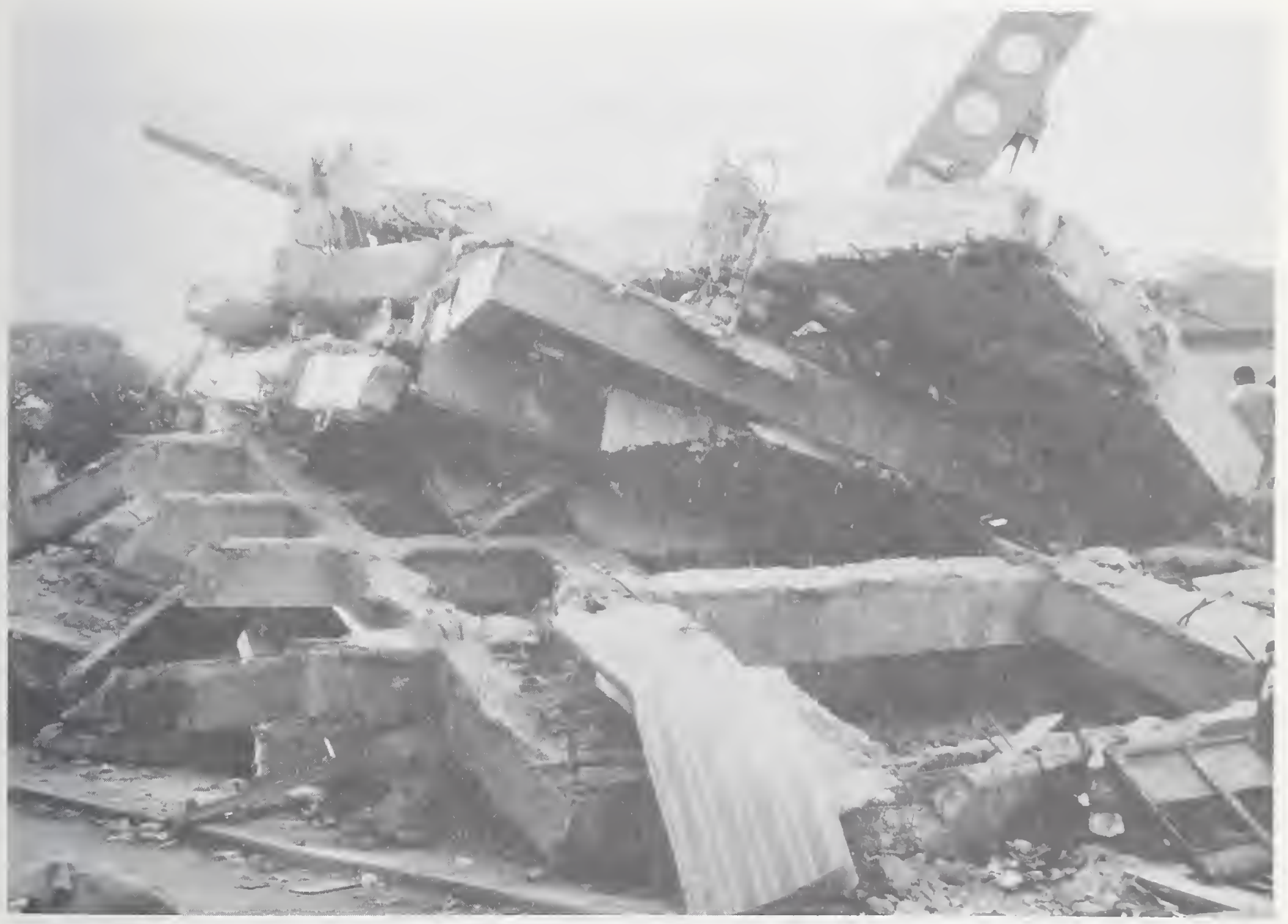

Figure 5.5. Debris from the collapsed Mexico General Hospital. 


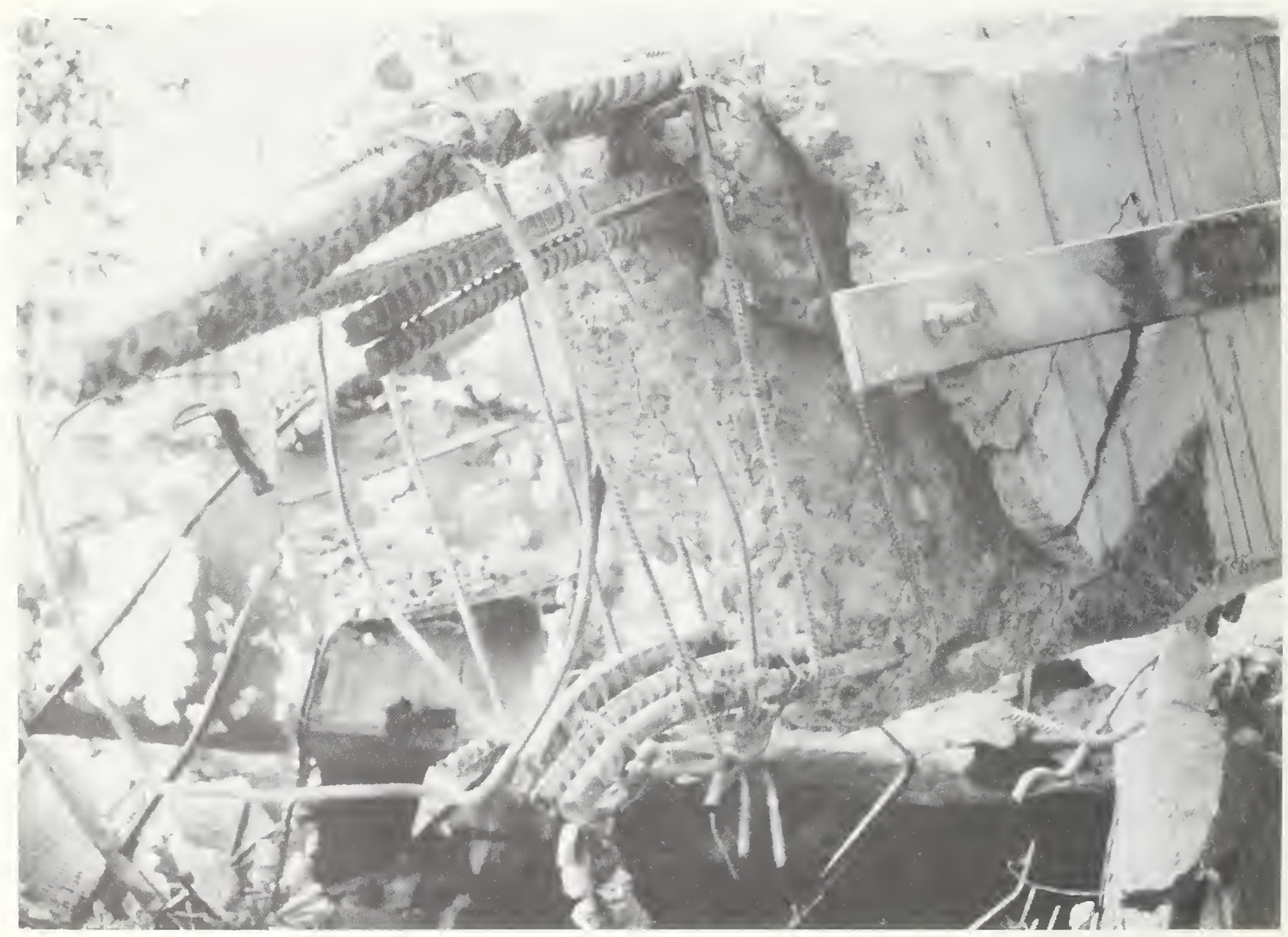

Figure 5.6. Edge column of collapsed General Hospital. 
current Mexico City building code specifications of 1976 [19], the required diameter of these stirrups, given the same spacing, should have been on the order of a \#5 bar, which is five times the cross sectional area of steel that was provided.. However, this same code restricts the maximum hoop spacing to $2-3 / 4-i n$ $(7 \mathrm{~cm})$. The General Hospital structures were built prior to the adoption of the 1976 code. Of particular interest was the performance of the new parking garage (upper center, figure 5.4) also a frame type structure. In contrast to the personnel building, however, the corners of this building contained reinforced concrete shear walls (see figure 5.7) which safely withstood the lateral forces during the quake. Figure 5.8 shows hairline cracks near beam column connections of the parking garage building.

Yet in another hospital building, the Maternity wing of the Juarez Hospital, eight blocks south of the Presidential Palace, 400 medical personnel and patients, notably infants, were trapped. This nine story reinforced concrete frame structure collapsed towards the east also (figures 5.9 and 5.10) exhibiting localized failures at the beam to column joints of each floor.

A close-up of various joint details (figure 5.11), indicates that the columns were generally well-proportioned to resist gravity loads. However, figure 5.11 and 5.13 clearly shows minimal to nonexistent confinement through the joints. Furthermore, many joints had longitudinal bar splices at these same critical moment locations. These factors probably contributed to joint failures after a relatively small number of cyclic load reversals.

The lack of such confinement, and the presence of splices in such critically underconfined joints -- which could lead to a loss of vertical load bearing continuity as soon as the bond strength is lost following core breakup -- directly contributed to the failure of the Juarez Hospital. This particular structure received considerable media attention as rescue personnel 


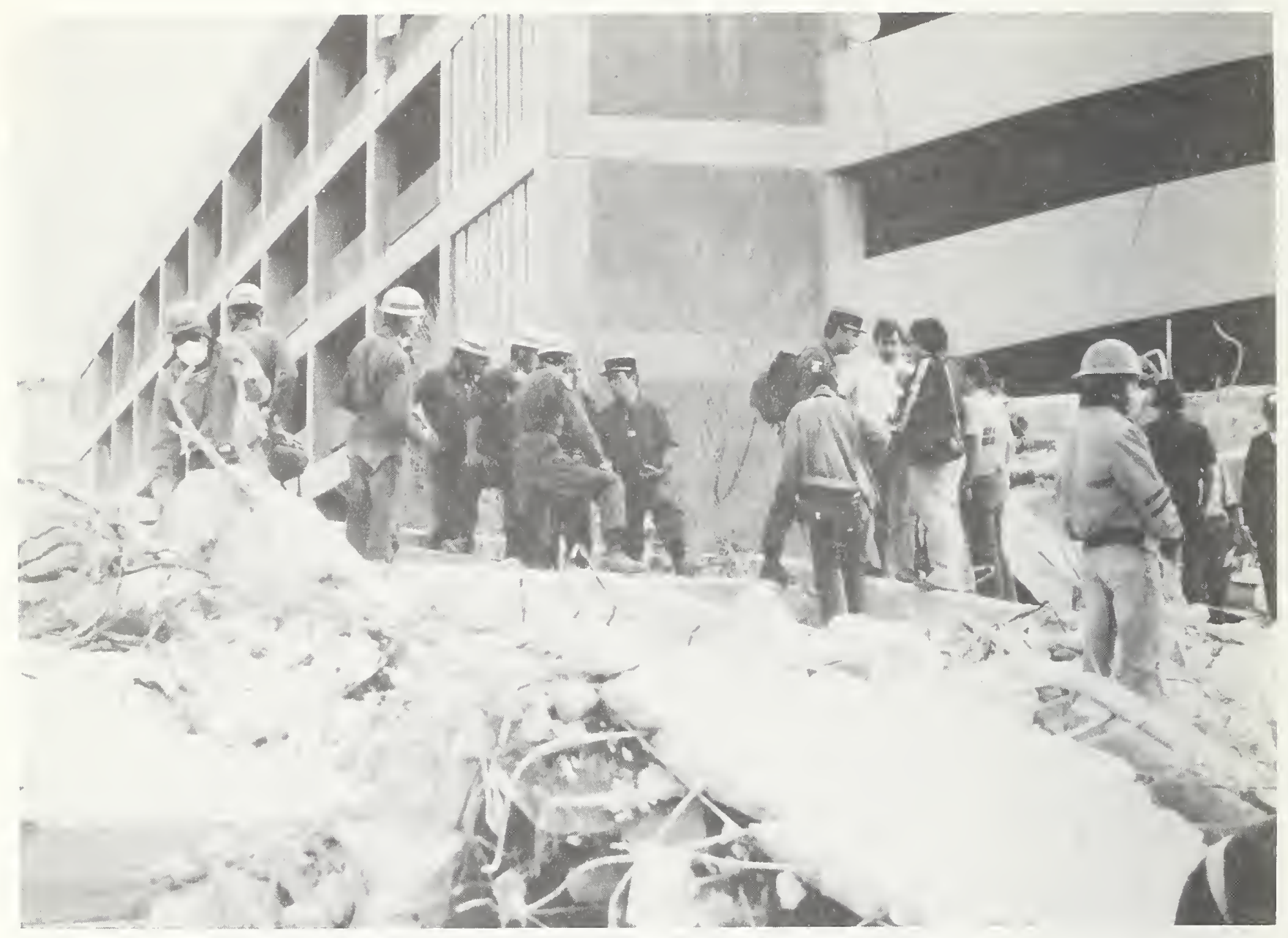

Figure 5.7. Reinforced concrete shearwalls in the corners of the parking garage of the Mexico General Hospital. The group standing in the foreground was part of the dog-rescue team from France. These teams successfully tracked down several survivors trapped in rubble of the buildings that collapsed. 


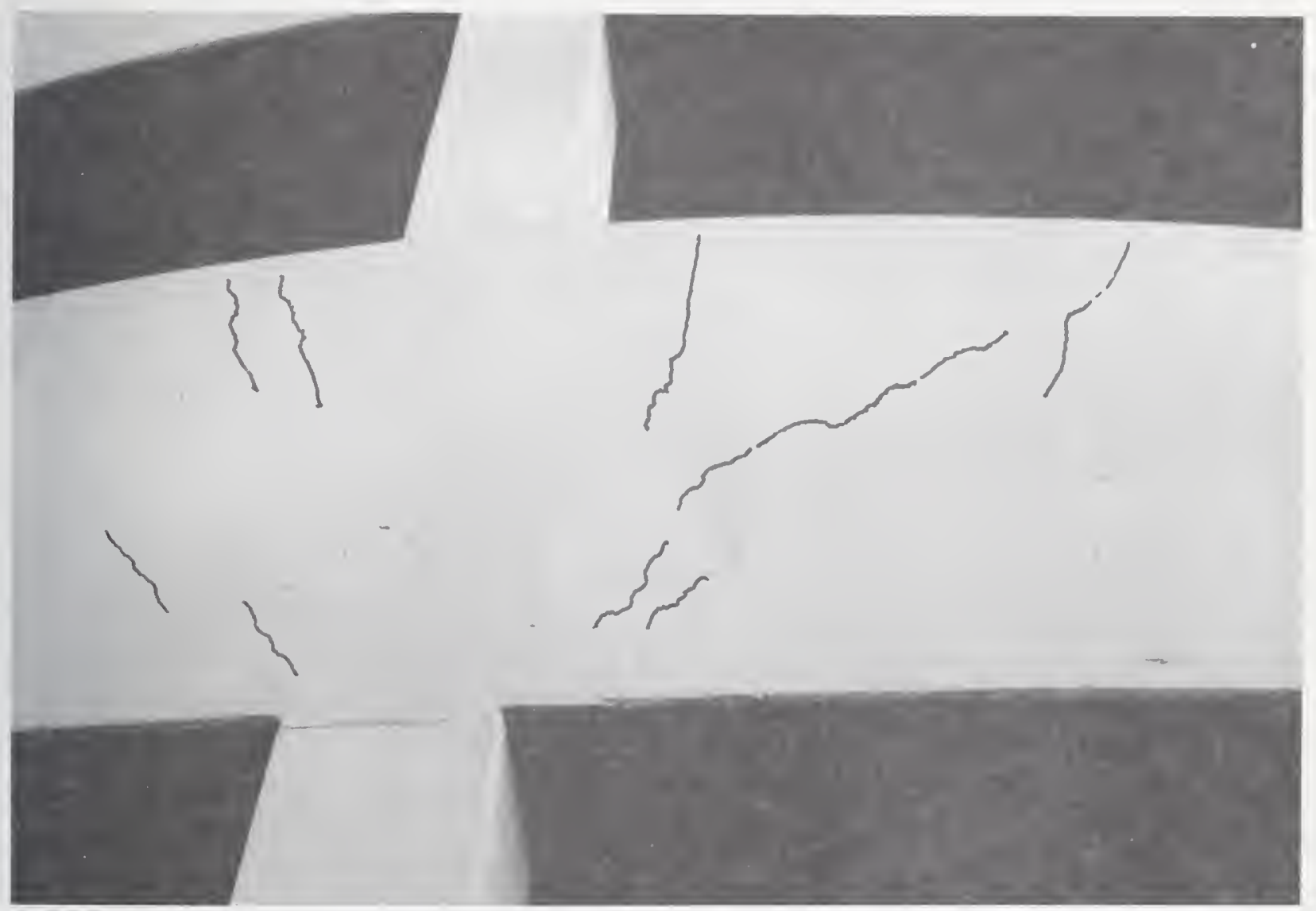

Figure 5.8. Pattern of hairline cracks near the beam column connection of the parking garage (cracks were highlighted for better visibility). 


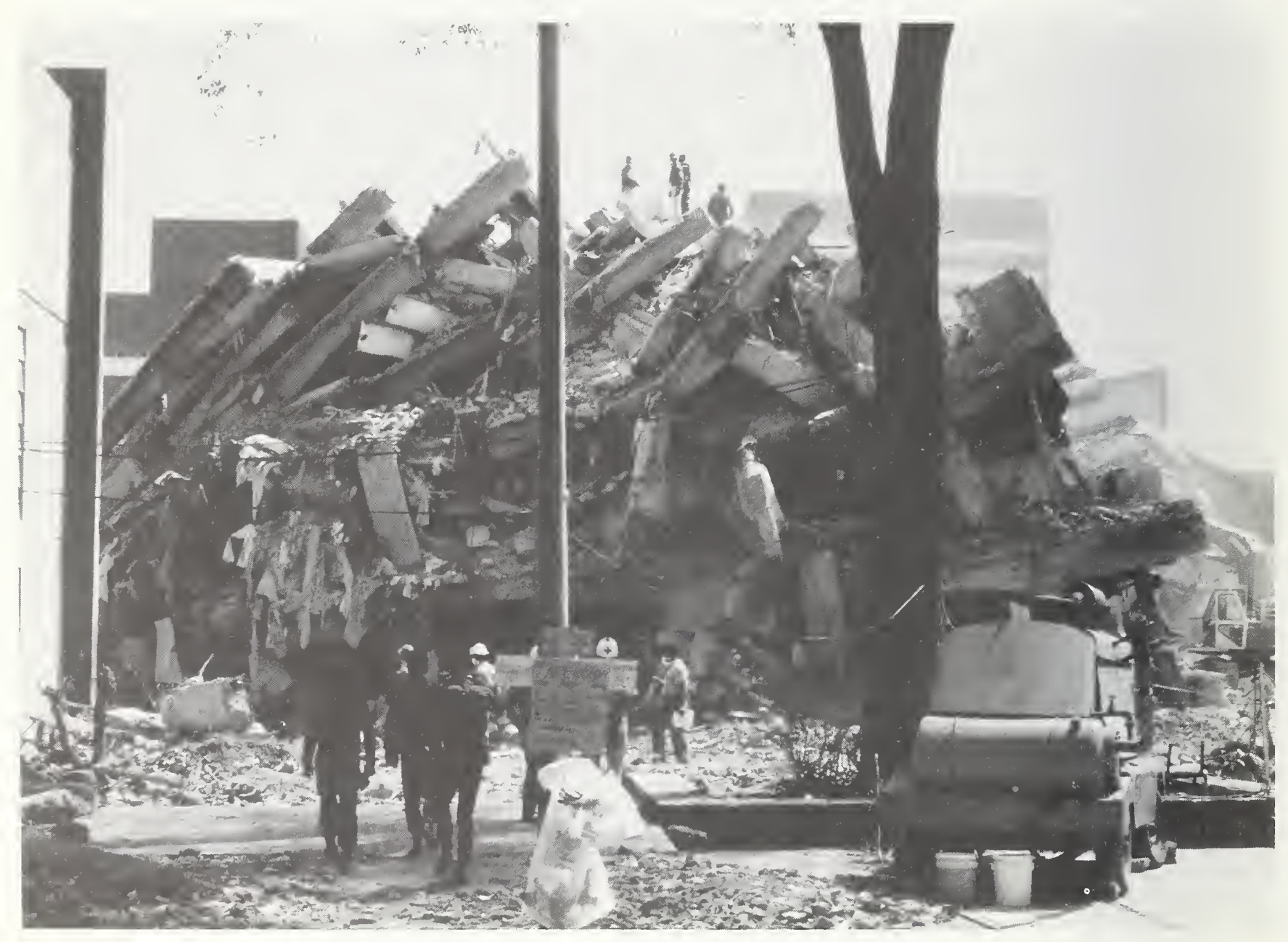

Figure 5.9. View of collapsed maternity wing of the Juarez Hospital looking south. 


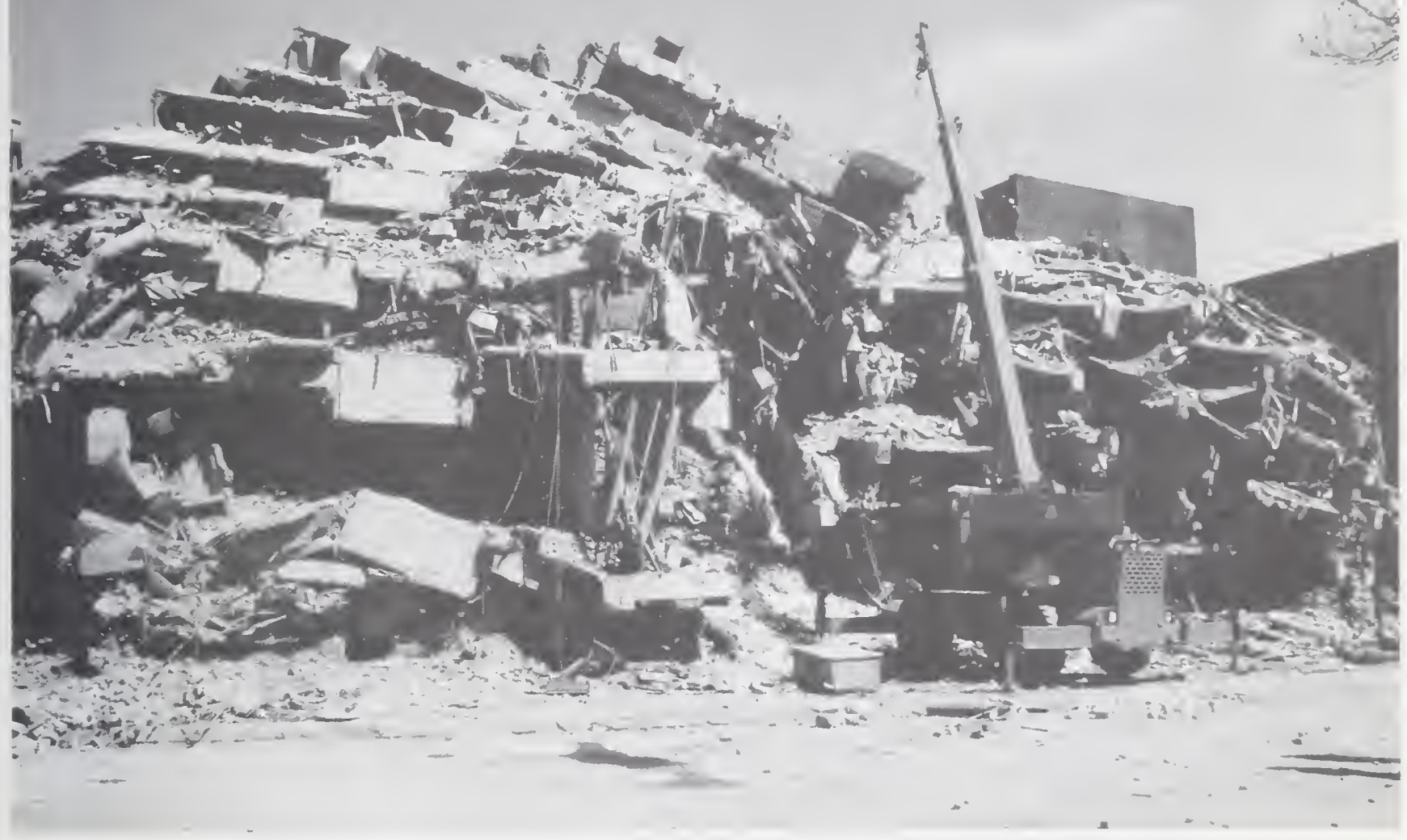

Figure 5.10. View of collapsed maternity wing of the Juarez Hospital looking east. 


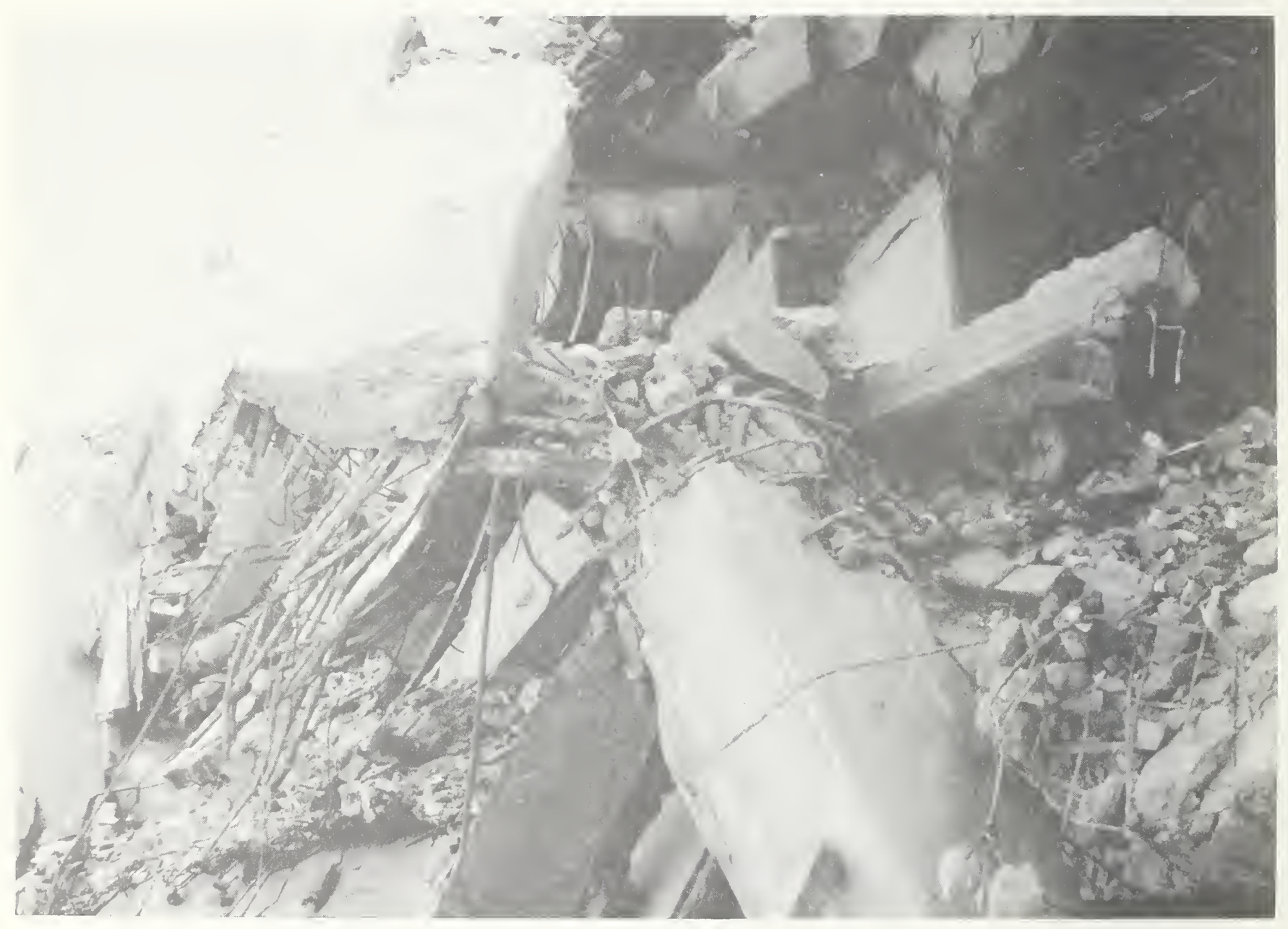

Figure 5.11. Close up joint details of collapsed Juarez Hospital indicating lack of sufficient confining reinforcement in the vicinity of the joint. 


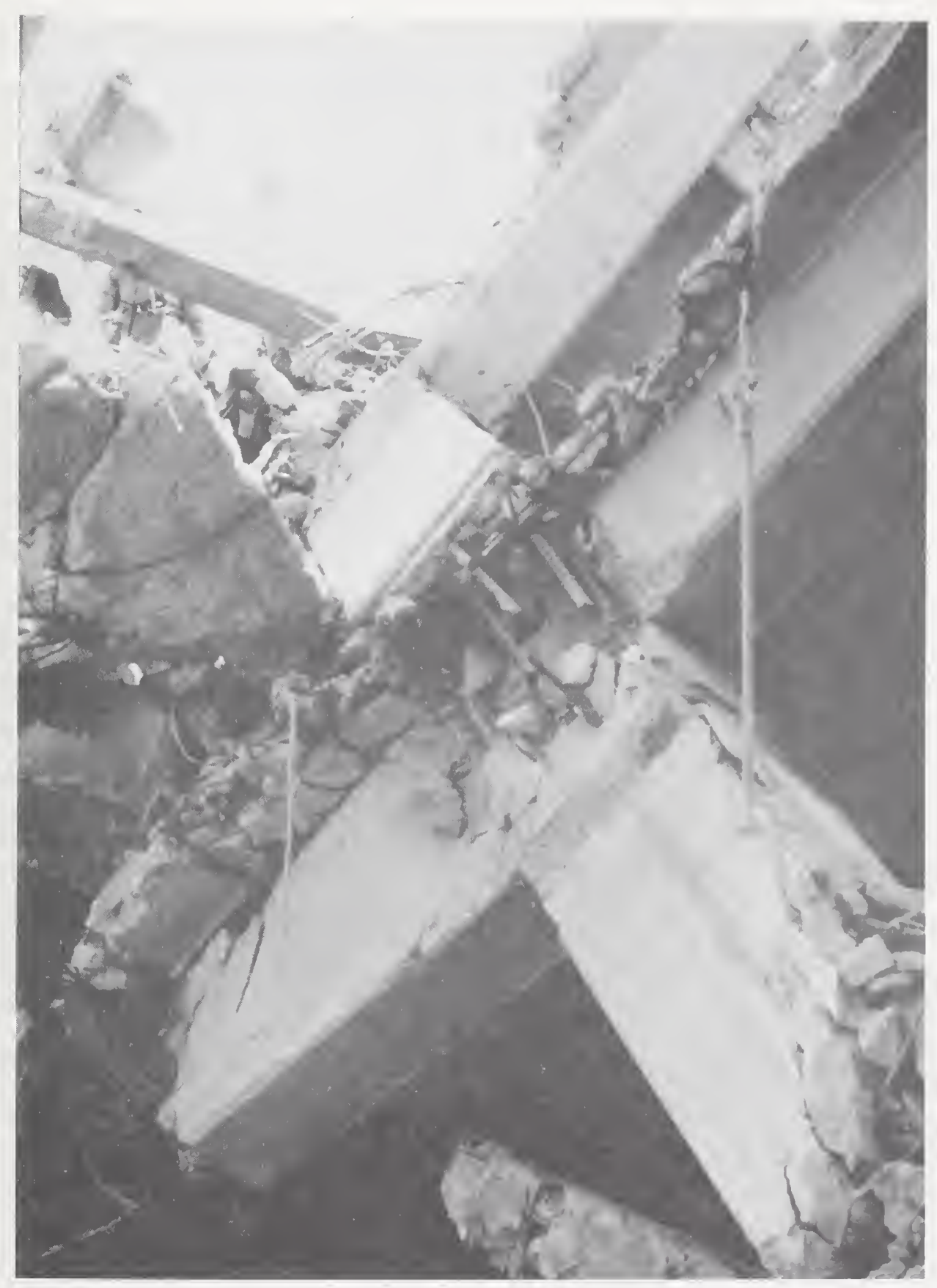

Figure 5.12. Joint details of collapsed Juarez Hospital indicating adverse effect of a splice. 


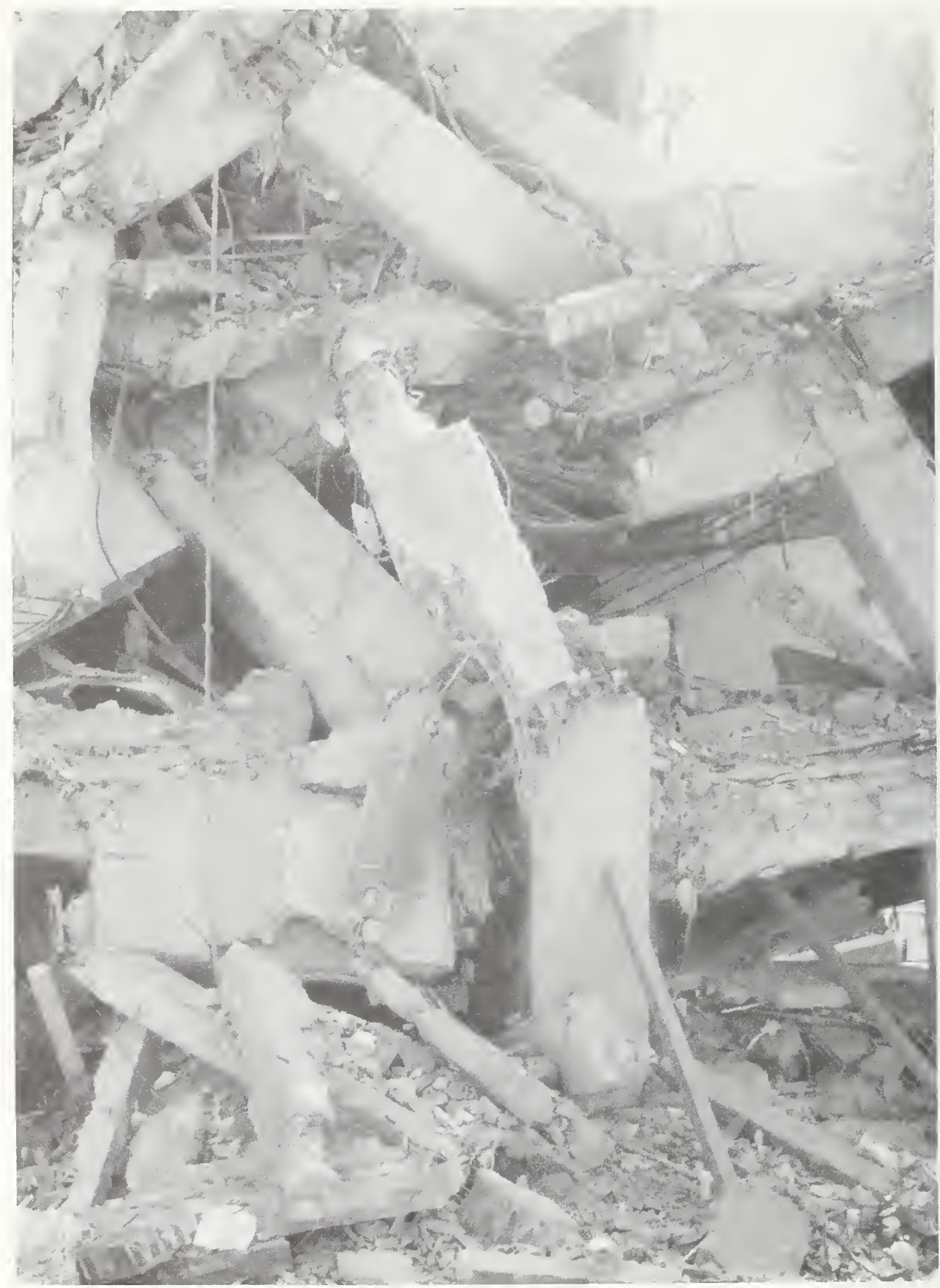

Figure 5.13. View looking south at Juarez Hospital showing how column hinging permitted rotation of successive floors toward the east. 
continued to retrieve survivors as late as ten days after the earthquake by tunneling through the debris between the floor slabs (see figure 5.10).

\subsubsection{Apartments}

Heavy damage was also sustained in the Urbana Juarez apartment complex, just west of the General Hospital (figure 5.14). One eight-story, one ten-story, and one thirteen-story reinforced concrete frame structures with brick masonry shear walls collapsed. From figure 5.14 it can be seen that three identical ten story apartments bound the southern edge of the complex. Only the middle one collapsed and damage in the remaining two appeared limited. A four-lane divided highway runs from south to north beneath the next row of apartments. These consisted of four identical eight-story structures, the northernmost of which collapsed. Finally, on the northern boundary of the complex, there were three low-rise (four-story) apartment buildings bounded to the west by two apartments identical to the southern group of three, and to the east by the thirteen story high-rise. The majority of the apartment structures at the Urbana Juarez site possibly had natural periods of vibration ranging between 1.1 and 1.6 seconds (calculated as $0.12 x$ story height). When allowance is made for soil-structure interaction, this is well within the resonance range of spectra of motions experienced in the lakebed zone. In general, these buildings were relatively narrow: average width was approximately 8-10 meters (one bent frame), while the length was typically 80 to 100 meters. Access to higher stories was usually by means of a central elevator, or an external stair tower on the north side of the structure.

The southern two-thirds of the thirteen-story complex, separated by a construction joint from the rest of the structure, remained standing but tilted out of plumb and was considered unstable (see figure 5.15). This was one of the first structures to be 


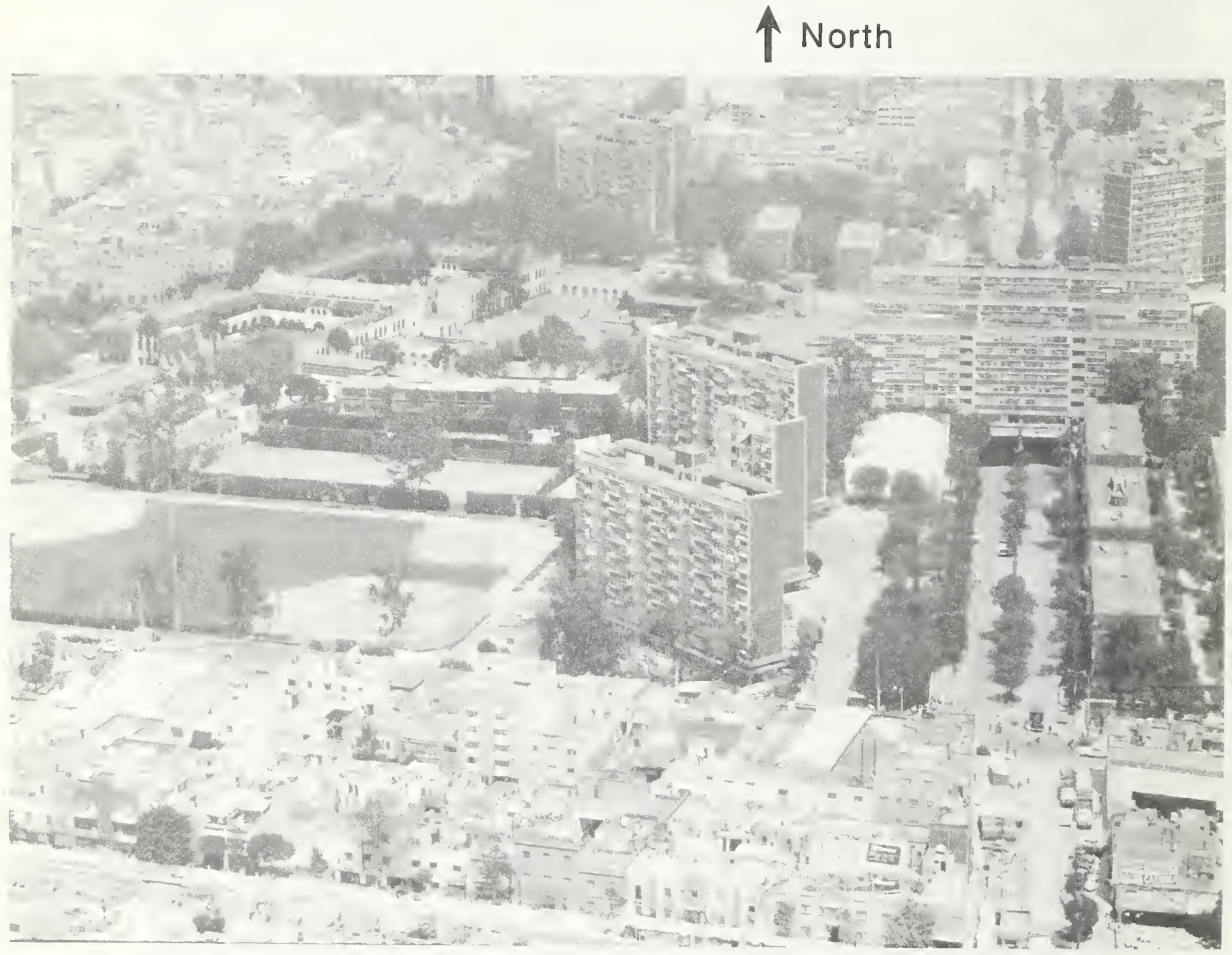

Figure 5.14. Damaged Urbana Juarez Apartment Complex west of General Hospital. 


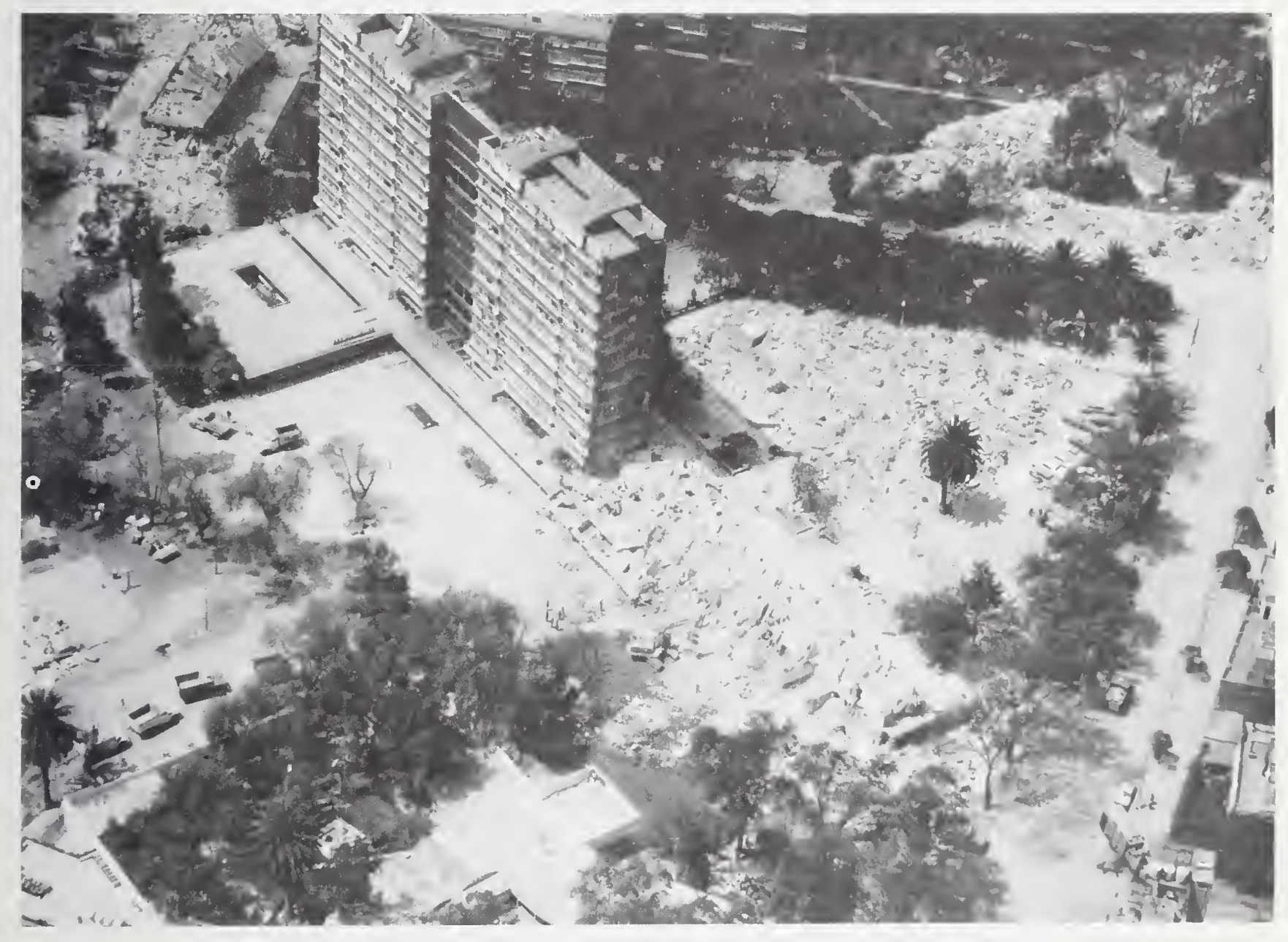

Figure 5.15. The southern two B towers of the Juarez Apartment complex which remained standing. 
dynamited approximately three weeks following the quake. Figure 5.16 shows a close-up of the first two stories of this structure following removal of debris. It can be seen that the column width was increased in the east-west direction in an effort to stiffen the resistance of the structure in the narrow direction. Nonetheless, based on the debris pattern following the collapse, it appeared that failure of this building was initiated by hinging of the columns in the east-west direction. It is likely that the presence of the thin connecting walkway (see aerial photo, figure 5.15) with the neighboring two towers to the south permitted sufficient independence for each tower to oscillate individually in the east-west direction. This explains why the northern tower was able to collapse without affecting the two southern towers.

Figure 5.17 shows an aerial view of the collapsed eight-story apartment immediately to the south of the thirteen story complex. This structure was similar in many respects to the one described above, with the notable exception that the aforementioned four lane highway ran directly underneath the center of the building. The reinforced concrete tunnel structure and road foundations may have stiffened the overall foundation, and hence increased the efficiency with which ground accelerations were transmitted to the frame. Each member in this group of four buildings was cast as a continuous unit with no obvious construction joints that might otherwise cause separate portions of the building to act independently under seismic loading. Figures 5.18 shows the "pancake" nature of the collapse, indicating hinging in columns during the earthquake. The skewed stacking of the slabs towards the east indicates that ultimate failure likely occurred during an eastward excursion. Figures 5.19 and 5.20 show views of this same structure looking north-east and east, respectively. The exterior stair tower, which experienced a shear failure in the support pylon at the first story, can be seen on the left side of 


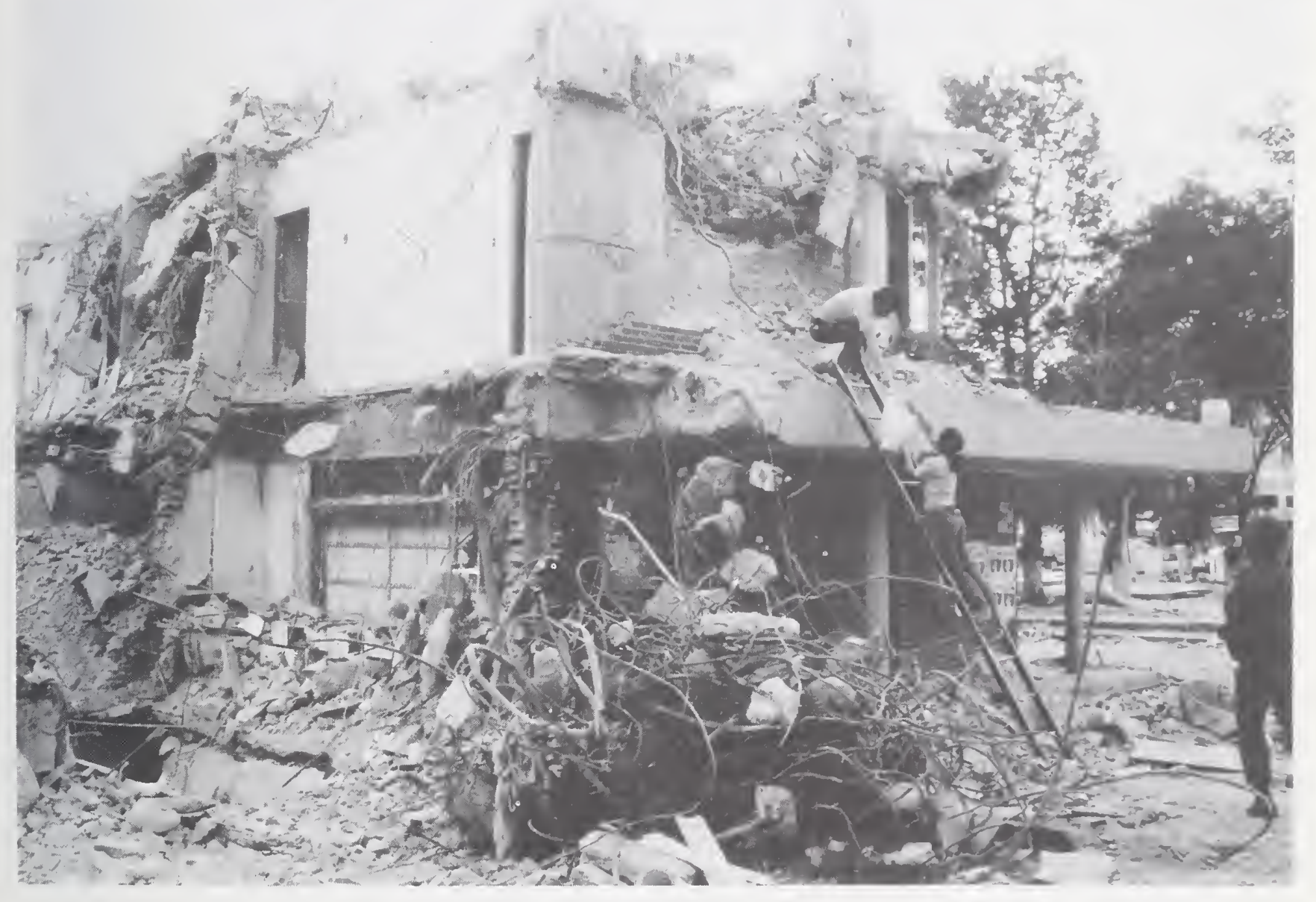

Figure 5.16. First two stories of Juarez apartment structure. 


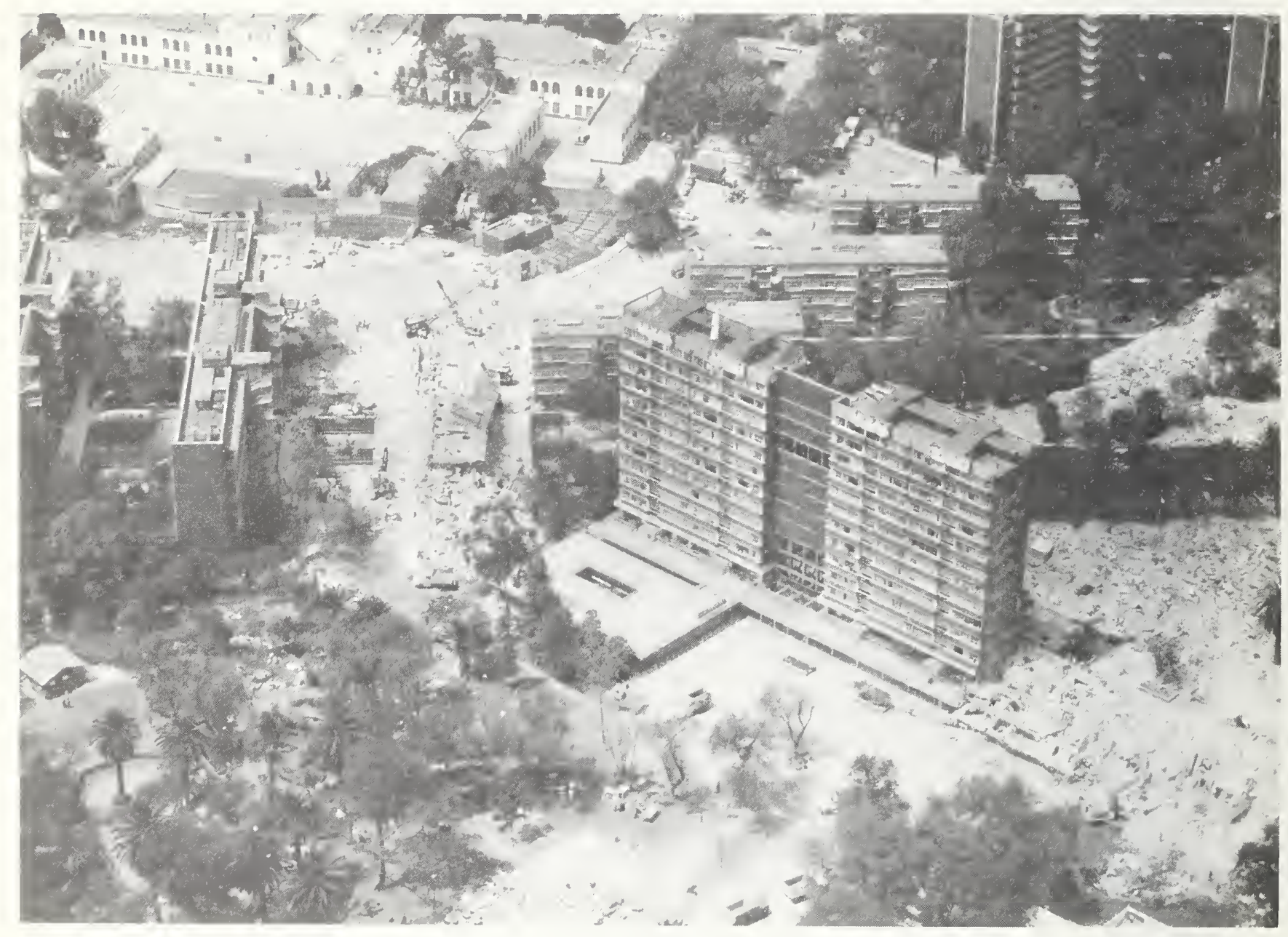

Figure 5.17. Aerial view of collapsed eight story apartment building. 


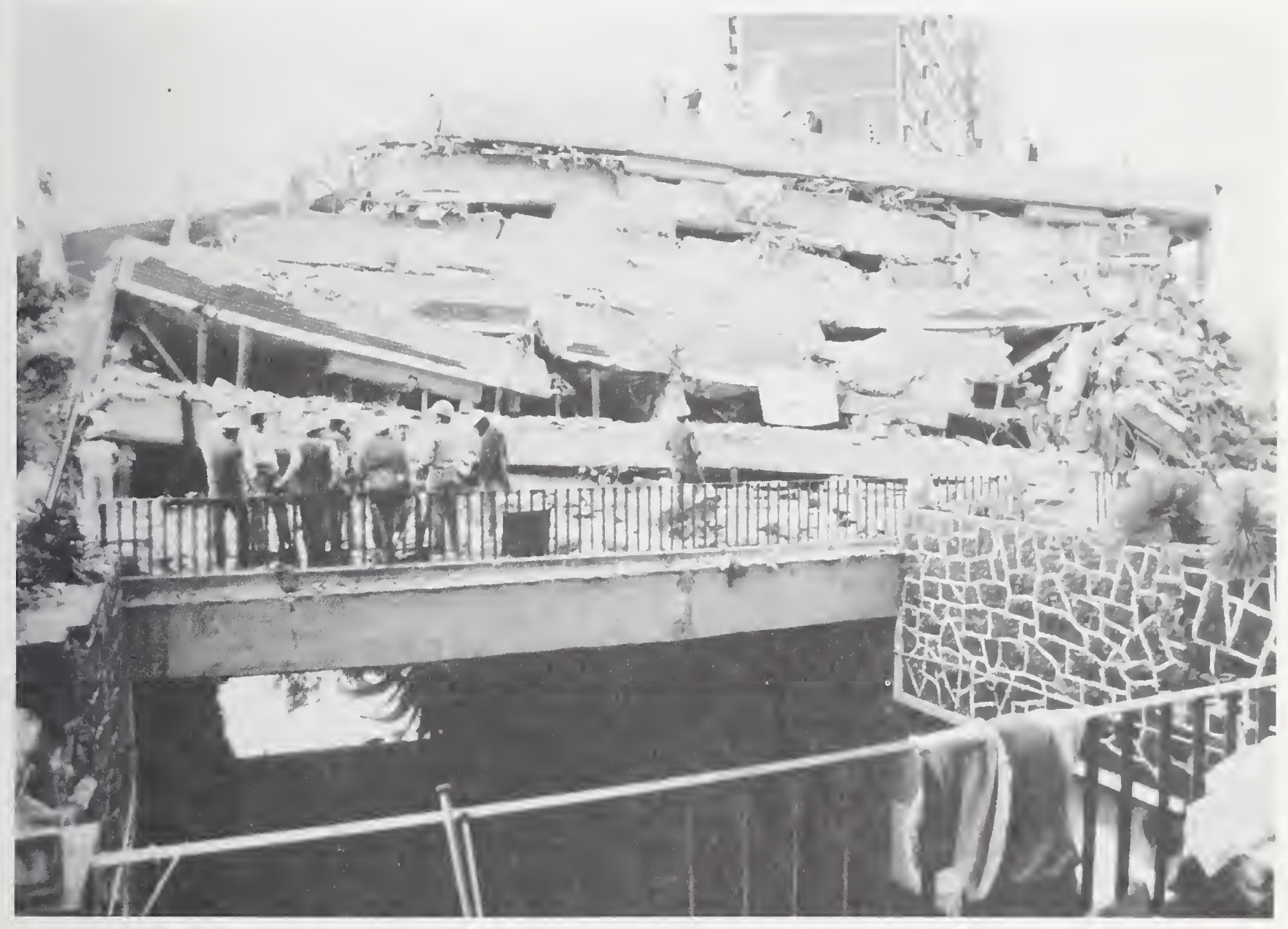

Figure 5.18. Pancake type collapse of eight story apartment. 


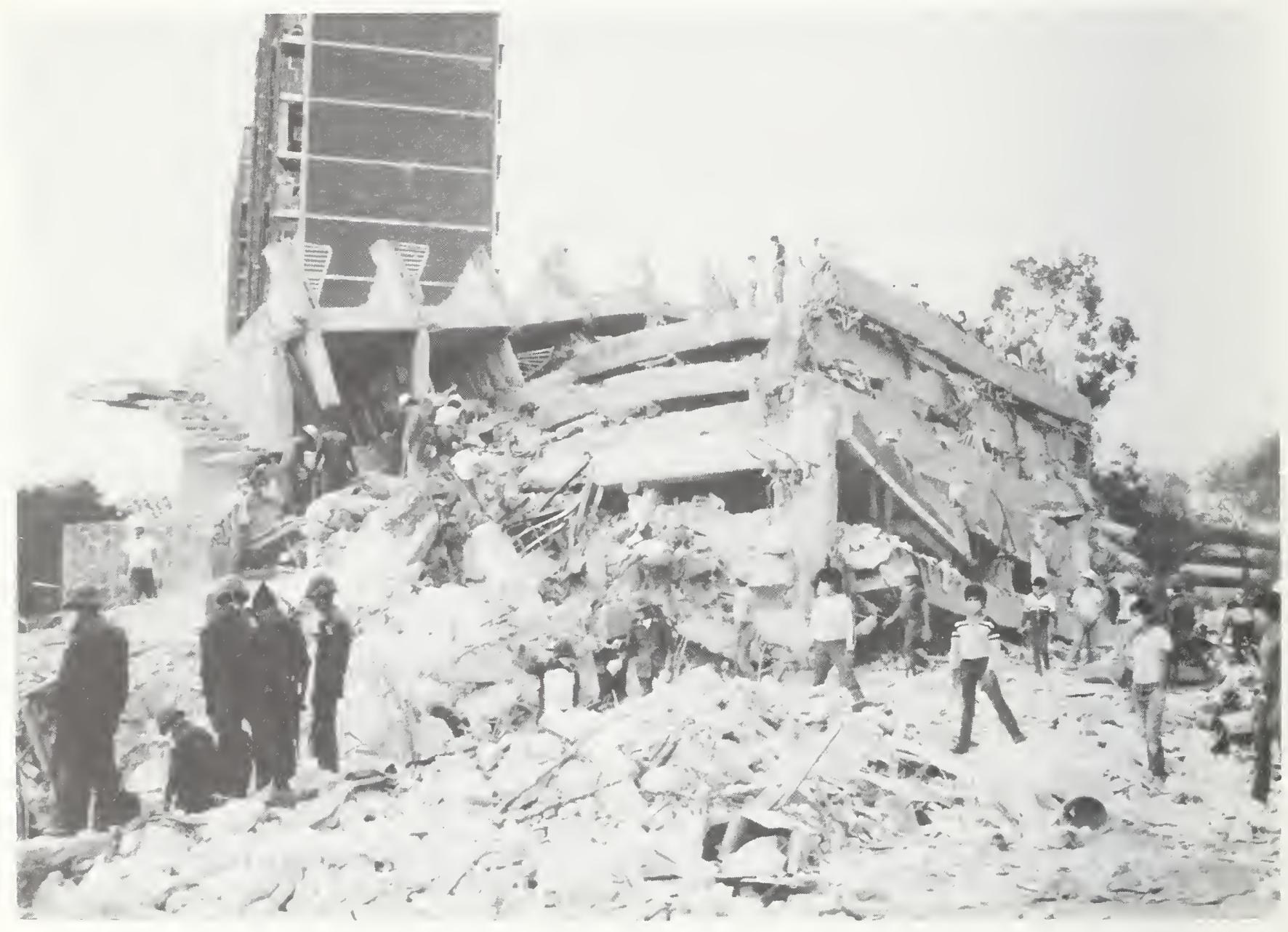

Figure 5.19. View of collapsed apartment looking northeast. 


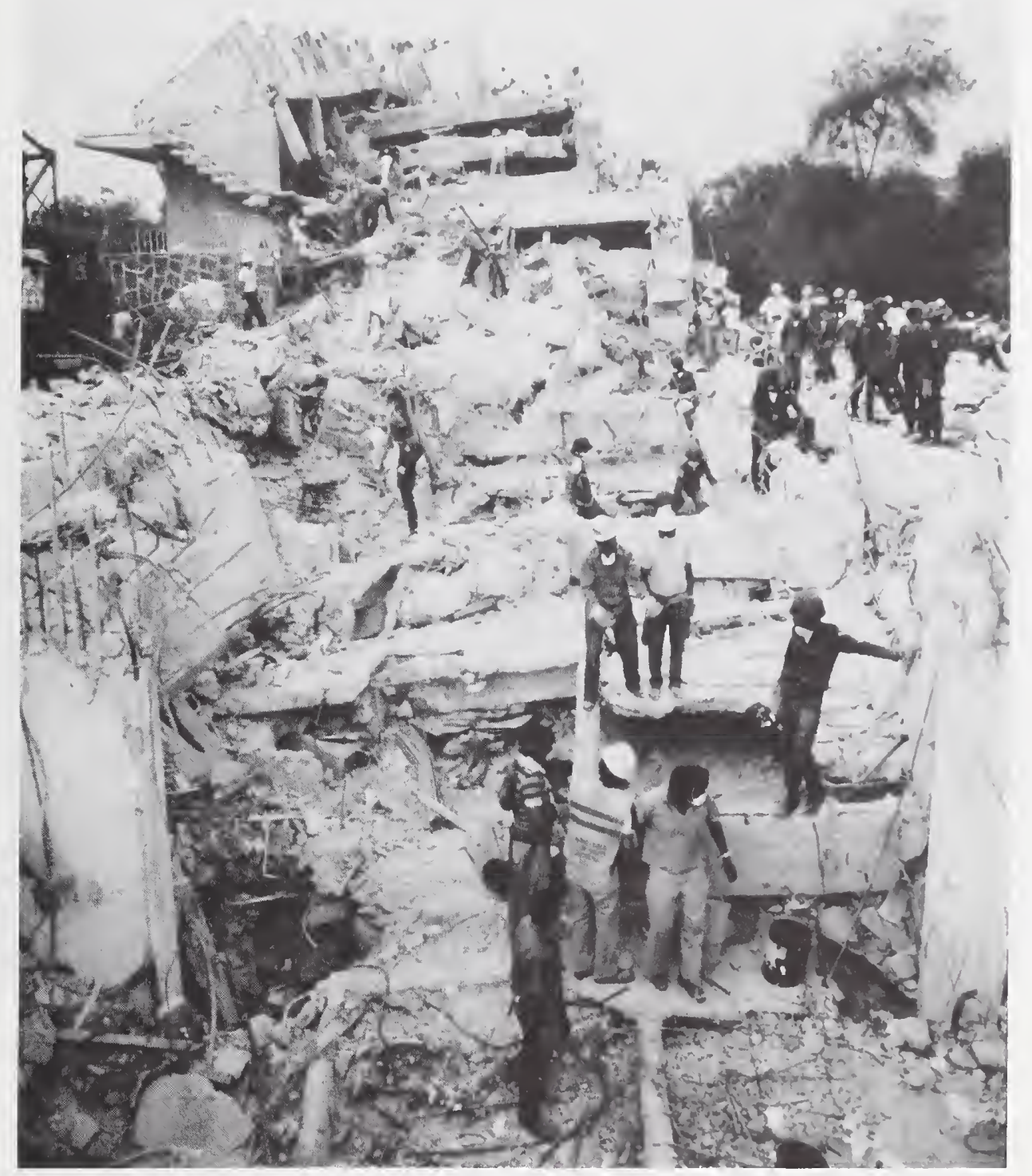

Figure 5.20. View of collapsed apartment structure looking east. 
beam and girder floor framing plan for a typical story after the deck slab has been jack-hammered free.

It is of particular interest to know why this particular building collapsed, while its three sister structures (figure 5.21) immediately to the south, did not. Part of the reason may be local variations in the soil consolidation, or perhaps differential-settlement induced stresses, as mentioned in section 5.2 .

Reference [28], in August of 1957, states "a separate commission also was appointed to determine whether the Urbana Benito Juarez housing project for 4,7, and 10 story buildings should be condemned. These structures, built of reinforced concrete, are long and narrow and have brick walls above the second floor. Each of the taller buildings has an inside, centrally located elevator and an outside stairway, with steps cantilevering from and circling a vertical concrete shaft. During the quake, one of these shafts collapsed, toppling the stairs to the ground. The stairs of several others became partly detached from the buildings but did not fall over. The pile-supported tall buildings in this group settled at the ends. Because of the skew, elevators jammed in their shafts. The lower buildings, probably on spread footings, sank 12-inches or more, tilting adjacent sidewalks about 45 degrees. Long narrow buildings subdivided by joints were damaged when the sections pounded each other during the quake and were left with a permanent lean. However, surface examination of exposed structural members and masonry end walls reveals little damage to these components." From the above it is apparent that significant settlement-induced stresses, and perhaps permanent, though unseen, structural damage was locked into these structures as a result of the 1957 quake. 


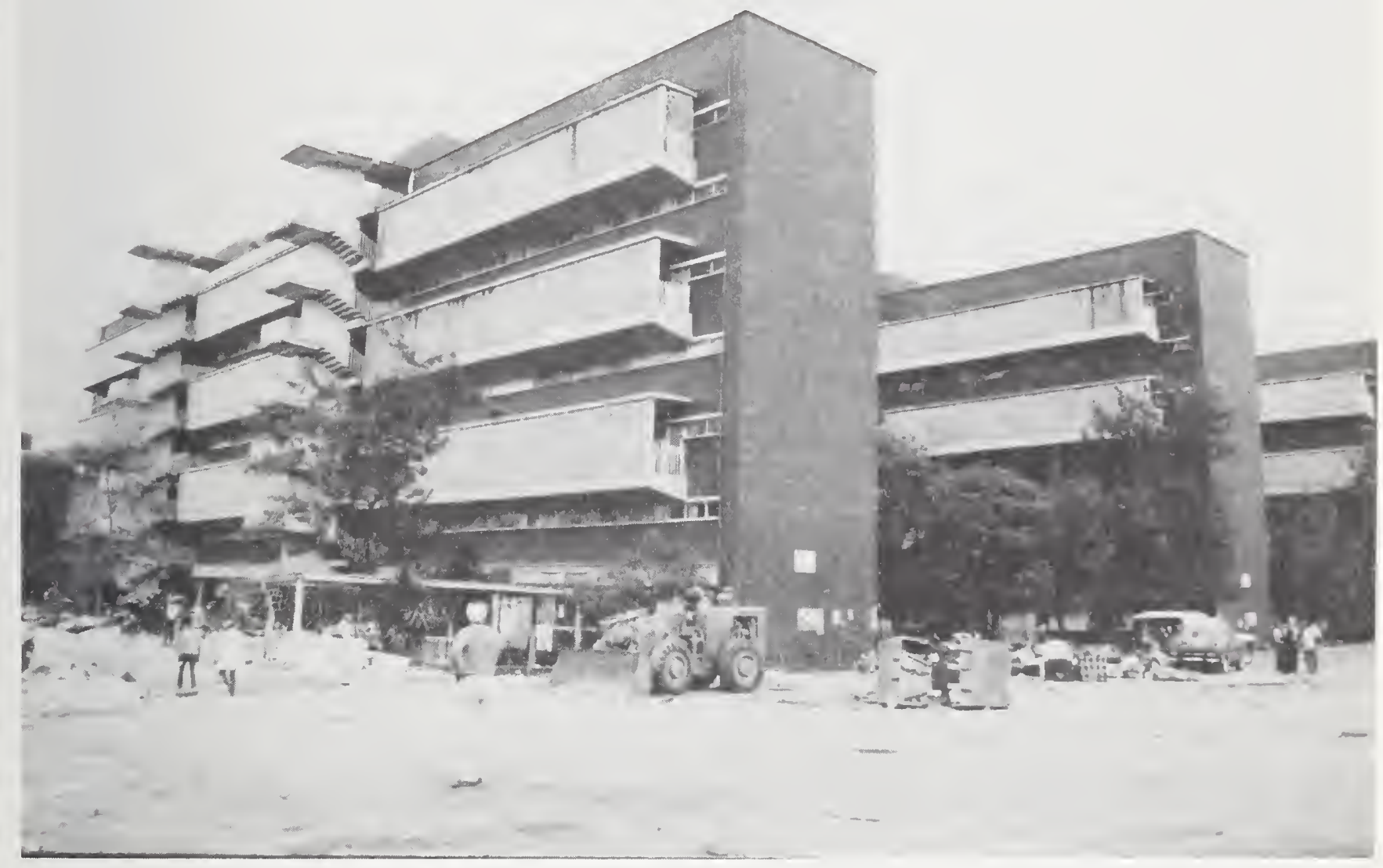

Figure 5.21. Undamaged apartment building near identical structure which collapsed. 
5.5 Flat Plate and Waffle Slab Buildings

\subsubsection{General}

By suitably proportioning and reinforcing the slabs, it is possible to eliminate supporting beams altogether. This type of construction is often referred to as "flat slab" construction. The slab is supported directly on the vertical columns, which transfer the load to the foundation. Figure 5.22 shows a typical flat slab floor. of particular importance in this type of construction are the thickened portions of the slab (drop panels) at the column, and the enlarged portions of the top of the columns (capitals). Both the drop panels and the column capitals serve the primary purpose of reducing the shear stress in the slab near the column supports. They also provide greater effective depth to resist negative bending moments.

Very few of the slab structures which collapsed were observed to have drop panels and column capitals. However, many of the buildings that sustained significant damage utilized 2-way ribbed slabs, a different type of design. As shown in figure 5.23, it is possible to greatly reduce the dead weight of the slab by creating void spaces at the underside of the slab. For the most part, the concrete removed by the voids is in tension and therefore does not contribute to the strength of the slab. The lighter floor, therefore, has approximately the same strength as a solid floor which is as thick as the ribs. Voids are usually shaped by using dome shaped steel forms (fig. 5.24), which are removed after the concrete slab had hardened. The lower flange of each dome contacts that of the adjacent dome, so that the concrete is poured against a metal surface, resulting in good finish appearance of the slab. A waffle-like appearance, which is often used to architectural advantage, is imparted to the underside of the slab. Because of this appearance two way ribbed slabs are commonly termed rib slabs or waffle slabs. 


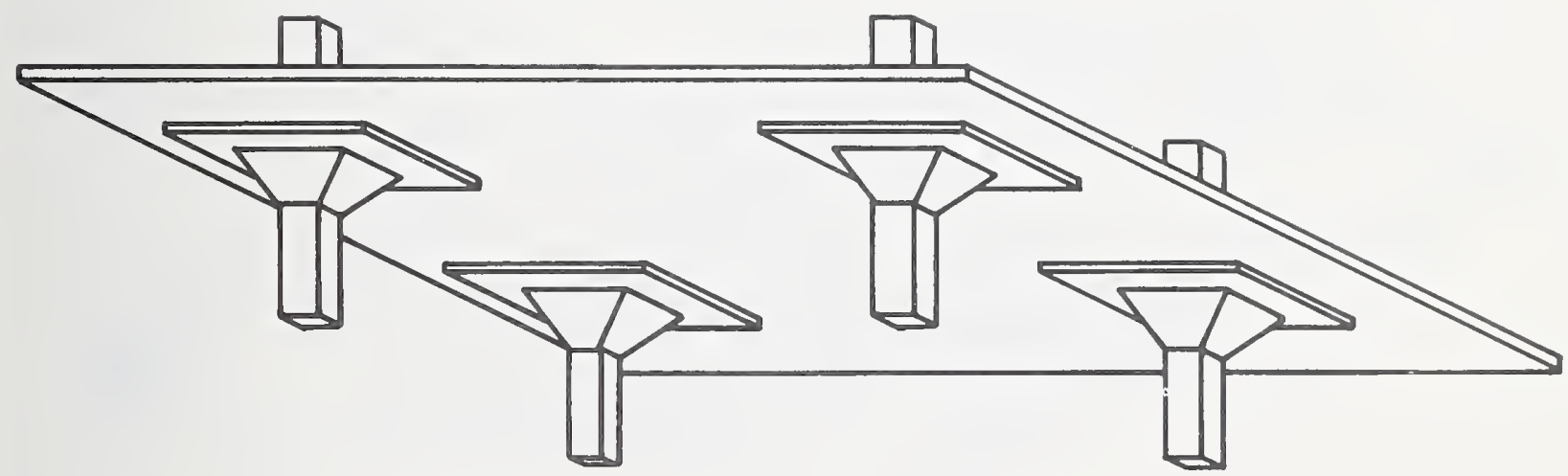

Figure 5.22. Schematic drawing of typical reinforced concrete flat slab floor. 


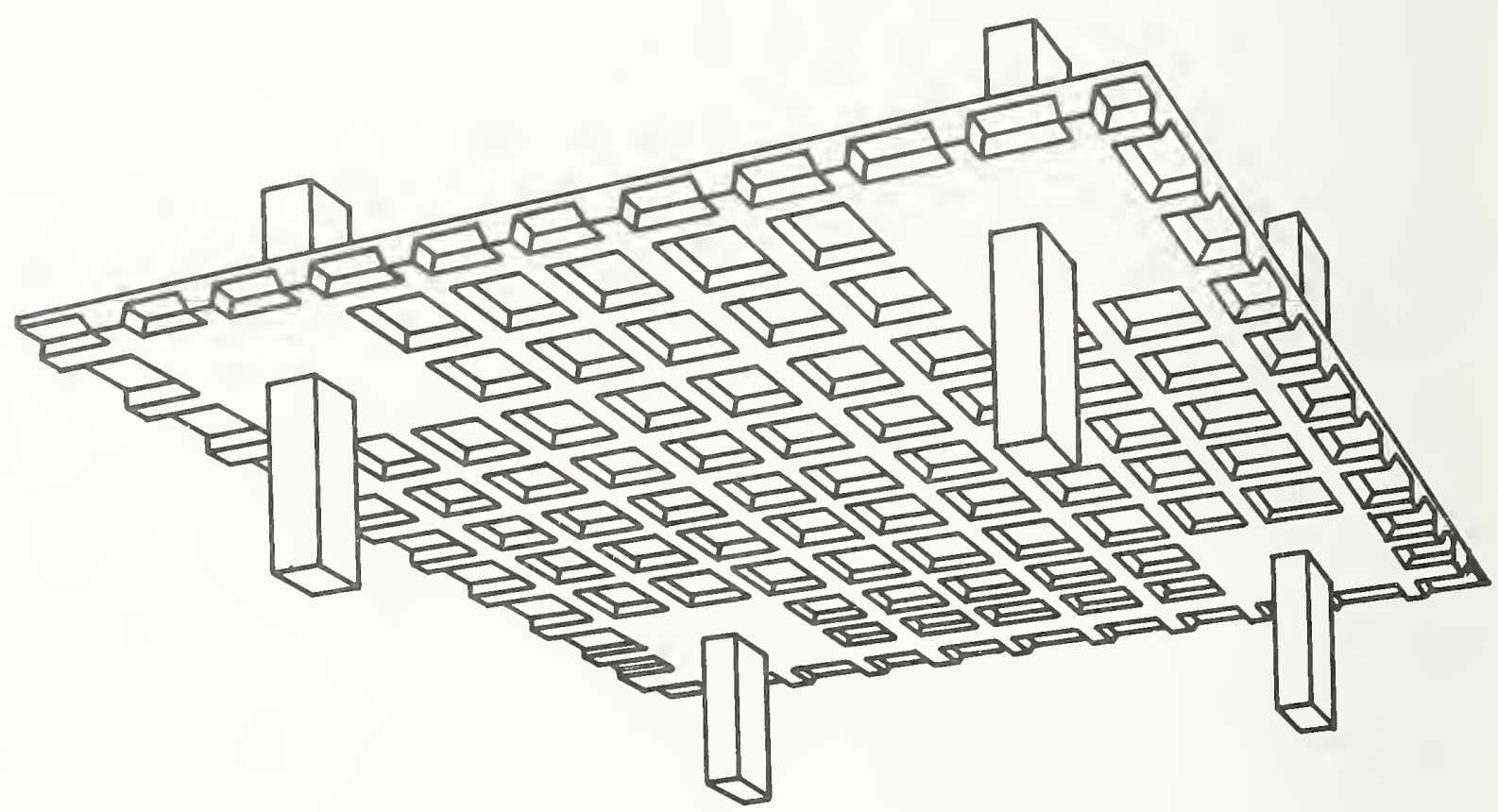

Figure 5.23. Schematic drawing of typical reinforced concrete ribbed slab. 


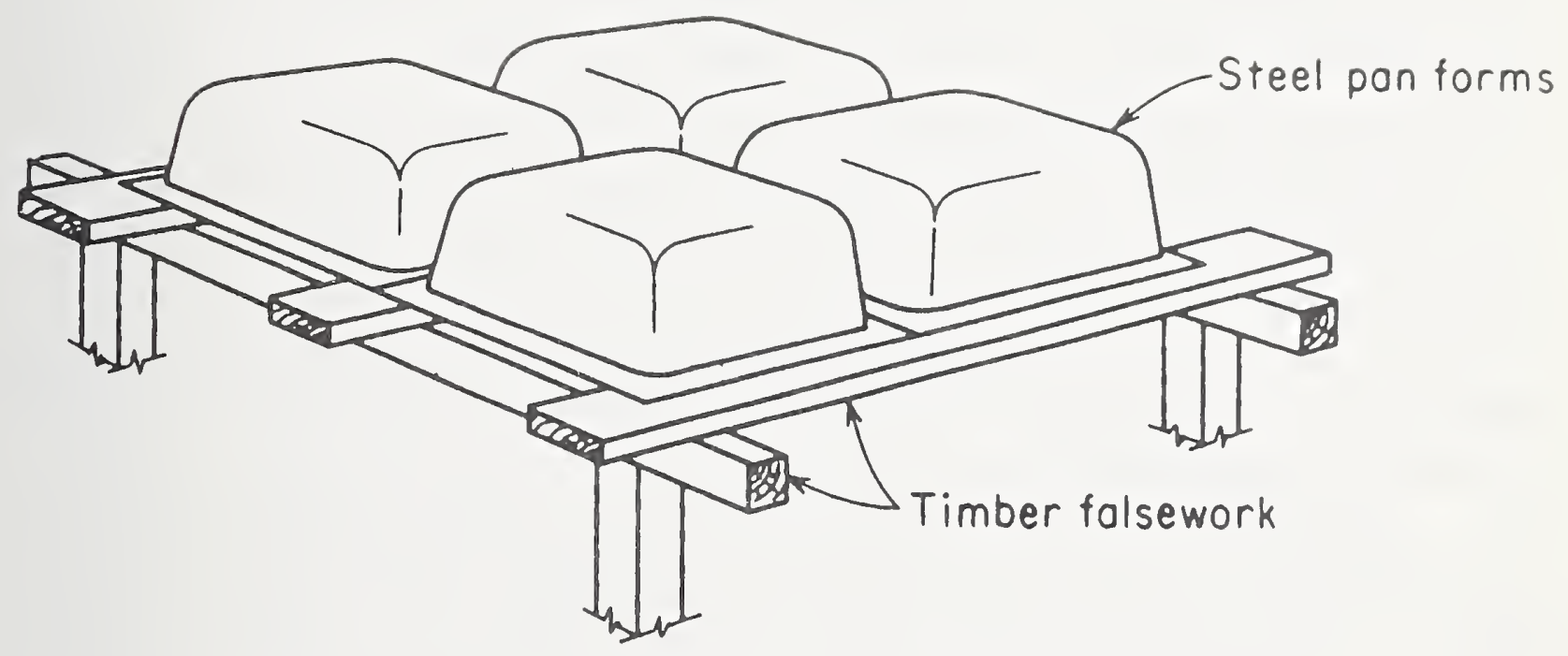

Figure 5.24. Steel forms for ribbed slab. 
Alternatively, another slab system that was commonly employed in Mexico City was flat plate construction. A "flat plate" floor is essentially a flat slab floor with the drop panels and column capitals omitted, so that a floor slab of uniform thickness is carried directly by prismatic columns (see figure 5.25). The construction depth for each floor is held to the absolute minimum, with resultant savings in the overall height and weight of the building. Flat plate apartment structures have thus found popularity in Mexico City, both from the viewpoint of their relative economy over other forms of concrete construction, and because of their ease of construction, and maintenance (e.g. painting or plastering). However, there is a price for such economy. Shear stress in the concrete is typically very high in the vicinity of the column-slab junction. Unless special supplementary reinforcement is provided in such areas (e.g. figure 5.26, from ref. 34) one runs the risk of a slab punching failure. Such problems have contributed to several collapses of flat plate structures acted upon only by the force of gravity [29, 30]. The need for this extra reinforcement, and the confinement of the joints, as mentioned under the discussion of RC frames above, is imperative in locations where the structure may be subjected to numerous cycles of lateral load reversals.

\section{5 .2 Column Failures}

Taller concrete structures with flat plates, such as apartment buildings over five stories, were particularly susceptible to earthquake damage. The 14-story Nuevo Leon building was part of the Tlaltelalco housing project (figure 5.27) near the intersection of Guerrero and Flores-Magon, approximately $2 \mathrm{~km}$ north of the area most heavily damaged by the quake. This structure consisted of three independent wings separated by construction joints. The two northernmost wings, each containing 


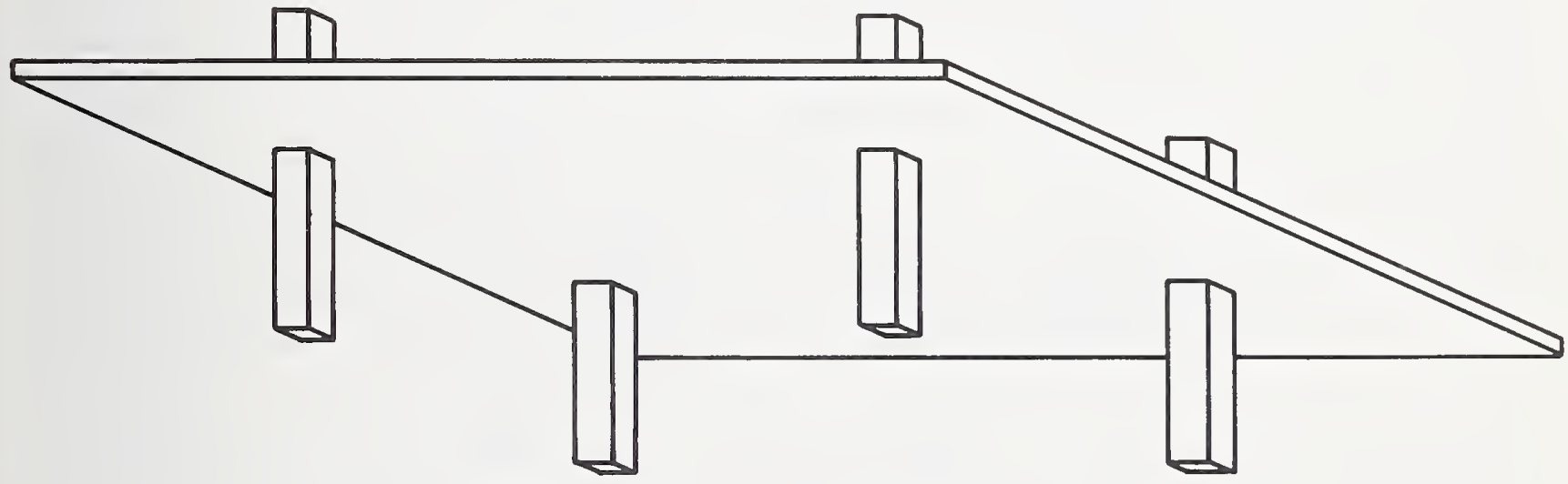

Figure 5.25. Typical flat plate reinforced concrete floor system. 


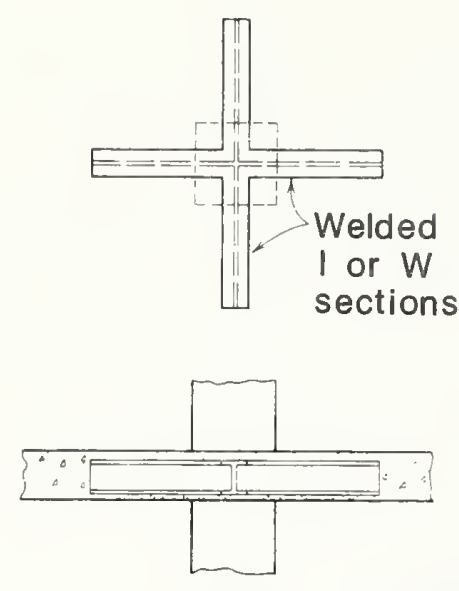

(a)
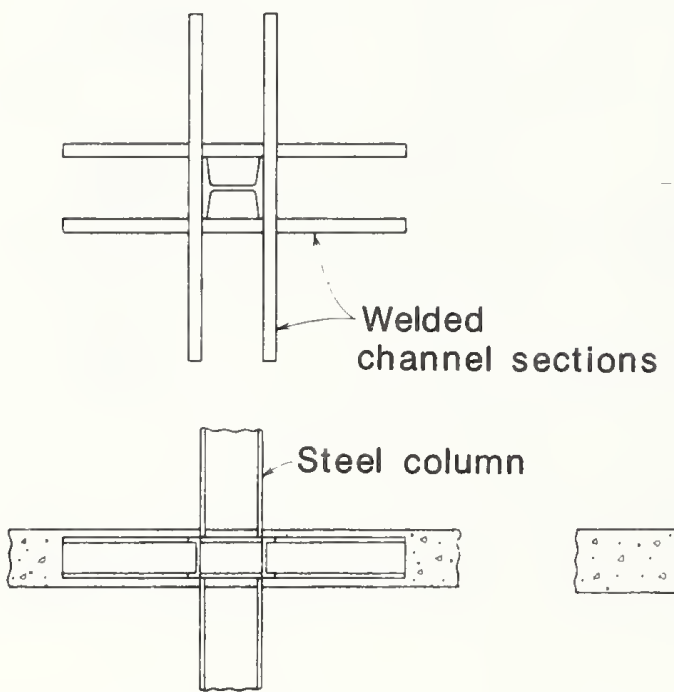

(c)

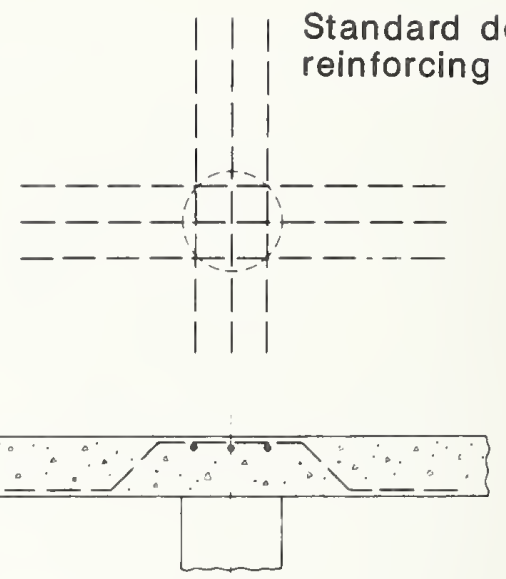

(b)
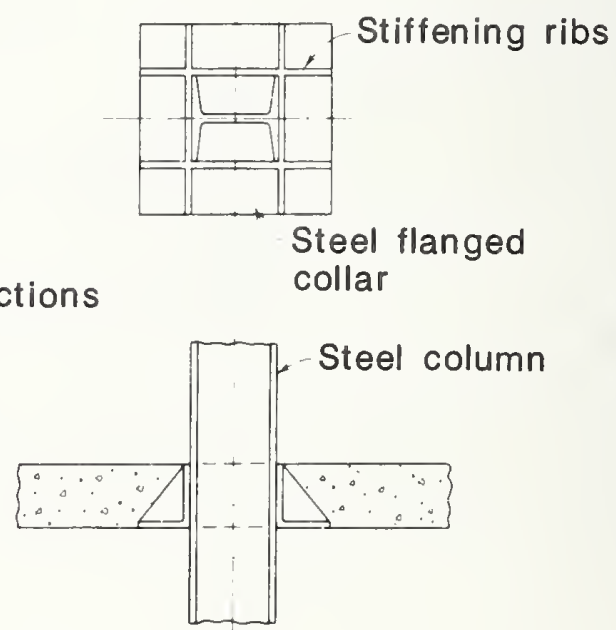

(d)

Figure 5.26. Typical shear reinforcement in a flat plate slab. 
196 apartments (see figs. 5.28 and 5.29), apparently collapsed due to overturning when a failure was initiated on the east side of the structure near the foundation level. Supporting columns were then sheared or pulled from the ground on the west side of the structure (figure 5.30), leading to the toppling of the building towards the east.

Although the floor levels behaved as flat slabs, they were in fact a special variety of waffle slab. This can be verified by inspection of figure 5.30 which shows the presence of porous blocks used to form the slab, revealed after the ceiling plaster spalled off during the final impact. Figure 5.31 shows the presence of regularly spaced reinforced concrete $x$-bracing as well as masonry infill walls which would have served to resist lateral forces during the earthquake. Figure 5.32, in fact, shows four structures identical to the Nuevo Leon building in the same vicinity which performed better during the quake.

Significant controversy has arisen over the Nuevo Leon building and in general all of the Tlaltelalco government housing project.

Following the 1979 Petatlan event, residents complained of noticeable settlements. Subsequently, some foundations, notably that of the Nuevo Leon building, were underpinned. The resulting difference in foundations may have contributed to the collapse: the stiffening of the foundation on the east side of the building led to an asymmetrical response condition whereby the east side columns would have been subjected to relatively greater lateral forces. Figure 5.33 shows failures that have occurred in the short column line on the east side of the remaining southern apartment tower, particularly on the level used as a passageway between blocks. 


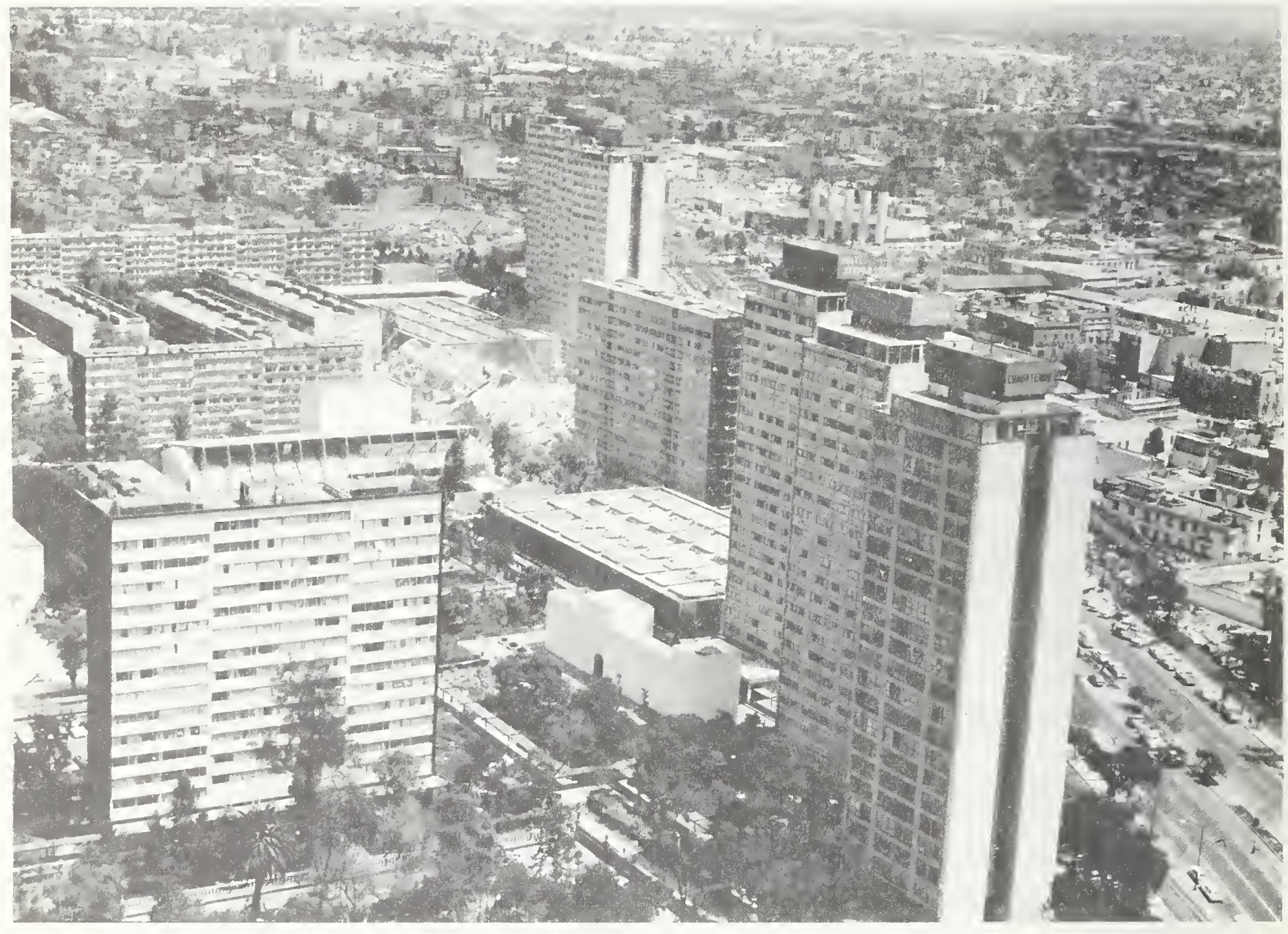

Figure 5.27. The Tlaltelalco Apartment Complex. Nuevo Leon building is located at center of photo. Aerial view looking northeast. 


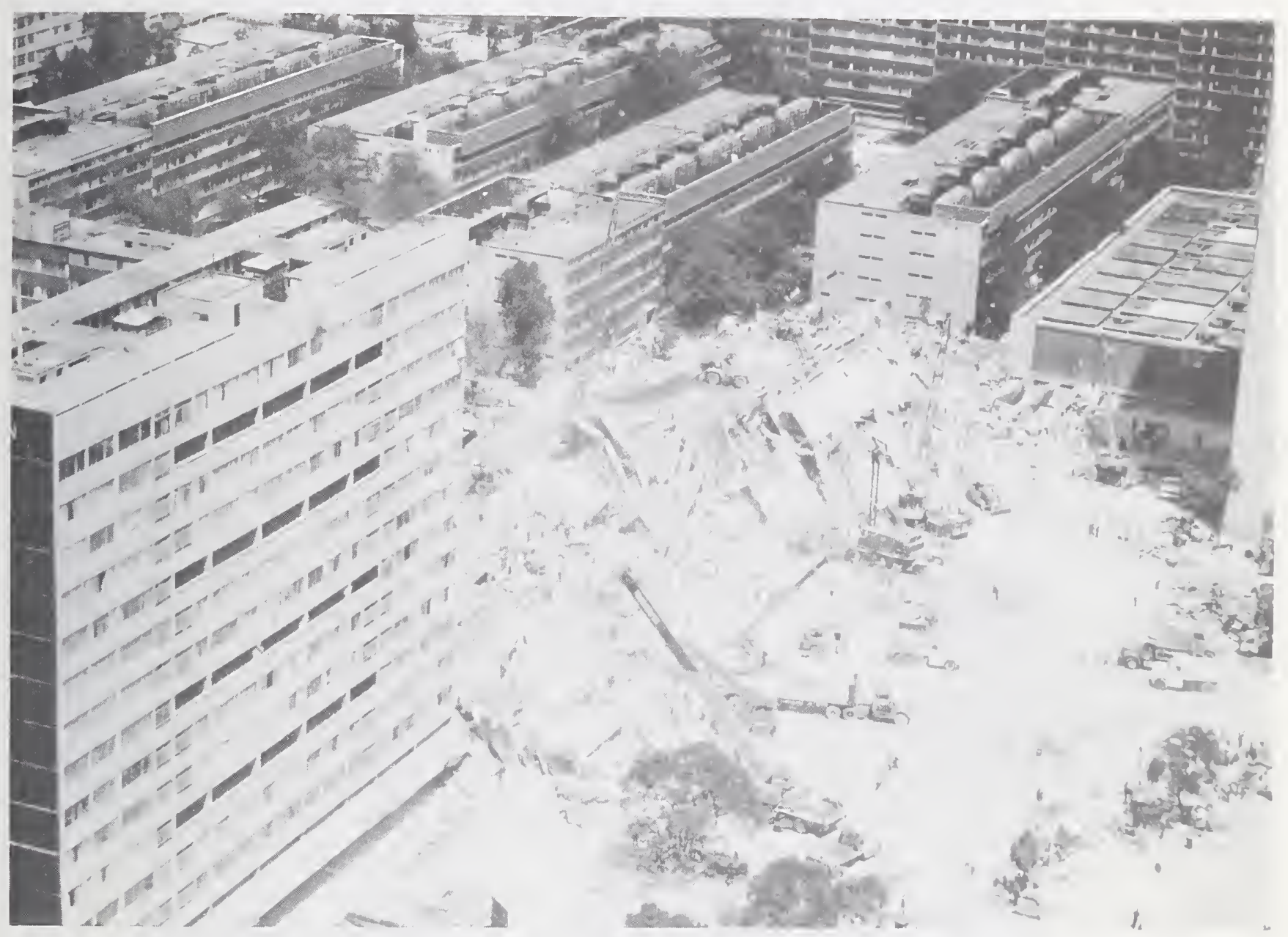

Figure 5.28. Aerial view looking northwest of the Nuevo Leon Apartment Complex. 


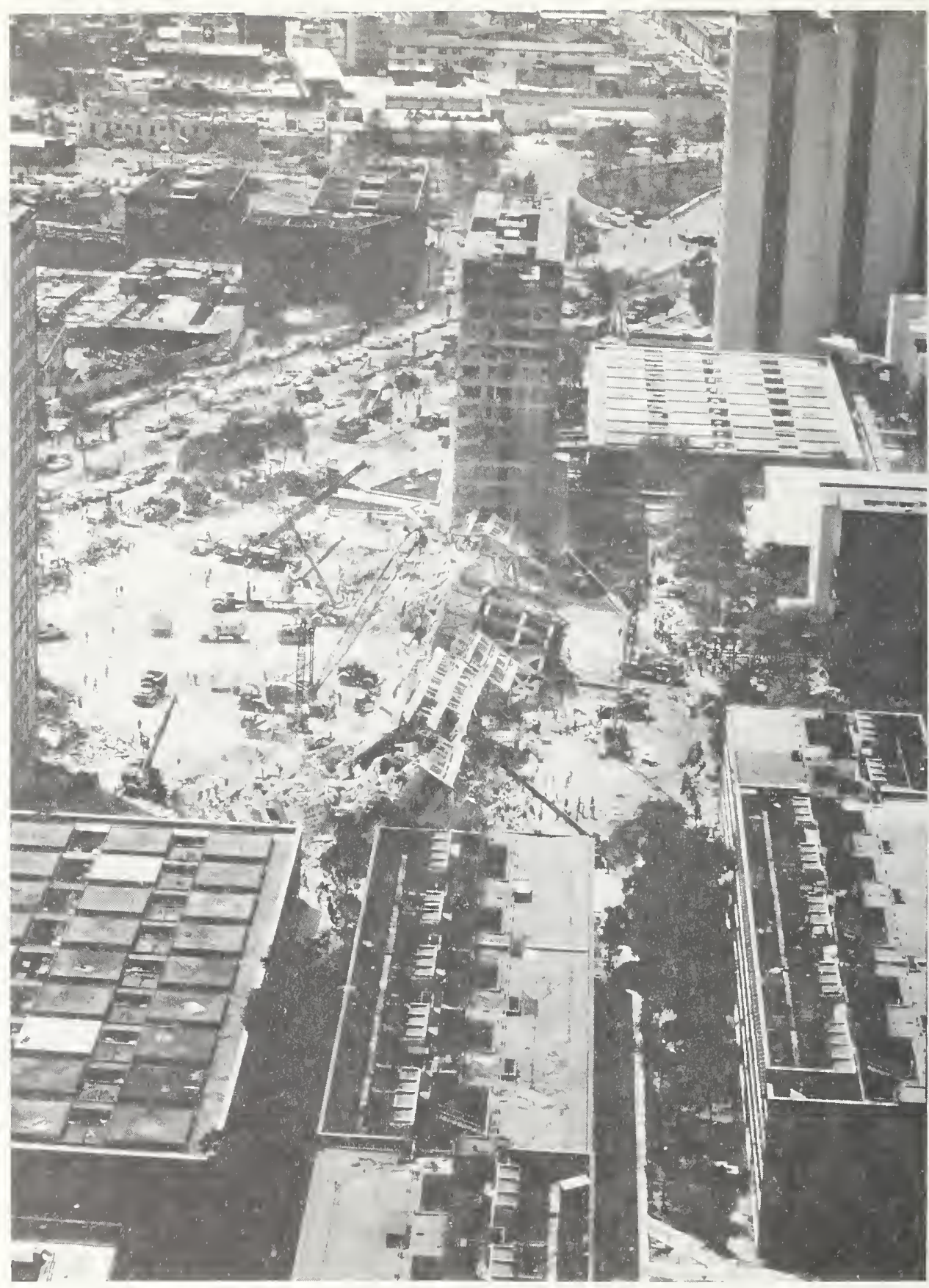

Figure 5.29. Aerial view looking south of the Nuevo Leon Apartment Complex. 


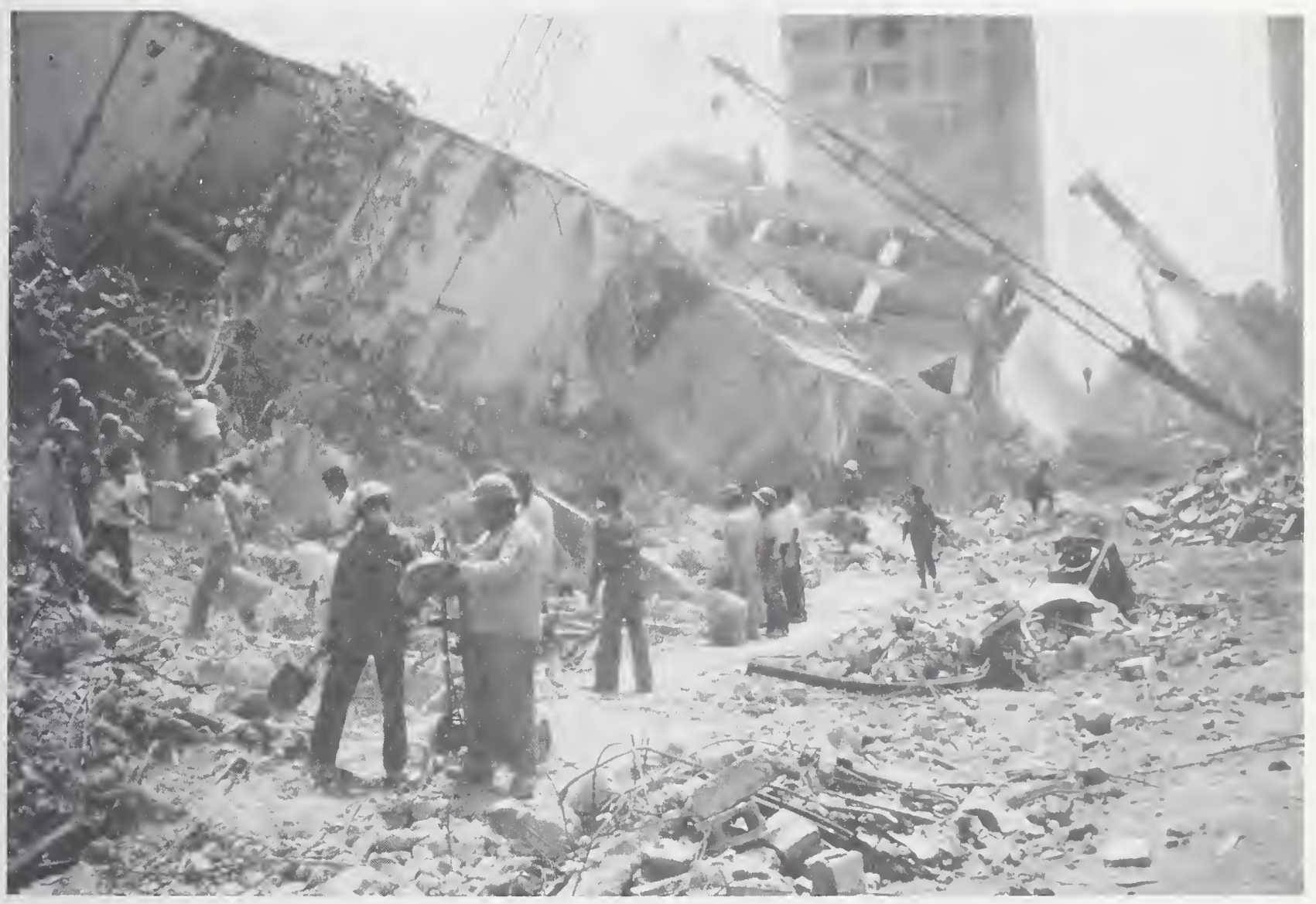

Figure 5.30. West side of the collapsed Nuevo Leon Apartment Complex. 


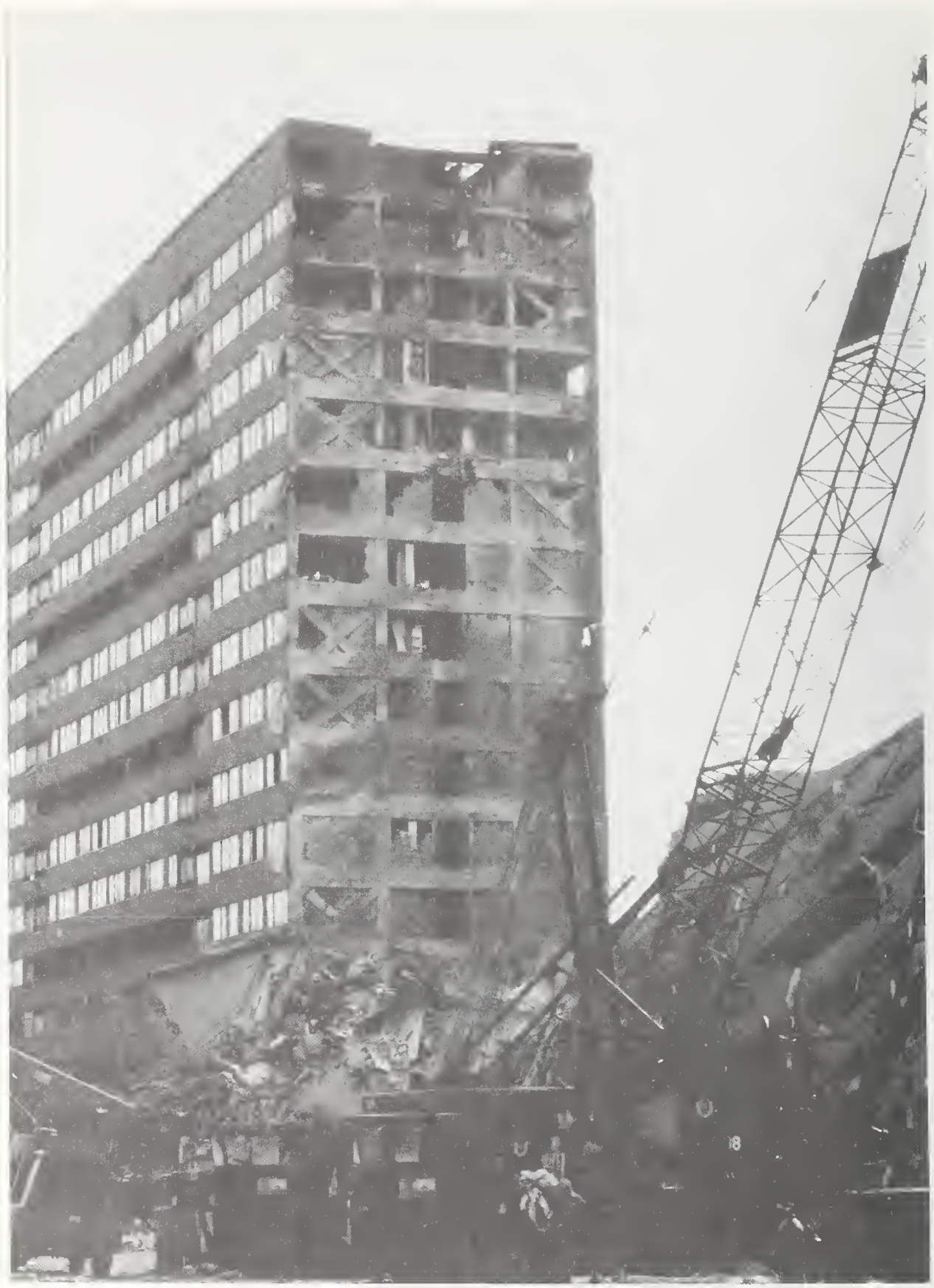

Figure 5.31. Concrete $X$-braces in remaining tower of Nuevo Leon Apartment Complex. 


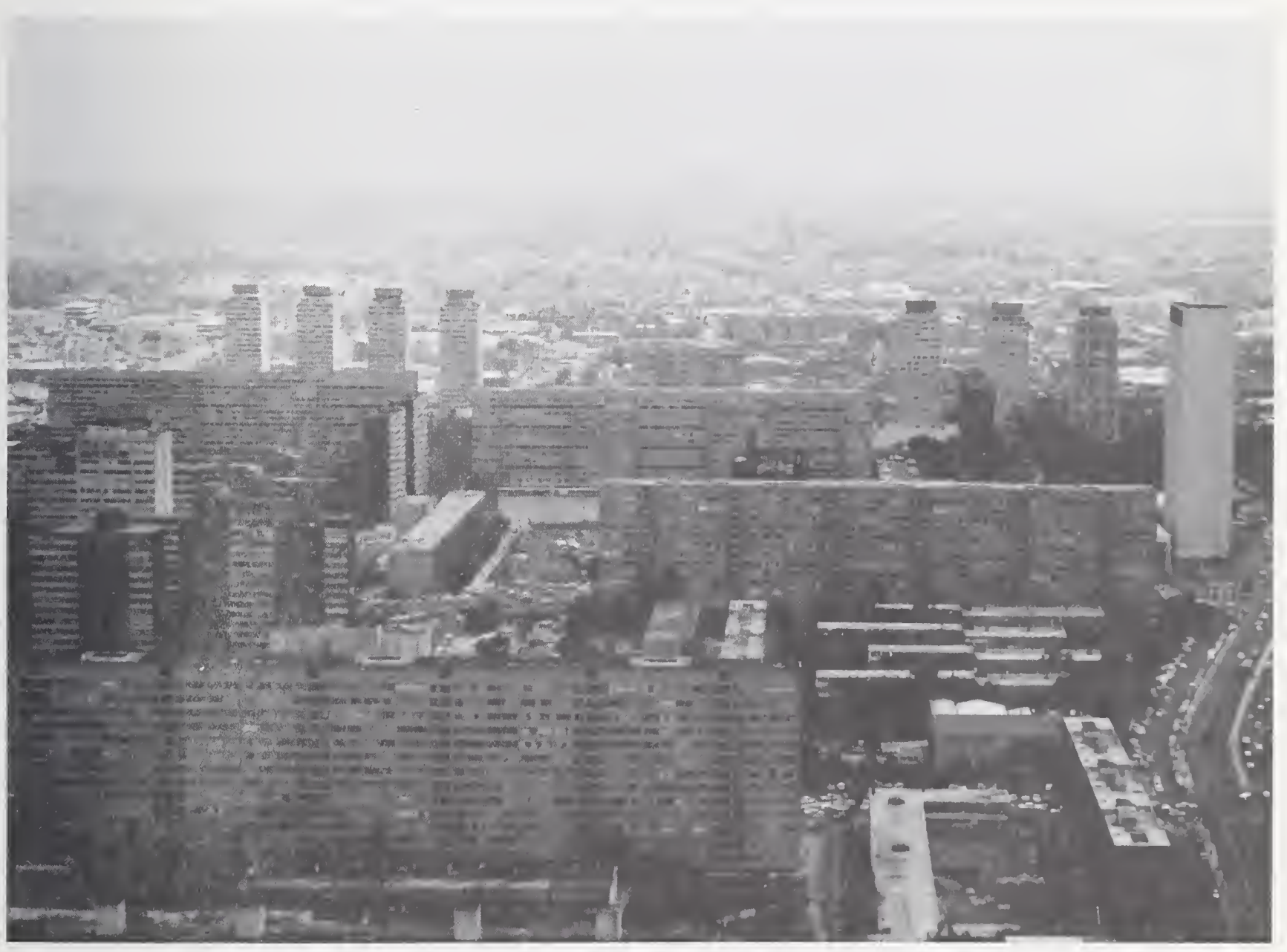

Figure 5.32. Four undamaged structures in the Tlatelalco Apartment Complex. 


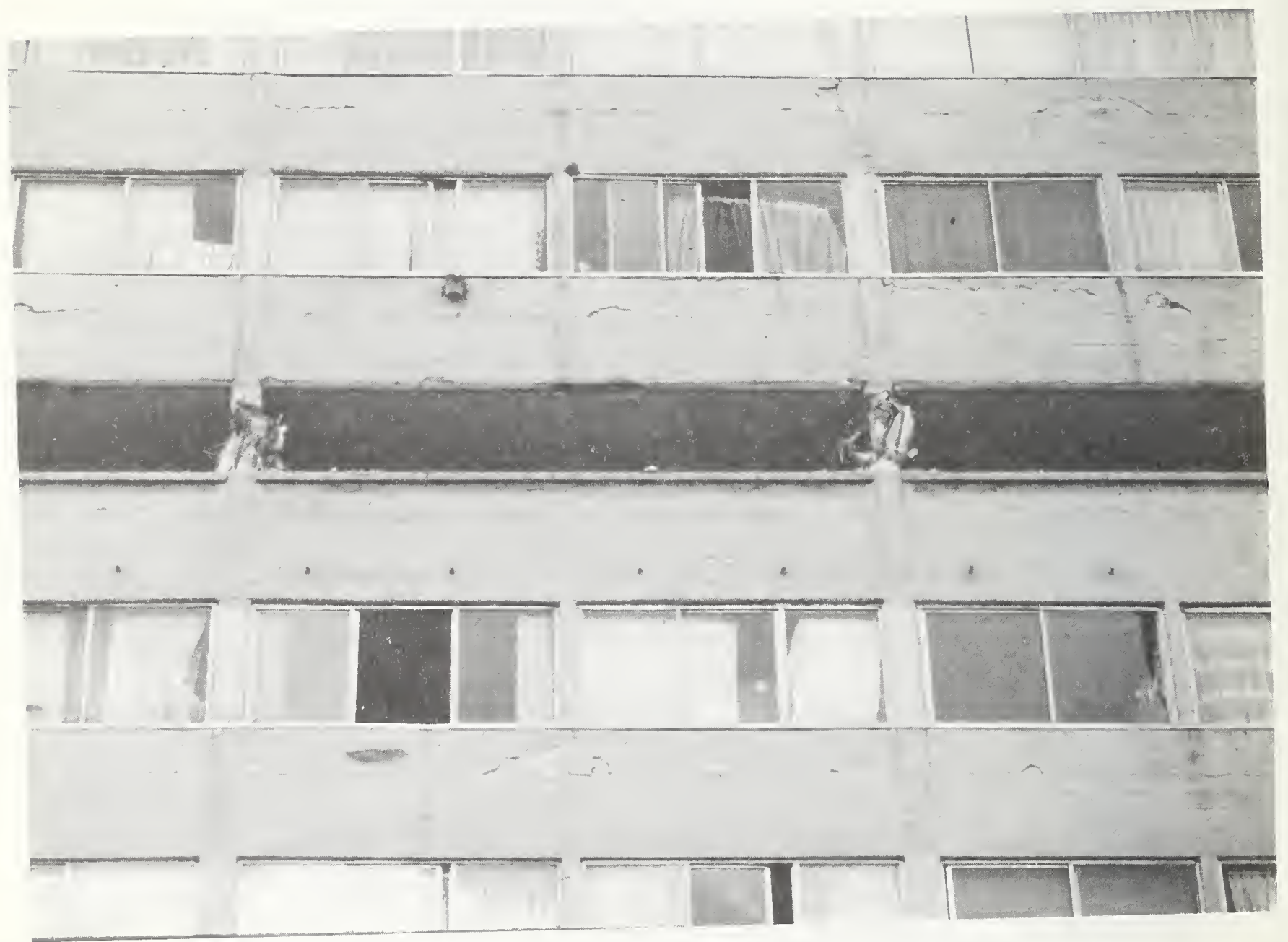

Figure 5.33. Failures in columns of the southern Nuevo Leon apartment tower (the only unit of the group of three to remain standing). 
This asymmetry in column loading may have induced a failure of the first story east column line in the two northern structures, due to the relatively lower stiffness associated with the first floor lobby. Shearing of the columns would then occur either at underconfined joints or at the story mid-heights between the $\mathrm{x}$-bracing. That the $\mathrm{x}$-bracing proved effective is demonstrated by the relatively intact nature of large sections of the structure after failure. This is to be contrasted with figures 5.34 and 5.35 which show an office structure near the corner of Neva and Barragan streets, similar in manny respects to the Noeva Leon building, with the exception of the lack of reinforced concrete $x$-bracing. The pancaking phenomenon is clearly evident.

\subsubsection{Punching Shear Failures}

A typical example of flat plate structural failure is shown in figure 5.36, of the ten story Bancomer Building at thecorner of Ave. Mier and 20 de Noviembre. This building was constructed recently, after the 1976 design code changes. In many cases the use of thin slabs precluded the placement of sufficient shear reinforcement in the vicinity of the slab-to- column junction. Under the reversed cyclic loading imposed by the earthquake, punching shear failures initiated a vertical progressive collapse, leaving the columns standing. Such failures were also seen at several other collapse sites involving flat plate construction. With the exception of projecting reinforcement at approximately 4 meter intervals, the columns appear bare in figure 5.36. Closer inspection showed that the floor plates slid down the columns, one on top of the other. The classical "shear cone" failure, shown in figure 5.37, is not visible here because the upper floors successively sheared off these cones from the top side as they fell.

The fact that there were a large number of flat-plate failures during the earthquake can be attributed to two reasons: a) the 


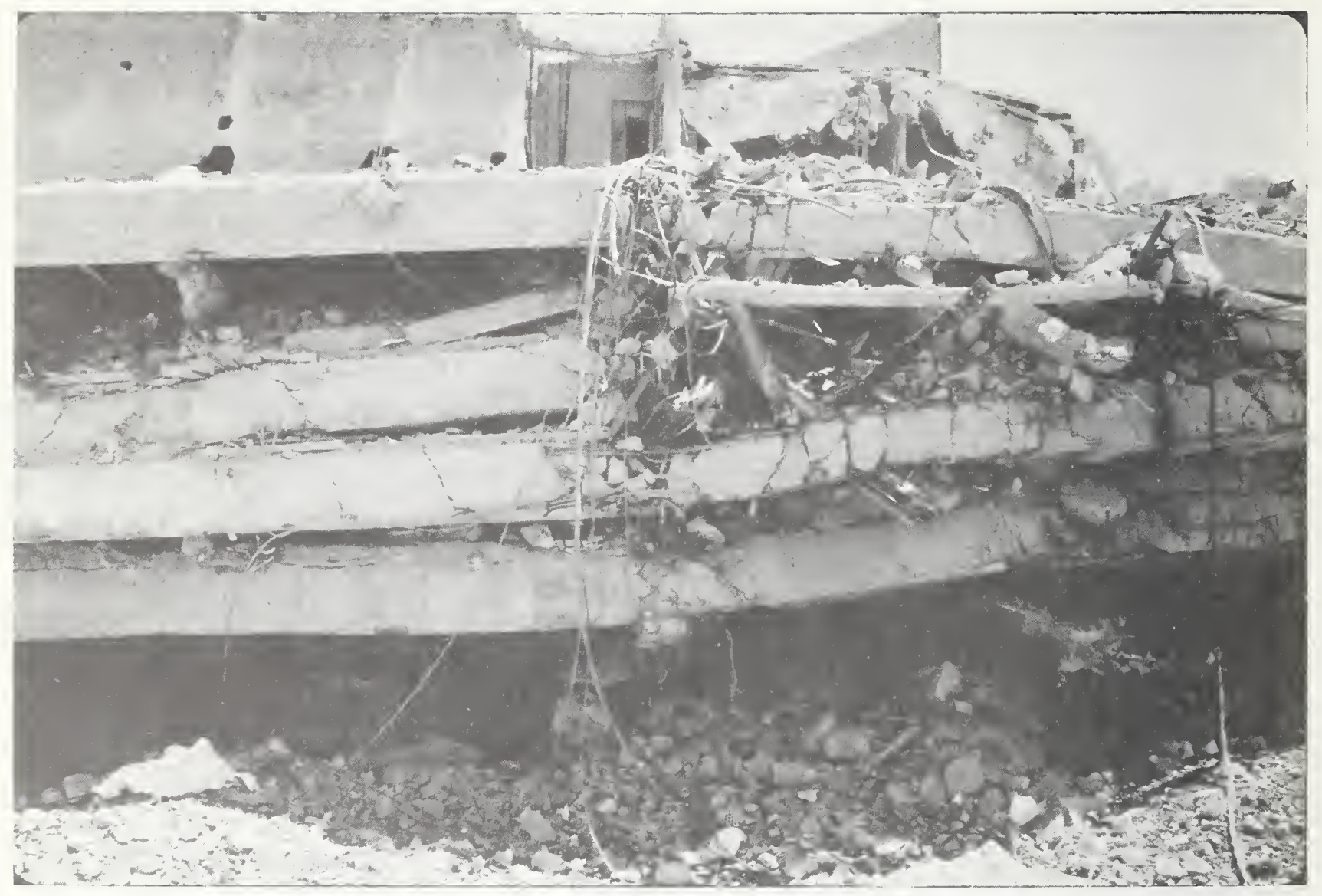

Figure 5.34. Collapsed office building near the corner of Neva and Barragan Streets. 


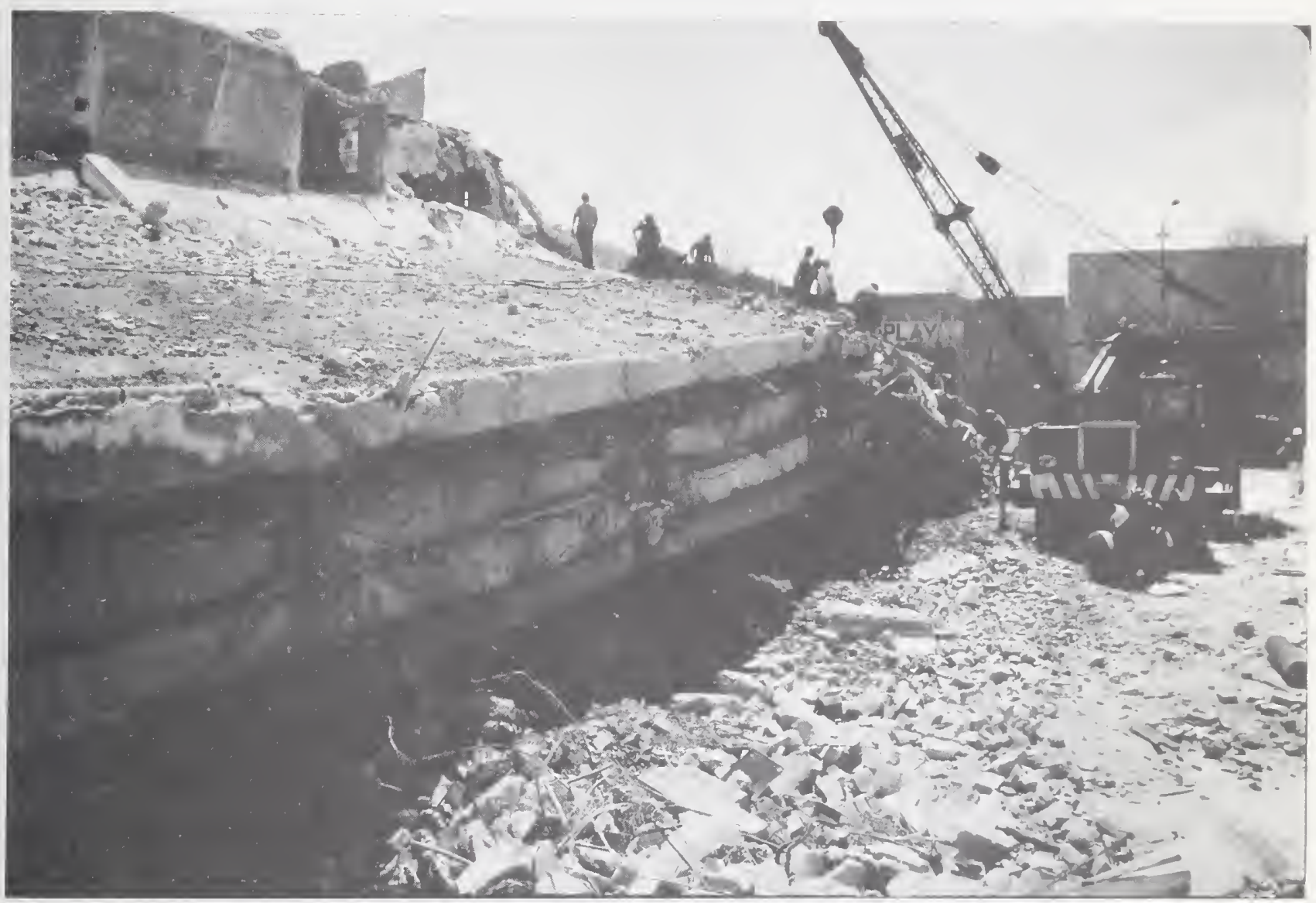

Figure 5.35. Collapsed office building near the corner of Neva and Barragan Streets. 


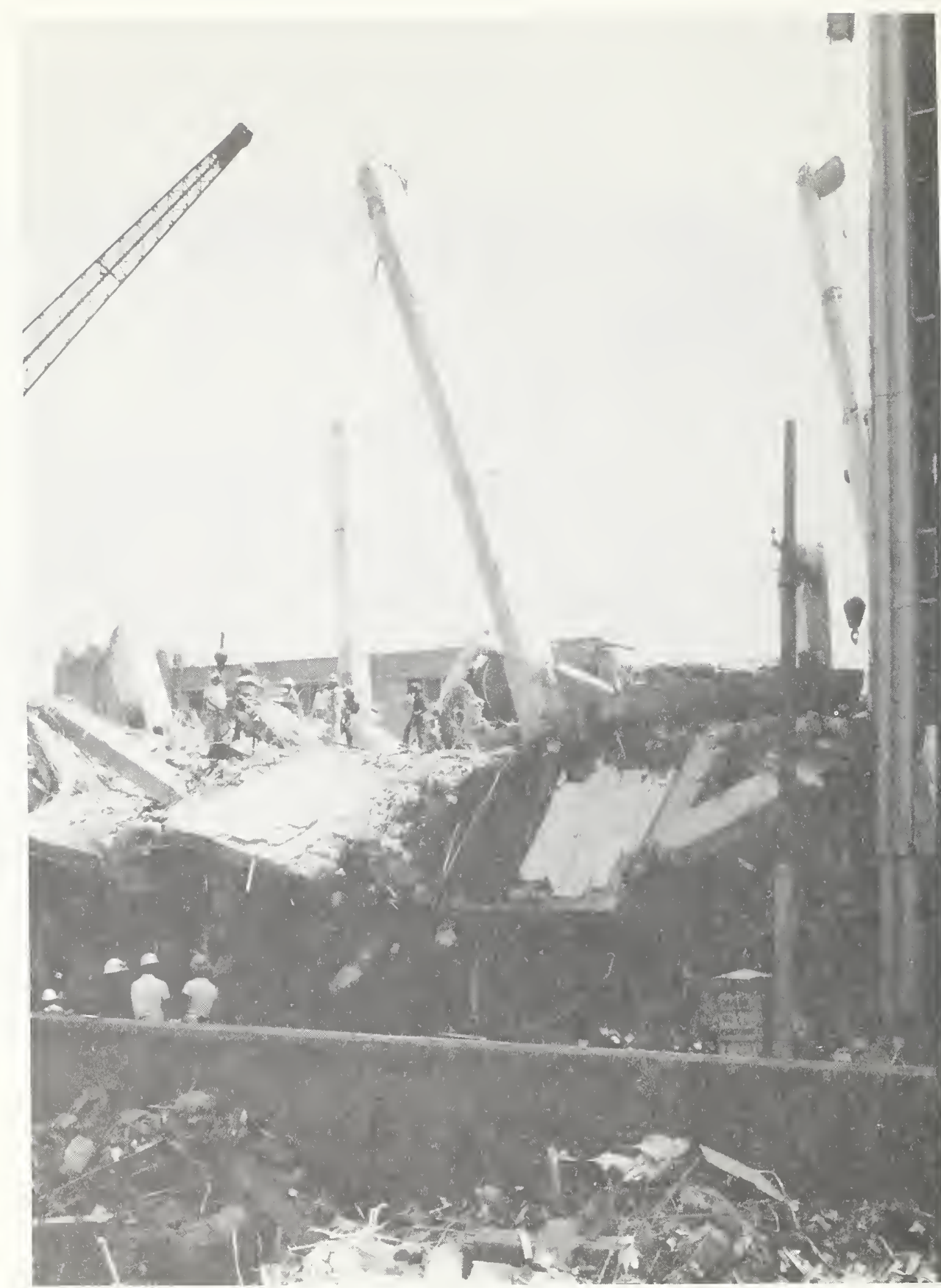

Figure 5.36. Punching shear failure of the 10 story Bancomer Building. 


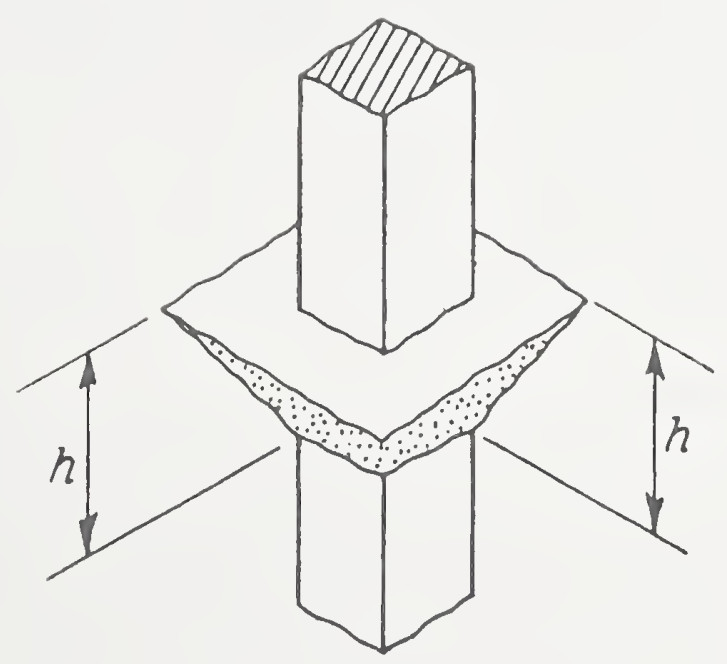

Figure 5.37. Shear cone resulting from punching shear failure. Ref. [24]. 
relatively low ductility at the slab-to-column junction which could have been improved through the use of special shear head reinforcement, as was mentioned in section 5.4 .1 above, b) the popularity of this form of construction -- due to its economy -following the 1976 design changes, giving rise to a larger percentage of structures in the 6-15 story range.

\subsection{Waffle Slabs}

\section{6 .1 General}

It has previously been mentioned that the vast majority of structural failures during this quake occurred in concrete structures. Although the total number of concrete frame structures which were damaged was high, proportionally there were a greater number of failures in buildings which employed waffle slab construction (see Table 5.1). It has been reported [31] that $2.9 \%$ of all concrete frame structures in the zone of major damage were either destroyed or required demolition. For waffle slab construction the percentage reported was $5.9 \%$.

\subsubsection{Column Failures}

Waffle slab structures generally have heavier floor dead weights than structures using beam/girder type floors. The waffle floor slab itself is quite stiff in its plane and therefore transfers by diaphragm action all of the seismic energy into the columns as concentrated story shears. As a consequence, the column ductility demand in this type of structure is high.

In many cases, the extent of damage to this type of structure was determined by the presence or absence of masonry exterior infill shear walls, as demostrated in figures $5.38 \mathrm{a}$ and $\mathrm{b}$. The infill walls shown in figure $5.38 \mathrm{a}$ failed, and in the process absorbed a 
substantial amount of energy prior to buckling outward. On the other hand, the Banco Vencen building near the corner of Ave. Trujano and Hidalgo (figure 5.38 b) was under construction and masonry walls were in the process of being added to some of the upper floors, but were not complete enough to prevent column shear failures from occurring along the entire eastern side of the frame at the third story. Those portions of the building where the infill walls had been completed remained standing. A typicalexample of a failure of a waffle-slab structure with flexible columns was the 10-story apartment building at the corner of Ave. Dinamarca and Chapultepec shown in figures 5.39 a and $\mathrm{b}$.

5.6.3 Porous Block Formed Waffle Slabs

Two unusual variations in waffle slab construction bear mentioning, as they proved to be particularly poor performers during this earthquake. Figure 5.40 shows a new parking garage north of the U.S. Embassy on Ave. Reforma under construction, using rectangular cinder blocks in place of the traditional metal pan forms. The rationale behind this technique was to use readily available, inexpensive cinder block to form the blockout, thereby avoiding the expense of an inventory of metal pan forms while also leaving a smooth ceiling surface for finishing. These cinder blocks are spaced similarly to their metal counterparts, but are left in the structure permanently. Because they are cast into the slab the cinder blocks add to the mass of each floor level.

Yet another variation of this form of construction employed standard hollow cinder building block, as shown in figures 5.41. This type of slab was particularly prone to bond failure during reversed cyclic loading, leading to the "floor drop out" pheonomenon shown in figures 5.42 and 5.43. In most cases, these same structures contained minimal slab reinforcement placed with 


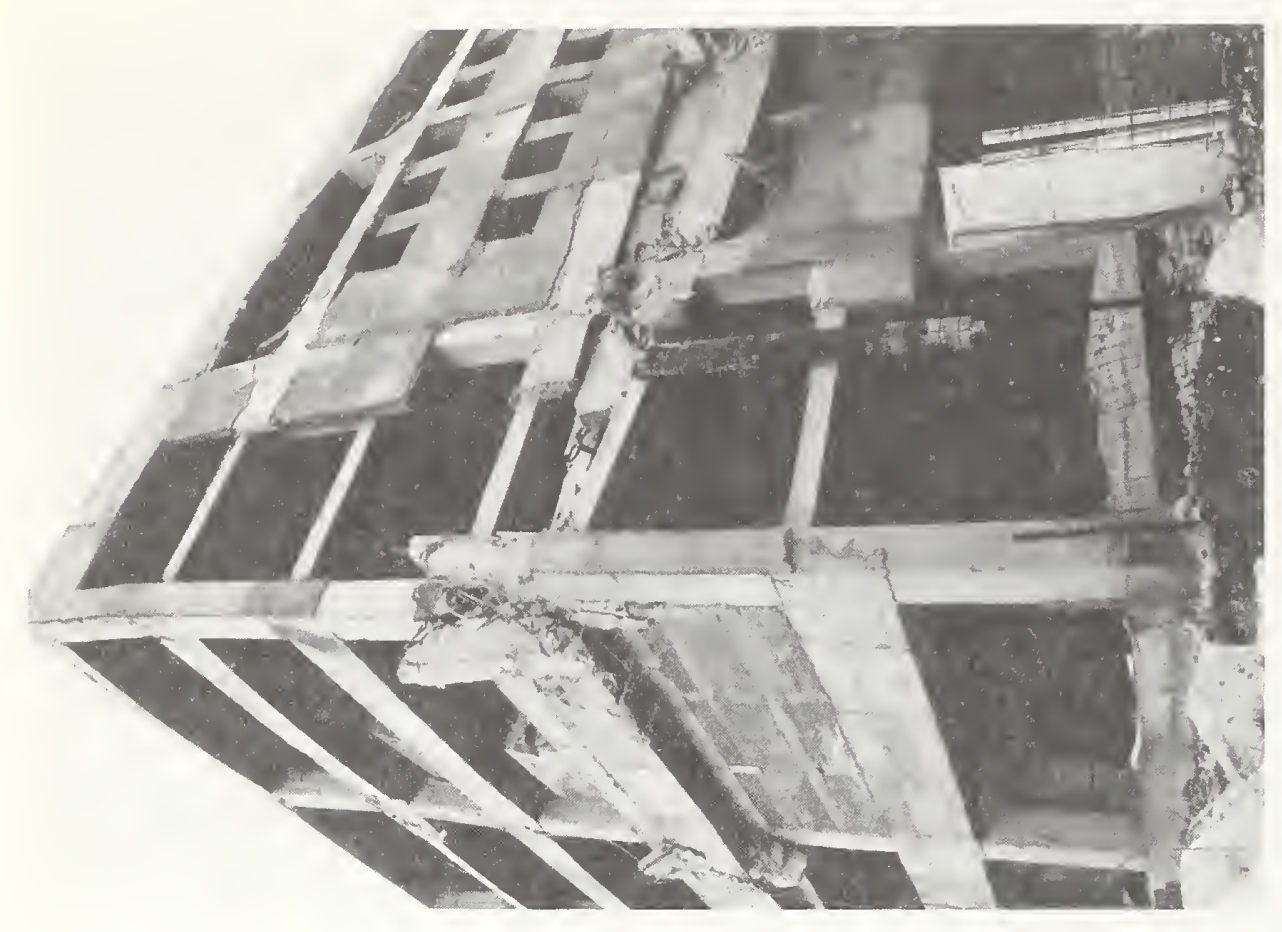

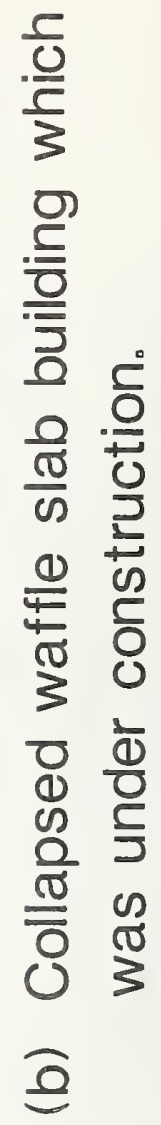
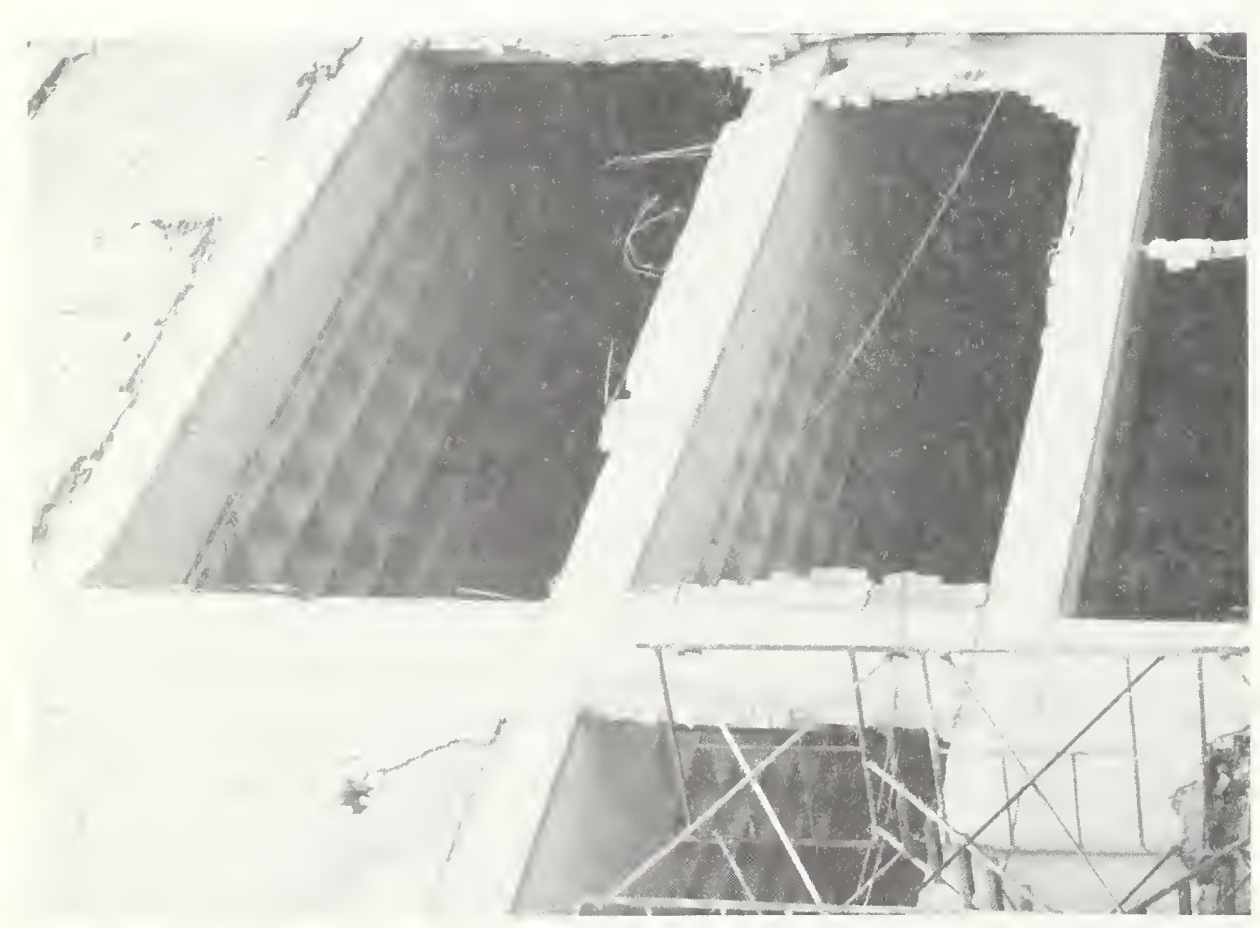

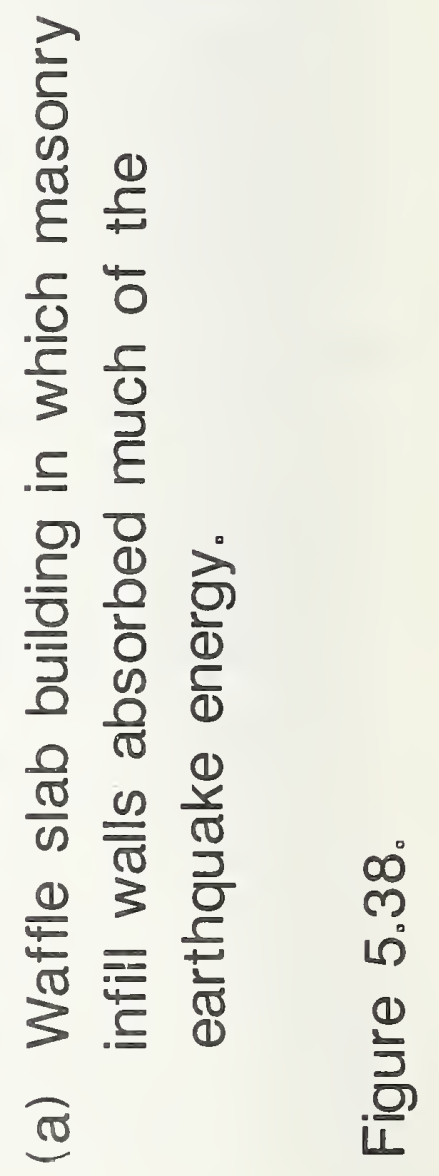



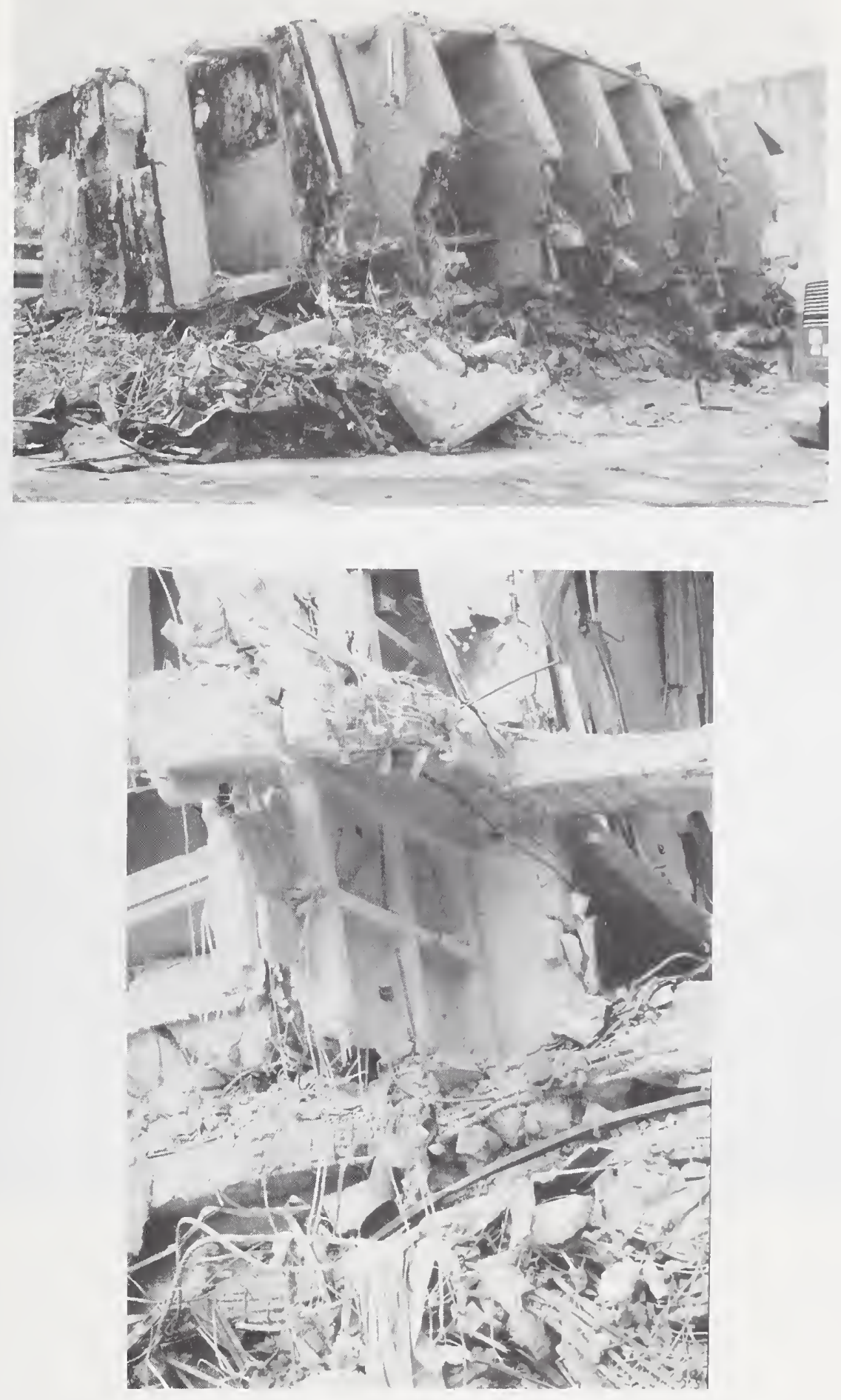

Figure 5.39. Collapsed 10 story apartment building in the corner of Dinamarca and Chapultepec. This waffle slab structure failure is attributed to base column failure and possible pounding with the neighboring structure. 


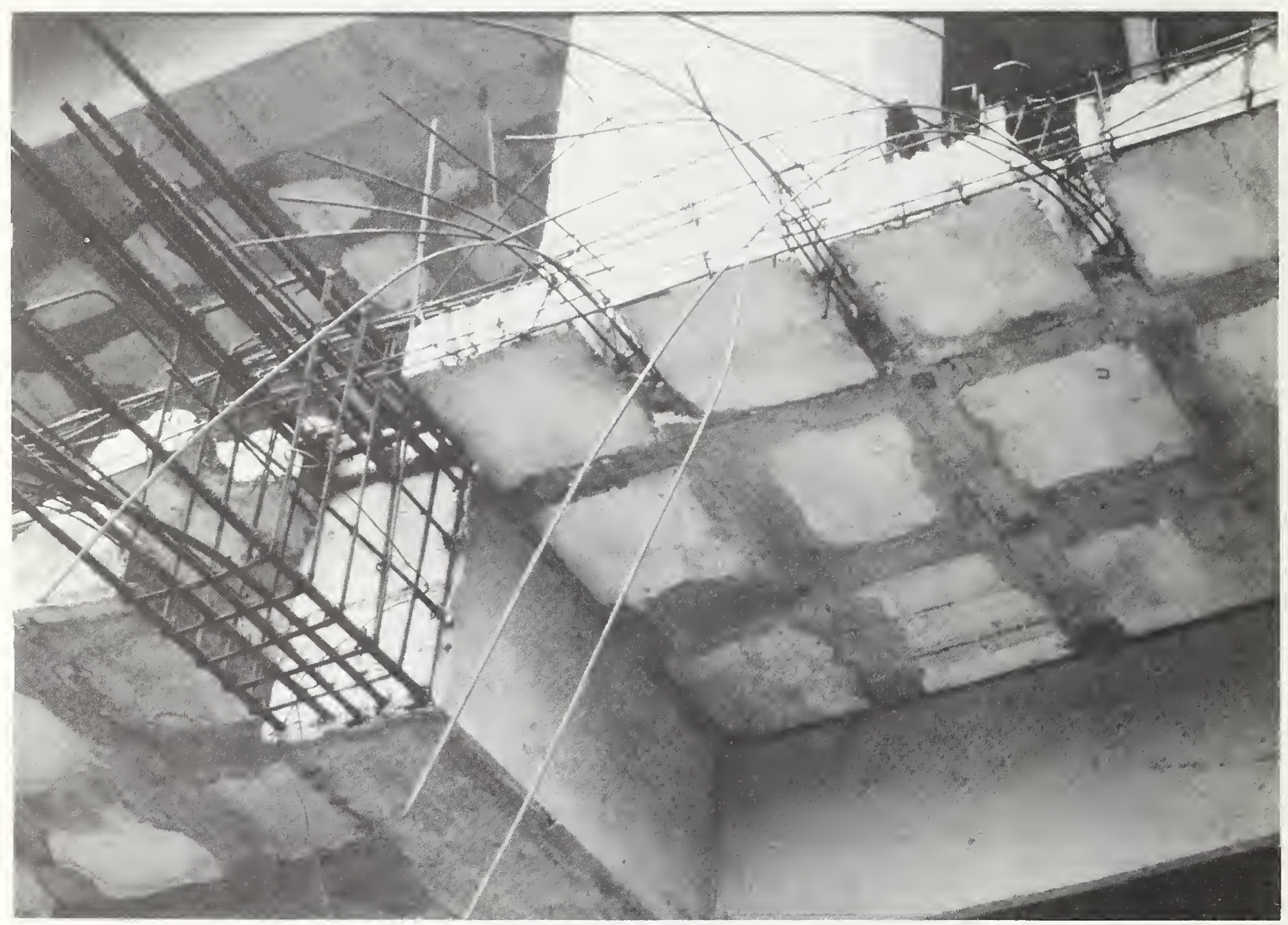

Figure 5.40. Parking garage under construction on Reforma, north of the U.S. Embassy. 


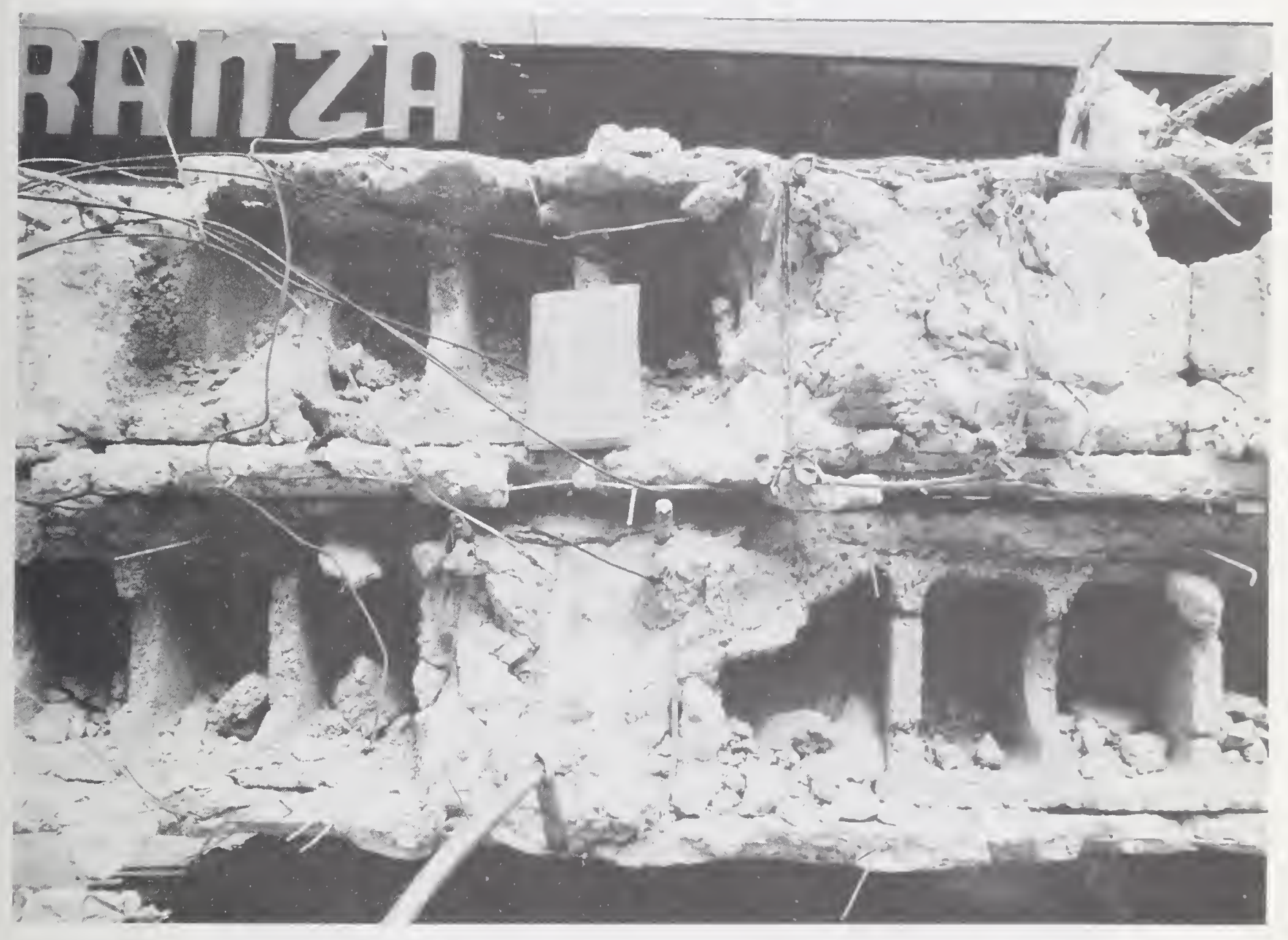

Figure 5.41. Waffle slab construction incorporating concrete block. 


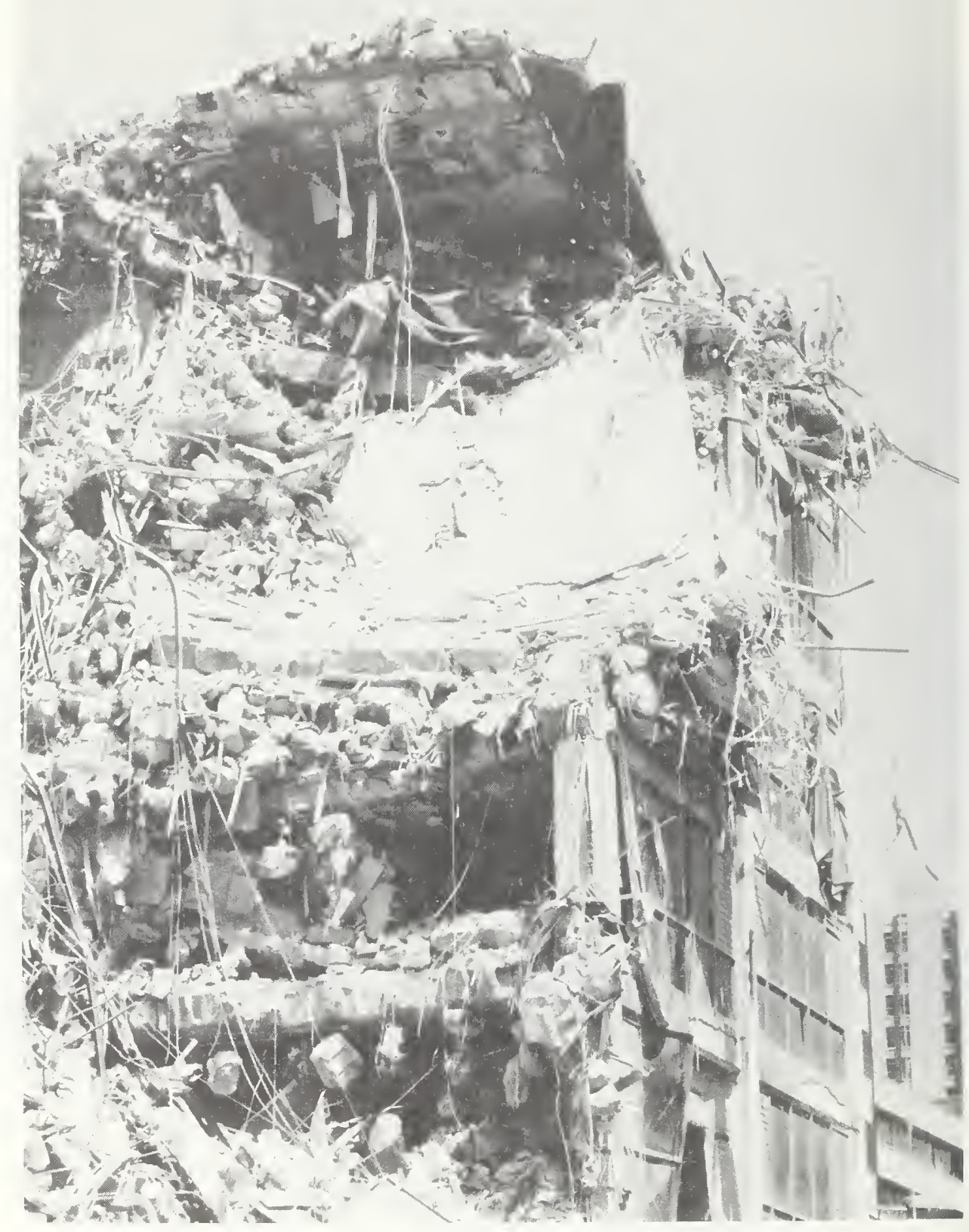

Figure 5.42. The "floor dropout" phenomenon observed in waffle slab structures with concrete block for pan forming. 


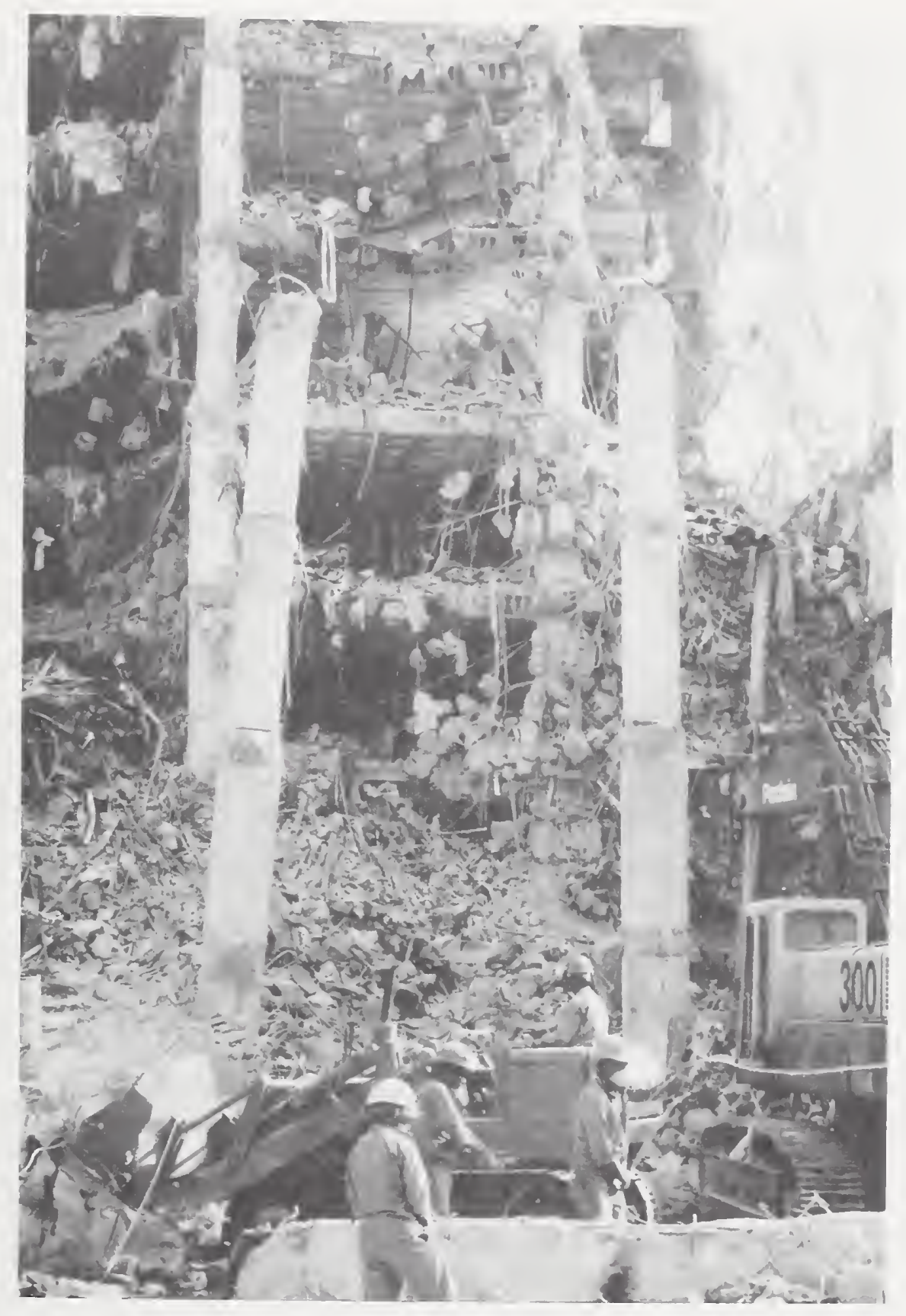

Figure 5.43. Punching shear failure in concrete-cinder block floor. 
negligible cover. As the building underwent successive cycles of lateral loading, the bottom (tensile) cover concrete spalled off, leaving the tension reinforcement exposed in a grid-like pattern. With further shaking the cinder blocks simply began falling out, eventually leading either to the "floor drop out" phenomenon if sufficient shear reinforcement was present to resist a punching shear failure or, more likely, a progressive punching shear failure (see figure 5.43) similar to that observed in flat plate construction. It was apparent from the extensive and specific damage that special design procedures should be developed for this method of construction in future design codes.

\subsection{Steel structures}

\section{7 .1 General}

The historical background of steel construction in Mexico City was discussed by Hanson et al. [25]. In the early part of this century some steel structures with masonry infill walls were constructed. Multistory building construction started in the 1950's. The Robles Building (24 stories), the Latino Americana tower (43 stories), the Abed building (35 stories) the Banco International (32 stories), and the seguros Anhuac and La Comercial buildings (27, 28, and 25 stories) are from that era. These moment - resisting frame buildings used imported wide flange beams and columns, and often columns consisting of two channels with welded cover plates. These buildings generally performed well in several earthquakes. However, we should keep in mind that, because of their longer natural periods, these buildings were not subjected to resonating seismic forces typical of the sites they were constructed on.

Failures in steel structures accounted for only ten out of the hundreds of buildings which collapsed during the earthquake. 
This can likely be attributed to two factors. The first is that as a percentage of the total, there are relatively few steel frame buildings in the Valley of Mexico. The second factor contributing to the low number of steel building failures is that steel, whether in the form of heavy rolled sections (imported) or built-up plate sections (domestic), was preferred in tall structures. These same tall structures had natural periods of vibration significantly greater than the predominant 2 second ground motion period and therefore were not likely to resonate. The study of those steel structures which did fail during this earthquake is thus of considerable importance.

During the last three decades the importation of large steel profiles were limited and Mexican mills produced rolled sections up to 18" (460mm) in depth. However, rolled plates of up to 5/8" $(16 \mathrm{~mm})$ in thickness were readily available. In several cases this led to steel construction using welded box columns andopen web joists in composite action with concrete decks.

\subsubsection{Steel Frame Structures That Failed}

Perhaps the most impressive failure resulting from the september 19 earthquake was that of the two southern towers of the five tower Consumo Pino suarez, a government office complex built in the early 1970's, located just west of the Juarez Hospital (See Fig. 5.44). The northern-most and southern-most buildings were 15 stories in height, while the central three buildings were 23 stories high (figure 5.45) all oriented linearly from north to south. Underlying the buildings were barrel arch type reinforced concrete tunnels housing the Pino suarez Metro station, a connecting station at the intersection of two subway lines. The weight of the buildings served to prevent uplifting of the metro station, a practice that is common in the lake bed of Mexico 


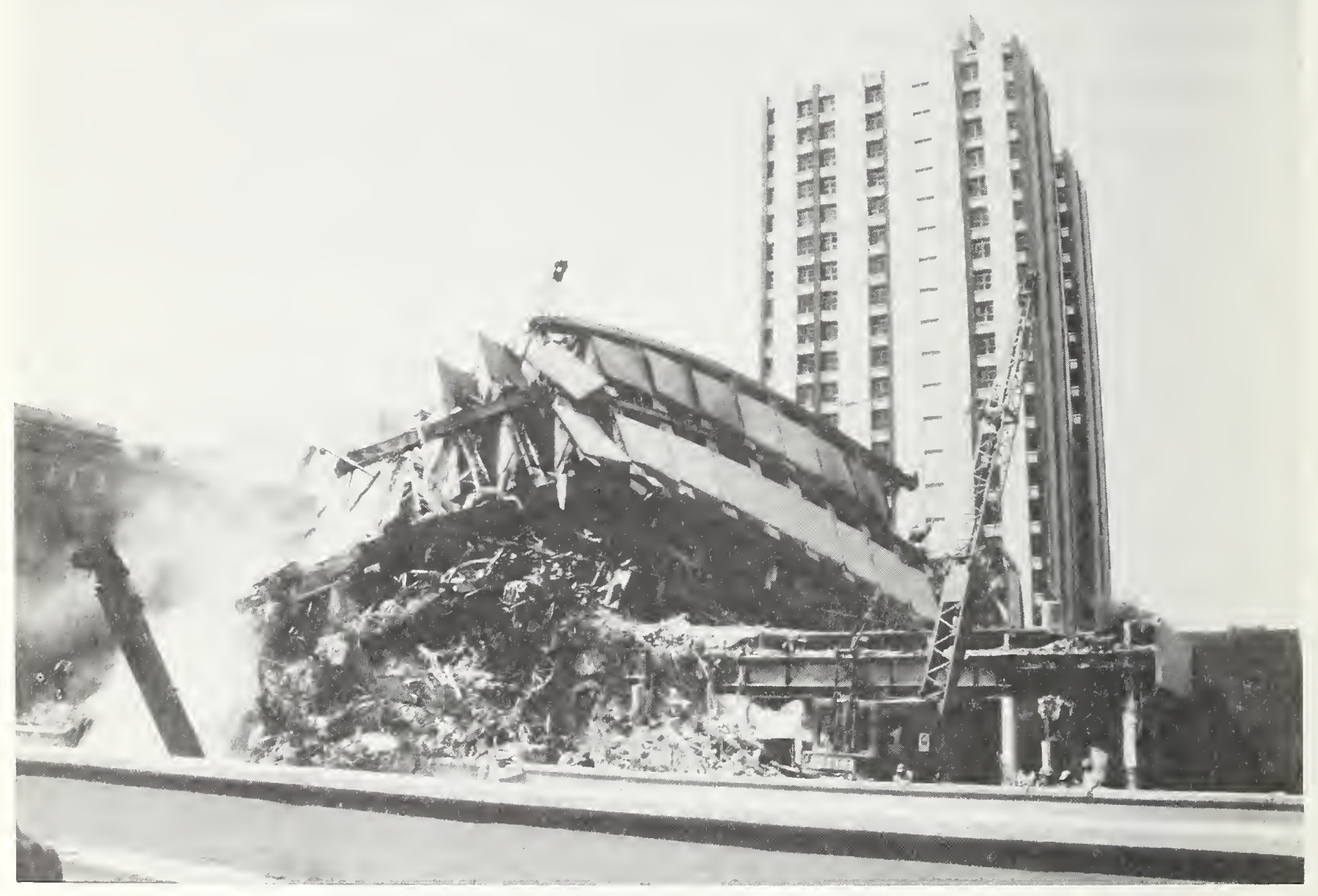

Figure 5.44. Southern towers of the Consumo Pino Suarez Complex shortly after collapse. 

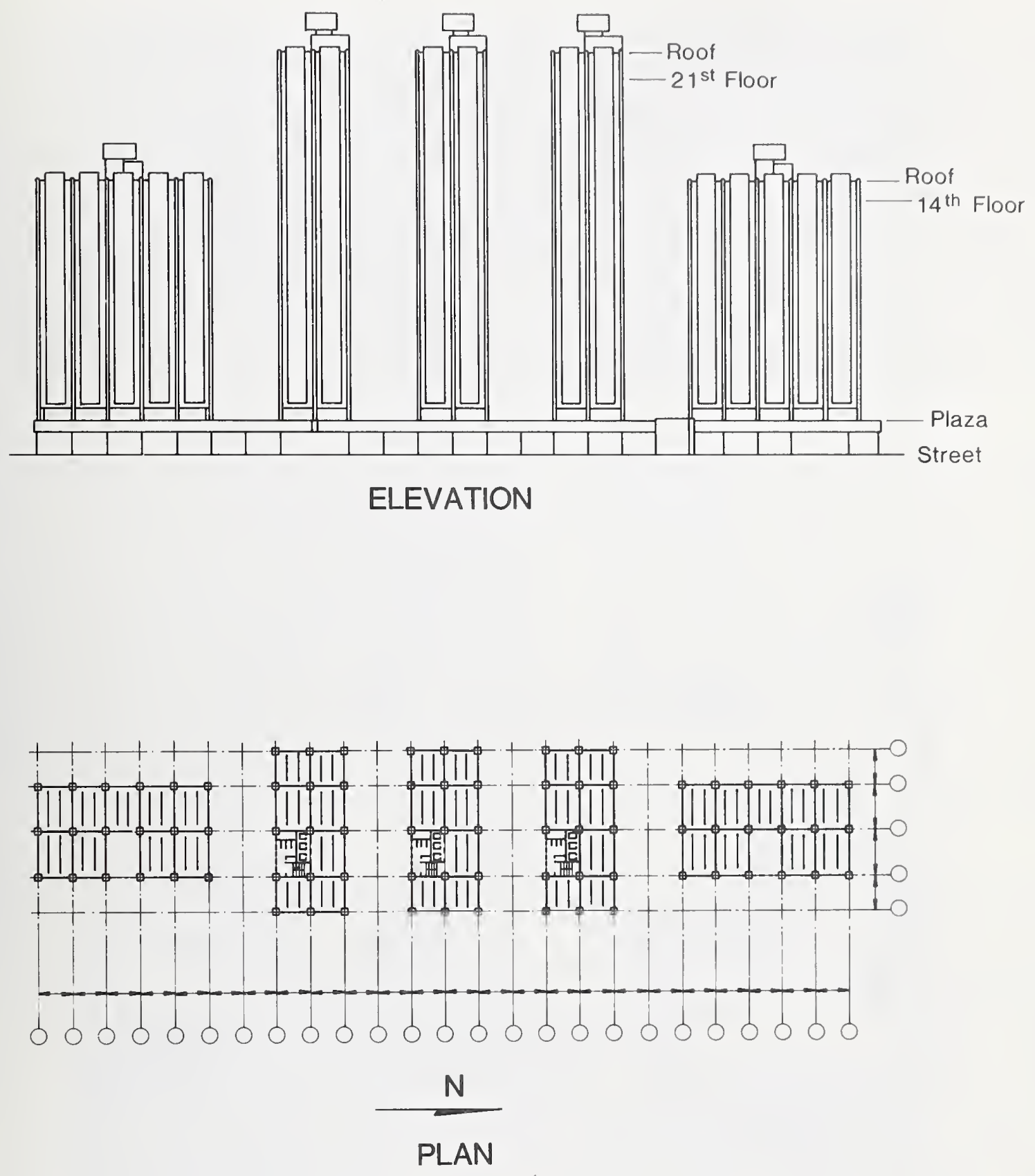

Figure 5.45 Plan and elevation of Pino Suarez Office Complex. 
city. The main line of the Metro runs approximately east west along Ave. Obregon, the street bordering the Pino suarez block on its northern side. The exact configuration of the foundation system beneath the southern half of the structure is unknown at the time of this writing, however all five buildings made use of a common two-story mezzanine and lobby (figure 5.46) and it is known that some of the building columns extend through the subway station itself* Therefore, the entire complex was subjected to the same base accelerations during the earthquake.

Each of the 23 story towers had two bays in the north-south direction (total width 12 meters), and four bays in the east-west direction (total length 28 meters), which in part helps to explain the collapse of the structures along the north-south axis despite the predominance of the east-westacceleration component of the quake. The third bay on the south side of each of the 23 story structures contained a braced elevator shaft and stairwell, as can be seen in figures 5.47 a and $b$, taken nine months after the earthquake following the removal of cladding and debris.

All five of the Pino suarez towers utilized a welded box column frame (see figure 5.48) and an integral composite slab system supported by truss beams (figure 5.49) fabricated from tubular sections with steel angles forming the inclined truss members in the shape of a simple Warren truss. The truss-to-column connections were designed to be moment resisting (See Fig. 5.50a). Lateral bracing for the building consisted of one bay of "V" braces along the exterior south wall adjacent the elevator shaft and stairwell, and two north-south oriented lines of $x$-bracing on either interior side of the elevator shaft and stairwell bay.

* Pers. Comm. Ing. Enrigue Del Valle-Calderon, August 1986 


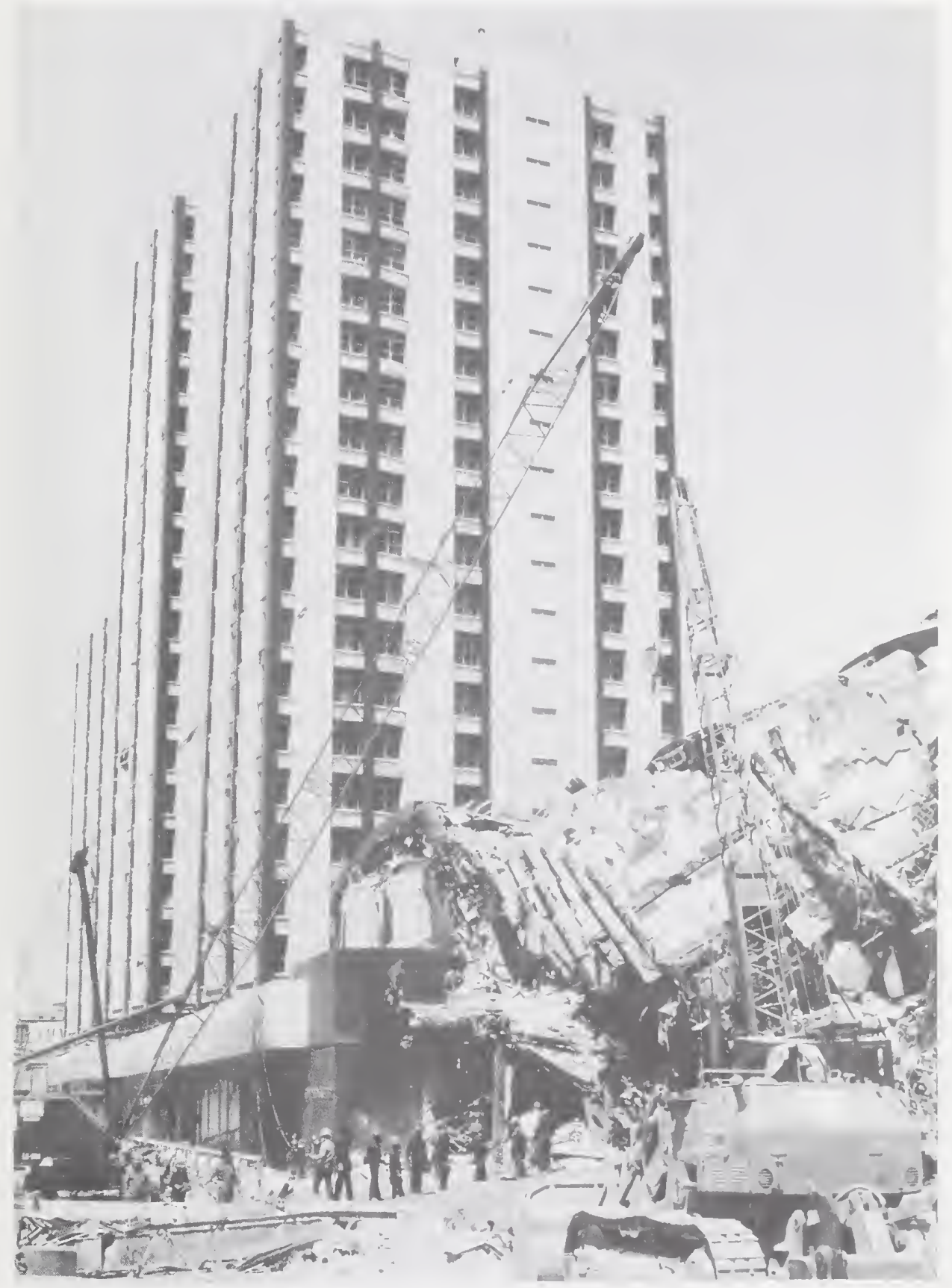

Figure 5.46. Middle 23-story tower and connecting ground level mezzanine for Pino Suarez Office Complex. 


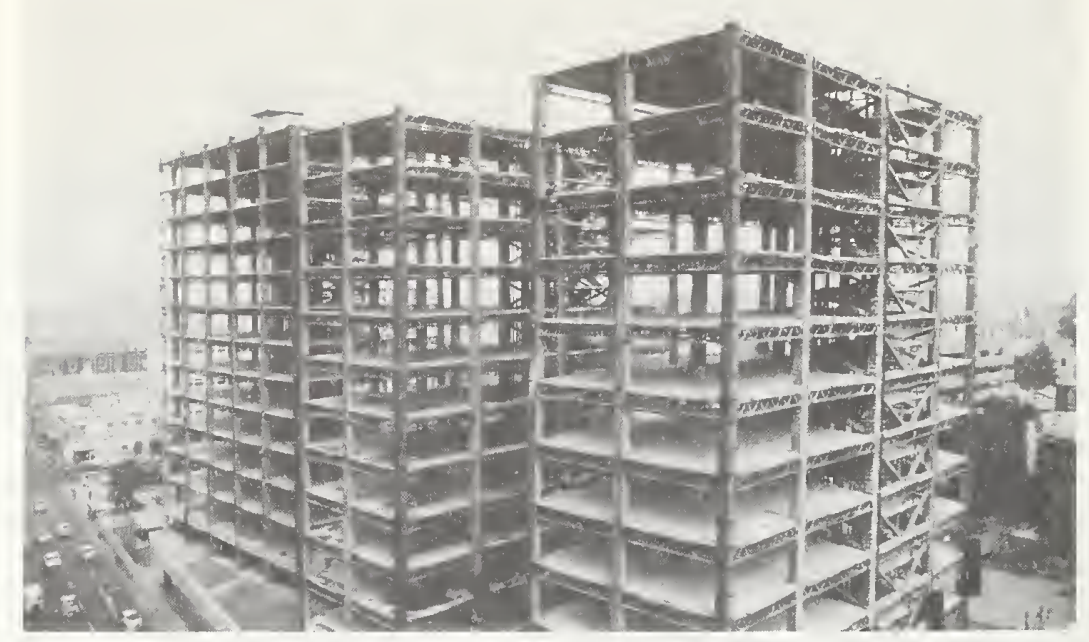

(a) Remaining three Pino Suarez towers.

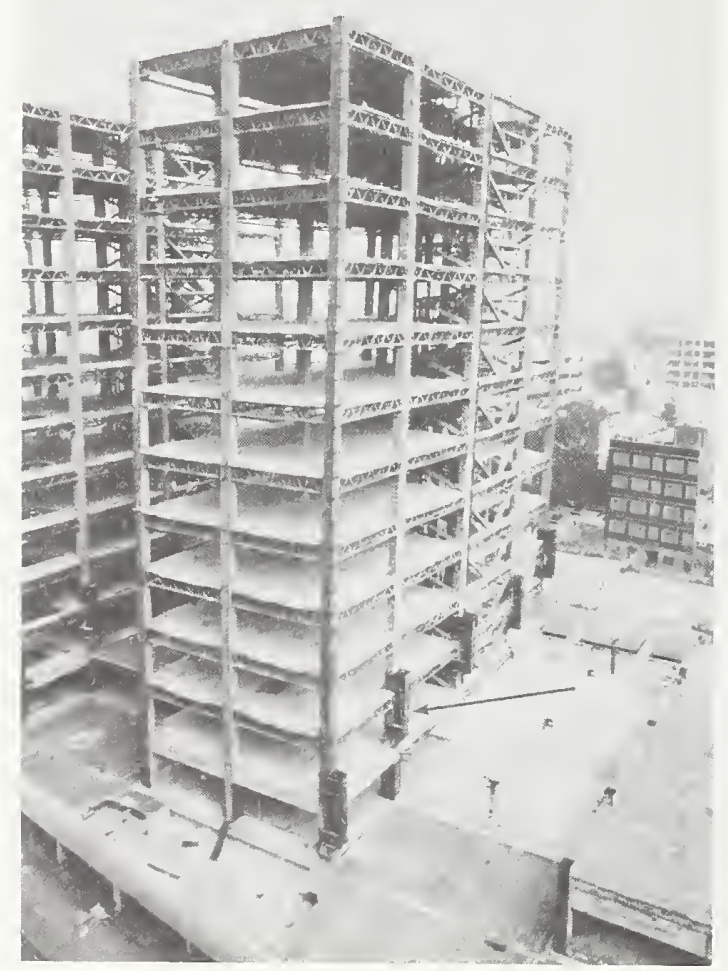

(b) Central 23-story tower (reduced to 14 stories) at Pino Suarez. Note " $\mathrm{C}$ " clamps at bottom right.

Figure 5.47. Remaining Pino Suarez structures shown during July 1986 . 


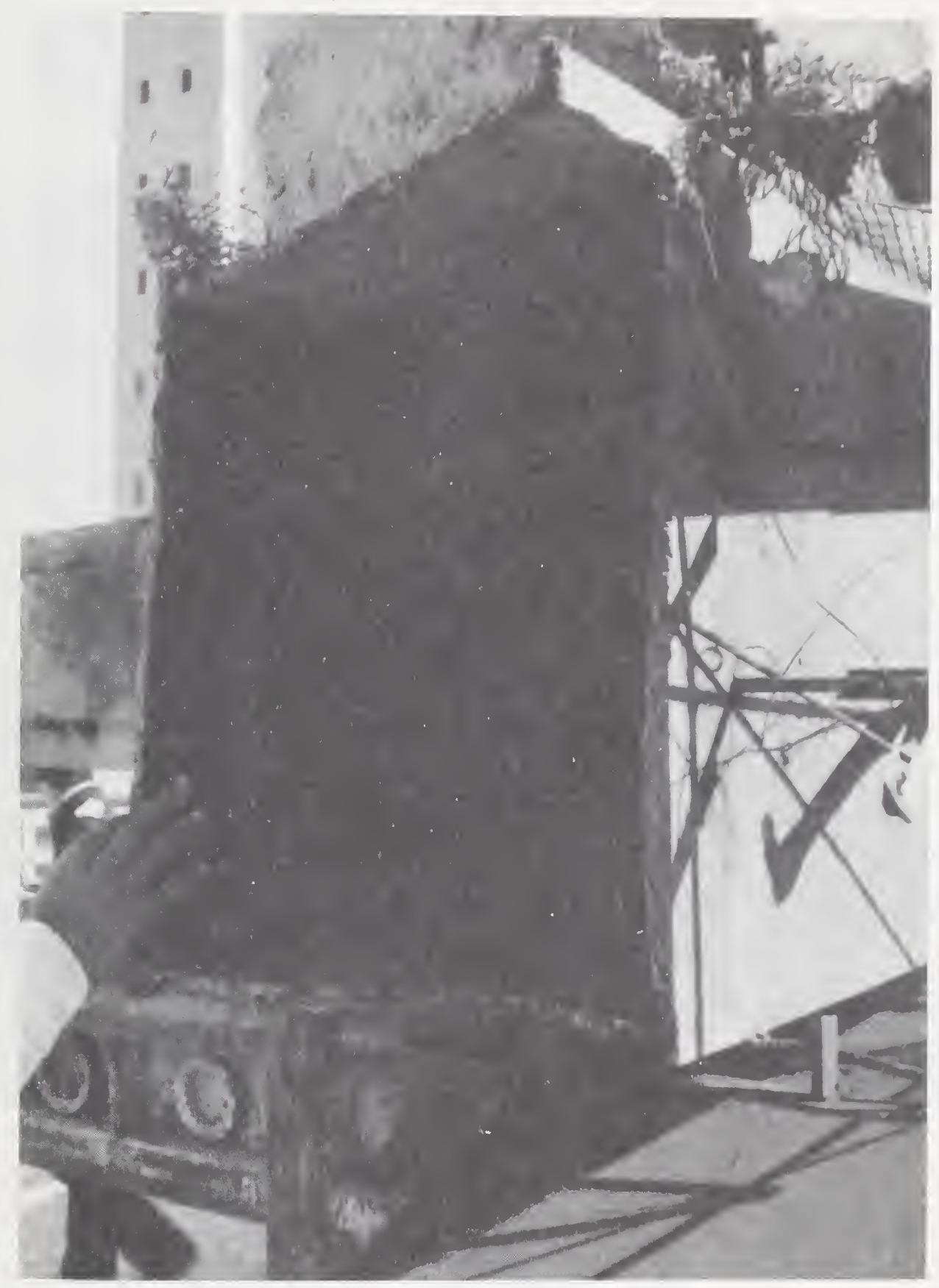

Figure 5.48. Typical box column cross section used in Pino Suarez Complex. (courtesy E. Martinez-Romero) 


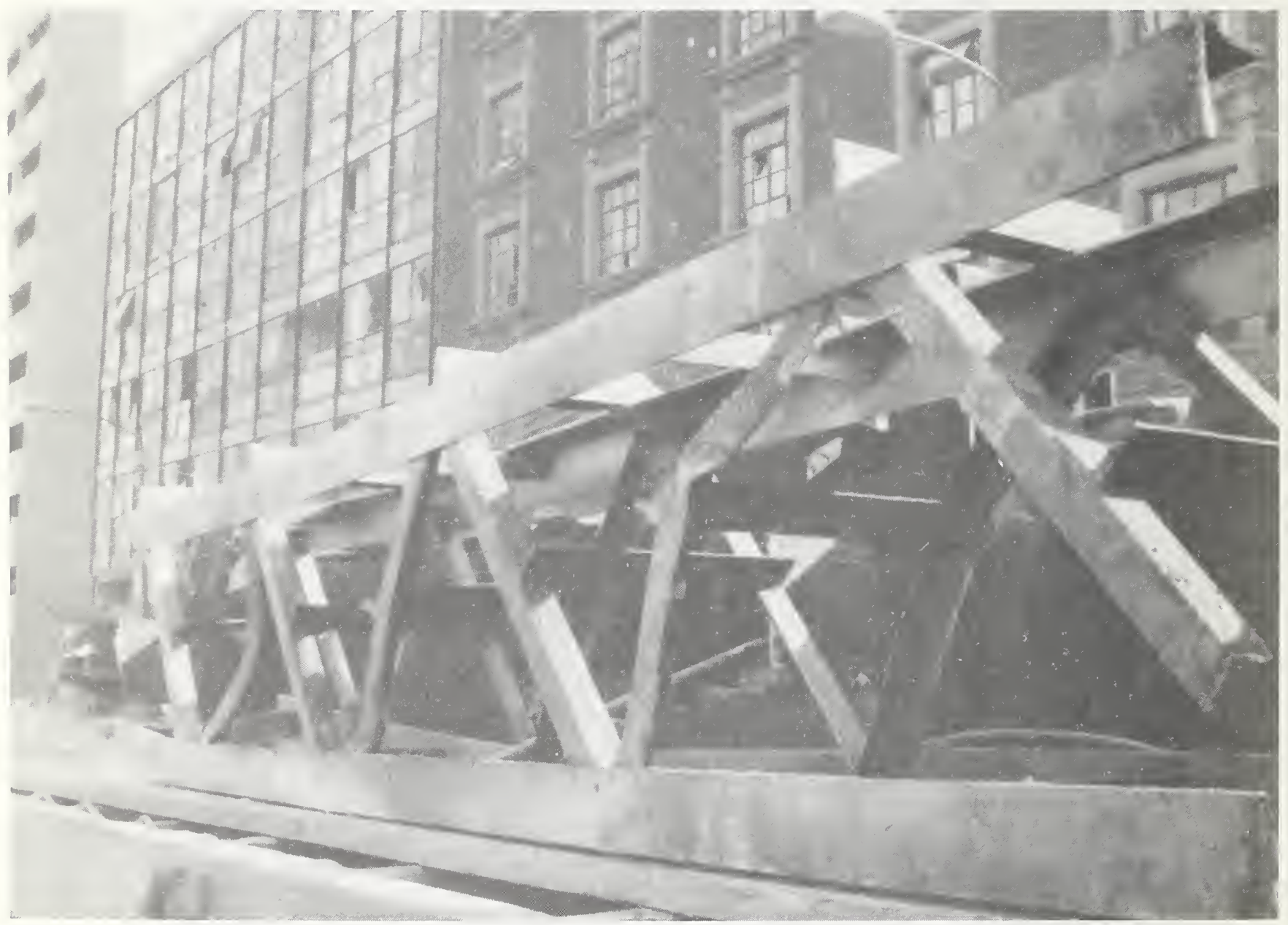

Figure 5.49. Truss beam detail used in Pino Suarez Complex. (courtesy E. Martinez Romero) 


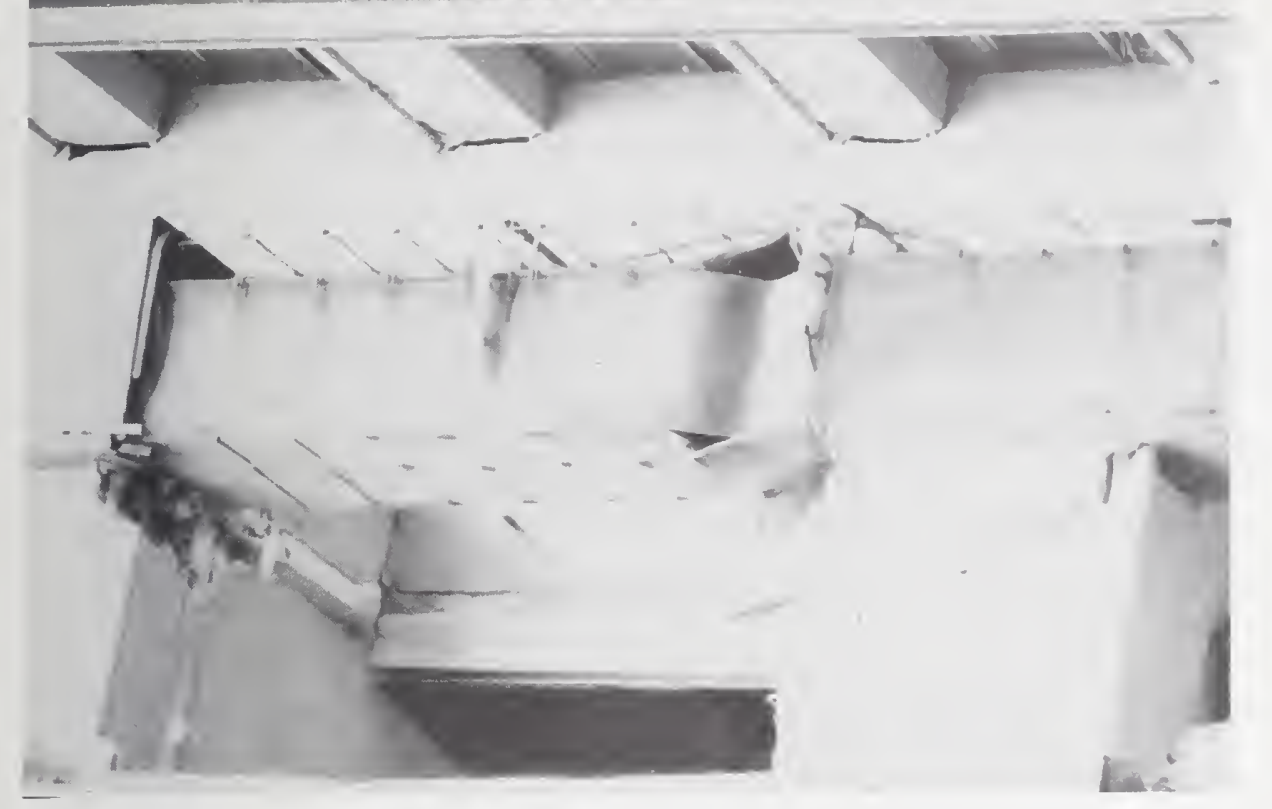

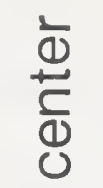

0

o

O 0 क

ज 光 을

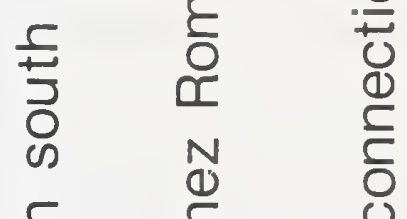

ᄃ

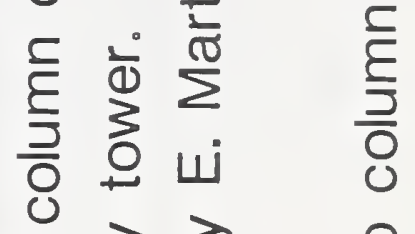

ठำ के 인

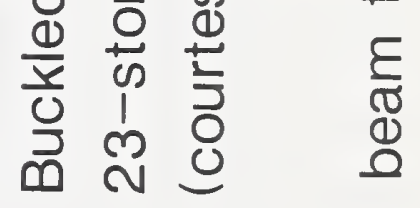

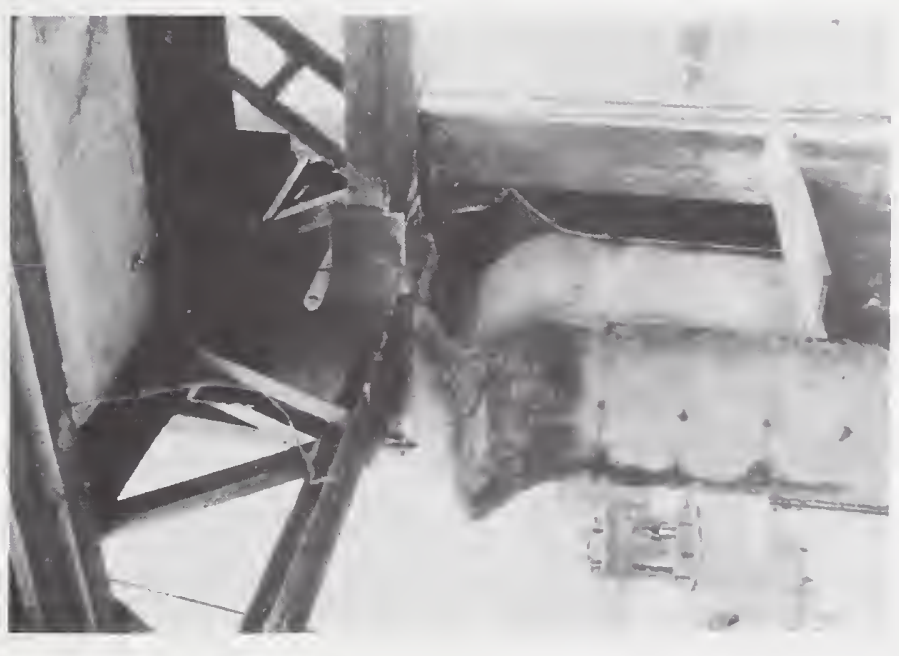

으

क

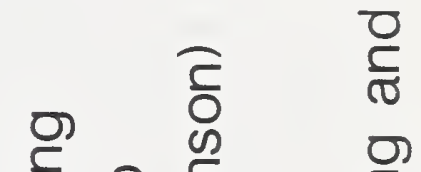

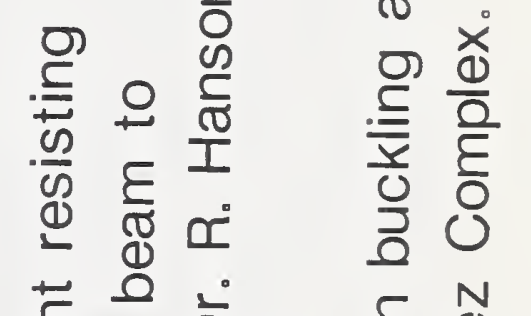

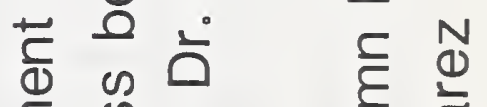

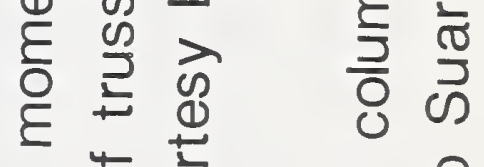

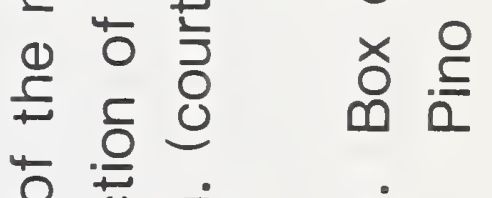

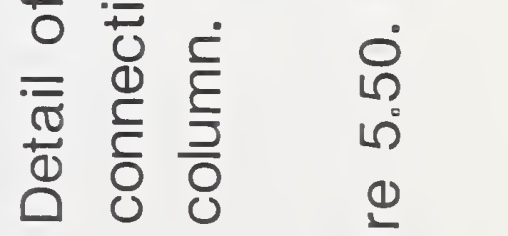

지 흔 
The columns were hollow box sections made of four plates with exterior fillet welds along the edges. Internal stiffner plates spaced at regular intervals and welded to three sides along the interior length and along all four sides at the column ends.

Prior to the September 1985 earthquake, through ambient vibration tests performed at the Pino suarez complex for 23 story towers, the fundamental period of vibration was determined as 2.0 seconds, clearly in resonance with the period of the ground accelerations at the SCT site.

From the plan view of the complex presented in figure 5.45, it is seen that the lateral bracing surrounding the elevator shaft of each tower created an eccentric center of stiffness, thus resulting in torsional vulnerability. This was confirmed through a simplified three dimensional computer model (figure 5.51). The first mode of vibration in the narrow direction was scaled to match the known period of 2 seconds, since precise element stiffnesses and masses were not available at the time of the analysis. The same scale factor was used in making a bestestimate of the periods for the higher order modes in the real structure. The first mode in the wide direction had a calculated period of 1.17 seconds and a distinct twisting component; and the pure torsional mode had a calculated period of 0.64 seconds, sufficiently long to have been excited by the september 19 earthquake. Column axial and bending forces would have been generated in the structure due to components from each of these modes of vibration and, during certain phases, these forces would be additive on certain structural elements, producing loads in excess of those that would be indicated from two dimensional dynamic analyses commonly employed in structural design.

Although the structure was designed as a moment resisting frame, it is evident that not much inelastic deformation developed in the beams. Rather, the individual truss diagonal elements 
buckled (see figure 5.50) indicating that they were not able to dissipate energy through inelastic action in the manner of typical rolled beam sections. This in turn had two adverse effects: primary ductility demand was transferred to the columns (for which they were not designed) and large lateral deflections gave rise to large p-delta effects, all of which served to overstress the southern, stiffer, column line. Eventually, local plate buckling -- amplified by weld tears at the plate joints -occurred in the most highly stressed columns along the south face near the top of the common mezzanine.

Buckling of columns, and deformations caused by other actions, induced substantial tilt towards the south, as can be seen in figure 5.52. It is highly probable that this situation existed in all three of the 23 story towers prior to the ultimate collapse of the southern-most tower. To complete the collapse mechanism, however, an additional failure was required. Figure 5.53 indicates that the final straw was likely a series of tensile fractures in the box-columns on the north side of the frame, presumably at a joint line near the second story. Lacking this crucial moment resisting element (viewing the structure as a whole) the tower was free to rotate southward, further crushing the southern column line in the process, and eventually impacting on its neighboring 14 story building. Both buildings were subsequently destroyed, leaving the two collapsed buildings in the configuration previously shown in figure 5.44 .

Information which became available in January of 1986* indicated that the upper floors of the southern-most 23-story structure contained a substantial amount of heavy goernment equipment which would have adversely affected the performance of the structure under the influence of lateral loads. Likewise, the presence of

* Personal communication: Ing. Enrique Martinez Romero 


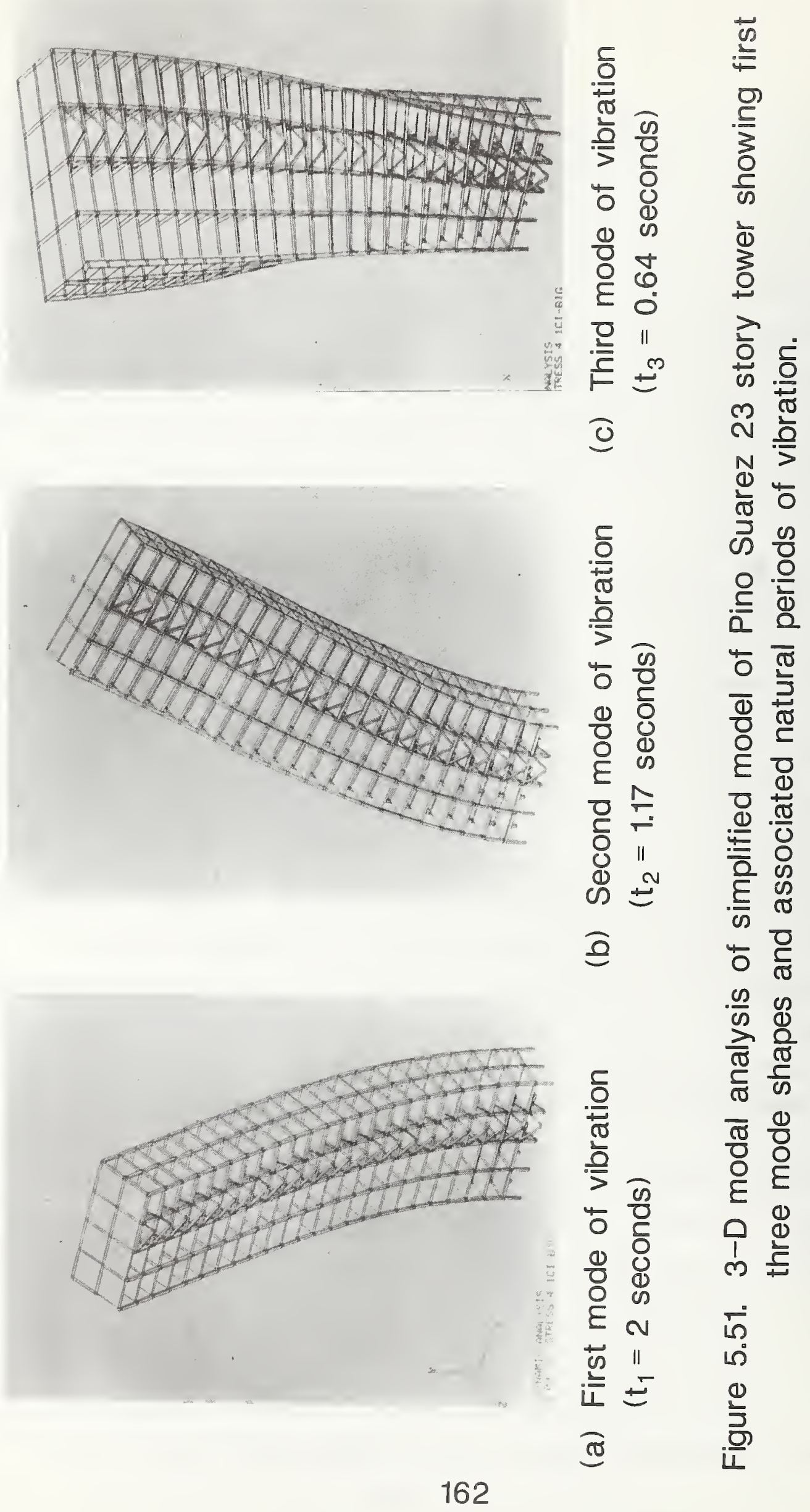




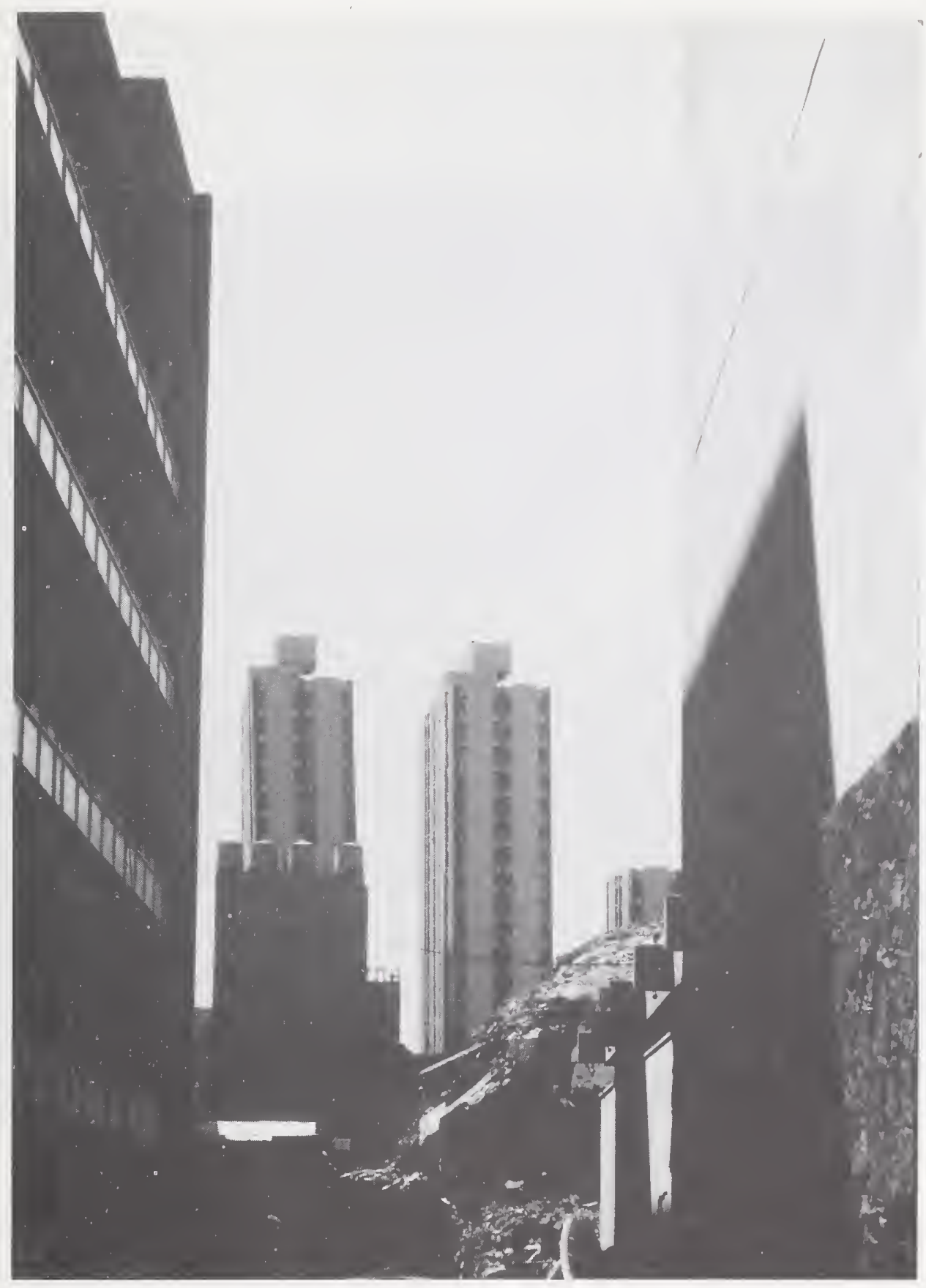

Figure 5.52. Tilted central 23-story tower at Pino Suarez Complex. Southern side of structure is to left side. 


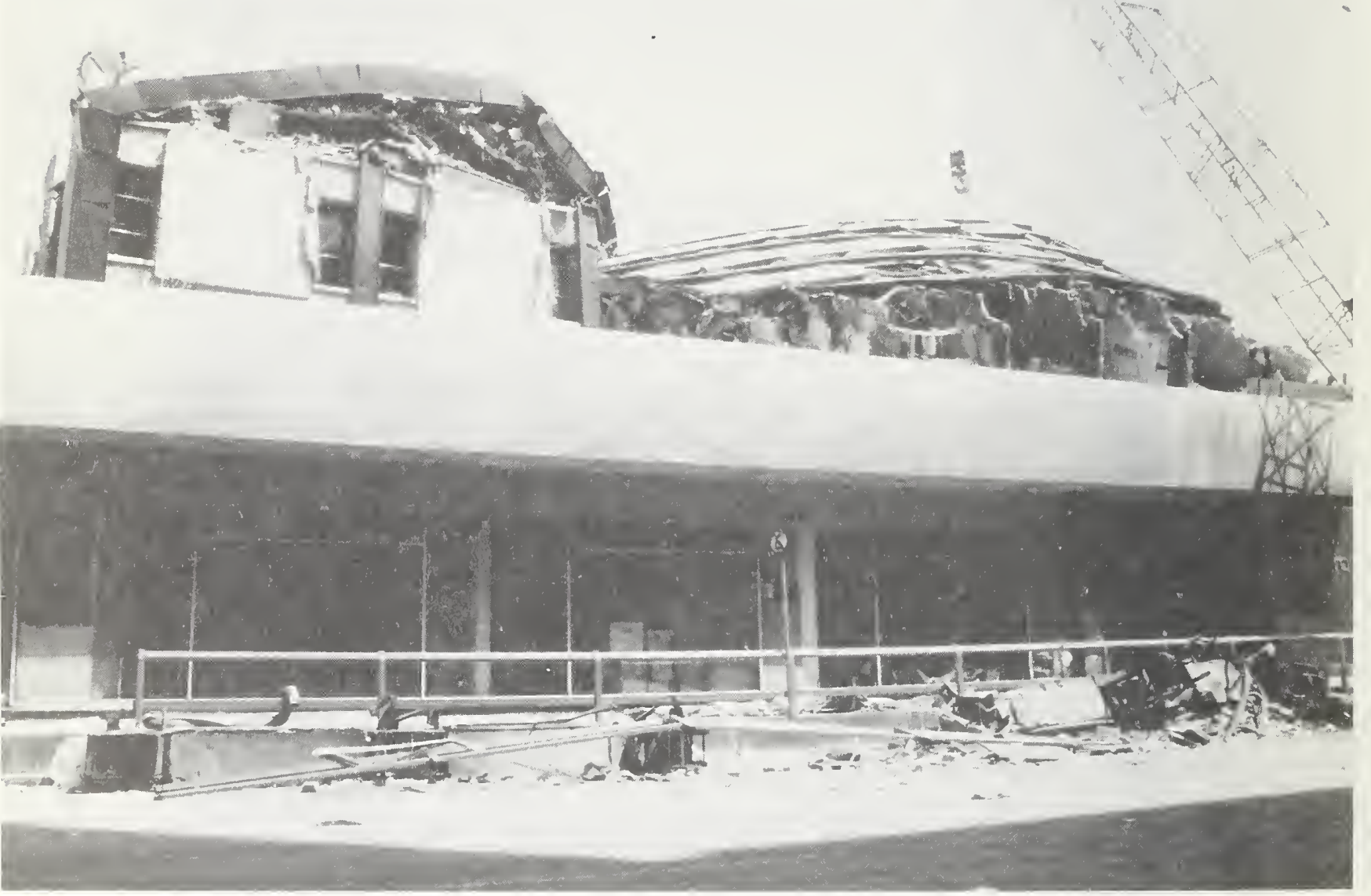

Figure 5.53. Closeup of fractured column line near second story, north side, of the southernmost 23-story structure in Pino Suarez Complex, shortly after collapse. 


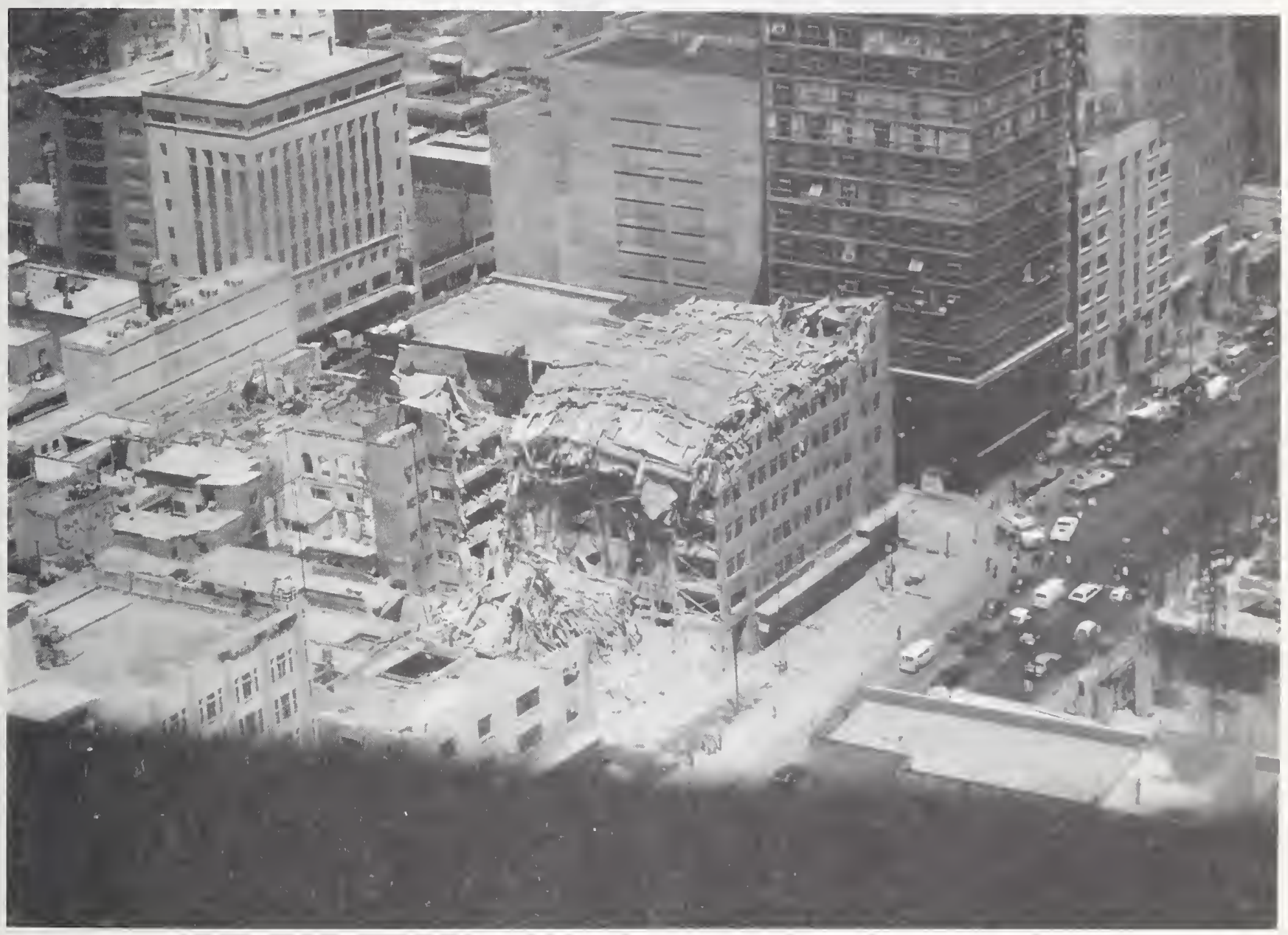

Figure 5.54. Aerial view of the Atlas Building, a typical steel frame structure constructed during the 1940's. 

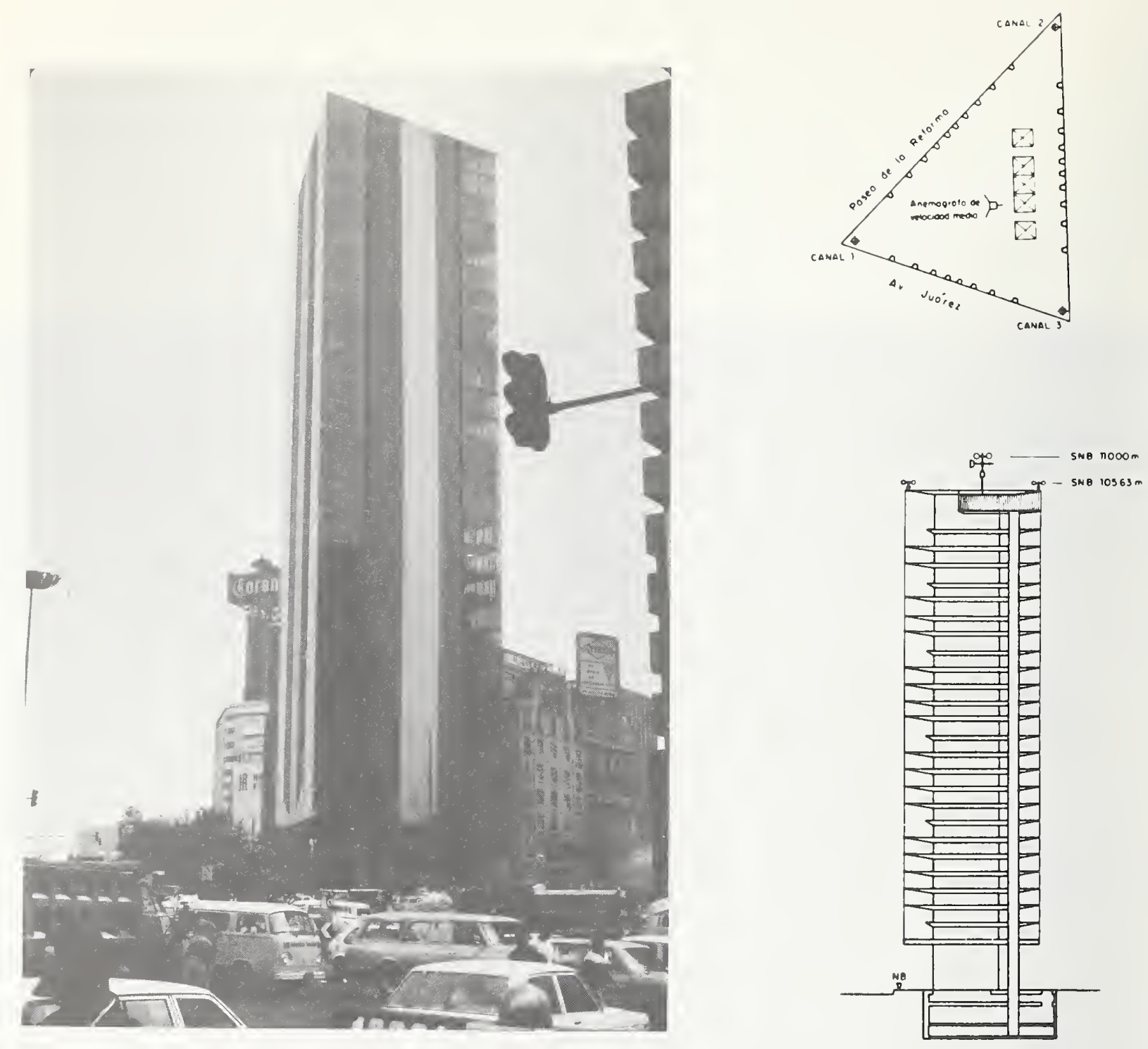

Figure 5.55. The 27 story triangular plan National Lottery Building performed well. 
the Pino Suarez Metro station beneath the complex may also have had a complicating effect on the dynamic response of the towers, since it created a more rigid foundation system, thus more efficiently transmitting earthquake energy into the towers.

Other steel frame structures performed quite differently from the Pino Suarez Buildings, depending on their location, elevation, and proximity to adjacent buildings. One such example is the Atlas Building (figure 5.54), a 14-story concrete-encased steel frame structure constructed during the 1940's and located just south of Alemeda Park on Avenida Lazaro Cardenas. During the 1957 quake this building suffered significant damage to moment-resisting knee braces (steel angles) and was later retrofitted with the diagonal cross bracing visible in figure 5.54 .

During the 1985 earthquake the upper seven stories of the building collapsed. The front of the adjacent seven story structure was also destroyed by falling debris from the Atlas building. In the case of the Atlas Building, field evidence indicated that pounding was the principal cause of collapse of the upper floors.

5.7.3 Tall Moment Resisting Steel Structures That Performed Well

High rise towers performed well during the september 19, 1985 event. Several examples of tall buildings include the Latin American Tower (43 stories), the Pemex Tower (54 stories), and the National Lottery Building (27 stories, figure 5.55), a triangular shaped structure 110 meters high with construction similar to that of the U.S. Steel Building in Pittsburgh.

The Torre Latino Americana (Latin American Tower) is undoubtedly the most famous steel structure in Mexico City (figure 5.56). The 1985 earthquake produced non-structural damage estimated at 


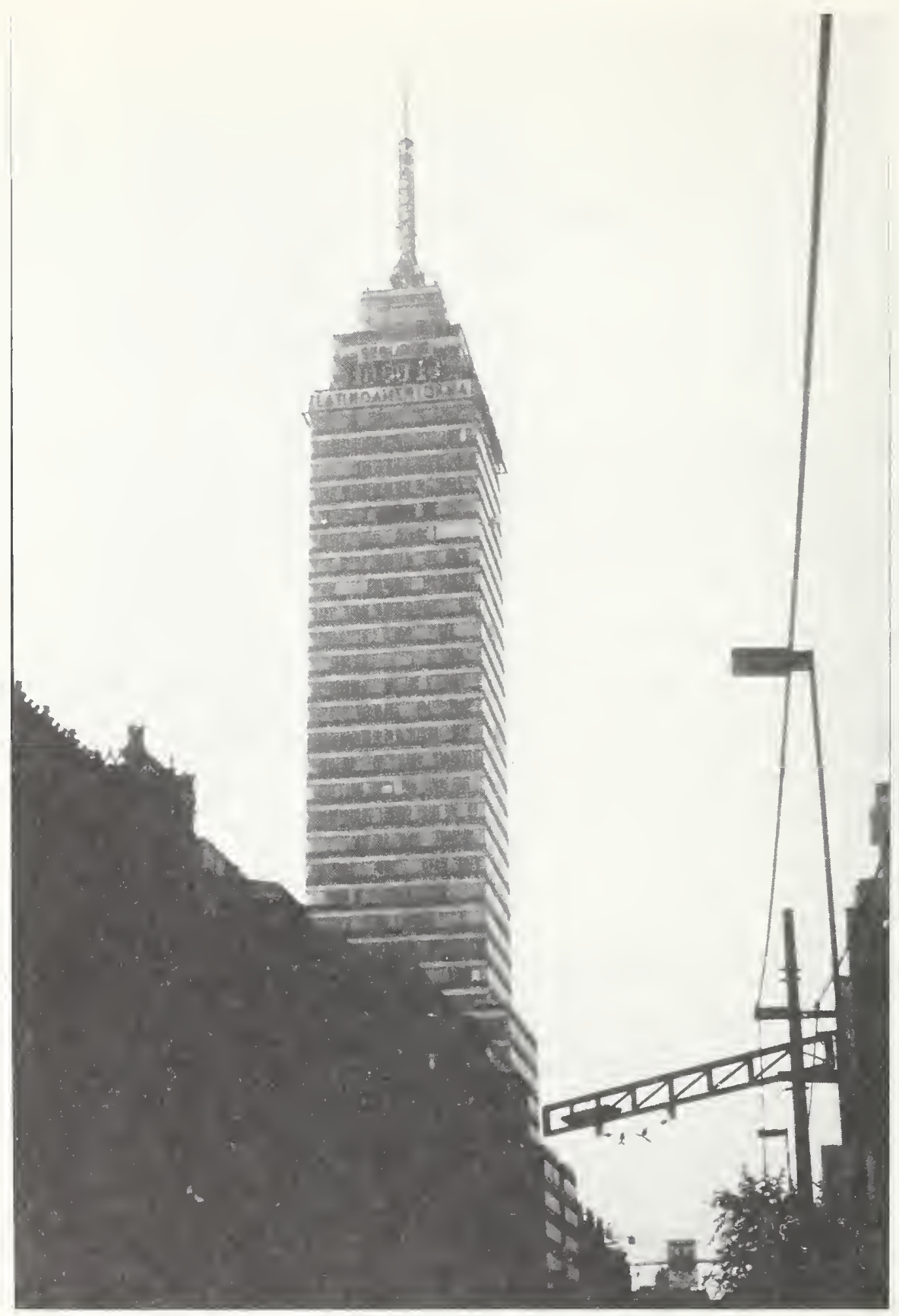

Figure 5.56. 43-story Torre Latino Americana, a steel frame structure constructed in the early 1950's. It was designed by Adolpho Zeevaert with consultations from N. Newmark and Leonardo Zeevaert. The structure survived the 1957, 1978, 1979 and the September 1985 earthquakes with minor nonstructural damage. 
\$5000. A visual and X-ray examination of the structural frame by the building engineers revealed no structural damage. The Torre Latino Americana is constructed from rolled structural shapes with lateral resistance being provided by riveted moment connections and composite floor beams.

The approximately five second natural period of the Torre Latino Americana placed it well outside the resonance period of the quake, and therefore outside the range of the most heavily damaged structures. The apparent lesson so clearly demonstrated by the performance of this structure (and other tall steel buildings in Central Mexico City) is the need to "detune" the structural system based on subsoil dynamic response characteristics for each specific construction site.

5.8 Building Configuration and Design Problems

\subsubsection{Building Separation (Hammering)}

(1) General Discussion

"Pounding" or Hammering" has been observed routinely by earthquake investigators over the past several decades. For example, in the 1972 Managua earthquake, the five story Gran Hotel suffered a complete collapse of its third story when the battering ram phenomenon occurred at the roof level of the adjacent two story building. [24]. In the Alaska 1964 earthquake, the fourteen story Anchorage Westward Hotel pounded against its low-rise ballroom and an adjoining six story wing, even though separated by a 4-inch gap [32].

The problem of two adjacent buildings or blocks of the same building pounding together during an earthquake is related to two basic issues: the width separating the two structures (or the width of a seismic "separation joint" if the buildings are 
architecturally connected to form one building), and the relative stiffnesses and vertical configuration of the two structural systems. Building codes address the separation problem in the form of required drift limits. For example, the 1985 uniform Building code [20] prohibits drift from exceeding $0.5 \%$ of the story height. In the case of a 16 story height, this drift would equal about 10 inches $(254 \mathrm{~mm})$. The 1976 Mexico City building code [19] permitted a value of $1 \%$. The proposed NEHRP provisions also permit 1\% [21]. Reference [35] mentions a Russian text as suggesting $1-1 / 4$ inches $(32 \mathrm{~mm})$ of separation for building heights of up to 16 feet $(4.9 \mathrm{~m})$ and $3 / 4$ inch $(19 \mathrm{~mm}$ ) additional separation for every 16 feet $(4.9 \mathrm{~m})$ above this.

Buildings sway during earthquakes. Adjacent buildings can sway out of phase -- first away from each other and then toward each other, each in its own natural period of vibration. This phenomenon is particularly pronounced where the difference in height between two adjacent structures is great and the duration of the earthquake is long... thus permitting each to reach maximum response (see computer model in figure 5.57). It is evident, therefore, that to prevent pounding, the clear space between buildings should be the sum of the individual maximum dynamic lateral deflections at a given story height. Whether or not this criterion is met by existing single-number code drift separation requirements (calculated as a percentage of building height) depends to a large extent on the ability of designers to predict actual deflections caused by an earthquake, taking into account the effect of inelastic excursions.

\section{(2) Separation Problems in Mexico City (1985)}

In more than 40 cases of heavily damaged buildings and in $15 \%$ of the damaged buildings examined (see table 4.1) there was evidence of pounding adjacent structures against one another. On some occasions the pounding caused only local damage in the structure 

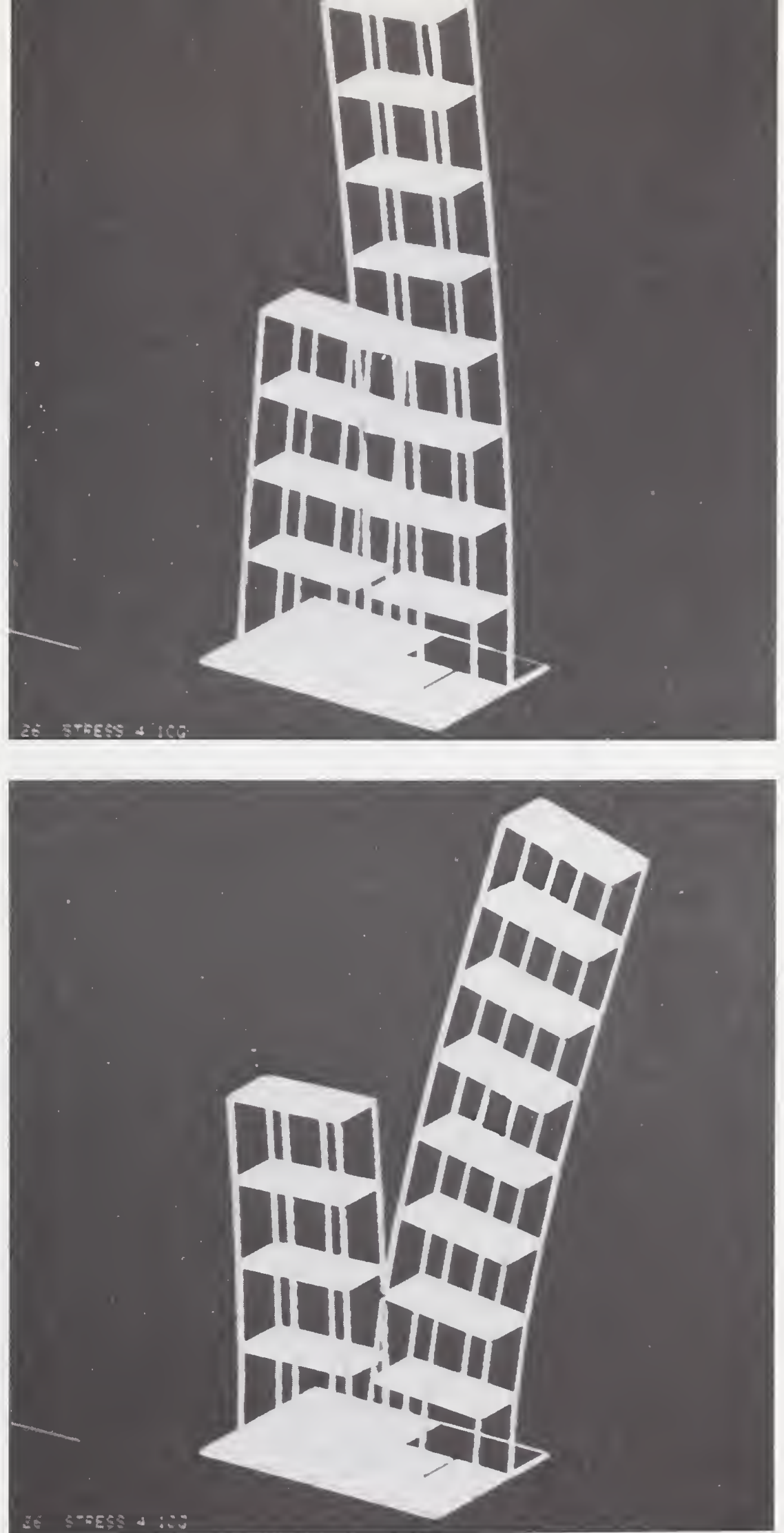

Figure 5.57. Computer simulation showing the pounding phenomenon when two buildings of unequal height vibrate out of phase. 
or in the cladding. However, there were several cases in which, due to non-alignment of story levels of adjacent buildings, the impact disabled the mid-story columns and was the primary cause of collapse. Pounding was responsible for many of the failures observed in upper stories as well. Building separations, in almost all instances, were less than that specified by the buildig code. The separation between adjacent buildings was commonly on the order of $10 \mathrm{~cm}$ which, according to building regulations, would be permitted for buildings of 10m (about 4 stories) or less height.

Figure 5.58 illustrates a typical example of the pounding phenomenon. A seven story office building (figure 5.58a) on Ave. 20 de Noviembre near the corner of Izazaga suffered a partial structural failure due to impact damage from the neighboring nine story building to the north (figure 5.58 b). A complicating problem in this particular case (and in many other buildings where pounding was observed) was the non-alignment floor level elevations between the two structures. This is effectively illustrated in figure 5.58 a where the second floor slab level of the southern building is seen to intersect the second story column of the northern structure at approximately mid-height, the worst possible situation for resisting lateral impact loads. Equally damaging shear loads were being imparted to the columns on the southern building eventually leading to the progressive collapse shown in figure $5.58 \mathrm{a}$.

In most cases, the building which collapsed during pounding was the taller structure. An example of such a collapse is illustrated in figure 5.59 where a nine floor clothing store at the corner of Ave. Jose Maria Izazaga and Isabel la Catolica impacted against its neighboring three story structure on the west. Figure $5.59 \mathrm{~b}$ shows that the separation between the two buildings was in the order of $10 \mathrm{~cm}$ and clearly insufficient to prevent contact when both buildings were vibrating out of phase. 


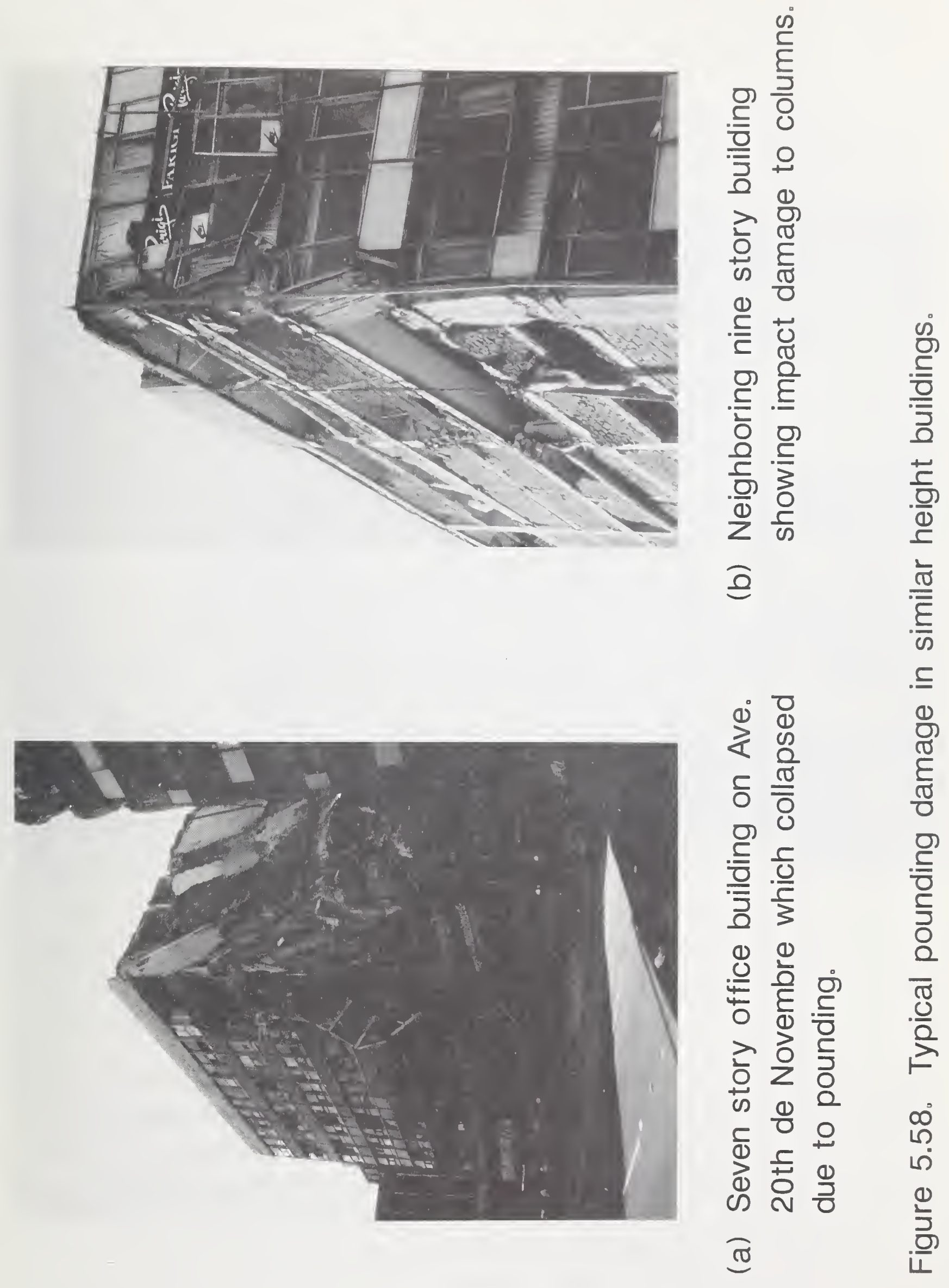




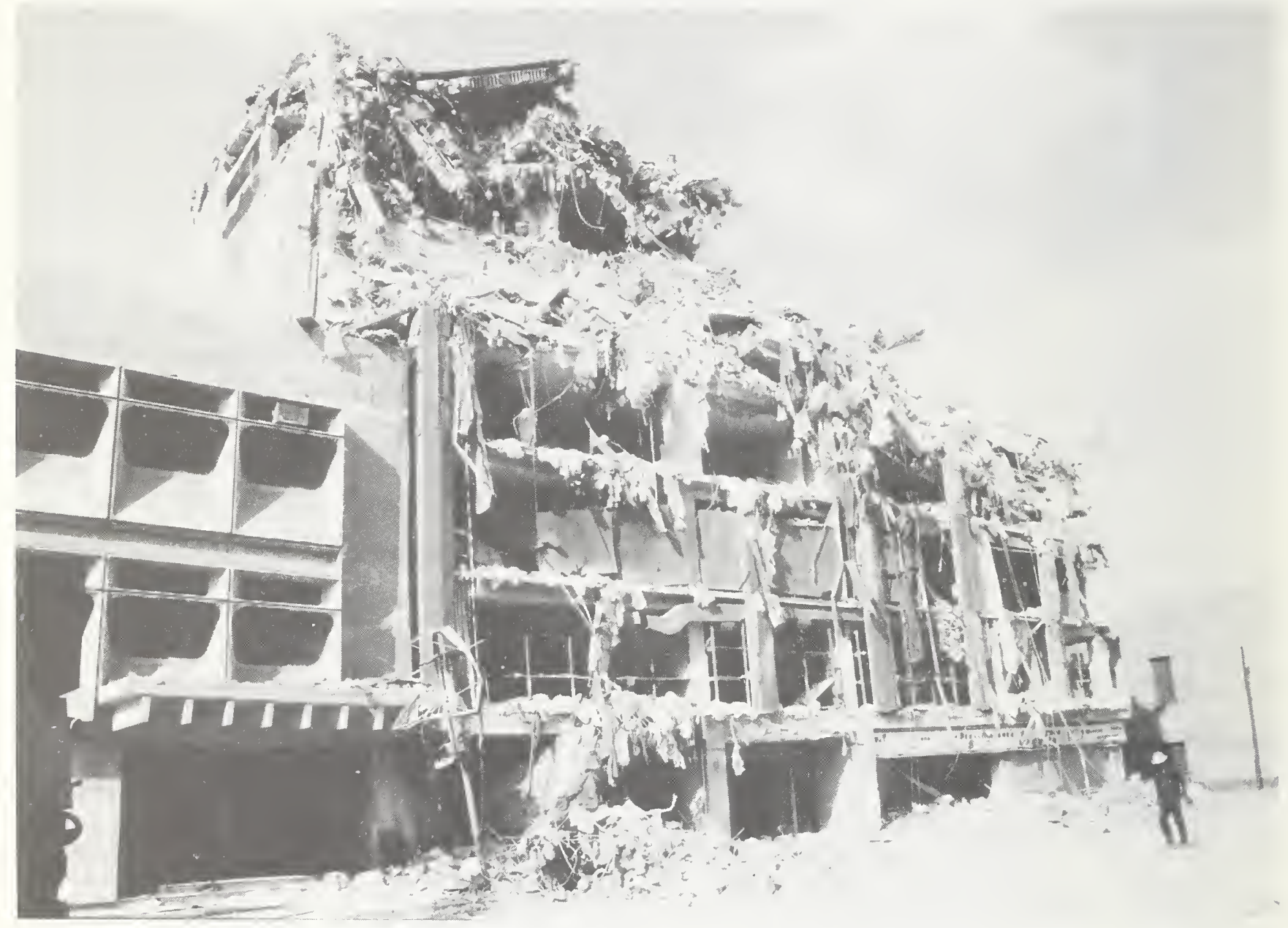

Figure 5.59. Pounding damage between buildings of dissimilar heights and stiffnesses. The upper floor of this 9floor clothing store collapsed following pounding with its much stiffer neighboring 3 -story structure. The separation between the structures was approximately $10 \mathrm{~cm}$. 
One variant on the pounding problem occurred where expansion joints existed within a structure and where it was possible for the separated substructures to vibrate independently, but where an insufficient "seismic gap" was provided to prevent pounding. An example of this type of failure was the Hotel continental on Avenida Reforma. The building was $\mathrm{V}$-shaped in plan, largely because of its street corner location, with two independent wings forming the "V" (see figure 5.60). The wing sections, each as tall as the main structure, apparently vibrated out of phase with the stiffer primary building and eventually suffered column failures due to pounding. This, in turn, led to the collapse shown in figure 5.61. Adequate separation between the wings of the building may have prevented such a failure.

\subsubsection{Torsional Effects}

If the center of mass of a structure does not coincide with its center of resistance the inertial loads imparted to the structure during an earthquake have a torsional component. Unfortunately this is often the case in actual structures because of lack of symmetry. It also can be induced by unsymmetrical arrangements of shear walls, lateral bracing or other horizontal-load resisting elements which may occur in corner buildings, first floor lobbies, or open areas facing a street. Torsion may also result from other causes, such as uneven load distribution, failure of structural members during an earthquake and differential foundation settlements.

Buildings that are either T-shaped, or L-shaped are unsymmetrical and create several problems: (1) Even if these buildings would act as one rigid unit, they would be subjected to large torsional moments. (2) Different portions of the buildings tend to have different rigidities. Stated differently, if either a $T$ or $L$ 


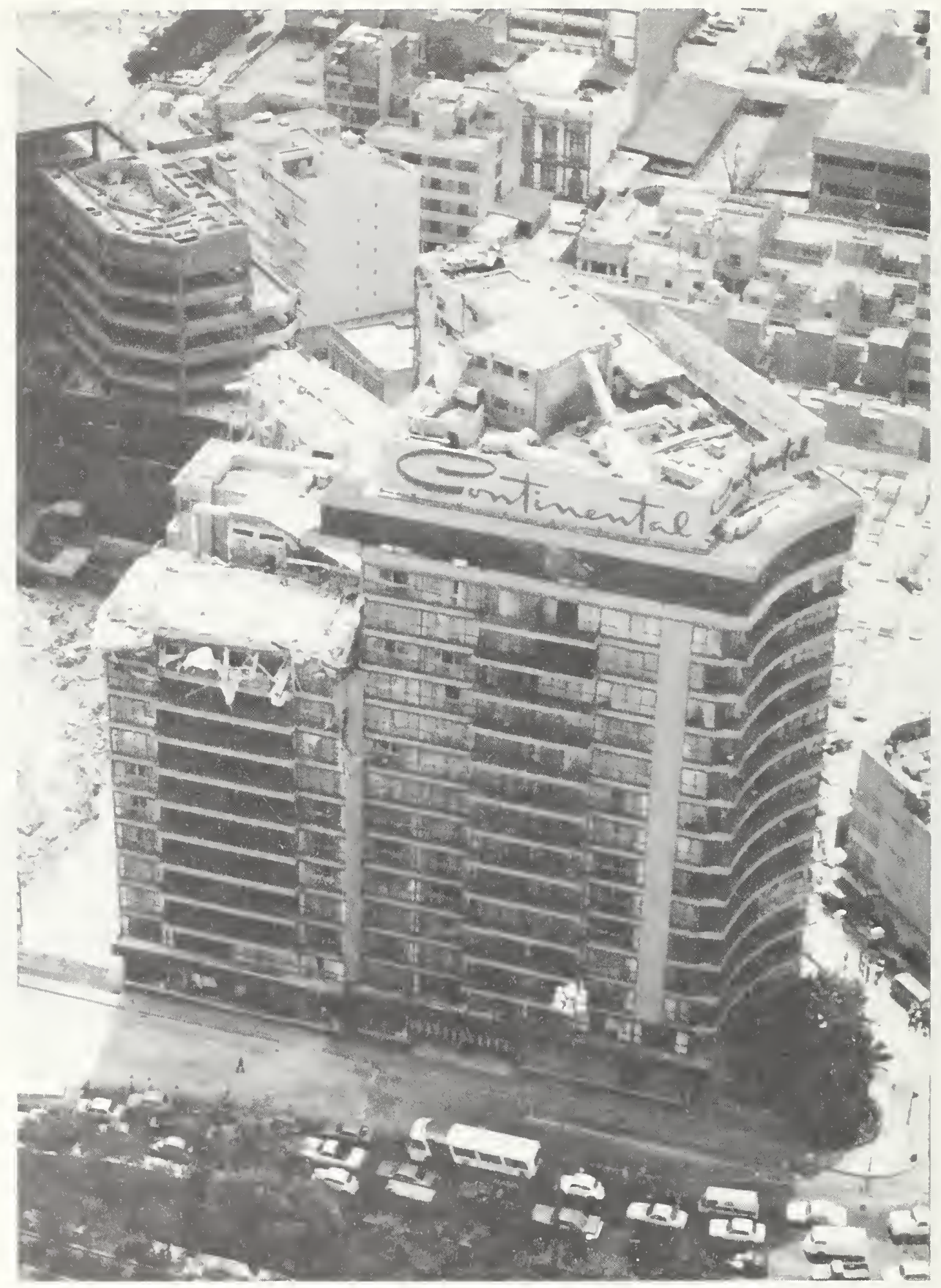

Figure 5.60. Aerial view showing " $V$ " shape of Continental Hotel on Paseo de la Reforma. 


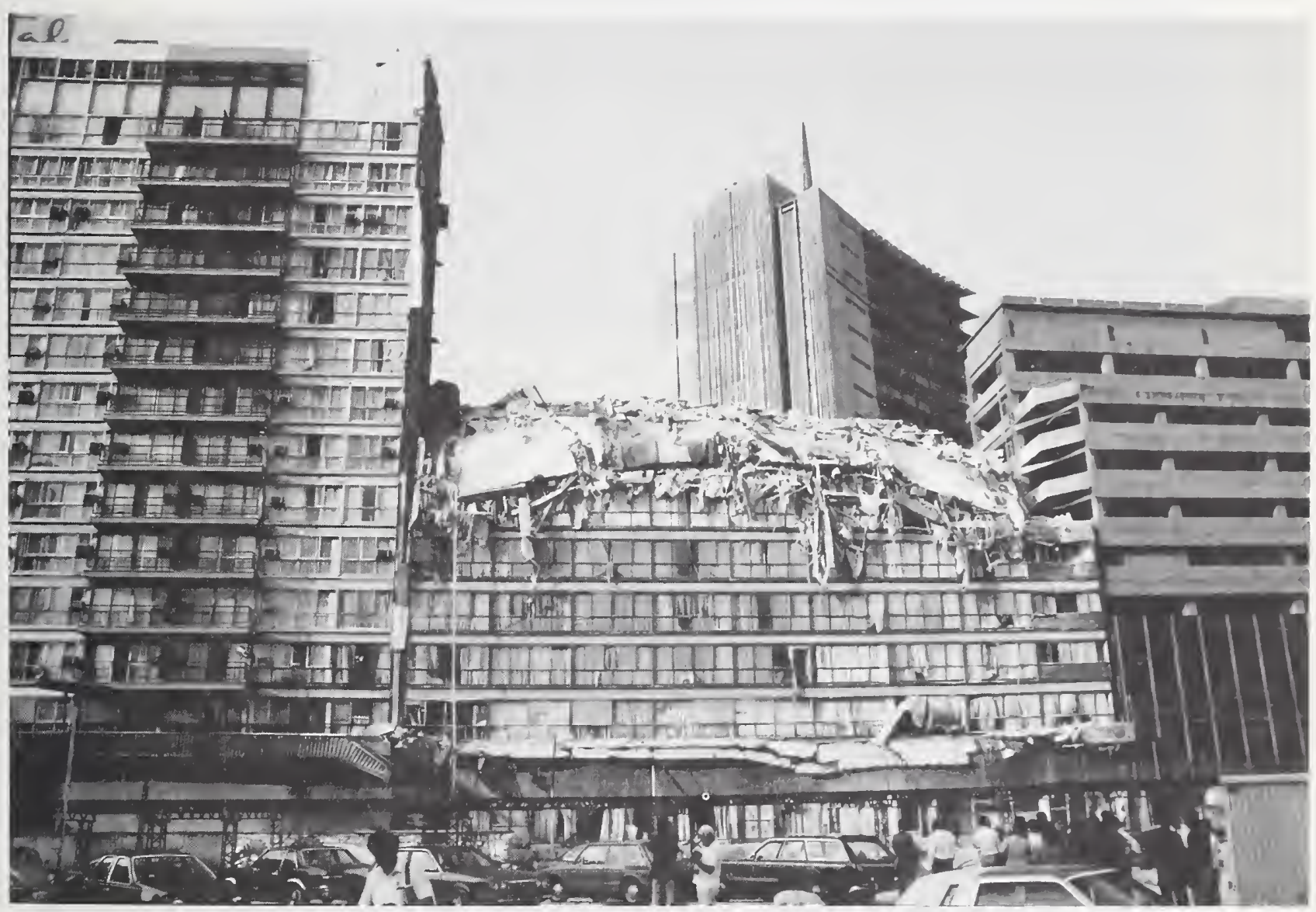

Figure 5.61. View looking north of collapsed southern wing of the Continental Hotel on Paseo de la Reforma. The entire complex was subsequently dynamited. 
shaped building were divided into symmetrical components each of the component structures would likely have vibrational modes which differ significantly from those of the others in any given direction. Combining these incompatible pieces into one structure produces large stress concentrations at the junction between the two parts of the building, and particularly at re-entrant corners.

An example in which building configuration appeared to have led to torsional response during the Mexico Earthquake is illustrated by the 12-story SCT (Secretaria de communicaciones y Telegrafos) complex (figure 5.62) on Ave. Lazaro Cardenas, approximately two kilometers south of the central historic portion of the city. The earthquake precipitated a progressive collapse which started near the top of the building at the inside northwest (re-entrant) corner as shown in figure 5.63. The collapse was probably triggered by failure of one of the upper columns (which are often of smaller cross-section and lighter-weight concrete in Mexico city) and then propagated by means of corner column failures along the north face of the west wing and the west face of the north wing of the $T$ as can be seen in figure 5.64. The resulting progressive slab collapse was arrested at the 8 th floor, where the 7th floor columns were sufficient to resist the impact load from the collapsing upper stories.

Because of the unusual geometry of the building (essentially a Tshape) and because of the asymetrical failure mode, a preliminary effort was made to understand the dynamic performance of the structure shortly after the NBS/USGS team returned to the United States in October 1985. A modal analysis was conduted on a simplified version of the building (as shown in the computergenerated image in figure 5.65), under the assumption that the complex could be modeled as a continuous $\mathrm{T}$-shaped structure. This analysis indicated that the fundamental mode of vibration for the SCT building was torsional. From this it was concluded 


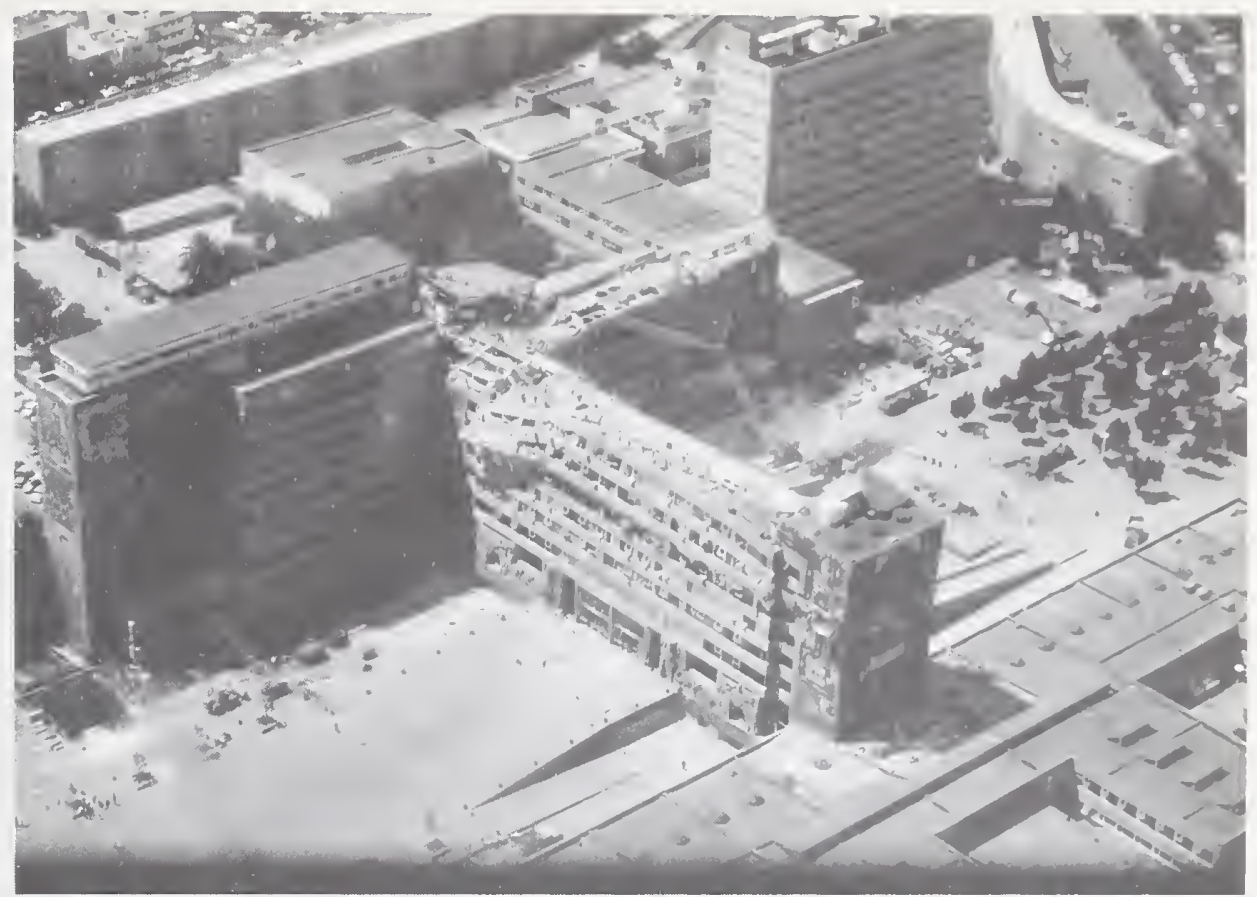

(a) Aerial view looking north.

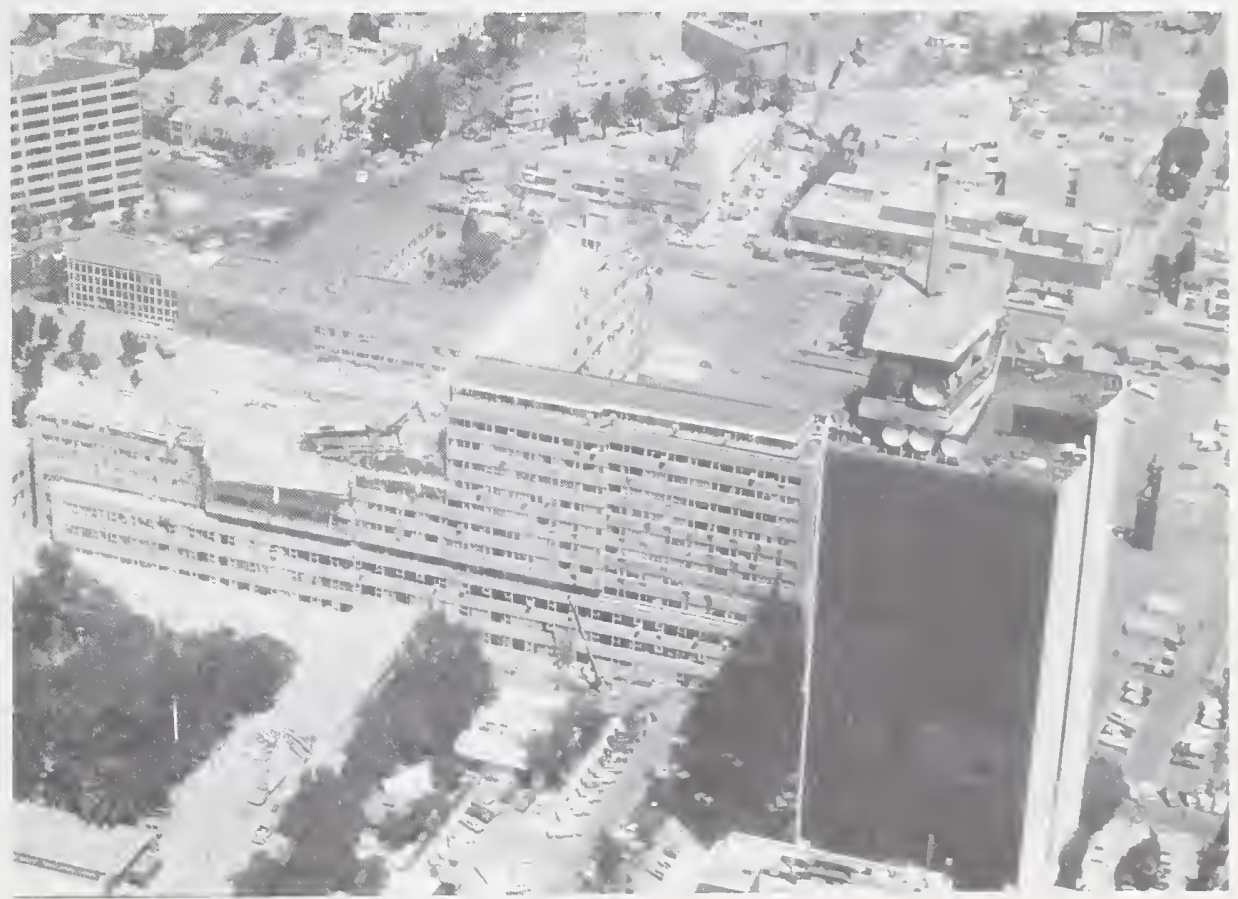

(b) Aerial view looking southwest.

Figure 5.62. Aerial view of SCT Communications Complex. 


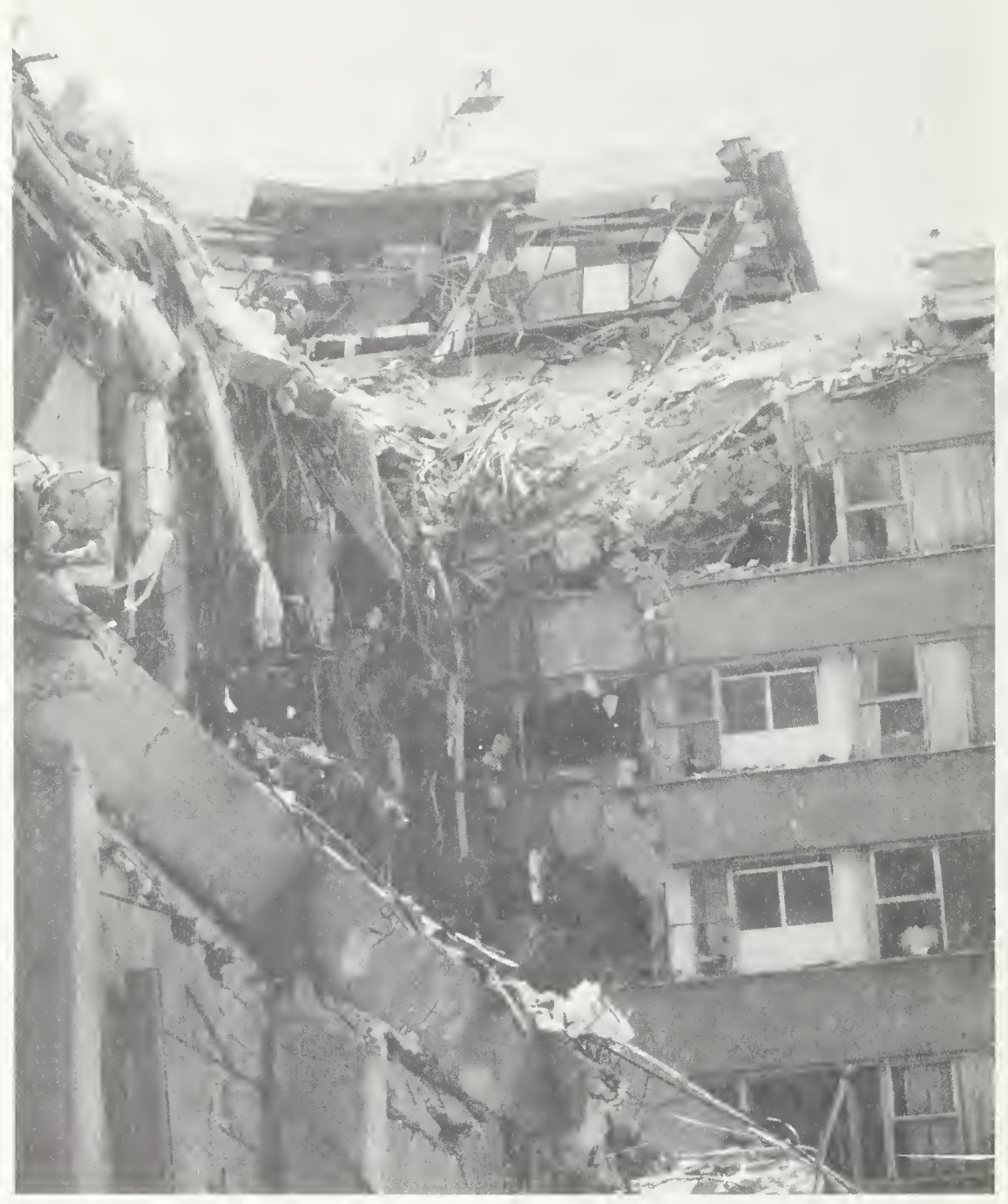

Figure 5.63. Northwest re-entrant corner of SCT Communications Building showing likely initiation point of collapse. 


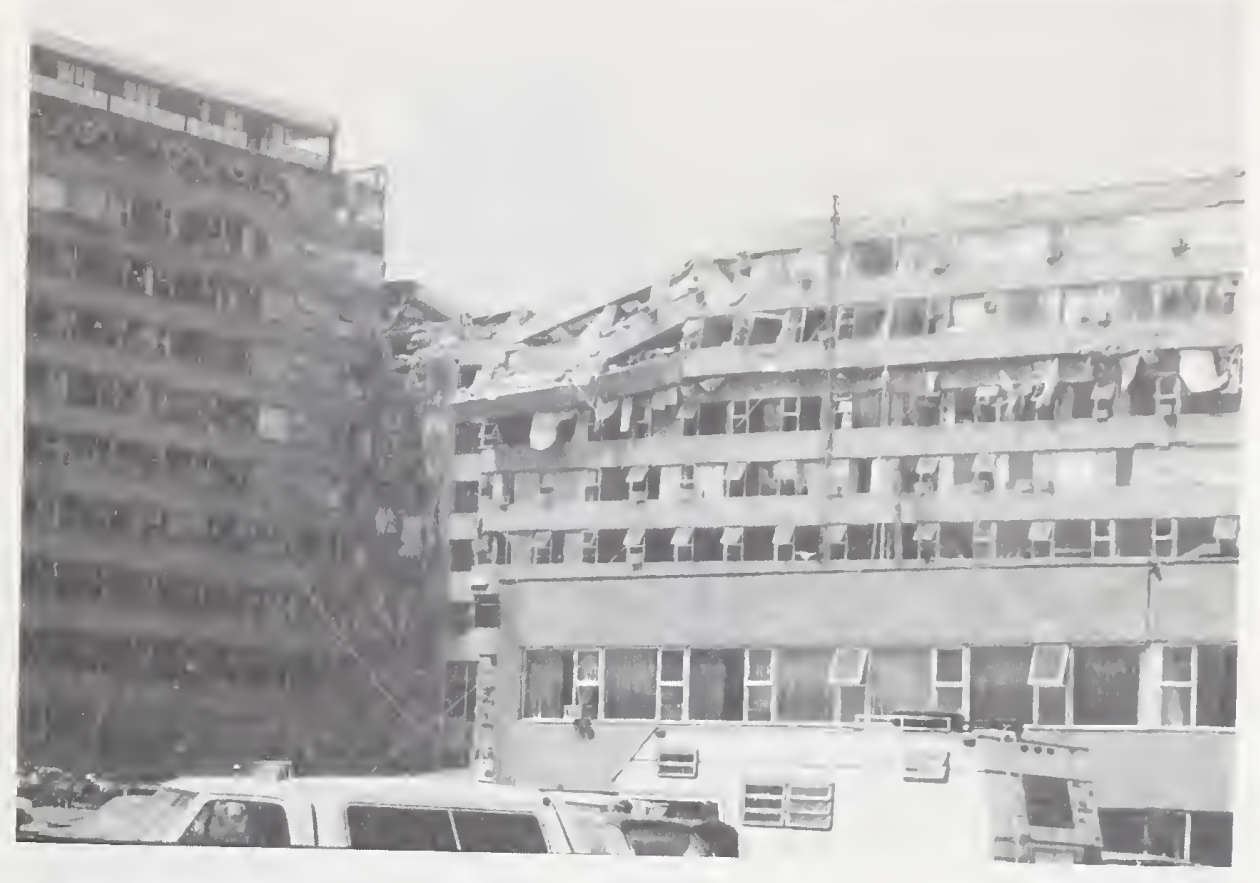

(a) East side of SCT Building.

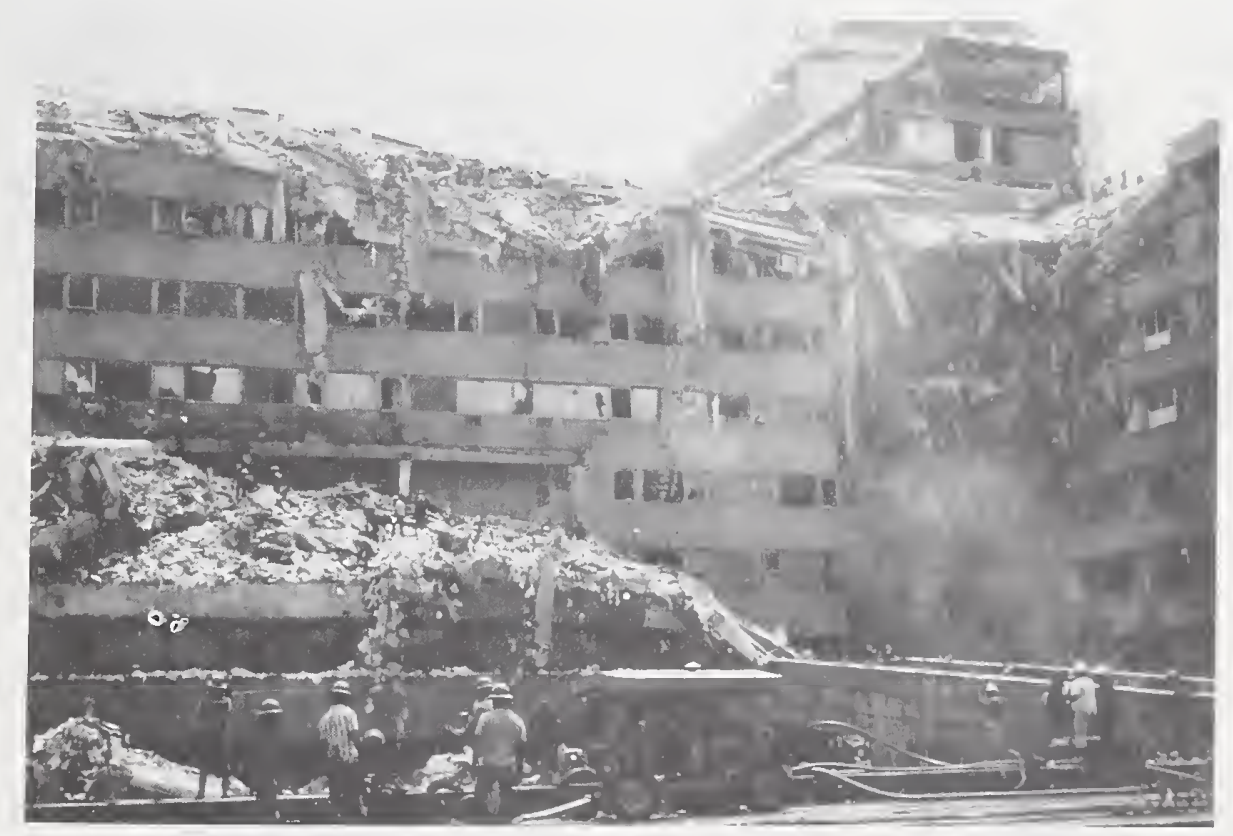

(b) West side of SCT Building.

Figure 5.64. SCT Communications Building showing extent of progressive collapse. 


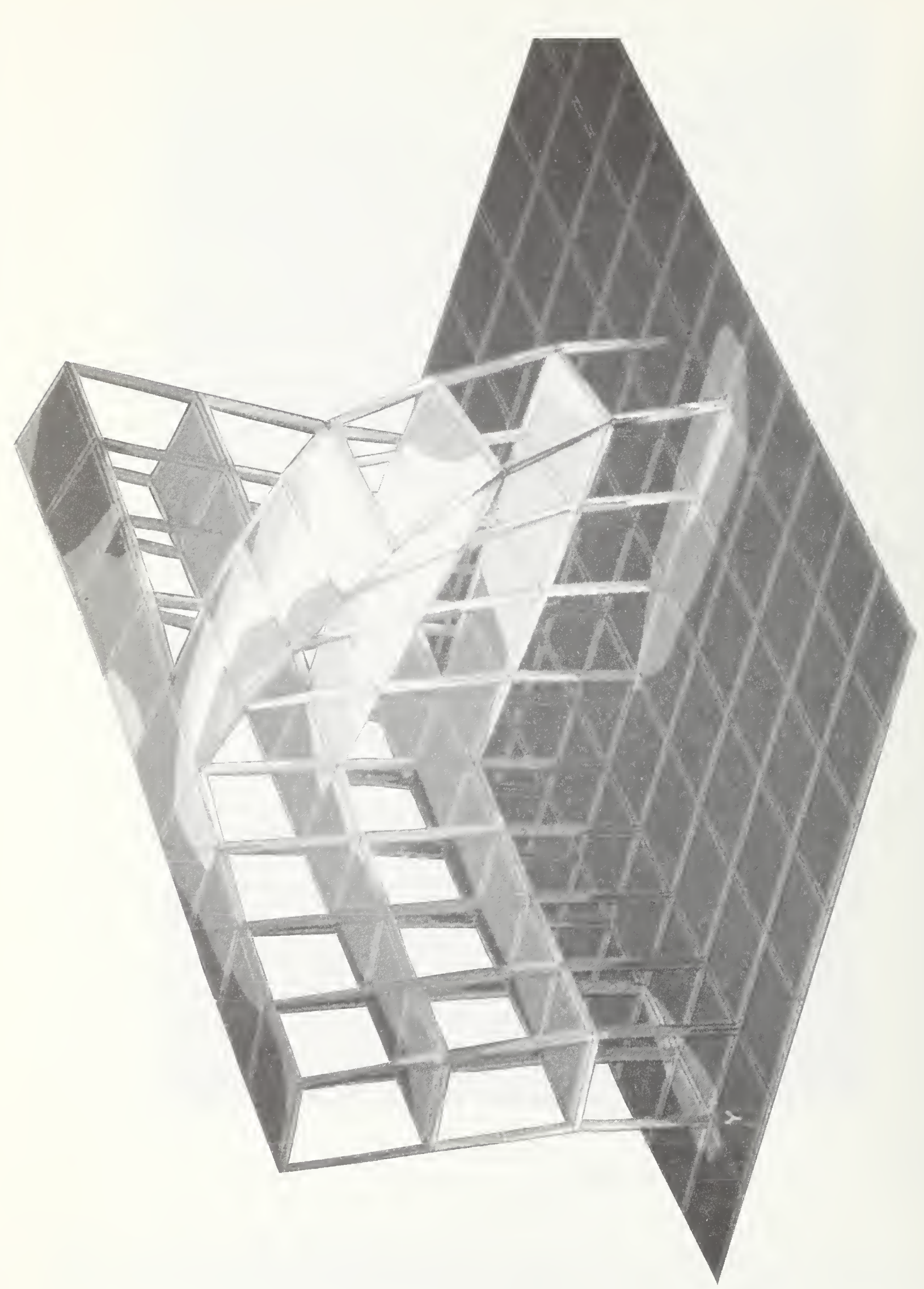

음

ڤ

की

()

음

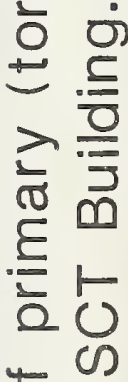

ㅇ

ป

(5)

E 0

丁 $\overline{0}$

응

ช

(1)

Qิ

㐫 है

है

ல

เก

10

는 믄 
that large shearing forces would have been generated at the reentrant corners leading to the initiation of the collapse.

Later discussions with Mexican engineers [36] indicated the presence of a vertical expansion joint between each of the wings, which partly explains why the damage did not progress into the eastern wing of the structure. This would have permitted independent vibration to take place in the various sections of the building leading inevitably to collisions between the various components (i.e., pounding). In either case, T-shaped section or construction joint with insufficient separation to prevent drift interaction, the brunt of the damage would have been sustained at the same junction location. The complex is undergoing renovation and the height was reduced to a uniform 5 stories as of september 1986. The nearby SCT tower sustained negligible damage and offices were in use shortly after the earthquake.

There are also examples of failures associated with asymmetry in structural stiffness, rather than shape. The first of these was alluded to in section 5.7.2 under the discussion of the dynamic mode shapes for the Pino suarez towers. Figure 5.51a indicates that the principal mode of vibration in the east-west direction (along the long axis of the structure) has a definite torsional component. The cause for this torsional response is the presence of the "V" and "X" bracing surrounding the stairwell and elevator shaft on the southern side of the structure. These braces, which have no symmetrical counterparts on the northern side of the buildings, serve to create an eccentricity between the center of rigidity and the center of mass causing torsional vibrations.

While it is clear that other complicating factors (local buckling) initiated the collapse of the Pino Suarez towers it seems likely that torsion was in large part responsible for the structural overload on the southern column line. 
If there is asymmetry in the arrangement of the perimeter walls of a building, the center of mass will not coincide with the center of resistance, and torsional forces will tend to cause the building to rotate around the center of resistance. This is particularly acute in corner buildings -- such as shops, offices etc. Which have shear walls on the interior edges and curtain walls or glass on the street sides. When shaken by an earthquake, the rear and side walls are quite rigid but the front wall is very flexible, and as a result the upper part of the building tends to rotate [24]. Columns in the front walls of the ground floor are highly stressed because they resist torsional shear in addition to the normal deflection loads and shears. The rotational motion of the building also induces stresses in the columns and shearwalls at higher floor levels where they may not have been anticipated in the design. Sometimes these stresses are in part the result of pounding of adjacent structures.

During the Mexico City earthquake a great number of corner buildings failed. (42\% of the total -- see table 4.1). For the most part these collapses can be attributed to the torsional effects just mentioned. Even though the lower floor columns are highly stressed in such a situation, failure of these columns was a relatively rare event. More generally, failure was initiated in the upper stories of the building and propagated downward until the collapse was arrested, usually several floors above street level. An example of such a failure is the building shown in figure 5.66, which is located just south of Alemeda park near the Torre Latino Americana. In such situations two additional characteristics were usually present: thinner columns in the upper floors (a practice permitted by the code), and generally very small separation gaps between adjacent buildings (a practice not permitted by the code). When such a corner structure is excited by earthquake motion, lateral displacements caused by its torsional response are greatest in the top story and, in most cases, this was apparently sufficient to permit pounding to 


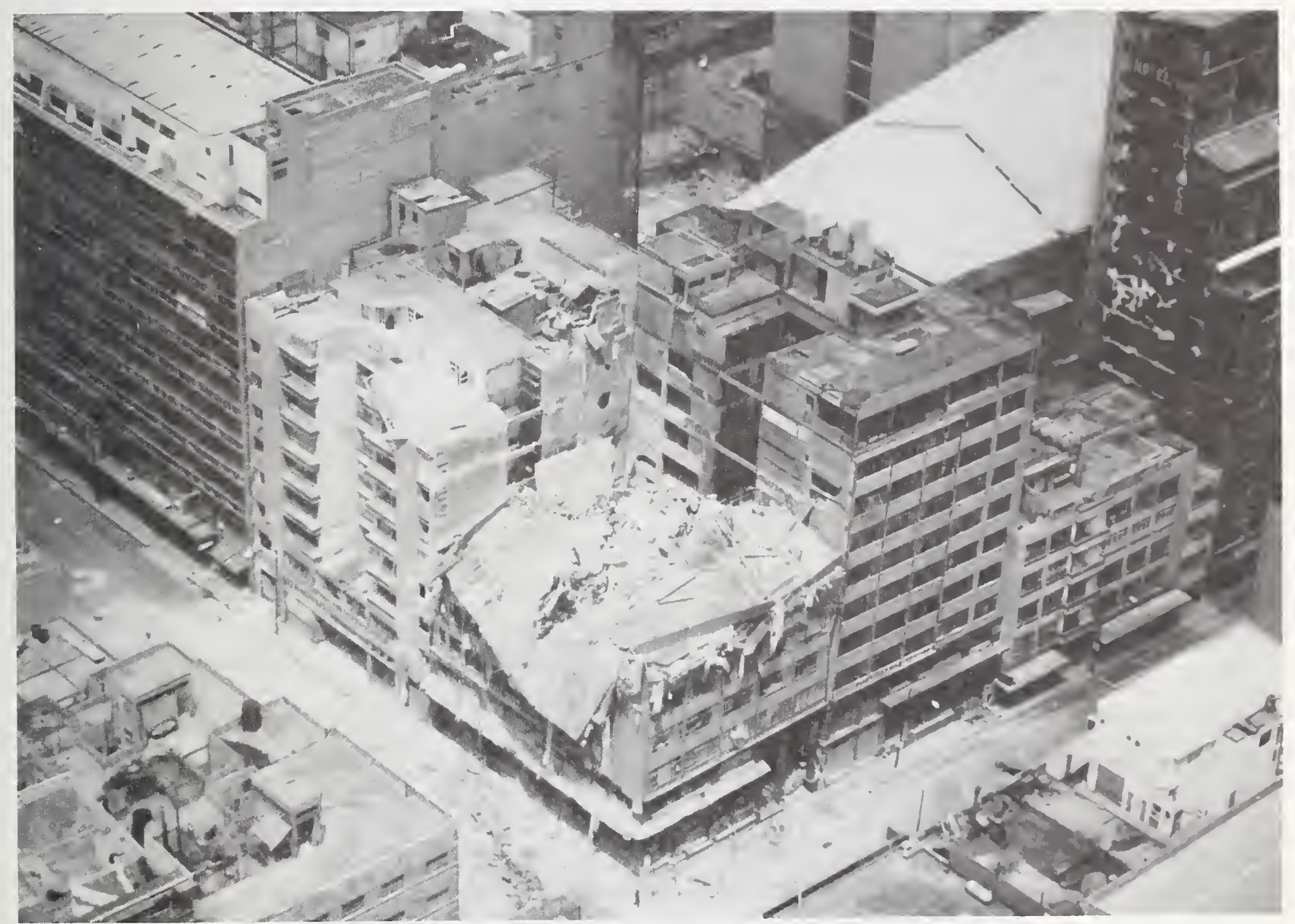

Figure 5.66. Torsionally induced pounding in corner building south of Alameda Park, near Torre Latino Americana. 
occur with adjacent structures. At this point one of two possibilities existed, depending on the relative stiffnesses of the impacting structures: either the building undergoing torsion sustained a failure in one or more of its upper level columns and a progressive collapse ensued to a level where the column size was sufficiently large to resist the load, or the adjacent structure underwent a similar fate. In either event, such undesirable response characteristics could be mitigated by enforcing adequate separation gaps and by stiffening the portal frames for the open first floors of the corner buildings to provide coincidence between the center of mass and the center of rigidity.

\subsubsection{Upper Story Collapses}

Lateral forces that a building must resist during an earthquake are greatest near the base of a structure. It is thus somewhat surprising that the third largest category of structural collapses listed in Table 4.1 was that of failures in the upper stories of buildings. In many cases observed during the field investigation (as for example the structures shown in figure 5.67), pounding was not a factor since there were no adjacent strutures. This left only two likely reasons for the ubiquitous nature of this failure mode. The first is the apparently common practice of reducing column dimensions with story height in an effort to save on material costs (which in Mexico are of greater concern than labor costs). This practice is clearly demonstrated in figures 5.68 and 5.69 which show the upper story collapse initiating at the point of a general change (reduction) in column stiffness. In the case of the building shown in figure 5.68 (the eight story LACSA Building on the corner of Reforma and Marne streets) the upper two story steel-framed penthouse was a later addition to the lower six story concrete frame. Figure 5.68 a indicates that most of the damage was confined to the penthouse. 


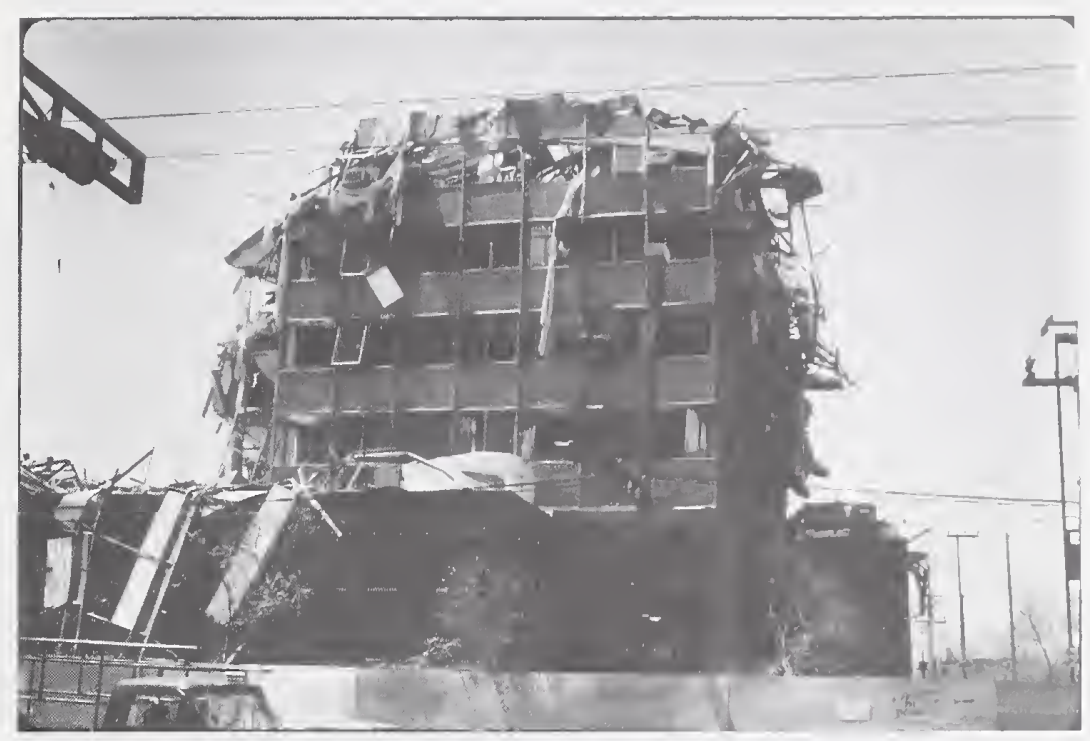

(a) Upper story failure in office building on Ave. Lazaro Cardenas.

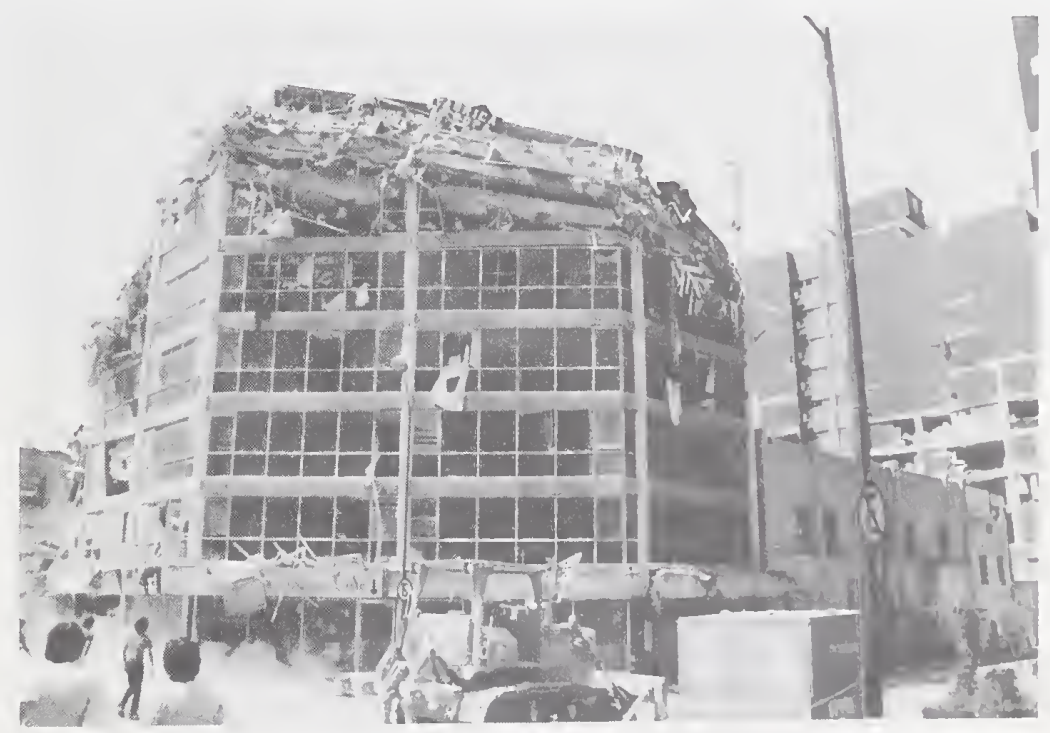

(b) Upper story failure in clothing store.

Figure 5.67. Typical upper story failures in building where pounding did not occur. 

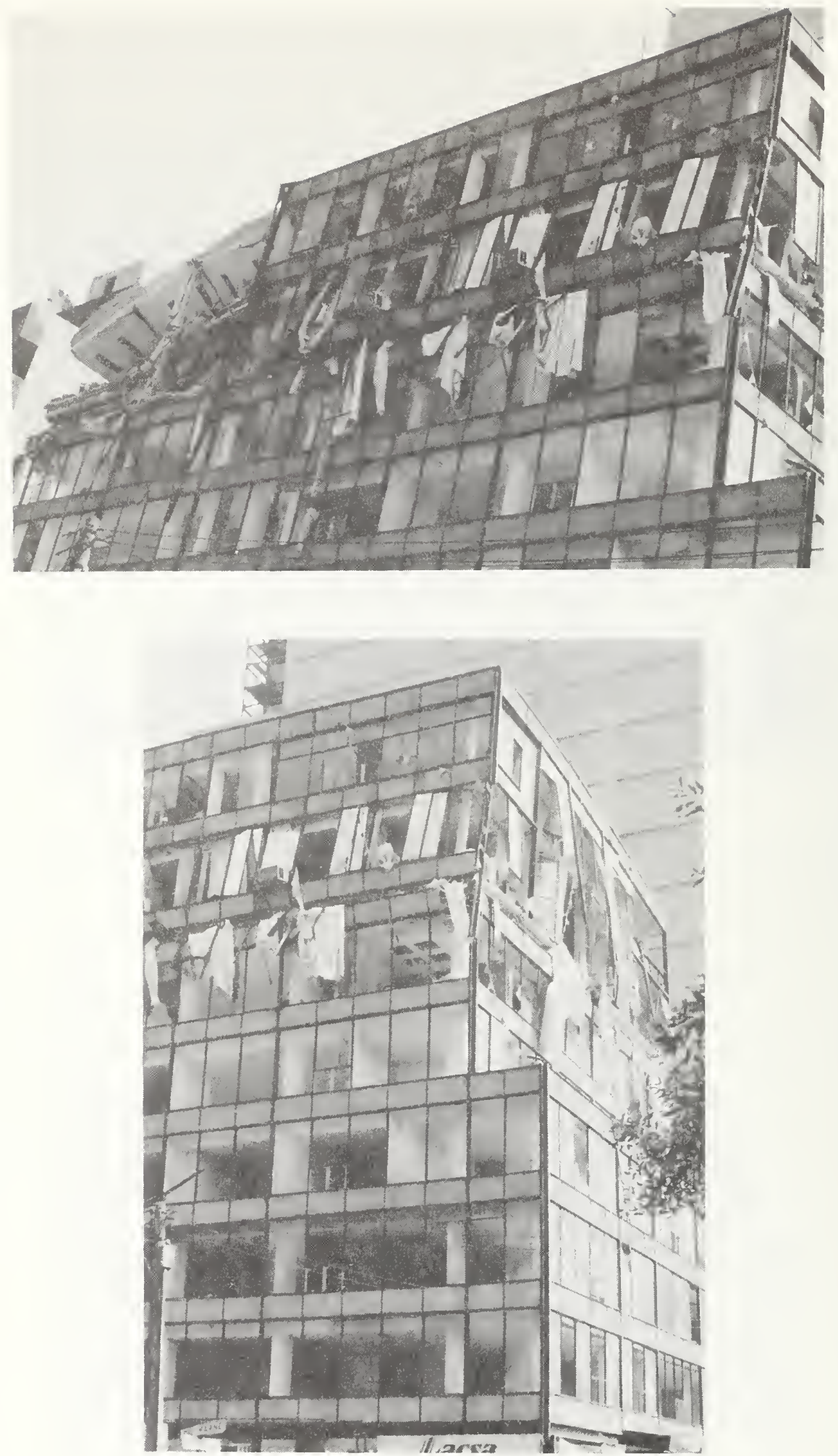

Figure 5.68. LASCA Building on Paseo de la Reforma and Marne, showing large change in column stiffness in upper two floor penthouse. 


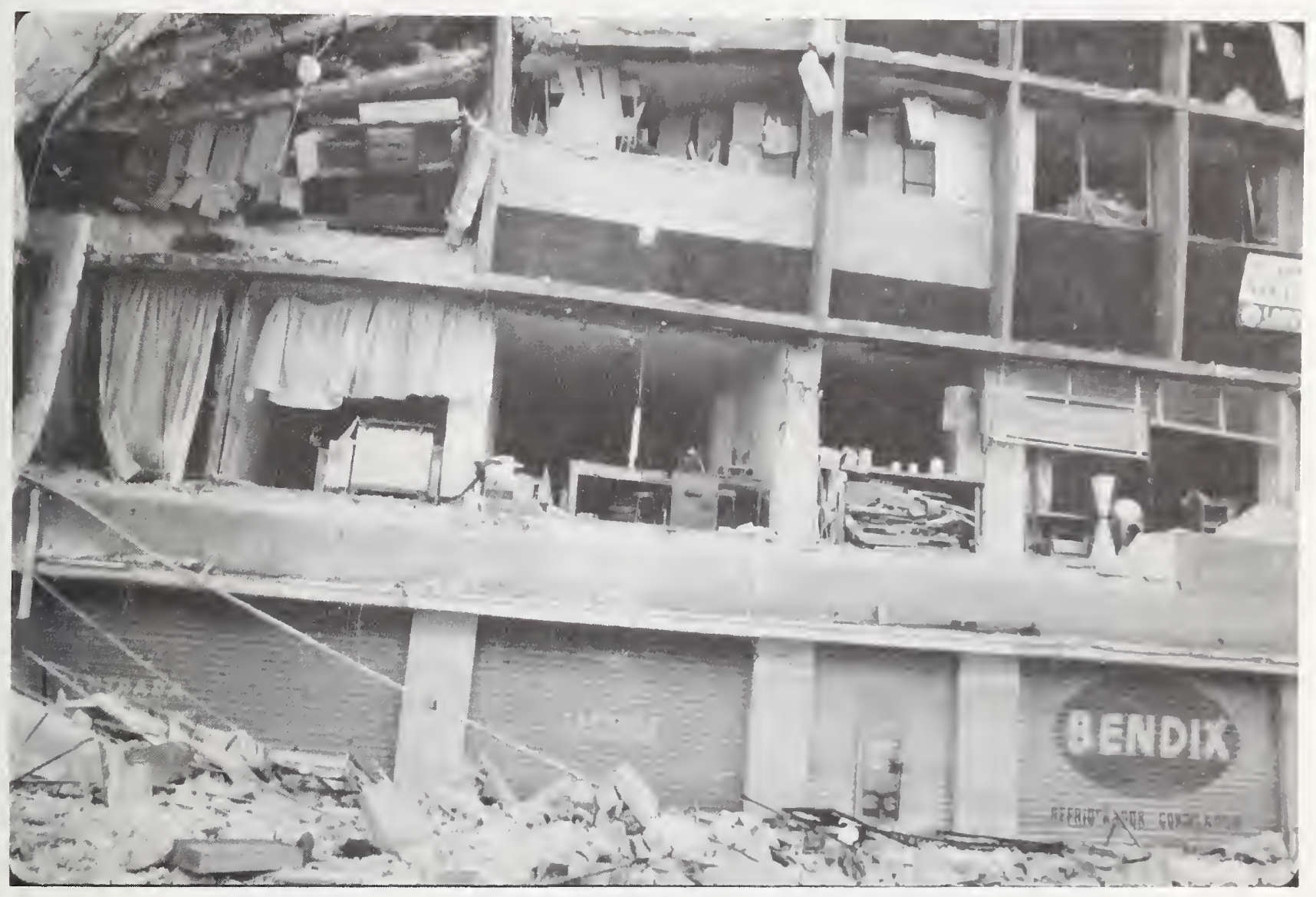

Figure 5.69. Commercial building showing large changes in column stiffness in upper stories. 
The tendency to make room for additional office space by constructing "add-on" upper floors is common practice throughout Mexico, particularly where land is at a premium in urban centers. Because of the desirable nature of the lower stories for office space and living quarters, the add-on upper stories are often used to store merchandise or archival records, especially in the case of federal government buildings.

\subsection{Masonry Structures}

Some of the most effective "survivors" in terms of structural performance during the 1985 earthquake were the historic stone masonry churches and colonial office buildings (see figure 5.70). These buildings have withstood numerous previous earthquakes. In terms of structural behavior the endurance of these buildings may be attributable primarily to their exceptional stiffness. Since the height of these buildings is limited, these structures in general have short fundamental periods of vibration. Therefore, in the lakebed of Mexico city, these structures were out of the range of the spectral peaks of the earthquakes. Furthermore, over the years, powerful earthquakes removed the less earthquake resistant structures.

There are few modern buildings in Mexico City which employed reinforced masonry, as is commonly used in other parts of the world. Low rise, unreinforced masonry construction is very common for houses, apartments, and commercial buildings. The most general use of masonry in Mexico City, however, is for unreinforced infill walls for high rise frame structures (figure 5.71). While a number of medium and high rise buildings did suffer infill wall damage (figure 5.72), infill walls generally had a beneficial effect on structural performance [27]. This was accomplished by increasing the structure's lateral stiffness and thus reducing its fundamental period of vibration, and by providing or augmenting lateral-load resistance. Both of these 

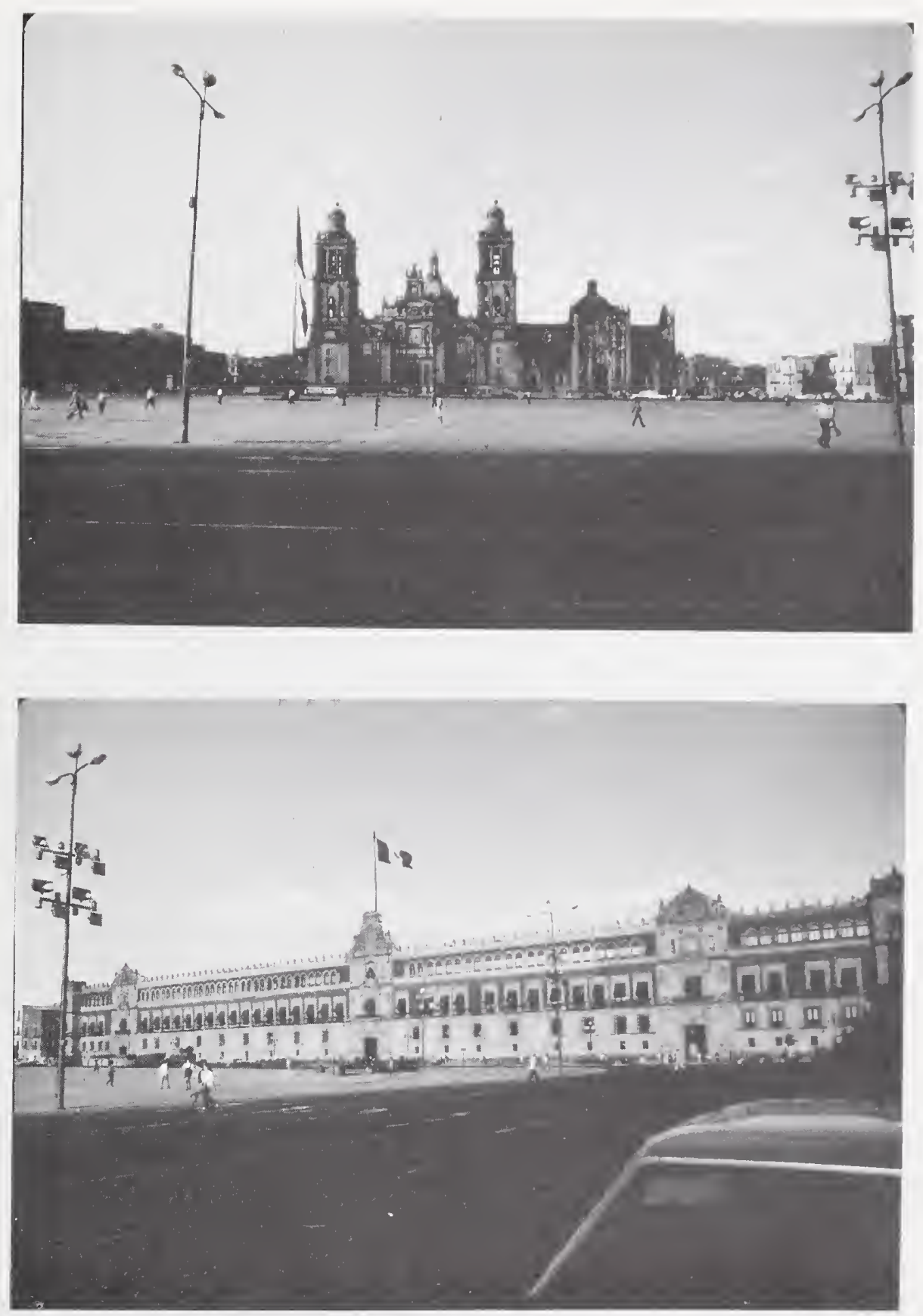

Figure 5.70. Colonial stone masonry structures (National Palace and Cathedral) have short natural periods of vibration and performed well in the earthquake. 


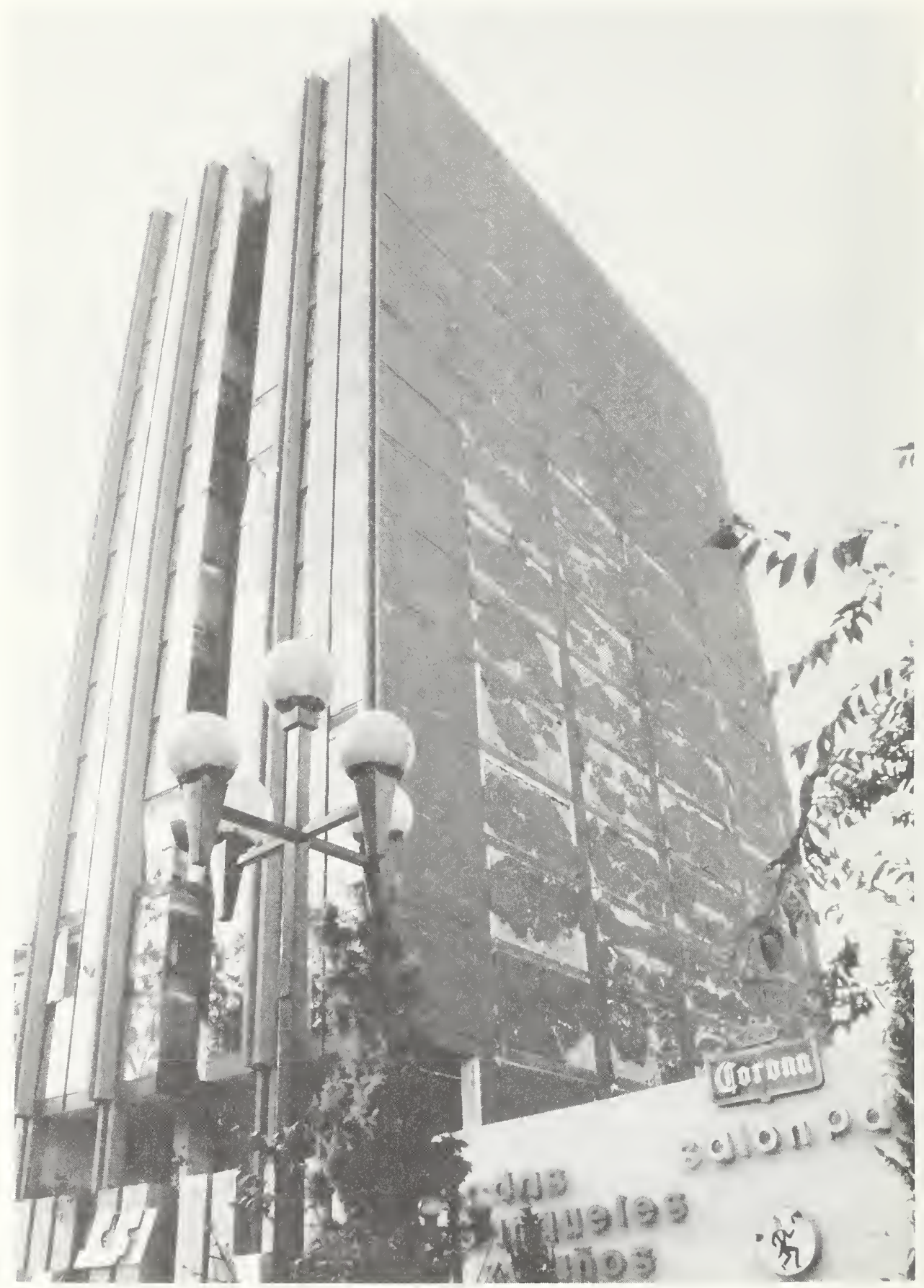

Figure 5.71. Typical high-rise reinforced concrete building with masonry infill walls. 


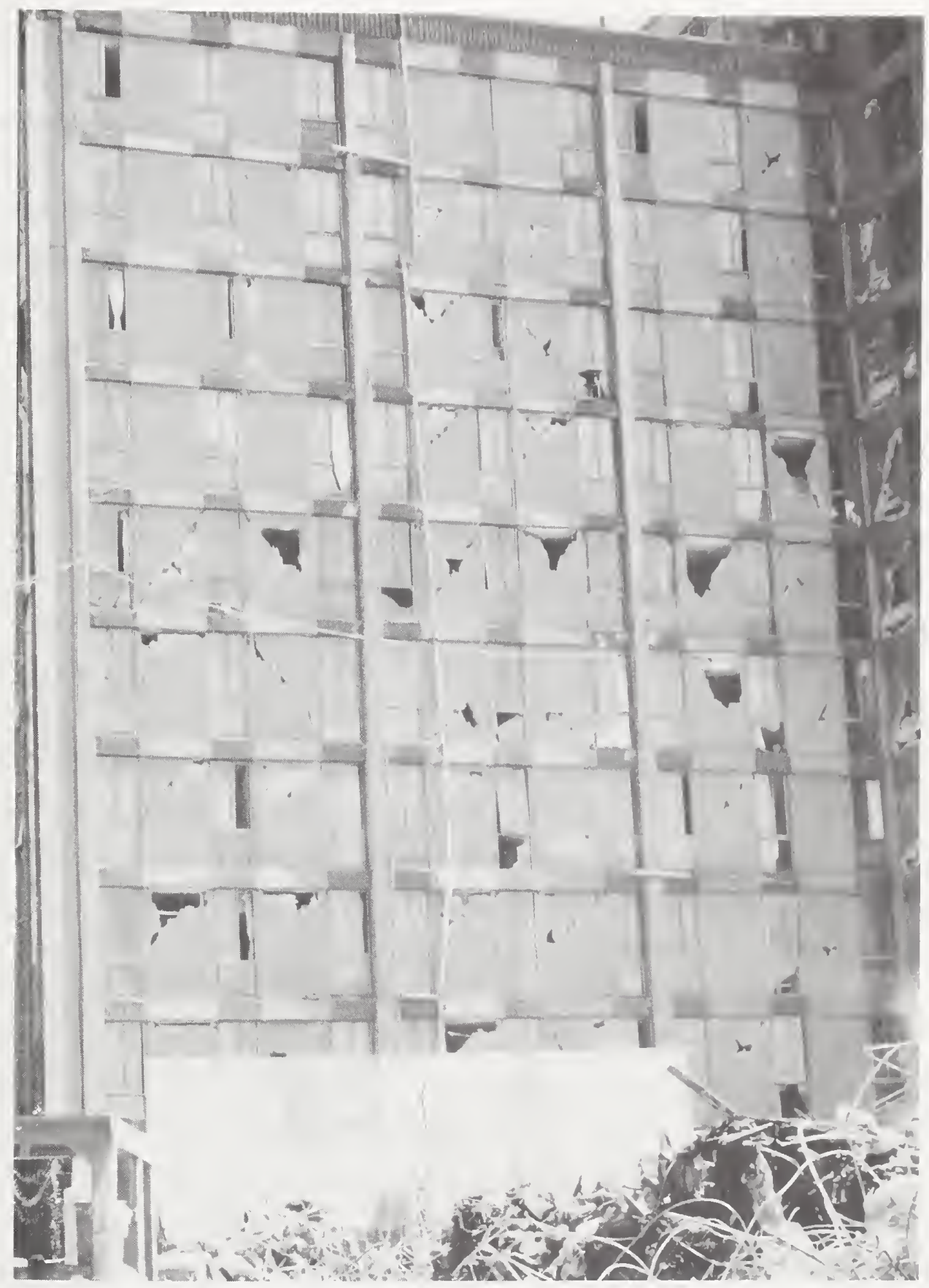

Figure 5.72. Significant diagonal shear cracking in a masonry infill structure on Ave. T. de Mier. Enough energy was dissipated in the walls to prevent collapse of the building. 
effects served to improve performance under earthquake loading. stiffening of structures was an advantage in Mexico City primarily due to the unusual soil conditions which produce ground motions with periods considerably longer than those experienced in most urban centers around the world. In those areas where relatively firm subsoil conditions exist, such stiffening could actually increase the lateral loads.

Certain types of reinforced concrete braced frames also made use of masonry infill, as shown in figure 5.3. These were typically employed in structures ranging from 7 to 12 stories and consisted of reinforced concrete "X" braces with brick infill. They were apparently very effective at resisting lateral loads, and no out-of-plane infill wall failures were observed with this type of bracing. One notable structure which used this system was the Nuevo Leon building described previously in section 5.5.2. Figure 5.32 shows a typical placement pattern for the $\mathrm{x}$-bracing in the remaining unit of the Nuevo Leon building. Failure in that particular building was surmised to have been initiated at the lobby-level crushing of the eastern column line, rather than by any localized failure on the part of the infill walls. 


\section{FINDINGS}

The september 19, 1985 Mexico City Earthquake provided a great deal of information in the areas of seismology, the effect of subsurface conditions on ground motions, the protection provided by existing and proposed design provisions and the performance of structures and foundations. It confirmed the effectiveness of some of the current practices in earthquake engineering and the validity of the underlying hypotheses, while giving us cause to question others. In terms of loss of human life, this was a devastating event, and one which the authors, who visited many sites where victims still lay trapped in the rubble, will not forget. It will always remind earthquake engineers of the importance of the efforts to further and perfect the state of the art in earthquake resistant design.

Earthquake origin and Characteristics

The earthquake originated in the state of Michoacan, about $400 \mathrm{~km}$ to the east of Mexico City, and occurred as a result of the subduction of the cocos plate beneath the North American plate. It ruptured much of the Michoacan gap, providing further confirmation of the validity of the hypothesis that major earthquakes can be predicted by identifying seismic gaps. The earthquake was well documented by the Guerrero array of instruments which was installed in anticipation of a major seismic event in one of two seismic gaps identified in the area. The primary earthquake had a Richter magnitude $\mathrm{M}_{\mathrm{S}}=8.1$ and a focal depth of approximately $18 \mathrm{~km}$. An aftershock of $\mathrm{M}_{\mathrm{S}}=7.5$ occurred a day and a half later.

Ground Motion Characteristics in Mexico City

A record from the area of deep lake deposits where most of the structural damage occurred indicates that the strong motion had a 
duration of approximately 60 seconds, and peak accelerations of 168 gal $\left(1 \mathrm{gal}=1 \mathrm{~cm} / \mathrm{s}^{2}=1.025 \times 10^{-3} \mathrm{G}\right)$ in the east-west direction, 98 gal in the north-south direction and 36 gal vertically. The resultant peak acceleration was calculated as 198 gal in the south $60^{\circ}$ east direction. There were 16 cycles of more than $1 / 2$ the peak acceleration in the east-west direction. Maximum velocities and displacements in the east-west direction were 61 $\mathrm{cm} / \mathrm{s}$ and $21 \mathrm{~cm}$, respectively. The ground motion had a dominant period of $2 \mathrm{~s}$ and was nearly sinusoidal. Longer dominant periods (up to $4 \mathrm{~s}$ ), and longer durations of strong motion, (in excess of $160 \mathrm{~s}$ ) but lower peak accelerations were recorded in areas of deeper and less consolidated lake bed deposits. Much lower peak accelerations (of the order of $40 \mathrm{gal}$ or less) were recorded in the foothill zone of Mexico City where soil deposits are shallow. From a record of the subsurface deposits underlying the lake bed region of the city it is estimated that the ground motion in the most damaged area had dominant periods ranging from 1.9 to $2.8 \mathrm{~s}$.

Effect of Subsurface Conditions on Ground Motion

Part of the area of Mexico City is located in the bed of Lake Texcoco which was drained after the spanish occupation and is underlain by deep deposits of soft clays and silts. Other parts are located in the foothill zone where there are shallow soil deposits over volcanic rock, and there is a transition zone between the lake bed region and the foothill zone. These variations in subsurface conditions account for the great differences between the ground motions recorded in different parts of the city and the resulting differences in earthquake damage. It has been shown that in the lake bed region the ground motion transmitted through the underlying bedrock was amplified by as much as a factor of 5 or more. The great amplification of the ground motion in the part of the lake bed region which has a fundamental site period of vibration close to 2 seconds is 
attributed to the frequency content of the strong motion of the underlying bedrock. It is inferred from spectral analyses of the strong motion recorded in the foothill zone that the motion of the underlying bedrock had a dominant period close to 2 seconds (unfortunately no strong motion records were taken directly on competent bedrock).

The amplification of the ground motion by the lake bed deposits is attributed to two factors: The low damping ratio of the clay deposits (about $6 \%$ at shear strains of $10^{-1} \%$ ) and the dominant period of the ground motion transmitted through the underlying bedrock. Similar amplifications have been observed in previous earthquakes, and ground motions of magnitudes similar to those observed in the most critical area have been previously predicted to have a 100 year mean recurrence interval.

While the subsurface conditions of Mexico City are in many respects unique, it cannot be ruled out that similar ground motion amplification could occur in other areas underlain by deposits of saturated clays.

Implications for Existing Design Provisions

Elastic response spectra for single degree of freedom resonators with $5 \%$ damping were compared with design spectra for non ductile structures specified in the 1976 Mexico Federal District Building Regulations, and with design provisions presently used in the U.S. or proposed for U.S. practice. The comparison indicates that even well designed buildings following the provisions of the Mexico code or those specified for the most severe conditions envisioned in present or proposed Us practice could have failed in the Mexico City earthquake if they had natural periods of vibra-

tion close to the $2 \mathrm{~s}$ site period. The implication of this finding is that perhaps special provisions for site - structure resonance 
should be considered for areas underlain by deep clay deposits similar to those found in Mexico City.

Damage Patterns

One of the unique aspects of this earthquake was the selective damage pattern. While some areas of Mexico City suffered devastating structural failures, other areas were only slightly affected. This phenomenon is attributed to the great amplification of the ground motion in areas of lake deposits which had natural periods close to 2 seconds. Within the danger zone, the damage pattern was also selective. A high percentage of the buildings in the height range of $6-17$ stories failed, while lower buildings and taller buildings performed relatively well. This phenomenon is attributed to the large number of cycles of nearly sinusoidal ground motion, which greatly affected buildings with fundamental periods close to that of the ground motion. In some locations the damage pattern was erratic. Some structures collapsed, while almost identical structures in the immediate vicinity suffered little damage. In one instance this phenomenon could be traced to the effect of past differential foundation settlements. Other possible causes suggested are uneven soil consolidation patterns caused by structural loads and groundwater pumping, poor construction quality control, and heavy live load concentrations in upper stories.

\section{Foundation Performance}

In spite of the difficult foundation condition prevailing in the lake region of Mexico City and the severity of the ground motion, structural foundations on the whole performed surprisingly well, even though some spectacular foundation failures occurred. This record is attributed to the low permeability of the clay deposits, which precludes large settlements associated with volume change of the subsoil within the time span of a seismic 
event, and to the cohesive strength of the clays which precludes liquefaction. However, settlements and rotational slides associated with shear deformations and failures did occur.

Foundation failures and distress observed included tilting and overturning of structures and loss of shear resistance of foundation piles which manifested itself as settlement of the soil surrounding pile supported buildings. The latter phenomenon is attributed to the sensitivity of the clay (it loses much of its shear strength when subjected to large shear deformations). In some cases of overturning, the connection between some of the foundation piles and the stiff box foundations they supported failed, leaving some piles in the ground and pulling others out. Several structural failures resulted from prior stressing of structural elements due to differential foundation settlements and tilting prior to the earthquake (Table 4.1). These conditions, together with irregular consolidation patterns caused by structural loading, excavation and groundwater pumping prior to the earthquake may have caused failure of some structures, while identical structures in their immediate vicinity survived. Some foundation failures, such as shear failures in piles, may have escaped detection.

Structural Performance

The severity of structural response (and similarly the degree of damage) of the buildings was directly related to the proximity of their fundamental period of vibration to the period of the ground motion. In the historic lake bed region of Mexico City, which experienced the most severe ground motions, this period was approximately two seconds. Failures were thus concentrated in buildings with story heights in the range of 6-17 stories, which had vibration periods close to that of the ground motion. Free vibration measurements taken after the earthquake indicated typical periods of $0.12 \mathrm{~s}$ per story. These periods tended to 
lengthen as a result of structure-foundation interaction and inelastic deformations in the structure (with an ensuing reduction in stiffness). These latter factors help to explain why so many structures with natural periods of $1-1.5$ seconds in the elastic range were ultimately destroyed: the dilation in period during the earthquake allowed these structures to vibrate themselves into the "zone of danger" where lateral accelerations were greatest.

The observed structural failures generally fall (in order of descending frequency) into the following categories:

1. Lack of ductile design characterized by inadequate detailing of beam-column and slab-column connections. Specifically the lack of sufficient confining reinforcement in concrete column joints, the use of vertical lap splices in column joints, and a lack of sufficient shear reinforcement connecting flat slabs to their respective columns in flat slab and flat plate construction.

2. Lack of plan symmetry in either structural configuration or structural rigidity. This led to torsional response mechanisms and subsequently high localized stresses, and possibly dynamic impacting of adjacent structures. This was particularly evident in corner buildings, where open store fronts on the first floor, combined with infill walls on the interior sides, produced torsional response leading to pounding against adjacent buildings.

3. Pounding of adjacent structures due to insufficient separation. The problem was complicated by the tendency of structures of dissimilar natural frequencies to vibrate out of phase with one another, 
such that at any given point in time the maximum dynamic lateral deflection of each structure could be towards the adjacent structure. Separation based only on the maximum deflection of one structure or the other would not have been sufficient to prevent collisions.

4. Abrupt changes in structural stiffness (or strength) with story height. Common practice in Mexico City has been to decrease column dimensions in the upper floors of multistory buildings. Also prevalent is the addition of flexible stories to the top of a structure at some time after completion of the original structure. Both of these can lead to upper-story collapses if pounding occurs or if high live loads (for example archives, as mentioned in 5 . below) are stored in the upper floors.

5. Large dead loads in upper floors. Office space in urban Mexico City is at a premium and there is a tendency to use lower floors for business (either offices or stores) and relegate storage to the upper floors. This practice serves to lengthen the period of vibration and increase the shear forces in the upper stories, since more mass is concentrated in the upper floors.

6. Unnecessarily heavy floor systems. Several types of concrete slab systems, produced unnecessarily heavy story loads which in turn led to high overturning moments and story shears.

Tall structures, in general, responded well to the earthquake, owing perhaps more to their natural periods of vibration which placed them well outside the two second "zone of danger" than to 
excellence in structural design. A great many of the taller buildings in Mexico City, such as the Torre Latino Americana (43 stories) and the Pemex Tower (53 stories), utilize steel frame construction. When assessing the good performance of the tall structures, many of which were in locations where widespread damage was caused in adjacent, lower-height structures, the importance of the relationship between the natural period of the structure and that of the site should be kept in mind. These same tall buildings may not have faired well at all had they been constructed in the virgin lake bed area near the sports palace, where periods of vibration in the vicinity of five seconds were recorded, or near the central Produce Market, where the period of the ground motion was four seconds and the duration approached three minutes. It is also reasoned that a 50-story concrete structure in the historic district would probably have performed as well as the tall steel structures. The underlying argument is that dynamic "detuning" of a structure to avoid resonance with the site period could be as important as the choice of the structural system.

One particular type of reinforced concrete slab system, known as Losa Reticular (waffle slabs) was responsible for a large portion of the cases of total collapse. This system employed cinder block (either solid or hollow) rather than metal pan forms during the casting of the waffle slab. These blocks were cast into the structure leading to high floor weights. Waffle slab structures suffering the greatest damage during the earthquake generally exhibited a lack of sufficient concrete cover on slab reinforcement and a lack of sufficient slab-to-column shear reinforcement. These factors led to numerous punching shear type failures, pancake collapses, and "drop out", a phenomena peculiar to this type of construction where the cinder blocks simply fell out of the floors after a number of inelastic load cycles. This type of construction practice should be subject to stringent specifications in future Mexico city building codes. 
Older, low-rise masonry buildings generally performed well, as did the massive stone masonry colonial churches and government offices. These structures have short periods of vibration and thus were not very vulnerable to the ground motion in the lake region of Mexico City. Modern high-rise framed structures which contained masonry infill walls (or shear walls) generally performed better than similar structures which did not. Infill walls increased the lateral stiffness of the structures and therefore served to decrease their natural period of vibration, thus making them less vulnerable to the long period ground motion. In most cases such walls were unreinforced and often suffered severe damage during the earthquake. However, in doing so they dissipated a substantial amount of energy and probably prevented collapse of numerous buildings. 


\section{REFERENCES}

[1] Serna, J.F., The Mexico City Earthquake: A technical challenge; an example of human solidarity, copy transmitted to the National Bureau of Standards on Dec. 27, 1985 by Francisco J. Serna, International Director, ASCE.

[2] Suzuki, S, Kiremidjian, A.S., The Mexico Earthquake of September 19, 1985, the John A. Blume Earthquake Engineering Center, Report No. 77, Stanford University, January 1986.

[3] Instituto de Ingenieria, UNAM, Effecto de los sismos de Septiembre de 1985 en las construcciones de la ciudad de Mexico, Aspectos Estructurales, Segundo Informe de Ingeniria de la Universidad Nacional Autonoma de Mexico, UNAM, Mexico City, November, 1985.

[4] Anderson, J.G. et al., Aspects of Strong Motion From the Michoacan, Mexico Earthquake of September 19, 1985. October 1985 (unpublished).

[5] Singh, S.K., L. Astiz, and J. Harskov, Seismic Gaps and Recurrence Periods of Large Earthquakes Along the Mexican Subduction Zone: a re-examination, Bull. Seism. Soc. Am. 71, pp 827-843, 1981.

[6] MCNally, K.C. and Minster, J.B., Nonuniform Seismic Slip Rates Along the Middle American Trench, J. Geophysical Research, 86, pp 4949-4959, 1981 .

[7] Mena, E., Carmona, C., Alcantara, L., Delgado, R., Analysis Del Accelerograma "Zacatula" del Sismo del 19 de Septiembre de 1985, Informe IPS 10E, Instituto de Ingenieria UNAM, 1985.

[8] Zeevaert, L., strong Motions Recorded During Earthquakes of May the 11th and 19th, 1962 in Mexico City, Bull. Seismic Society of America, 54, pp 209-231, 1964.

[9] Marsal, R. J. The Lacustrine clays of the Valley of Mexico, International clay Conference, Mexico City, Universidad National Autonoma de Mexico, Instituto de Ingenieria, E16, Mexico City, July 1975.

[10] Marsal, R.J. and Mazari, M., The Subsoil of Mexico City, Universidad National Autonoma de Mexico, Instituto de Ingenieria, Mexico City, September 1959 (Second Edition, 1969). 
[11] Resendiz, D., springall, G., Rodriguez, J.M., Esquivel,R., Informacion Reciente Sobre Las Caracteristicas del Subsuelo y la Practica de la Ingenieria de cimentationes en la cindad de Mexico, 5th National Meeting of the Mexican society of Soil Mechanics, 1970.

[12] Prince, J., et al., Accelerogramas en Ciudad Universitaria del Sismo del 19 de septiembre de 1985, Informe IPS-10A, 210985 Instituto de Ingenieria UNAM, September 20, 1985.

[13] Mena, E., et al., Accelerograma en el Centro Scop de la Secretaria de Comunicaciones y Transportes, Sismo del 19 de Septiembre de 1985, Informe IPS-10B, 200985 Instituto de Ingenieria UNAM, September $21,1985$.

[14] Quaas, R., et al., Los Dos Accelerogramas de Sismo De Septiembre 19 de 1985, Obtemidos en La Central de Abastos en Mexico, D.F., Informe IPS-10C, 230985 Instituto de Ingeneria UNAM, september 23, 1985.

[15] Anderson, J.G., Bodin, P., Brune, J. N., Prince, J., Singh, S. K., Quaas, R., Duate, M., strong ground motions from the Michoacan, Mexico, Earthquake, Science Magazine, Vol 233, pp. 1043-1049, sept. 5, 1986.

[16] Rosenbluth, E., Seismic Design Requirement in a Mexican 1976 Code, Earthquake Engineering and structural Dynamics, Vol. 7, 1979 .

[17] Faccioli, Ramirez Flores, J., Repuestas Sismicas Maximas Probables en las Ascillas de la ciudad de Mexico, Instituto de Ingenieria UNAM, Report No. 359, 1975.

[18] Forell, F., Nicoletti, J.P., Mexico Earthquakes, Oxcalla, Nov. 29, 1978, Guerrero, March 14, 1979, Earthquake Engineering Research Institute, October 1980.

[19] Manual De Diseno Por Sismo, Segun el Reglamento de Construcciones Para el Distrito Federal, series del Instituto de Ingenieria, No. 406, July 1977.

[20] International Conference of Building officials, Uniform Building code, Whittier, CA, May 1985.

[21] Building Seismic Safety Council, NEHRP Recommended Provisions for the Development of Seismic Regulations for New Buildings, Washington, D.C.,1985.

[22] Seismology Committee, structural Engineers Association of California, Tentative Lateral Force Requirements, SEAOC, Sacramento, CA, october 1985. 
[23] Rosenblueth, E. and Meli, R., The Earthquake of 19, September 1985: Effects in Mexico City, Report by Subcommittee on Norms and Construction Procedures, committee for Mexico City's Metropolitan Area.

[24] Arnold, C., Reiterman, R. ,Building Configuration and Seismic Design, J. Wiley \& Sons, 1982 .

[25] Hanson, R., Martin, H., Martinez-Romero, e., Performance of steel structures in the september 19, and 20, 1985 Mexico City Earthquakes, Proc. Natl. Earthquake Engineering Conf., AISC, Nashville, TN, June 1986.

[26] American Concrete Institute, Building Code Requirements for Reinforced Concrete, ACI 318-83, American Concrete Institute, Detroit, MI, Nov. 1983 ( as well as 1979 edition)

[27] International Masonry Institute, Mexico Earthquake, September, 1985, Washington, D.C., 1986.

[28] Merritt, F.S., Earthquake Revealed Defects in Design and construction, Engineering News Record, August 15, 1957.

[29] Leyendecker,E.V. and Fattal, S.G., Investigation of the Skyline Plaza Collapse in Fairfax County, Virginia, NBS Building Science series 94, Natl. Bur. of stand., February 1977.

[30] Lew, H.S. et al., Investigation of construction Failure of Harbor Cay Condominium at Cocoa Beach, Florida, NBS Building Science Series 145, Natl. Bur. of Stand., August 1982.

[31] Meli, R., Efectos de los Sismos de Septiembre de 1985 en las Construcciones de la Ciudad de Mexico--Aspectos Estructurales, Segundo Informe de Instituto de Ingenieria, UNAM, November 1985.

[32] Blume, J.A., Newmark, N.M., Corning, L.H., Design of Multistory Concrete Buildings for Earthquake Motion, Portland Cement Association, Skokie, IL, 1961.

[33] U.S. Senate Committee on Commerce, Science and Transportation, subcommittee on Science, Technology and space, Testimony Presented by Dr. Dallas L. Peck, Director, United states Geological survey, in October 3, 1985 hearing on the September 19, 1985 Mexico City Earthquake.

[34] Winter, G., and Nielson, A.H., Design of Concrete Structures, MC Graw Hill, New York, NY, 1972. 
[35] Newmark, N.M., and Rosenbluth, E., Fundamentals of Earthquake Engineering, Prentice-Hall, Englewood Cliffs, NJ, 1971.

[36] Vazquez-Vera, A., and del Valle-Caldron, E., Damage Pattern and Characteristics, Proc. Int. Conf. on September 19, 1985 Mexico City Earthquake, Mexico City, September 19-21, 1986, American Society of Civil Engineers, New York, NY. 

NBS.114A (REV. 2-8C)

J.S. DEPT. OF COMM.

BIBLIOGRAPHIC DATA

SHEET (See in structions)

1. PUBLICATION OR
REPORT NO.
NBS / BSS -165

2. Performing Organ. Report No 3. Publication Date

NBS/BSS -165

May 1987

4. TITLE AND SUBTITLE

Engineering Aspects of the September 19, 1985 Mexico Earthquake

5. AUTHOR(S) William C. Stone, Felix Y. Yokel, Mehmet Celebi, Thomas Hanks, Edgar $V$. Leyendecker

6. PERFORMING ORGANIZATION (If joint or other than NBS, see instructions) U.S. Department of Commerce

National Engineering Laboratory

National Bureau of Standards

Center for Building Technology

Gaithersburg, MD 20899

U.S. Department of the Interior

Geological Survey

Office of Earthquakes, Volcanoes, and Engineering

Menlo Park, CA 94025

Golden, CO 80401

7. Contracd Grant No.

9. SPONSORING ORGANIZATION NAME AND COMPLETE ADORESS (Street, City, State, ZIP)

8. Type of Report \& Period Covered Final

U.S. Department of Commerce

National Engineering Laboratory

National Bureau of Standards

Center for Building Technology

Gaithersburg, MD 20899

10. SUPPLEMENTARY NOTES

Library of Congress Catalog Card Number: 87-619819

[Document describes a computer program; SF-185, FIPS Software Summary, is attached.

11. ABSTRACT (A 200-word or less factual summary of most significant information. If document includes a significant bibliography or literature survey. mention it here)

Following the September 19, 1985 Mexico earthquake, a team consisting of four engineers and one seismologist from the National Bureau of Standards (NBS) and the United States Geological Survey (USGS) was dispatched to Mexico City to provide technical advice to the US rescue effort and to assess structural damage. This report is primarily based on data gathered by the team, but it also contains a compilation of other available information. The report addresses the origin and characteristics of the observed ground motion, the ability of buildings designed in accordance with present and proposed seismic design provisions to resist this type of ground motion, and observed data on structural and foundation failures.

12. KEY WORDS (Six to twelve entries; alphabetical order: capitalize only proper names: and separate key words by semicolons) building codes; earthquake; foundations; geology; geotechnical engineering; ground motion; response spectra; seismology; seismic design; standards; structural engineering

13. AVAILABILITY

[x] Unlimited

For Official Distribution. Do Not Release to NTIS

[x] Order From Superintendent of Documents, U.S. Government Printing Office, Washington, D.C. 20402.

14. NO, OF PRINTED PAGES

Order From National Technical Information Service (NTIS), Springfield, VA. 22I6I
215

15. Price 





\section{Periodical}

Journal of Research-The Journal of Research of the National Bureau of Standards reports NBS research and development in those disciplines of the physical and engineering sciences in which the Bureau is active. These include physics, chemistry, engineering, mathematics, and computer sciences. Papers cover a broad range of subjects, with major emphasis on measurement methodology and the basic technology underlying standardization. Also included from time to time are survey articles on topics closely related to the Bureau's technical and scientific programs. Issued six times a year.

\section{Nonperiodicals}

Monographs-Major contributions to the technical literature on various subjects related to the Bureau's scientific and technical activities.

Handbooks-Recommended codes of engineering and industrial practice (including safety codes) developed in cooperation with interested industries, professional organizations, and regulatory bodies.

Special Publications-Include proceedings of conferences sponsored by NBS, NBS annual reports, and other special publications appropriate to this grouping such as wall charts, pocket cards, and bibliographies.

Applied Mathematics Series-Mathematical tables, manuals, and studies of special interest to physicists, engineers, chemists, biologists, mathematicians, computer programmers, and others engaged in scientific and technical work.

National Standard Reference Data Series-Provides quantitative data on the physical and chemical properties of materials, compiled from the world's literature and critically evaluated. Developed under a worldwide program coordinated by NBS under the authority of the National Standard Data Act (Public Law 90-396).

NOTE: The Journal of Physical and Chemical Reference Data (JPCRD) is published quarterly for NBS by the American Chemical Society (ACS) and the American Institute of Physics (AIP). Subscriptions, reprints, and supplements are available from ACS, 1155 Sixteenth St., NW, Washington, DC 20056.

Building Science Series-Disseminates technical information developed at the Bureau on building materials, components, systems, and whole structures. The series presents research results, test methods, and performance criteria related to the structural and environmental functions and the durability and safety characteristics of building elements and systems.

Technical Notes-Studies or reports which are complete in themselves but restrictive in their treatment of a subject. Analogous to monographs but not so comprehensive in scope or definitive in treatment of the subject area. Often serve as a vehicle for final reports of work performed at NBS under the sponsorship of other government agencies.

Voluntary Product Standards-Developed under procedures published by the Department of Commerce in Part 10, Title 15, of the Code of Federal Regulations. The standards establish nationally recognized requirements for products, and provide all concerned interests with a basis for common understanding of the characteristics of the products. NBS administers this program as a supplement to the activities of the private sector standardizing organizations.

Consumer Information Series-Practical information, based on NBS research and experience, covering areas of interest to the consumer. Easily understandable language and illustrations provide useful background knowledge for shopping in today's technological marketplace.

Order the above NBS publications from: Superintendent of Documents, Government Printing Office,

Washington, DC 20402.

Order the following NBS publications-FIPS and NBSIR's-from the National Technical Information Service, Springfield, VA 22161.

Federal Information Processing Standards Publications (FIPS PUB)-Publications in this series collectively constitute the Federal Information Processing Standards Register. The Register serves as the official source of information in the Federal Government regarding standards issued by NBS pursuant to the Federal Property and Administrative Services Act of 1949 as amended, Pubiic Law 89-306 (79 Stat. 1127), and as implemented by Executive Order 11717 (38 FR 12315, dated May 11, 1973) and Part 6 of Title 15 CFR (Code of Federal Regulations).

NBS Interagency Reports (NBSIR)-A special series of interim or final reports on work performed by NBS for outside sponsors (both government and non-government). In general, initial distribution is handled by the sponsor; public distribution is by the National Technical Information Service, Springfield, VA 22161, in paper copy or microfiche form. 
U.S. Department of Commerce

National Bureau of Standards

Gaithersburg, MD 20899

Official Business

Penalty for Private Use $\$ 300$ 